CÁSSIA ALVES DE FREITAS

NANOCOMPÓSITOS POLIMÉRICOS DE POLI (TEREFTALATO DE BUTILENO) - PBT

Tese de Doutorado apresentada à Escola Politécnica da Universidade de São Paulo para obtenção do título de Doutor em Engenharia. 


\section{NANOCOMPÓSITOS POLIMÉRICOS DE POLI (TEREFTALATO DE BUTILENO) - PBT}

Tese de Doutorado apresentada à Escola Politécnica da Universidade de São Paulo para obtenção do título de Doutor em Engenharia.

Área de Concentração: Engenharia de Materiais

Orientadora: Profa. Dra. Nicole Raymonde Demarquette 
Este exemplar foi revisado e alterado em relação à versão original, sob responsabilidade única do autor e com a anuência de seu orientador.

São Paulo, 1 de julho de 2010.

Assinatura do autor

Assinatura do orientador

FICHA CATALOGRÁFICA

Freitas, Cássia Alves de

Nanocompósitos Poliméricos de Poli (tereftalato de butileno) - PBT / C. A. Freitas. São Paulo, 2010

$179 p$

Tese (Doutorado) - Escola Politécnica da Universidade de São Paulo. Departamento de Engenharia Metalúrgica e de Materiais.

1.Polímeros 2.Nanocompósitos 3.Tenacificação I.Universidade de São Paulo. Escola Politécnica. Departamento de Engenharia Metalúrgica e de Materiais II.t 


\section{CURRICULUM VITAE}

\section{Formação Acadêmica}

* Mestre em Engenharia de Materiais pela Escola Politécnica da Universidade de São Paulo, EPUSP, 2005. "Estudo da Morfologia de Misturas Poliméricas Ternárias de PP/PS/PMMA Compatibilizadas", Orientadora: Profa. Dra. Nicole Raymonde Demarquette

* Engenheira Química formada pela Faculdade de Engenharia Industrial, FEl, 2002.

\section{Prêmios}

- Prêmio CREA-SP de Formação Profissional, Honra ao Mérito, conferido pelo Conselho Regional de Engenharia e Arquitetura - São Paulo (CREA-SP) em 13/08/2002.

* Prêmio Lavoisier, Honra ao Mérito, conferido pelo Conselho Regional de Química - IV Região (CRQ-IV) em 13/08/2002.

* Honra ao Mérito, conferido pelo Colégio Padre Anchieta, pelo excelente desempenho escolar durante o $2^{\circ} \mathrm{Grau}$.

\section{Títulos}

* Representante dos Alunos de Pós-Graduação, Departamento de Engenharia Metalúrgica e de Materiais da Escola Politécnica da USP, 2005-2008.

\section{Bolsas Obtidas}

* Bolsista de Doutorado, 2006-2010, organização financiadora CAPES - Coordenação de Aperfeiçoamento de Pessoal de Nível Superior

* Bolsista do Programa de Aperfeiçoamento de Ensino, 2007-2008, organização financiadora CAPES - Coordenação de Aperfeiçoamento de Pessoal de Nível Superior

* Bolsista de Mestrado, 2003-2005, organização financiadora FAPESP - Fundação de Amparo à Pesquisa do Estado de São Paulo (Projeto $n^{\circ}$ 02/10253-9).

* Bolsista de Auxílio Educacional (Monitoria), 1999-2000, organização financiadora FCA - Fundação de Ciências Aplicadas.

\section{Congressos com apresentação de trabalho}

* FReitAs, C. A. de; DEMARQuetTE, N. R.. Rheological Study of PBT/Brazilian Clay Nanocomposite using quaternary ammonium and phosphonium salts. In: 5th Annual European Rheology Conference, 2009, Cardiff, Wales, UK. 5th Annual European Rheology Conference, 2009.

* Freitas, C. A. de; Demarquette, N. R.. Nanocomposites of PBT / Brazilian Clays. In: Arcus Bresil - Thematic School - Nano - 
Organic-based nanostructured materials: From synthesis to macroscopic properties, 2009, Annecy, France, 2009.

* FReITAS, C. A. de; DEMARQuetTE, N. R. Characterization of PBT/Brazilian Clay Nanocompósitos using quaternary ammonium and phosphonium salts. In: Polymer Processing Society 24th Annual Meeting - PPS24, 2008, Salerno (SA) / Italy. Polymer Processing Society 24th Annual Meeting - PPS24, 2008.

* FReitAs, C. A. de; FERnANDES, L. L.; DEMARQuetTE, N. R.; FECHINE, G. J. M. Mechanical behavior of polypropylene / high impact photodegraded blend. In: Modification, Degradation and Stabilization of Polymers, 2008, Liege, Belgium. MODEST 2008, 2008.

* FReitas, C. A. de; FERnANDES, L. L.; DEMARQuetTE, N. R.; FECHINE, G. J. M.. Photodegradation of polypropylene / High Impact Polystyrene Blends. In: 23rd Polymer Processing Society Meeting, 2007, Salvador, Bahia, Brazil. 23rd Polymer Processing Society Meeting, 2007.

* FERnANDES, L. L.; FREITAS, C. A. de; DEMARQuetTE, N. R.; FECHINE, G. J. M.. Avaliação da influência do tipo de PP nas propriedades mecânicas e morfológicas da blenda PP/HIPS. In: 9 Congresso Brasileiro de Polímeros, 2007, Campina Grande, PB, Brazil, 2007.

* FReitAas, C. A. de; FERnANDES, L. L.; DEMARQUETTE, N. R.; FECHINE, G. J. M.. Comportamento mecânico do poliestireno de alto impacto (HIPS) fotodegradado. In: $9^{\circ}$ Congresso Brasileiro de Polímeros, 2007, Campina Grande, PB, Brazil, 2007.

* Freitas, C. A. de; VAlerA, T. S.; DeMARQuette, N. R. Compatibilized Ternary Polymer Blends. In: World Polymer Congress - 41st International Symposium on Macromolecules, 2006, Rio de Janeiro, RJ - Brazil. Macro 2006 - CD. p. 235.

* Freitas, C. A. de; VAlerA, T. S.; DeMARQuette, N. R. Morphology of the Compatibilized Ternary Polymer Blends. In: 3rd International Conference on Times of Polymers and Composites, 2006, Ischia, NA - Italy. Book of Abstracts - TOP2006. p. 18.

* FReitas, C. A. de; DEMARQuetTE, N. R. Rheological Behavior of Compatibilized PP/PS Blends with SEBS and Graft Copolymers PPg-PS. In: America's Regional Meeting, 2005, Quebec / Canada. America's Regional Meeting Proceedings, 2005.

* FReitas, C. A. de; DEMARQuetTE, N. R., Linear Viscoelastic Behaviour of Compatibilized PP/PS Blends, Americas Regional Meeting of The Polymer Processing Society, PPS-2004, Florianopolis, SC, Brazil, November 7-10, 2004, p. 545-546, CDROM. 


\section{Congressos sem apresentação de trabalho}

* I Seminário "Indústria do Plástico", Valor Econômico, realizado em 06 de outubro de 2004, em São Paulo, SP, Brasil.

\section{Artigos Completos Publicados em Periódicos}

* Freitas, C. A. de; Valera, T. S.; SouzA, A. M. C.; DEMARQUETTE, Nicole Raymonde . Morphology of Compatibilized Ternary Blends. Macromolecular Symposia, v. 247, p. 260-270, 2007.

\section{Desempenho no Exame Nacional de Cursos}

* Nota Individual: A, Nota da Instituição: B, (2002)

\section{Atividades Exercidas}

* Monitoria / Programa de Aperfeiçoamento de Ensino

Disciplina

Blendas e Compósitos Poliméricos

Departamento de Engenharia Metalúrgica e de Materiais - USP

Fevereiro à Junho de 2007

* Monitoria / Programa de Aperfeiçoamento de Ensino

Disciplina

Reologia dos Materiais

Departamento de Engenharia Metalúrgica e de Materiais - USP

Fevereiro à Junho de 2008

* Monitoria / Programa de Aperfeiçoamento de Ensino

Disciplinas:

Mecânica dos Fluidos

Termodinâmica e Transmissão do Calor

Departamento de Energética - Faculdade de Engenharia Industrial - FEI

Fevereiro de 1999 a Dezembro de 2000

\section{Disciplinas Cursadas durante Pós-Graduação}

- Mestrado

PMT5825
PMT5783
PMT5848
PMR5219
PMT5843
PME5011
PMT5854

$\begin{array}{rr}\text { Blendas Poliméricas } & \text { A } \\ \text { Fundamentos da Ciência e a Engenharia dos } & \text { A } \\ \text { Materiais } & \\ \text { Plásticos de Engenharia } & \text { A } \\ \text { Processamento Mecânico de Polímeros: Teoria e } & \text { A } \\ \text { Práticas } & \\ \text { Tópicos Especiais em Enga Metalúrgica e de } & \text { A } \\ \text { Materiais } & \\ \text { Mecânica dos Meios Contínuos } & \text { A } \\ \text { Tecnologia de Polímeros } & \text { A }\end{array}$


* Doutorado

TNM5796 Materiais Compósitos Poliméricos: Fundamentos, A Tecnologia e Aplicações

PMT5826 Reologia de Materiais: Relação entre as Propriedades A Químicas e Físicas de Materiais e as Propriedades

Reológicas

PEA5900

Tecnologia de Ensino de Engenharia

A

PMT5861

Caracterização de Polímeros

A 
Dedico este trabalho aos meus pais, Willany e Geanete, à minha avó Geny e à minha irmã Fabiana 


\section{AGRADECIMENTOS}

A Deus pela oportunidade suprema de viver a vida.

Aos meus pais Willany e Geanete. Jamais pouparam esforços para que eu pudesse conquistar os meus objetivos. Às vezes esqueço que cresci! Ainda hoje, me sinto a 'vossa menina'. Menina que foi incentivada a seguir o caminho dos estudos. Educaram-me com tanto amor, carinho e dedicação. Herança nobre. Ninguém pode tirar de mim. Mas eu cresci. Hoje colhemos os frutos das sementes plantadas por vocês em minha vida.

À minha avó Geny. Pessoa mais "bunitinha" que Deus colocou na minha vida. Super brincalhona e, por vezes, brava! Traz-me tanta experiência de vida. Não era para menos: 91 anos. Espero chegar lá também, Niiii! Uma benção divina poder ter alguém tão especial ao meu lado, desde que nasci.

À minha irmã Fabiana. Compartilhamos problemas, alegrias, risadas e várias 'babaquices'. Sempre é o meu apoio, companheira de todas as horas. Acredito que todos nós temos um anjo da guarda. Bi, você é o meu!

Nada melhor, depois de horas de trabalho, poder voltar para casa e encontrá-lo! O fiel companheiro de 4 patas: Phary, o nosso cão. Metade da minha vida estou ao seu lado, 15 anos de convívio. Não existe amizade mais sincera.

À minha orientadora Profa. Nicole. Pela paciência e sua incansável dedicação aos alunos. Seus conselhos, sugestões, discussões, reuniões semanais. Pelas reuniões-pizza repletas de esfihas, os bolos de chocolate, os cookies (maravilhosos)!

Aos colegas do laboratório de polímeros e do departamento, que caminharam juntos, cada um com seu objetivo específico, sua luta individual, mas todos unidos pela mesma motivação: retribuir a confiança depositada em nós no sentido de contribuir para a ciência e pesquisa no Brasil, além de todos os professores e funcionários. Ao apoio insubstituível do técnico Danilo que, com grande empenho e profissionalismo, sempre esteve ao meu lado nos mais diversos e complicados problemas cotidianos nos laboratórios.

À Universidade de São Paulo, à Universidade Mackenzie e ao Laboratório Nacional de Luz Síncroton, pela infraestrutura e condução de análises.

Às empresas Kaoré Tecnologia, Sabic Innovative Plastics, Dishman, Clariant, Bentonita do Nordeste, Arkema e Braskem pela infraestrutura, doação de materiais e condução de análises.

À CAPES, CNPq e FAPESP pelo apoio financeiro.

Peço a Deus que abençoe a todos aqueles que contribuíram para a realização deste trabalho, que caminharam ao meu lado em todos os momentos ou que apenas cruzaram o meu caminho. 
Mensagem...

As dificuldades não foram poucas e caminharam o tempo todo comigo...

Os desafios foram muitos, dos mais diversos tipos, nasceram nas mais inusitadas horas...

Os obstáculos, muitas vezes, pareciam intransponíveis. Muitas vezes me senti só...

O desânimo quis contagiar, porém, a garra e a perseverança foram mais fortes, sobrepondo esse sentimento, fazendo-me seguir a caminhada, apesar da sinuosidade do caminho.

Agora, posso olhar para trás. Recordar que os longos tempos de leitura e digitação, a experiência que não deu certo, o resultado que não aparecia. As inúmeras discussões avaliadas de diversos aspectos, uma angústia de muitas vezes não conseguir o êxito, também por problemas estruturais e burocráticos. Enfim, por diversas vezes, a sensação de tempo perdido se fez presente.

Mas hoje, tenho a sensação do dever cumprido. Posso concluir que para todo o trabalho realizado, para cada discussão argumentada, por mais infrutíferos que parecessem ser... nada foi em vão.

Sobrevivi. Estou muito mais forte hoje do que quando entrei nessa batalha. Porém, a guerra continua...

"É muito melhor arriscar coisas grandiosas, alcançar triunfos e glórias, mesmo expondo-se a derrota, do que formar fila com os pobres de espírito que nem gozam muito nem sofrem muito, porque vivem nessa penumbra cinzenta que não conhece vitória nem derrota." Theodore Roosevelt 


\section{RESUMO}

Neste trabalho, nanocompósitos de PBT, poli(tereftalato de butileno) e argila brasileira montmorilonita (MMT) modificada organicamente, foram obtidos com e sem agente tenacificante. Sais quaternários de amônio e fosfônio com estruturas químicas diferentes foram utilizados para modificar as argilas. Nanocompósitos de PBT com argilas comerciais, dos Estados Unidos, modificadas com de sais de amônio, foram obtidos para comparação das propriedades. As argilas e os polímeros foram misturados utilizando um misturador e uma extrusora dupla rosca, acoplados a um reômetro de torque. A qualidade da troca catiônica foi avaliada por difração de Raios-X (XRD), inchamento em solventes e análises termogravimétricas (TGA). O estado das argilas modificadas (OMMT) na matriz de PBT foi avaliado por XRD, microscopia ótica e microscopia eletrônica de transmissão (TEM). A dispersão do agente tenacificante foi avaliada por microscopia eletrônica de varredura (SEM). As propriedades mecânicas e de flamabilidade também foram avaliadas. Os resultados de flamabilidade foram explicados com ensaios de (TGA).

Os resultados de espaçamento basal obtidos por XRD e inchamento em solventes foram dependentes da arquitetura do sal quaternário utilizado. Os espaçamentos basais ficaram maiores para os sais quaternários de longas cadeias alquílicas. Entretanto, o sal quaternário em excesso não foi eliminado na lavagem. A maior estabilidade térmica foi obtida com sais quaternários de fosfônio.

Após a adição ao PBT, foi observado que a adição da argila organofílica na matriz polimérica não contribuiu para a significativa melhora das propriedades mecânicas que, em alguns casos, foram inferiores àquelas do PBT. Entretanto, a retardância a chama apresentou melhores resultados na presença de argila organofílica, sendo ainda melhores apenas na presença de sais quaternários de fosfônio. No sentido de melhorar as propriedades de flamabilidade do PBT sem perder em propriedades mecânicas, utilizou-se o agente tenacificante $\mathrm{P}(\mathrm{E}-\mathrm{co}-\mathrm{MA}-\mathrm{co}-\mathrm{GMA})$, copolímero etileno - acrilato de metila - metacrilato de glicidila. Desta forma, foram preservadas as propriedades mecânicas e retardância à chama. 


\begin{abstract}
In this work, nanocomposites of PBT, poly (butylene terephthalate) and Brazilian clay montmorillonite (MMT) organically modified were obtained with and without further addition of toughening agent. Quaternary ammonium and phosphonium salts with different chemical structures were used to organically modify the clays. PBT nanocomposites with commercial organoclays were also obtained for comparison. The materials were mixed using a mixer and a twin screw, coupled to a torque rheometer. The efficiency of cation exchange was evaluated by X-ray diffraction (XRD), swelling and thermogravimetric analysis (TGA). The dispersion of PBT with modified clay (OMMT) was evaluated by $X R D$, optical microscopy and transmission electron microscopy (TEM). The toughness dispersion was evaluated by scanning electron microscopy (SEM). The flammability and mechanical properties were also evaluated. Thermogravimetric analysis (TGA) of the OMMTs and PBT / OMMTs was also studied.

The basal spacing obtained from XRD analysis were shown to depend on the architecture of the quaternary salt used and were larger for long alkyl chains. The quaternary salt excess was not removed during the washing step. The highest thermal stability was obtained with quaternary phosphonium salts.

After adding the PBT, it was observed that the addition of organoclay to the polymer matrix did not contribute to a significant improvement of mechanical properties and in some cases even resulted in a decrease of mechanical properties. However, the flame retardancy showed best results in the presence of organoclay. The best results for the flammability properties were observed in the presence of only quaternary phosphonium salts. However, these materials were very fragile. In order to improve the flammability properties of PBT maintaining the mechanical properties, a toughening agent $\mathrm{P}(\mathrm{E}-\mathrm{co}-\mathrm{MA}-\mathrm{co}-$ GMA), copolymer ethylene - methyl acrylate - glycidyl methacrylate was used. In doing so both the mechanical and flame retardancy were preserved.
\end{abstract}




\section{LISTA DE FIGURAS}

Figura 2.2.1.1 - Estrutura cristalina de uma esmectita em vista estereoscópica (Carastan, 2007)

Figura 2.2.2.1 - Figura esquemática de uma troca catiônica (Fischer, 2003) 6

Figura 2.2.2.2 - Descrição das regiões de localização do sal após a troca catiônica (adaptada de Valera et al., 2009)

Figura 2.2.3.1 - Derivadas da perda de massa para sal de amônio (N-4C8) e sal de fosfônio (P4C8) (adaptada de Xie et al., 2002)

Figura 2.2.3.2 - Substituição nucleofílica conduzindo à decomposição de um surfactante de amônio (Cui et al., 2008) ……............................................................................... 9

Figura 2.2.3.3 - Reação de eliminação do tipo Hoffmann (Cui et al., 2008) ............................. 10

Figura 2.2.3.4 - Ativação de um grupo hidroxietil com a presença de um Al em uma argila organofilica (Cui et al., 2008)...

Figura 2.2.3.5 - Reações de degradação para sais tetraalquil fosfônio (adaptada de Xie et al., 2002)

Figura 2.2.3.6 - Reações de degradação para sais tetrafenil fosfônio (adaptada de Xie et al., 2002)

Figura 2.2.3.7 - Reações para sais tetrafenil fosfônio intercalados na montmorilonita (adaptada de Xie et al., 2002).

Figura 2.3.2.2.2.1 - Desenho esquemático do inchamento das argilas ................................... 24

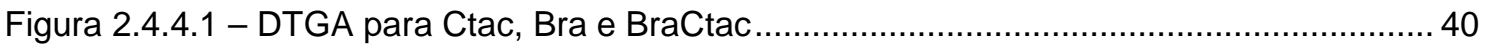

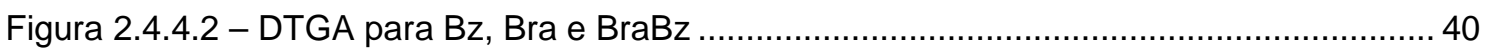

Figura 2.4.4.3 - DTGA para BraCtac, BraPraep e BraTdc …................................................ 43

Figura 2.4.4.4 - DTGA para Praep, Bra e BraPraep .................................................................. 44

Figura 2.4.4.5 - DTGA para BraDod, BraBz, BraTtb e BraTbb ................................................. 45

Figura 3.2.1.1 - Estruturas que podem ser obtidas com os nanocompósitos (adaptada de

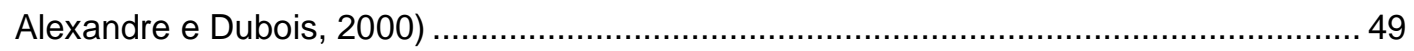

Figura 3.2.1.2 - Esquema de um nanocompósito esfoliado (Fischer, 2003) ............................ 50

Figura 3.2.3.1.1 - Esquema das camadas de argila e cadeias poliméricas............................... 52

Figura 3.2.3.2.1 - Esquema da evolução da queima nas regiões vizinhas às camadas de argila 53

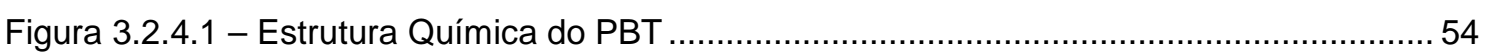

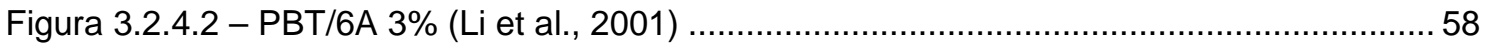

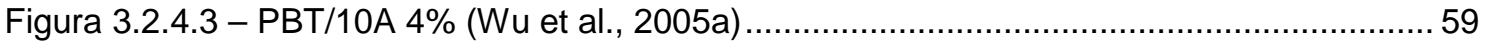

Figura 3.2.4.4 - a) PBT-A/30B; b) PBT-B/30B (Chang; Kim; Kyung, 2005) ............................... 61

Figura 3.2.4.5 - XRD para Cloisite 25A e PBT/25A, 9\% (adaptada de Scatteia; Scarfato;

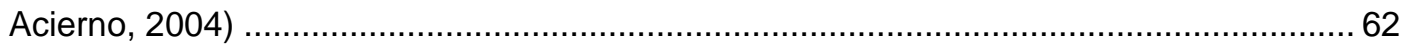

Figura 3.2.4.6 - MET para PBT/25A, 9\% (Scatteia; Scarfato; Acierno, 2004) .......................... 62

Figura 3.2.4.7 - XRD para Cloisite 25A e Nanofil 919, 9\% (adaptada de Scarfato et al., 2005) 63

Figura 3.2.4.8 - XRD para 25A e 43B, 9\% (adaptada de Scatteia; Scarfato; Acierno, 2006)... 63 
Figura 3.2.4.9 - Adição de BHET, 6\% NaMod. (adaptada de Acierno et al., 2007).....

Figura 3.2.4.10 - (a) PBT+ (3 \% MMT+ 0,5\% CPC); (b) PBT+ (3\% MMT+ 1\% CPC); (c) PBT+

(3 \% MMT+ 2\% CPC), e (d) PBT+ (3\% MMT+ 3\% CPC) (Xiao et al., 2005b) ................ 66

Figura 3.2.4.11 - Difratogramas de PBT, PBT/PE-g-MA, PBT/MMT, PBT/PE-g-MA/MMT e MMT

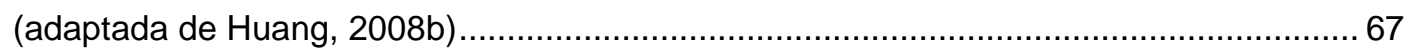

Figura 3.2.4.12 - Micrografia de PBT/PE-g-MA/MMT (Huang, 2008b) ..............................6 67

Figura 3.2.4.13 - Difratograma para PBT/30B com e sem adição de epóxi (adaptada de Li et al., 2004)

Figura 3.2.4.14 - Difratograma para PBT/30B e PBT/EVA-g-MAH/30B, com epóxi (adaptada de Li et al., 2004). 70

Figura 3.2.4.15 - TGA de PBT/EVA-g-MAH e PBT/EVA-g-MAH/30B (6\%) (adaptada de Li et al., 2004) 71

Figura 3.2.4.16 - Efeito da quantidade de argila modificada no alongamento na ruptura para PBT/OMMTs (adaptada de Chang, Kim, Kyung, 2005) 75

Figura 3.2.4.17 - Taxa de liberação de calor (HRR) para PBT, PBT+[3\%MMT+0,5\%CPC] e PBT+[3\%MMT+1\%CPC] (adaptada de Xiao et al., 2005b) ................................... 76

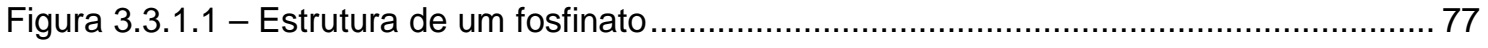

Figura 3.3.2.2.6.1 - Esquema de um ensaio de flamabilidade pela norma UL94 HB ............... 81

Figura 3.4.2.1 - Difratogramas para PBT/Praep.................................................. 83

Figura 3.4.3.1 - Microscopia eletrônica de transmissão para PBT/BraPraep .......................... 84

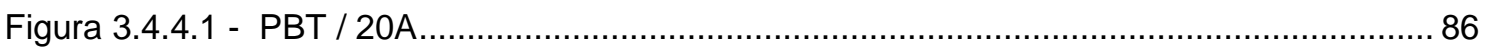

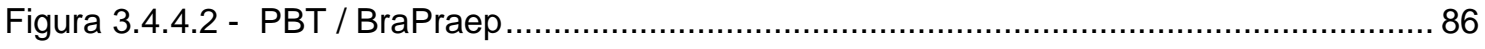

Figura 3.4.5.1 - Tensão x Deformação para o PBT, PBT/Bra, PBT/20A e PBT/30B................8 87

Figura 3.4.5.2 - Tensão x Deformação para PBT, PBT/BraCtac, PBT/BraDod e PBT/BraPraep

Figura 3.4.5.3 - Tensão x Deformação para PBT, PBT/BraBz, PBT/BraTtb, PBT/BraTbb,

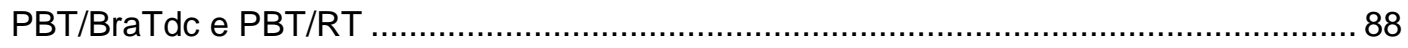

Figura 3.4.5.4 - Resistência ao impacto para PBT/OMMTs (amostras não entalhadas)........... 88

Figura 3.4.6.1 - Perda de massa em função da temperatura para PBT e PBT/OMMTs ...........93

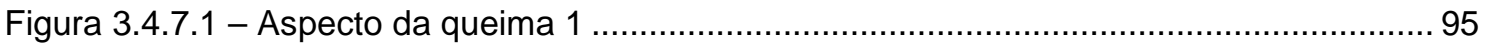

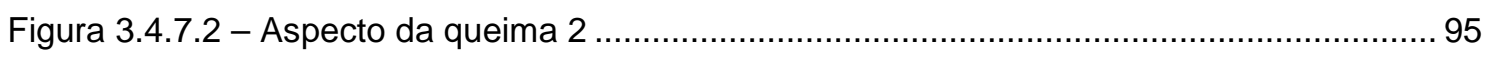

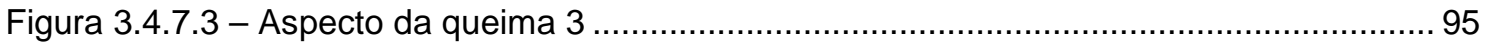

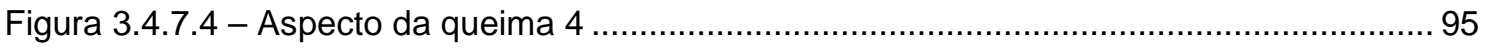

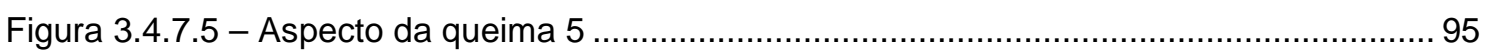

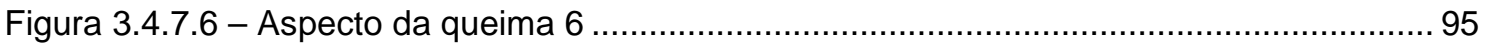

Figura 3.4.7.7 - Esquema da evolução da resistência à chama ...................................... 98

Figura 4.2.1.1.1 - Tenacificação por microfibrilações............................................... 102

Figura 4.2.1.1.2 - Tenacificação por escoamento .................................................. 103

Figura 4.2.1.1.3 - Efeito da distância entre partículas do agente tenacificante (Bezzan, 2006) 
Figura 4.2.1.2.1 - Estrutura do tenacificante, copolímero P(E-co-MA-co-GMA) ................... 105

Figura 4.2.1.2.2 - Reações entre PBT e P(E-co-MA-co-GMA) (Martin et al., 2001) ............... 106

Figura 4.2.1.2.3 - Reações de reticulação do P(E-co-MA-co-GMA) (Martin et al., 2001)........ 106

Figura 4.2.1.2.4 - Influência dos parâmetros na compatibilização de PBT / P(E-co-MA-co-GMA) (adaptada de Martin et.al., 2003) 108

Figura 4.2.1.2.5 - Micrografia por SEM para PBT / P(E-co-MA-Co-GMA) a) (90/10) b) (80/20 c) (70/30), em massa (Yu et al., 2004) 110

Figura 4.2.3.1 - Difratrogramas dos nanocompósitos contendo 3\% em peso de argila (de cima para baixo: Cloisite 25A, PA-I, PA, TUDO, IA-P e PI-A) (adaptada de Yilmazer e Alyamac, 2007b). 113

Figura 4.2.3.2 - Módulo de Elasticidade e resistência à tração em função da concentração de argila para as várias seqüências de processamento (adaptadas de Yilmazer e Alyamac, 2007b). 114

Figura 4.4.1.1 - Torque no misturador para PBT / P(E-co-MA-co-GMA) (79/21) 119

Figura 4.4.1.2 - Espectros por FTIR para PBT, P(E-co-MA-co-GMA) e PBT/P(E-co-MA-coGMA) (79/21) . 121

Figura 4.4.1.3 - Espectros por FTIR para PBT, P(E-co-MA-co-GMA) e PBT/P(E-co-MA-co-

GMA)/BraPraep para as várias seqüências de processamento 122

Figura 4.4.1.4 - Difratogramas para as diversas seqüências de processamento ................. 124

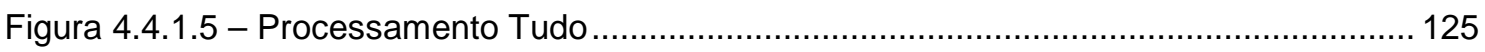

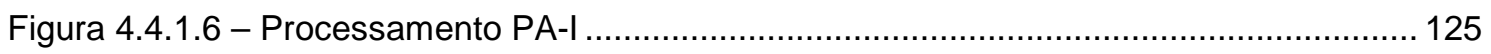

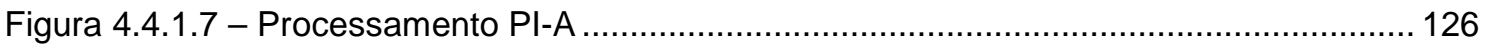

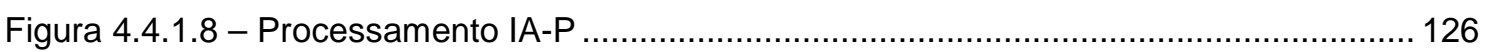

Figura 4.4.1.9 - Tensão x Deformação para as várias condições de processamentos utilizadas para a obtenção de PBT/P(E-co-MA-co-GMA)/BraPraep..... 127

Figura 4.4.1.10 - Módulo de Elasticidade, resistência à tração e alongamento para as várias seqüências de processamento utilizadas para a obtenção de PBT/P(E-co-MA-coGMA)/BraPraep (79/17/4). 128

Figura 4.4.2.1 - Torque no misturador para P(E-co-MA-co-GMA), P(E-co-MA-co-GMA)/20A, P(E-co-MA-co-GMA)/Bra, P(E-co-MA-co-GMA)/BraPraep e P(E-co-MA-co-GMA)/BraTdc, na composição (80/20) 129

Figura 4.4.2.2 - Torque no misturador para P(E-co-MA-co-GMA)/Praep e P(E-co-MA-coGMA)/Tdc 130

Figura 4.4.2.3 - Difratogramas para 20A, PBT/20A (95/5), P(E-co-MA-co-GMA)/20A (80/20) e PBT/P(E-co-MA-co-GMA)/20A (79/17/4) 131

Figura 4.4.2.4 - Difratogramas para BraPraep, PBT/BraPraep (95/5), P(E-co-MA-coGMA)/BraPraep (80/20) e PBT/P(E-co-MA-co-GMA)/BraPraep (79/17/4) 132

Figura 4.4.2.5 - Difratogramas para BraTdc, PBT/BraTdc (95/5), P(E-co-MA-co-GMA)/BraTdc (80/20) e PBT/P(E-co-MA-co-GMA)/BraTdc (79/17/4) 133

Figura 4.4.2.6 - PBT/ P(E-co-MA-co-GMA)/20A (79/17/4) 134 


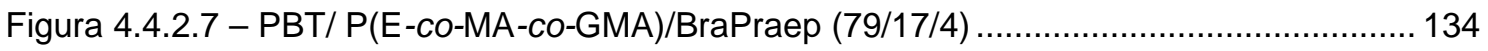

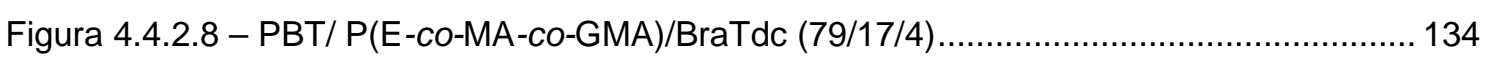

Figura 4.4.2.9 - Tensão x Deformação para o PBT, PBT/20A e PBT/BraPraep, PBT/BraTdc com e sem adição de P(E-co-MA-co-GMA) .................................................... 135

Figura 4.4.2.10 - Módulo de Elasticidade, resistência à tração, alongamento e resistência ao impacto para PBT, PBT/20A e PBT/BraPraep, PBT/BraTdc com e sem adição de P(E-coMA-CO-GMA) 136

Figura 4.4.2.11 - DTGA em função da temperatura para PBT, PBT/P(E-co-MA-co-GMA) e PBT/P(E-co-MA-co-GMA) com 20A, BraPraep e BraTdc ...................................... 137

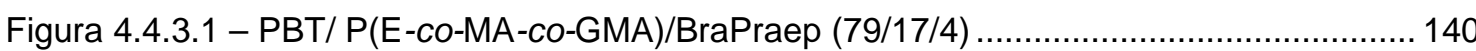

Figura 4.4.3.2 - PBT/ P(E-co-MA-co-GMA)/BraPraep $(91 / 7 / 2)$.................................... 140

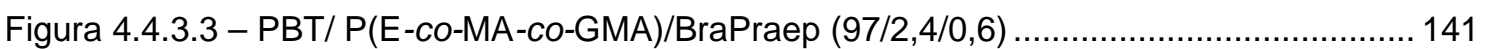

Figura 4.4.3.4 - Tensão x Deformação para PBT e PBT/P(E-co-MA-co-GMA)/BraPraep (79/21/0), (79/17/4), (91/7/2) e (97/2,4/0,6)

Figura 4.4.3.5 - Módulo de Elasticidade, resistência à tração, alongamento e resistência a tração para PBT e PBT/P(E-co-MA-co-GMA)/BraPraep (79/21/0), (79/17/4), (91/7/2) e

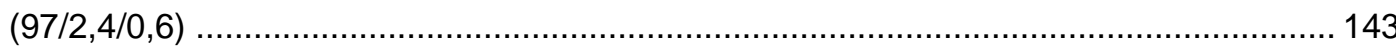

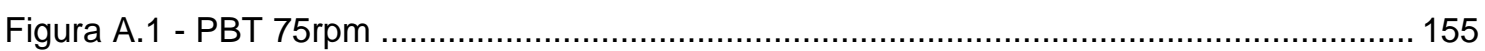

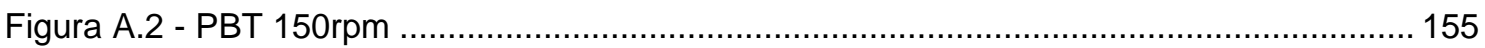

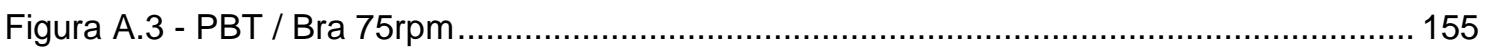

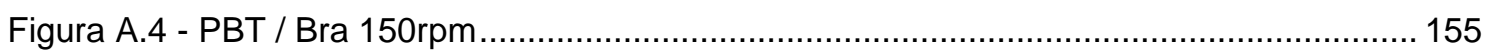

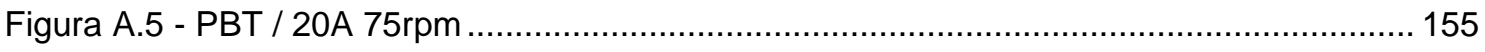

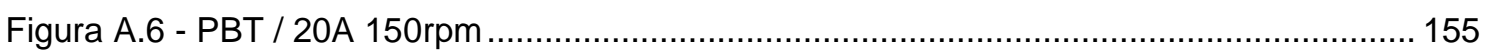

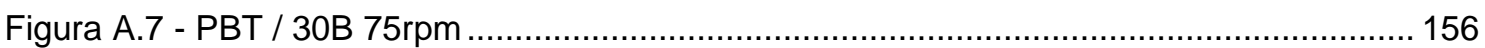

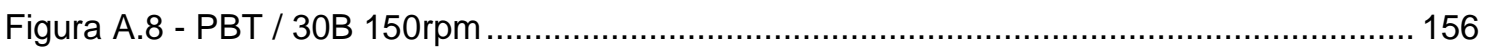

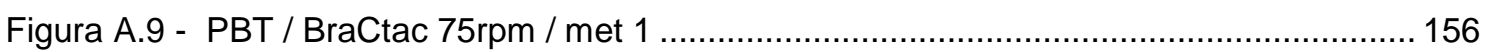

Figura A.10 - PBT / BraCtac 150rpm / met 1 ....................................................... 156

Figura A.11 - PBT / BraCtac 75rpm / met 1 mod .................................................... 156

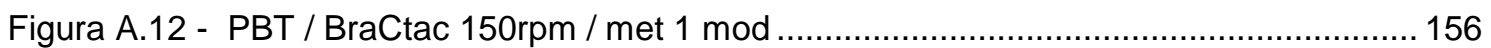

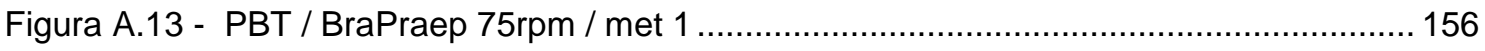

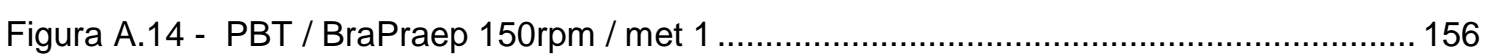

Figura A.15 - PBT / BraPraep 75rpm / met 1 mod ................................................... 157

Figura A.16 - PBT / BraPraep 150rpm / met 1 mod ........................................... 157

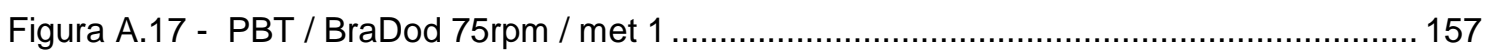

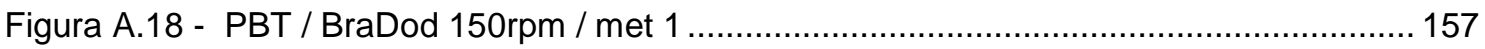

Figura A.19 - PBT / BraDod 75rpm / met 1 mod .................................................... 157

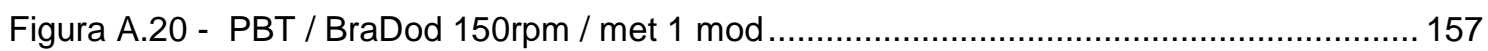

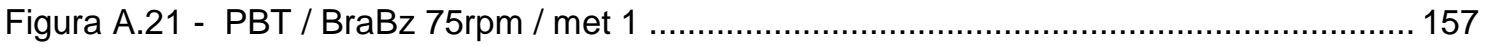

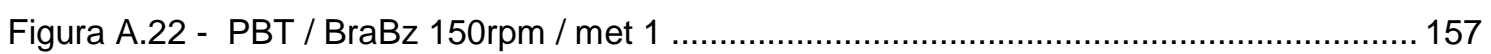

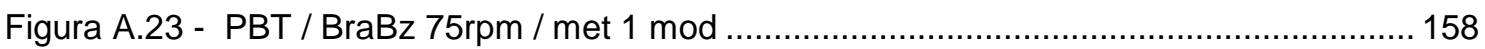




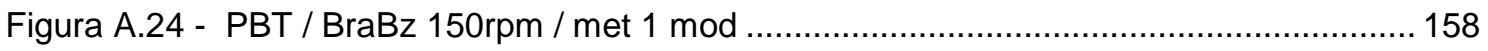

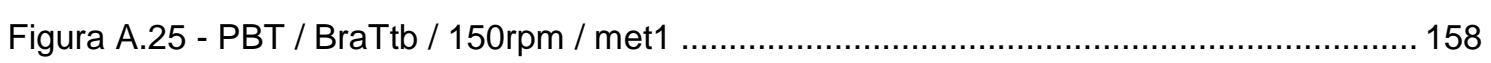

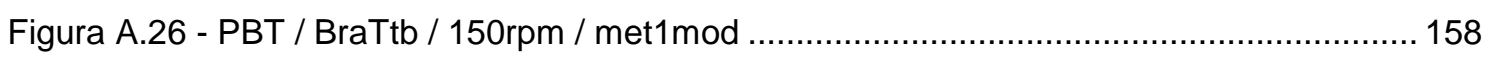

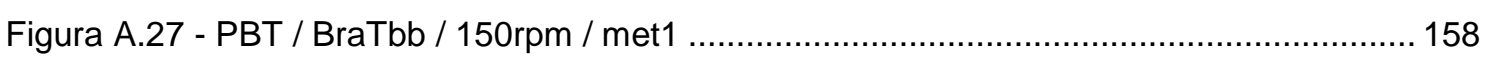

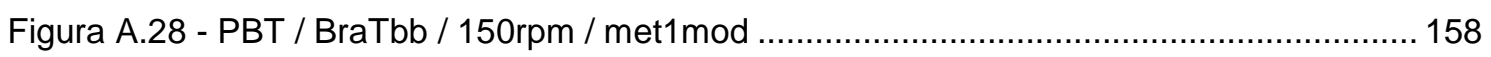

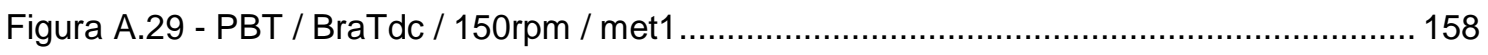

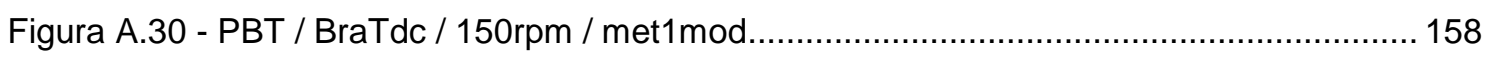

Figura A.31 - Módulo de Elasticidade a 75rpm e método 1 ........................................... 159

Figura A.32 - Módulo de Elasticidade a 75rpm e método 1 modificado............................... 159

Figura A.33 - Módulo de Elasticidade a 150rpm e método 1 ........................................... 160

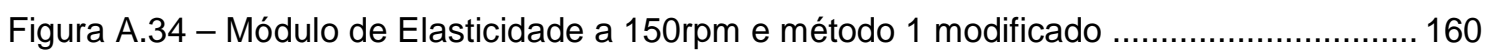

Figura A.35 - Resistência ao impacto a 75rpm e método 1 ............................................ 161

Figura A.36 - Resistência ao impacto a 75rpm e método 1 modificado................................... 161

Figura A.37 - Resistência ao impacto a 150rpm e método 1 modificado............................. 162

Figura B.1 - Perda de massa para sais de amônio e fosfônio ......................................... 163

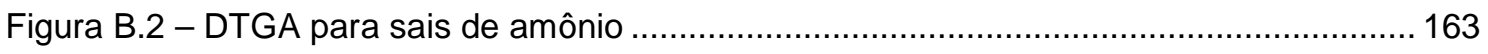

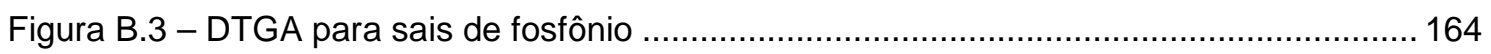

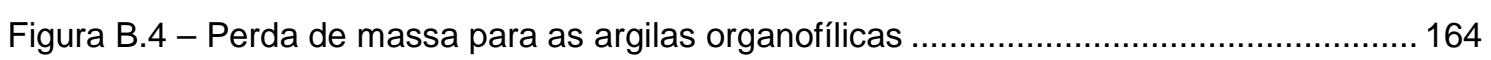

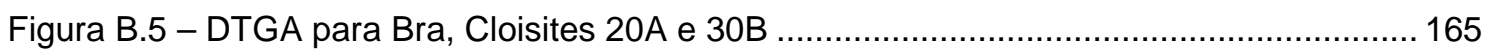

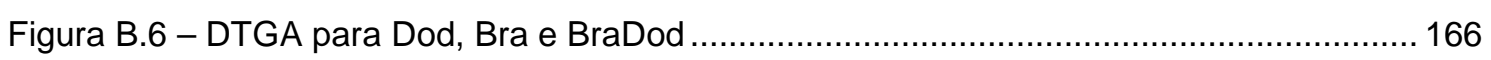

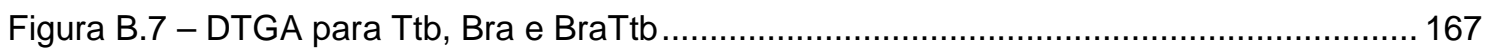

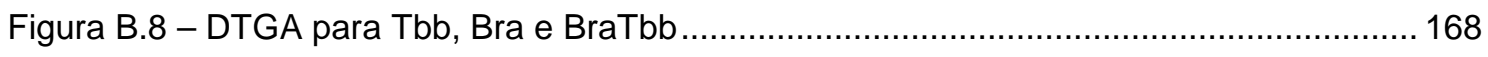

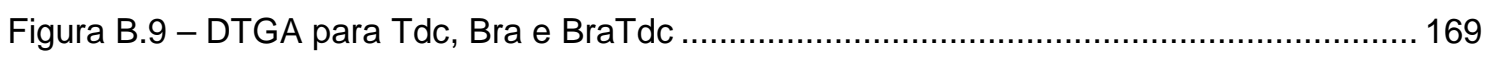

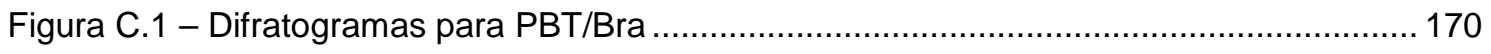

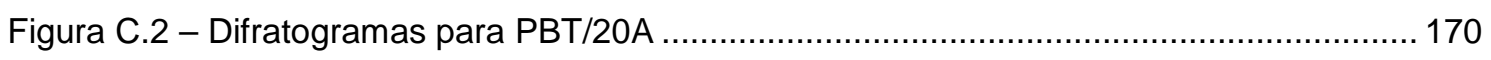

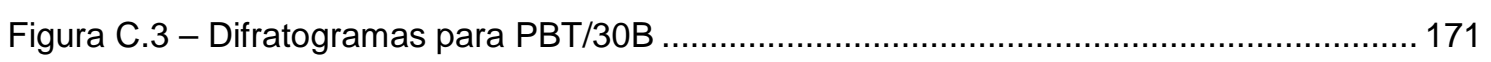

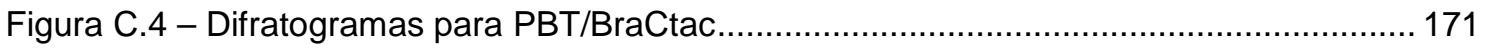

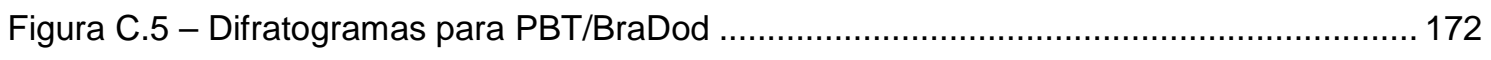

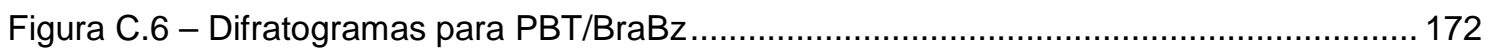

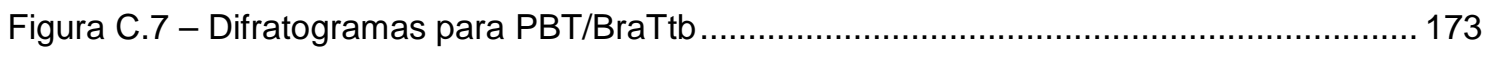

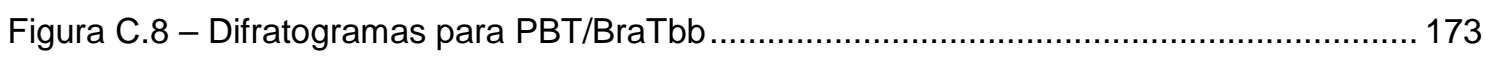

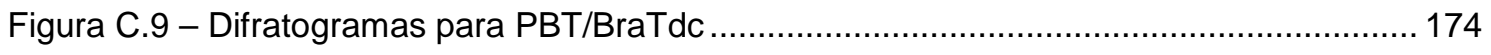

Figura C.10 - Microscopia eletrônica de transmissão para PBT/BraCtac............................ 175

Figura C.11 - Microscopia eletrônica de transmissão para PBT/BraTtb ............................... 176

Figura C.12 - Microscopia eletrônica de transmissão para PBT/BraTdc ........................... 177

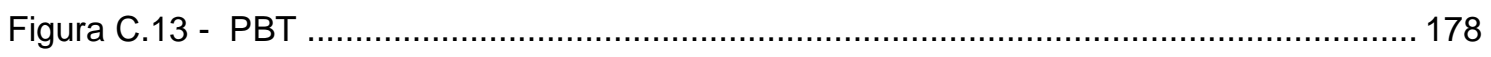

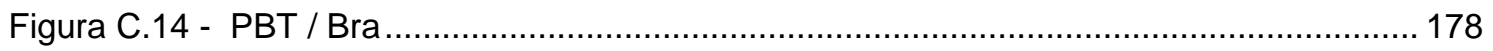

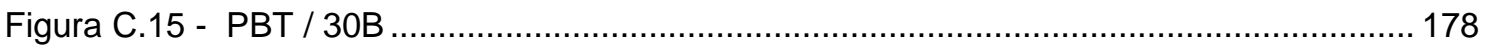

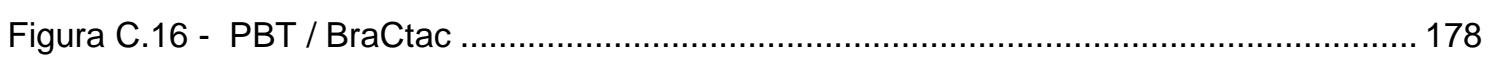

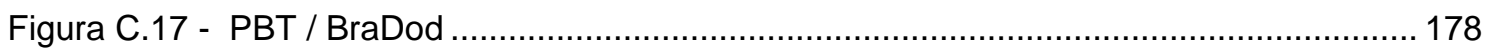


Figura C.18 - PBT / BraBz 178

Figura C.19 - PBT / BraTtb.. 178

Figura C.20 - PBT / BraTbb. 178

Figura C.21 - PBT / BraTdc. 179 


\section{LISTA DE TABELAS}

Tabela 2.3.1.1 - Composição Química da Brasgel (Valera et al., 2010) .................................... 14

Tabela 2.3.1.2 - Fórmulas e estruturas dos sais quaternários ................................................. 16

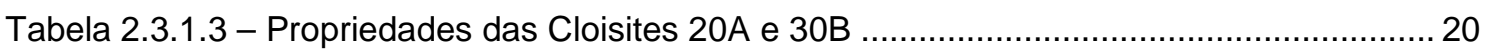

Tabela 2.3.2.1.1 - Teor de argila após a troca catiônica, lavagem e secagem .......................... 22

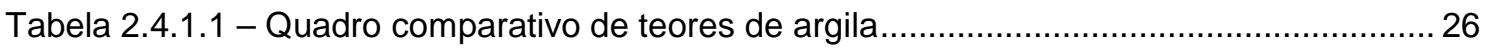

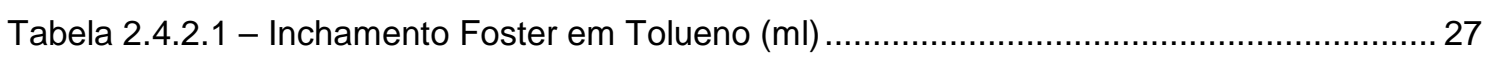

Tabela 2.4.2.2 - Inchamento Foster em Fenol / Clorofórmio (ml) …......................................... 27

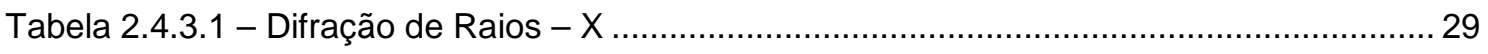

Tabela 2.4.3.2 - Quadro comparativo do espaçamento basal para sais de amônio.................... 30

Tabela 2.4.3.3 - Quadro comparativo do espaçamento basal para sais quaternários de fosfônio

Tabela 2.4.4.1 - Temperatura e perda de massa correspondente à desidratação e

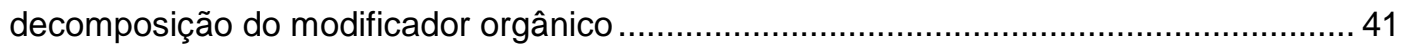

Tabela 3.2.4.1 - Resumo dos trabalhos reportados em literatura............................................... 55

Tabela 3.2.4.2 - Resultados de espaçamento basal para PBT/Cloisite 6A (Li et al., 2001) ...... 59

Tabela 3.2.4.3 - Resultados de espaçamento basal para PBT/Cloisite 10A, variando a concentração 60

Tabela 3.2.4.4 - Resultados de espaçamento basal para PBT/Cloisite 30B variando o tipo de

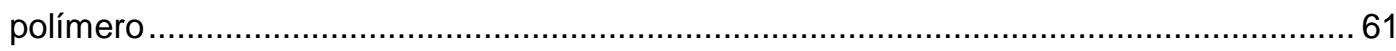

Tabela 3.2.4.5 - Resultados de espaçamento basal para PBT/MMT não tratada ....................... 64

Tabela 3.2.4.6 - Resultados de espaçamento basal para PBT/MMT-CPC .............................. 65

Tabela 3.2.4.7 - Resultados de TGA para PBT, PBT/NaMod, PBT/MEE e PBT/25A (adaptada

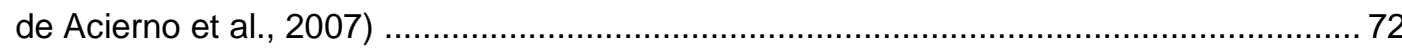

Tabela 3.2.4.8 - Resultados de TGA para PBT/10A com e sem epóxi (adaptada de Wu et al., 2005a)

Tabela 3.2.4.9 - Propriedades mecânicas obtidas por (adaptada de Li et. al, 2004) ................ 74

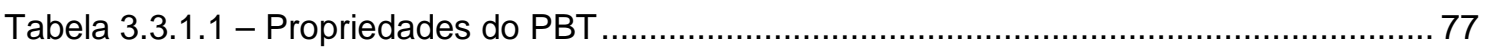

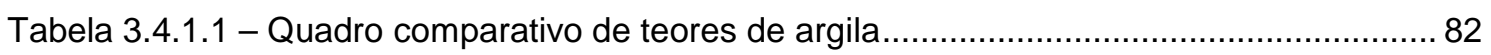

Tabela 3.4.2.1 - Quadro comparativo de espaçamento basal após a adição ao PBT................ 83

Tabela 3.4.5.1 - Módulo de Elasticidade, Resistência Tração e Alongamento na Ruptura para

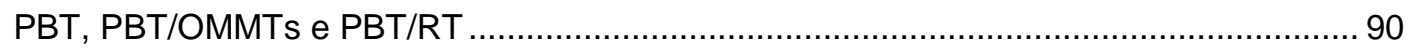

Tabela 3.4.6.1 - Análise térmica para PBT e PBT/OMMTs ……........................................... 93

Tabela 3.4.7.1 - Classificação de flamabilidade observada para PBT/OMMT e PBT/RT...........96 Tabela 4.4.2.1 - Análise térmica para PBT, PBT/P(E-co-MA-co-GMA) e PBT/P(E-co-MA-coGMA) com 20A, BraPraep e BraTdc 138

Tabela 4.4.2.2 - Classificação de flamabilidade observada para PBT/P(E-co-MA-coGMA)/OMMT 139 


\section{LISTA DE ABREVIATURAS, SIGLAS}

$15 \mathrm{~A}$

$20 \mathrm{~A}$

$25 A$

30B

43B

$6 A$

APM

ASTM

BDHAC

BHET

Bra

$\mathrm{Bz}$

CAPES

CPC

Ctac

CTC

Dod

DTGA

EPUSP

EVA-g-MAH

FAPESP

FTIR
Argila comercial Cloisite 15A

Argila comercial Cloisite 20A

Argila comercial Cloisite 25A

Argila comercial Cloisite 30B

Argila Dellite 43B

Argila comercial Cloisite 6A

3-amino propil trimetóxi silano

American Society for Testing and Materials

Cloreto de benzil dimetil n-hexadecil amônio

Tereftalato de bis-hidróxi etileno

Argila brasileira Brasgel

Cloreto de benzil trifenil fosfônio

Coordenação de Aperfeiçoamento de Pessoal de Nível Superior

Cloreto de cetil piridínio

Cloreto de cetil trimetil amônio

Capacidade de troca catiônica

Cloreto de alquil dimetil benzil amônio

Derivada da temperatura curva termogravimétrica TGA

Escola Politécnica da Universidade de São Paulo

Copolímero de acetato de vinil etileno enxertado com anidrido maleico

Fundação de Amparo à Pesquisa do Estado de São Paulo

Espectrometria no Infravermelho com Transformada de Fourier 
HB

HTAB

HRR

ICPM

IFUSP

IQUSP

LNLS

MEE

Meq

MMT

$\mathrm{N}-4 \mathrm{C} 8$

N919

OM

OMMT

OMT-C16

P(E-co-MA-co-GMA)

P-4C8

PA-6

PBT

PE

PE-g-GMA

PEO

PET
Queima horizontal

Brometo de hexadecil trimetil amônio

Taxa de liberação de calor

3-isocianato propil trimetóxi silano

Instituto de Física da Universidade de São Paulo

Instituto de Química da Universidade de São Paulo

Laboratório Nacional de Luz Síncrotron

Argila Somasif MEE

Miliequivalente

Montmorilonita

Brometo de tetraoctil amônio

Argila Nanofil 919

Microscopia ótica

Montmorilonita modificada organicamente

Montmorilonita modificada com cloreto de hexadecil trimetil amônio

Copolímero etileno-acrilato de metila-metacrilato de glicidila

Brometo de tetraoctil fosfônio

Poliamida - 6

Poli (tereftalato de butileno)

Polietileno

Polietileno enxertado com metacrilato de glicidila

Poli (óxido de etileno)

Poli (tereftalato de etileno) 
Ph

PMI

PMMA

PMT

PP

PP-g-MA

Praep

PS

R

RT

SEM

Tbb

Tdc

TEM

TGA

Ttb

UL94HB

USP

XRD

Fenil

Departamento de Engenharia de Minas e Petróleo

Poli (metacrilato de metila)

Departamento de Engenharia Metalúrgica e de Materiais

Polipropileno

Polipropileno enxertado com anidrido maleico

Cloreto de estearil dimetil amônio

Poliestireno

Cadeia carbônica

Retardante à Chama

Microscopia Eletrônica de Varredura

Brometo de tetrabutil fosfônio

Cloreto de tributil tetradecil fosfônio

Microscopia Eletrônica de Transmissão

Análise Termogravimétrica

Brometo de trihexil tetradecil fosfônio

Underwriters Laboratories Horizontal Burning

Universidade de São Paulo

Difração de Raios - X 


\section{LISTA DE SÍMBOLOS}

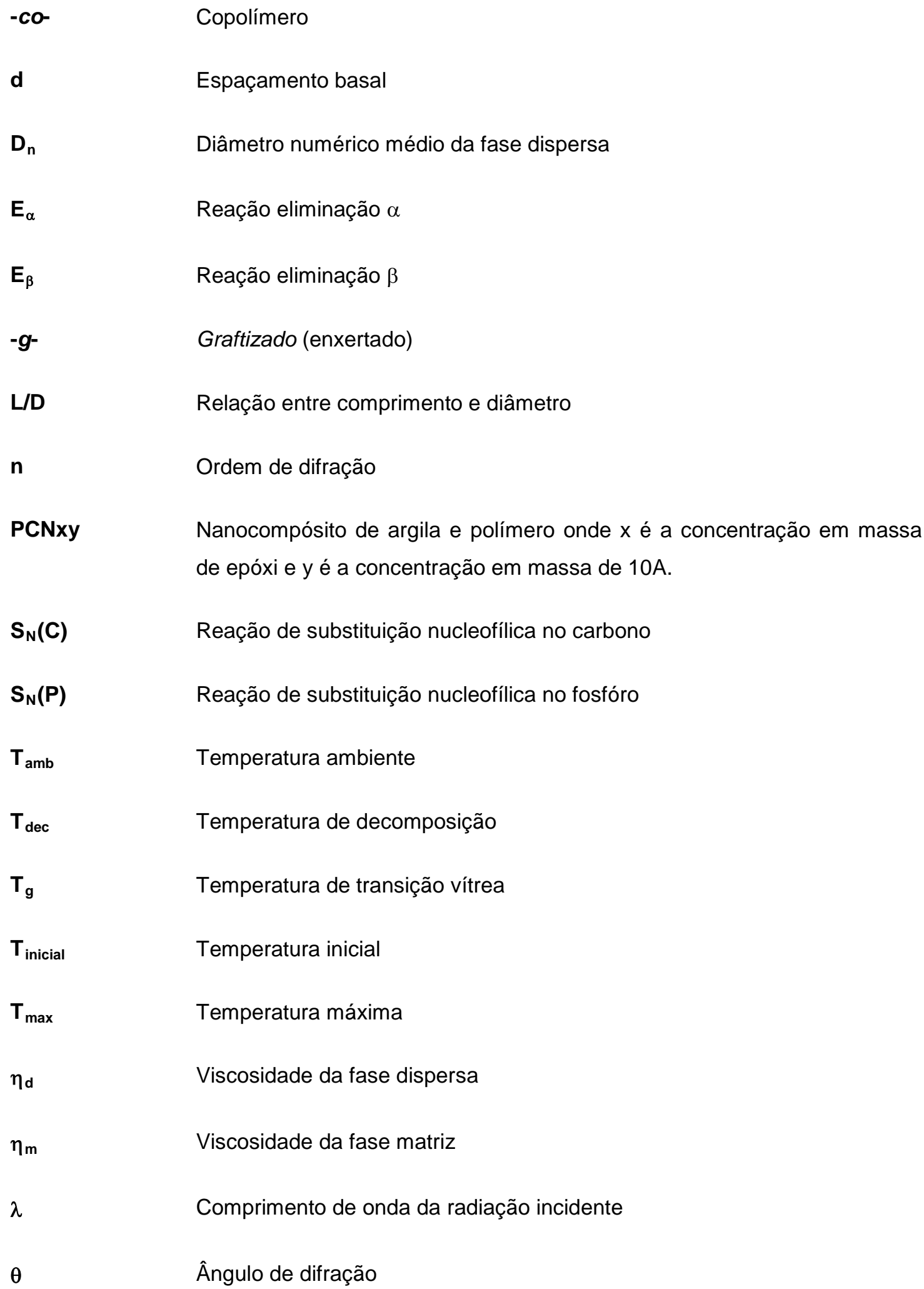

Temperatura de decomposição

Temperatura de transição vítrea

Temperatura inicial

Temperatura máxima

Viscosidade da fase dispersa

Viscosidade da fase matriz

Comprimento de onda da radiação incidente

Ângulo de difração 


\section{SUMÁRIO}

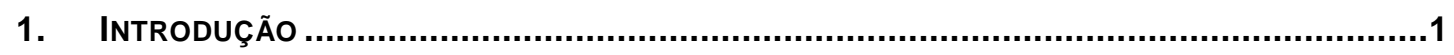

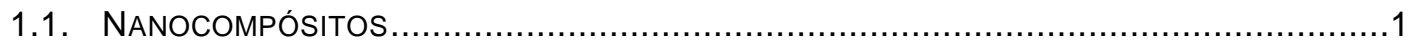

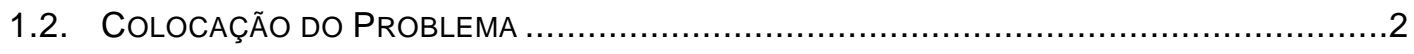

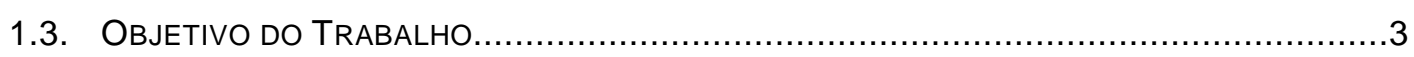

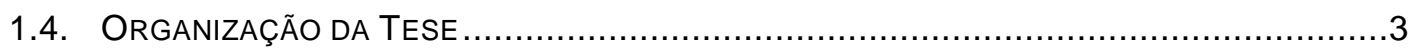

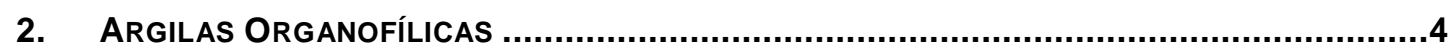

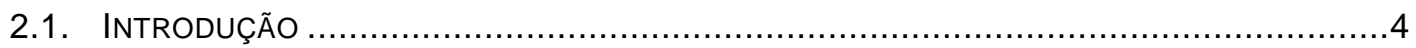

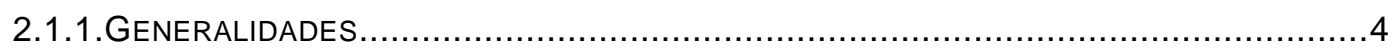

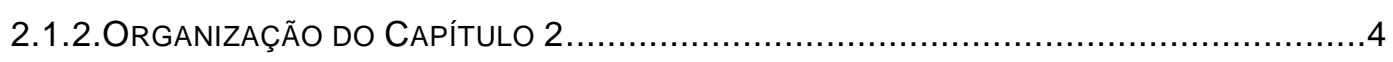

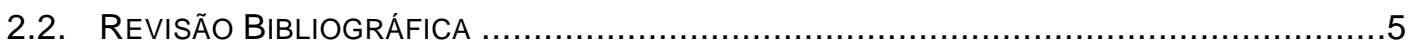

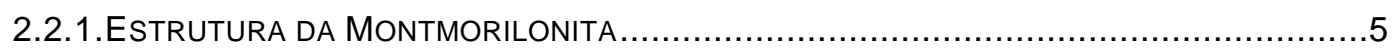

2.2.2. MODIFICAÇÃO ORGÂNICA DA MONTMORILONITA........................................... 6

2.2.3. Estabilidade TÉrmica da MontMorilonita Modificada ORganiCAMENTE ...........7

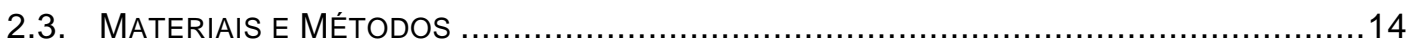

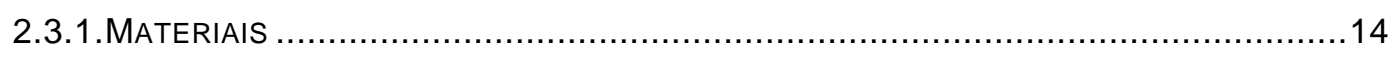

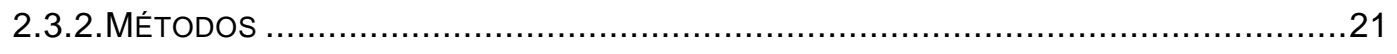

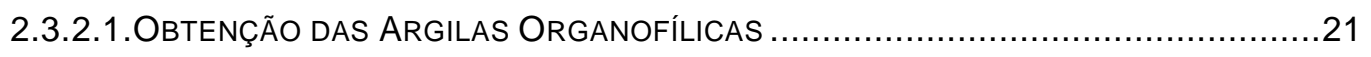

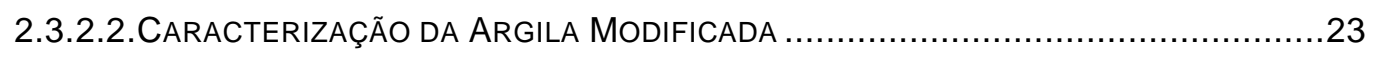

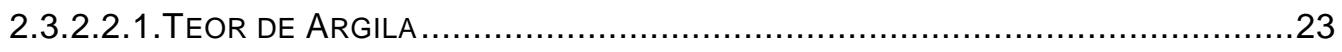

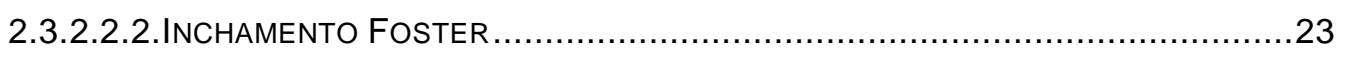

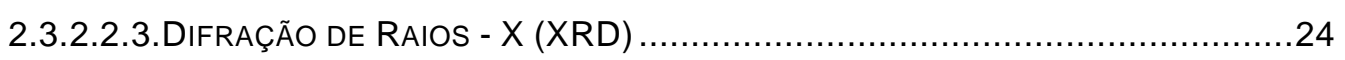

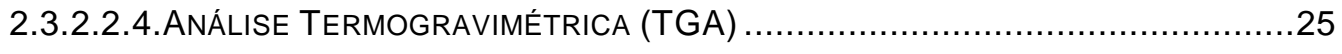

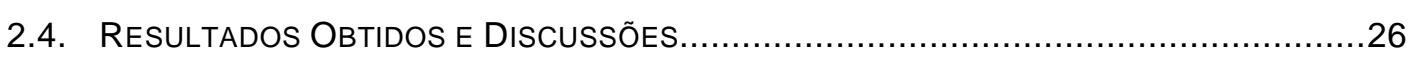

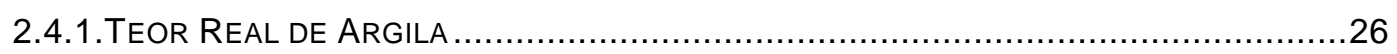

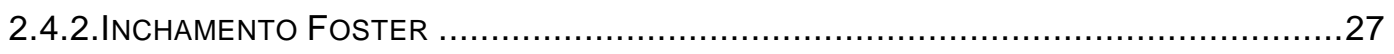

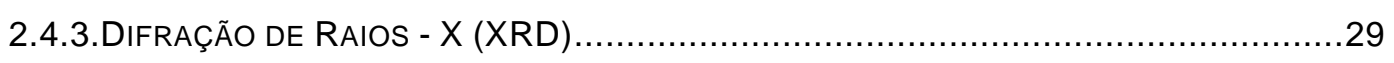

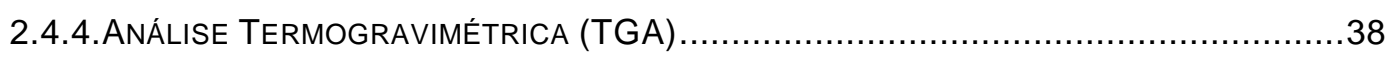

3. Propriedades de Engenharia de PBt/OMmts Sem agente tenacificante .........48

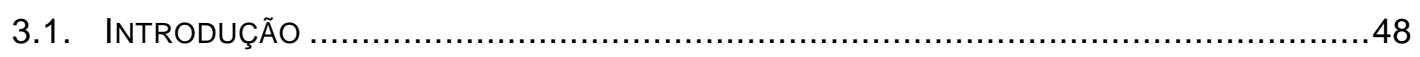

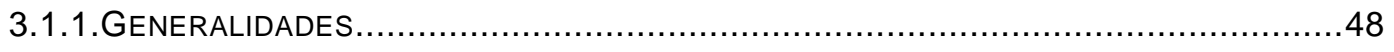

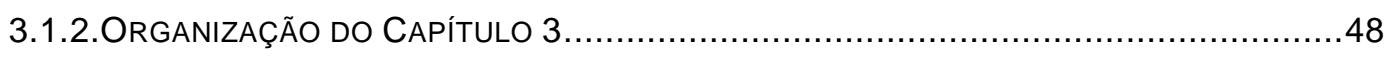

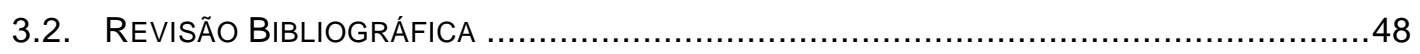

3.2.1.ESTRUTURA DOS NANOCOMPÓSITOS POLIMÉRICOS ......................................48

3.2.2. OBTENÇÃO DOS NANOCOMPÓSITOS POLIMÉRICOS ........................................50

3.2.3.PROPRIEDADES DOS NANOCOMPÓSITOS PoliMÉRICOS ......................................51 


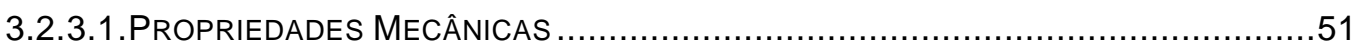

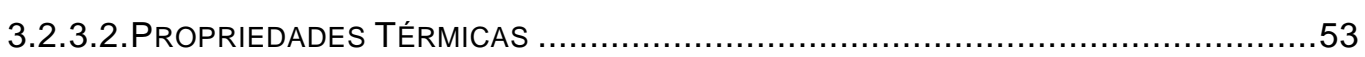

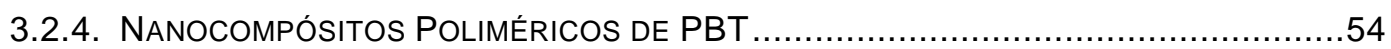

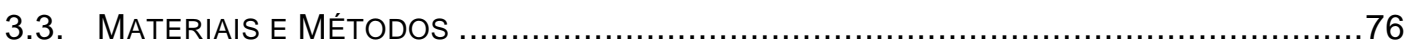

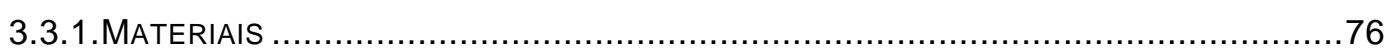

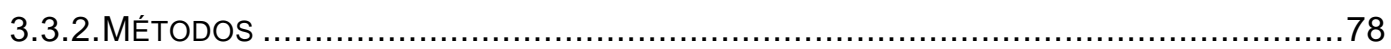

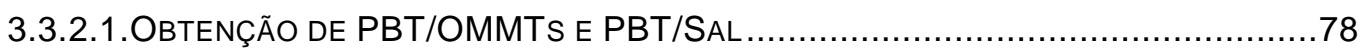

3.3.2.2. CARACTERIZAÇÃO E PROPRIEDADES DOS MATERIAIS .................................. 79

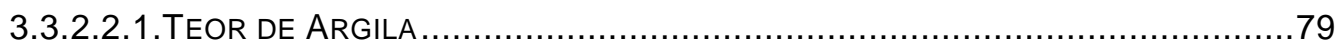

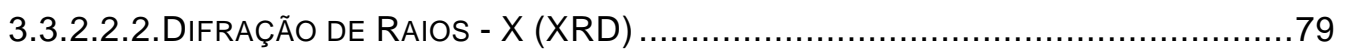

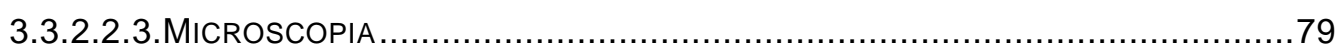

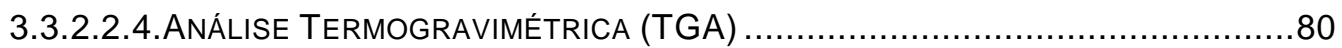

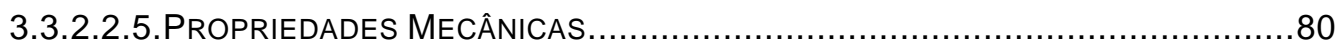

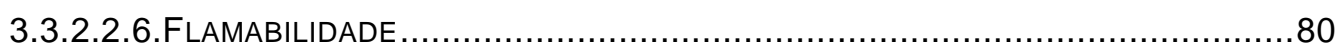

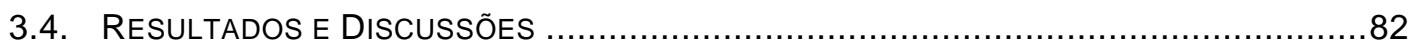

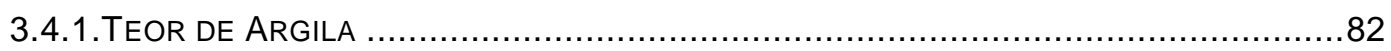

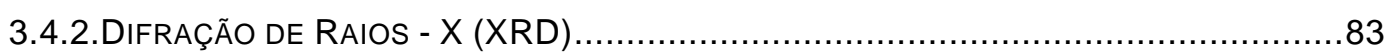

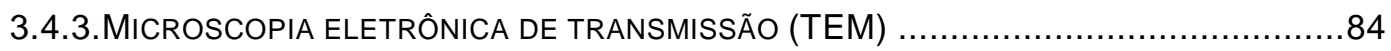

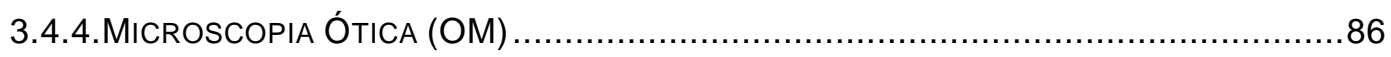

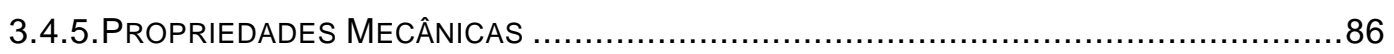

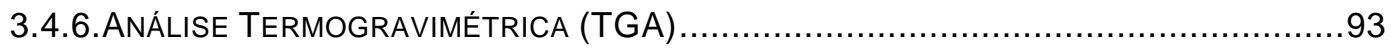

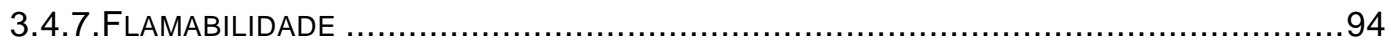

4. Propriedades de Engenharia de PBT/OMMTs com agente tenacificante.......100

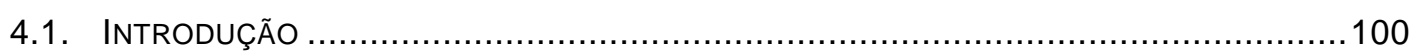

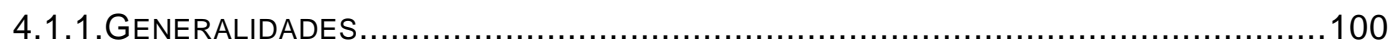

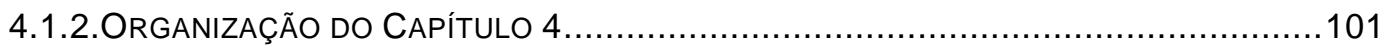

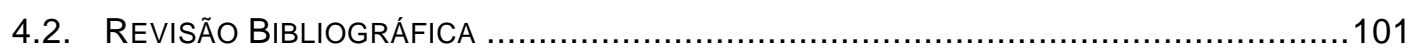

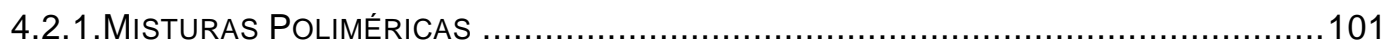

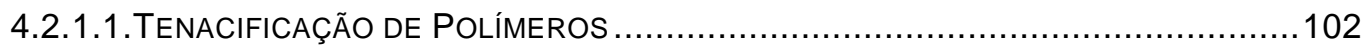

4.2.1.2. MISTURAS POLIMÉRICAS DE PBT / P(E-CO-MA-CO-GMA) .......................... 104

4.2.2. NANOCOMPÓSITOS DE MISTURAS POLIMÉRICAS .................................. 111

4.2.3. NANOCOMPÓSITOS DE MistuRAs POLIMÉRICAS CONTENDO P(E-CO-MA-CO-GMA) 112

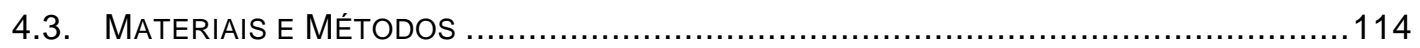

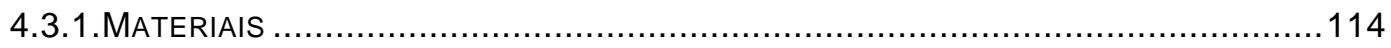

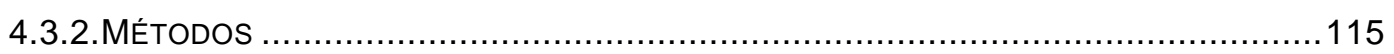

4.3.2.1. OBTENÇÃO DE PBT/ P(E-CO-MA-CO-GMA)/OMMTS ........................... 115

4.3.2.2.CARACTERIZAÇÃO E PROPRIEDAdES DOS MATERIAIS .............................117

4.3.2.2.1.MICROSCOPIA ELETRÔNICA DE VARREDURA (SEM) ........................118 
4.3.2.2.3.ESPECTROMETRIA NO INFRAVERMELHO COM TRANSFORMADA DE FOURIER (FTIR)

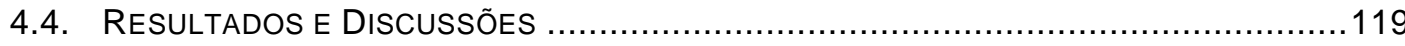

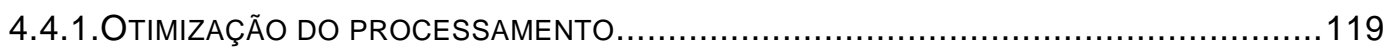

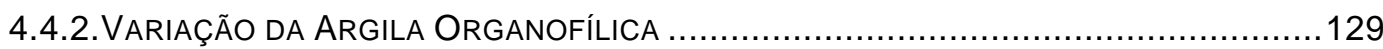

4.4.3. VARIAÇÃO DA COMPOSIÇÃO DA MISTURA POLIMÉRICA PBT/ (P(E-CO-MA-COGMA)/BRAPRAEP).

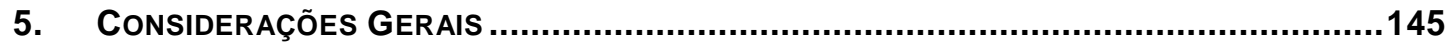

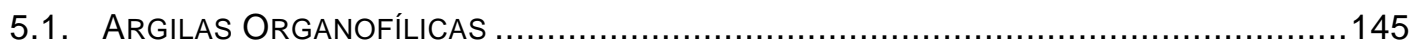

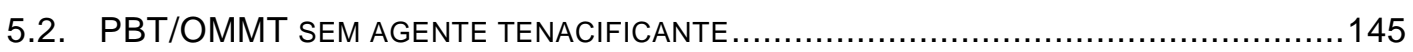

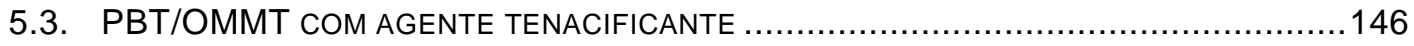

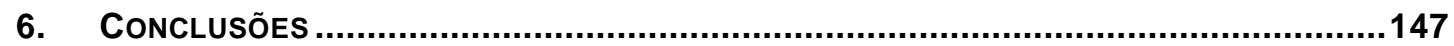

7. Contribuições Ao ConhECIMENTO ........................................................... 148

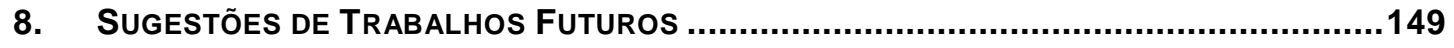

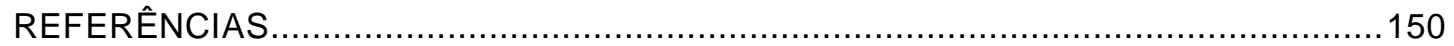

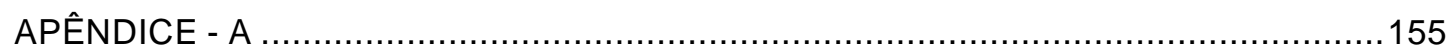

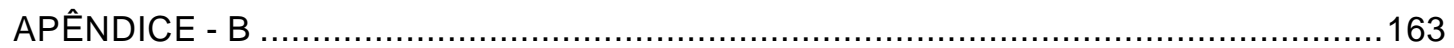

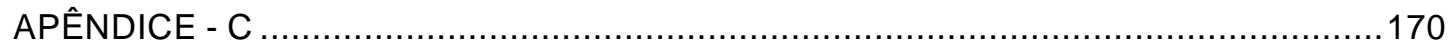




\section{Introdução}

\subsection{Nanocompósitos}

Por muito tempo, inúmeros trabalhos e pesquisas foram conduzidos no sentido de melhorar as propriedades de materiais poliméricos. Em particular cargas tais como partículas metálicas, cargas minerais ou fibras eram misturadas para obter compósitos poliméricos. Estes compósitos poliméricos convencionais geralmente requerem uma alta concentração de carga (20 a $35 \%)$ para apresentarem melhores propriedades e, geralmente, resultam em materiais mais pesados, o que pode representar um problema, por exemplo, em aplicações militares e aeroespaciais, ou na indústria de embalagens onde materiais mais leves são desejados.

Nos últimos anos começou a se utilizar cargas com dimensões muito menores e surgiram os nanocompósitos. Um nanocompósito é um material compósito no qual a fase dispersa possui uma, duas ou três dimensões nanométricas. Em particular, os nanocompósitos poliméricos podem ser obtidos a partir de combinações de polímeros e de argilas, em que estes últimos se encontram altamente dispersos nos primeiros. Os nanocompósitos de matriz polimérica reforçados com argilas são então obtidos com uma concentração bem pequena de argila, 2-10\% (Garcia, 2003; Silva; Oliveira; Sales, 2010).

Certos tipos de minerais, tais como argilas esmectitas têm a capacidade de esfoliarem em lamelas com espessuras da ordem de um nanômetro (1nm) e podem servir como cargas em polímeros. O comprimento e a largura das lamelas podem ter dimensões maiores (de 100 a 1000nm). Esta alta razão de aspecto (relação entre o comprimento e a espessura) confere uma grande área interfacial entre as argilas e os polímeros. Como conseqüência, ocorre uma mudança da natureza do polímero na vizinhança com a argila, como polímeros adsorvidos na superfície das lamelas de argila ou confinados entre estas lamelas. Se não há uma dispersão favorável, com fraca homogeneidade e a área de interação entre argila e polímero é ineficiente, o compósito resultante se apresenta como um compósito convencional, mesmo com partículas em escala nanométrica. Entretanto, como a obtenção de boa dispersão das 
partículas de argila no polímero resulta em uma área de interação muito alta entre a argila e o polímero, se desenvolvem propriedades também excepcionais no composto, como uma maior resistência ao calor, um módulo elástico alto, baixa viscosidade, estabilidade dimensional, boa aparência da superfície e propriedades de barreira melhoradas (Morgan; Wilkie, 2007).

Entre as argilas utilizadas nos nanocompósitos está a montmorilonita (MMT), uma argila do tipo esmectita. A MMT é hidrofílica, o que dificulta a dispersão em polímeros convencionais que têm caráter hidrofóbico. Por esta razão, normalmente se modifica a MMT através da substituição de seus íons de sódio por íons de caráter orgânico, oferecendo como resultado uma argila modificada organicamente (argila organofílica) que é compatível com os materiais plásticos, de maneira que as camadas da argila individuais possam se dispersar mais facilmente na matriz polimérica.

Uma vez dispersa nos materiais poliméricos, a argila organofílica pode se apresentar com várias morfologias: as suas lamelas podem ser agrupadas em aglomerados microscópicos (tactóides), separadas por moléculas de polímeros, mas ainda com certa organização (morfologia intercalada) ou totalmente isoladas resultando em uma morfologia chamada de esfoliada. Como dito anteriormente, de acordo com a dispersão da argila e o tipo de morfologia obtido, são desenvolvidas melhores propriedades para diversas aplicações.

\subsection{Colocação do Problema}

De uma forma geral, a obtenção de nanocompósitos poliméricos traz melhorias nas propriedades finais quando comparadas com as da matriz pura. Essas propriedades dependem principalmente da qualidade da dispersão da argila na matriz polimérica e do tipo de interação química e física entre as mesmas (aglomerados, intercalada ou esfoliada). A indústria acredita neste novo mercado e confia na potencialidade dos nanocompósitos para serem utilizados em várias aplicações. Assim, há muito que fazer para garantir a constância e a reprodutibilidade de propriedades, não sendo suscetível a alterações oriundas de envelhecimento, degradação, solicitação mecânica, térmica ou ambiental. 
O PBT é um plástico de engenharia, que possui as seguintes características: boa estabilidade dimensional, alta resistência química e excelentes propriedades de processamento, mas é passível de hidrólise. 0 PBT pode ser utilizado para obter materiais antichama que são aplicados em produtos que estão sujeitos a situações de risco de incêndio (Sabic Innovative Plastics). Todavia, para esta aplicação a resistência à chama do PBT tem que ser aperfeiçoada. Esta resistência à chama pode ser melhorada pela adição de halogênios, os quais não são ambientalmente corretos. Uma alternativa de melhorar as propriedades de resistência à chama do PBT é através da adição de nanopartículas. Na literatura existem poucas referências que tratam de nanocompósitos de PBT e não existe, do nosso conhecimento, trabalho sobre obtenção de nanocompósitos de PBT com argila brasileira beneficiada. Os trabalhos reportados em literatura relatam a utilização de argilas comerciais ou com beneficiamento de argilas oriundas de outras fontes.

\subsection{Objetivo do Trabalho}

Obtenção de nanocompósitos de PBT com argila brasileira modificada organicamente com sais quaternários de fosfônio e amônio a fim de obter melhoradas propriedades antichama, conservando as propriedades mecânicas.

\subsection{Organização da Tese}

A parte remanescente da tese está dividida da seguinte forma: nos capítulos 2. Argilas Organofílicas, 3. Propriedades de Engenharia de PBT/OMMTs sem agente tenacificante e 4. Propriedades de Engenharia de PBT/OMMTs com agente tenacificante, revisão bibliográfica, materiais e métodos, caracterização estrutural, propriedades avaliadas e resultados são apresentados. O capítulo 5. Considerações Gerais apresenta um sumário dos pontos mais importantes. O capítulo 6. Conclusões apresenta as conclusões deste trabalho, seguido do capítulo 7. Contribuições ao Conhecimento e capítulo 8. Sugestões de Trabalhos Futuros. Os Apêndices mostram resultados anexos. 


\section{Argilas Organofílicas}

\subsection{Introdução}

\subsubsection{Generalidades}

Argilas são materiais cerâmicos naturais de granulometria fina compostos principalmente de sílica, alumina e água. Embora argilas sejam abundantes na natureza e de custo relativamente baixo, a sua principal desvantagem é apresentar uma composição variável e numerosos contaminantes que são difíceis de serem eliminados (Utracki; Sepehr; Boccaleri, 2007), ou seja, as argilas são rochas compostas por um ou mais tipos diferentes de argilominerais, contendo impurezas em menor ou maior quantidade.

Quando se obtém nanocompósitos de matriz polimérica reforçados com argilas se utilizam freqüentemente argilas do grupo das esmectitas, entre elas a montmorilonita (MMT), mais utilizada e reportada em literatura, além da saponita e hectorita. Maiores detalhes sobre argilas podem ser encontrados em (Santos, 1975). A argila MMT é hidrofílica e a maioria dos polímeros é hidrofóbica. Dessa forma, esse caráter hidrofílico da argila deve ser modificado para organofílico, tornando-a compatível com polímeros.

Neste trabalho, a argila MMT foi modificada organicamente, por meio da troca catiônica, com a adição de sais quaternários de amônio e fosfônio. A avaliação da eficiência da troca catiônica foi avaliada por difração de Raios - X, inchamento em solventes e análise termogravimétrica.

\subsubsection{Organização do Capítulo 2}

Neste capitulo após uma revisão bibliográfica sobre a estrutura da montmorilonita, modificação orgânica e estabilidade térmica, a descrição dos materiais e métodos utilizados para a avaliação da troca catiônica em função da estrutura química dos sais quaternários é apresentada. Por fim os resultados obtidos são apresentados com as discussões. 


\subsection{Revisão Bibliográfica}

\subsubsection{Estrutura da Montmorilonita}

A montmorilonita (MMT), que é uma das argilas mais utilizadas para obtenção de nanocompósitos, consiste de lamelas de silicatos (silicato estratificado) que pertencem a uma família estrutural conhecida como filossilicatos 2:1 (grupo das esmectitas). A estrutura de seus cristais consiste de duas folhas de tetraedros de sílica com uma folha central de octaedros de óxido e hidróxido de alumínio unidas entre si por oxigênios comuns a estas folhas. A Figura 2.2.1.1 mostra a estrutura de uma argila esmectita.

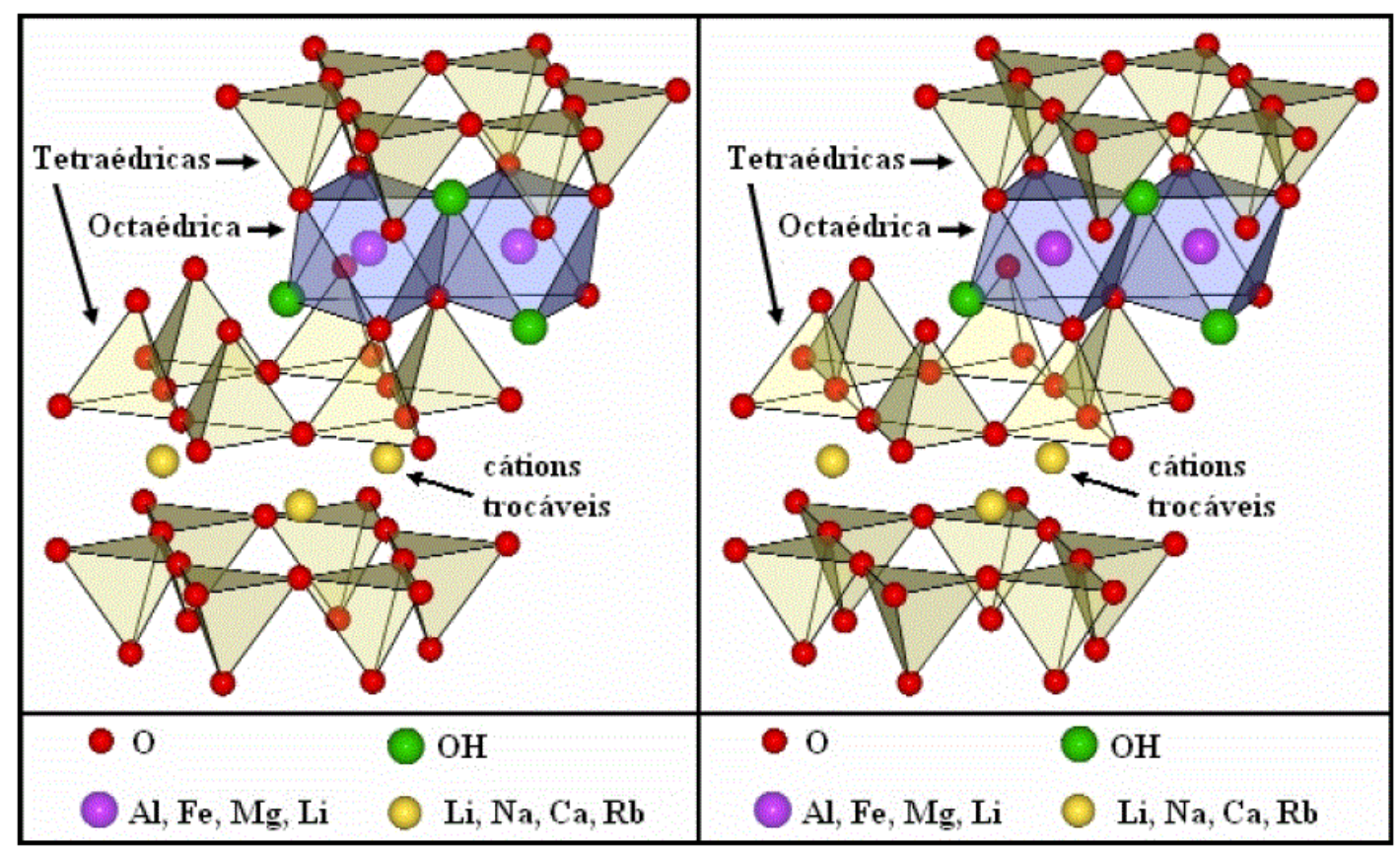

Figura 2.2.1.1 - Estrutura cristalina de uma esmectita em vista estereoscópica (Carastan, 2007)

A espessura da lamela é de aproximadamente $1 \mathrm{~nm}$ e as dimensões laterais destas lamelas podem variar de $30 \mathrm{~nm}$ a vários micrômetros ou mais, dependendo da argila. O empilhamento das lamelas conduz a um espaçamento regular que é chamado de interlamelar, galeria ou espaçamento basal. O empacotamento das lamelas é mantido por forças de van de Waals. A substituição isomórfica dentro das lamelas (por exemplo, $\mathrm{Al}^{3+}$ substituído por $\mathrm{Mg}^{2+}$ ou por $\mathrm{Fe}^{2+}$, ou $\mathrm{Mg}^{2+}$ substituído por $\mathrm{Li}^{+}$) gera cargas negativas que são 
contrabalanceadas por cátions alcalino ou alcalino terroso dentro das galerias, como, por exemplo, cátions de sódio ( $\left.\mathrm{Na}^{+}\right)$(Sinha Ray; Okamoto, 2003).

Com o objetivo de tornar a argila hidrofílica em organofílica é realizada a troca dos íons metálicos interlamelares por íons (cátions) que contém moléculas orgânicas. Esse processo é descrito brevemente a seguir.

\subsubsection{Modificação Orgânica da Montmorilonita}

A argila modificada organicamente (hidrofóbica), possui uma reduzida energia superficial, maior espaçamento entre as lamelas e deve ser mais compatível com a matriz polimérica (Turri, 2005). A Figura 2.2.2.1 mostra um esquema da troca catiônica.

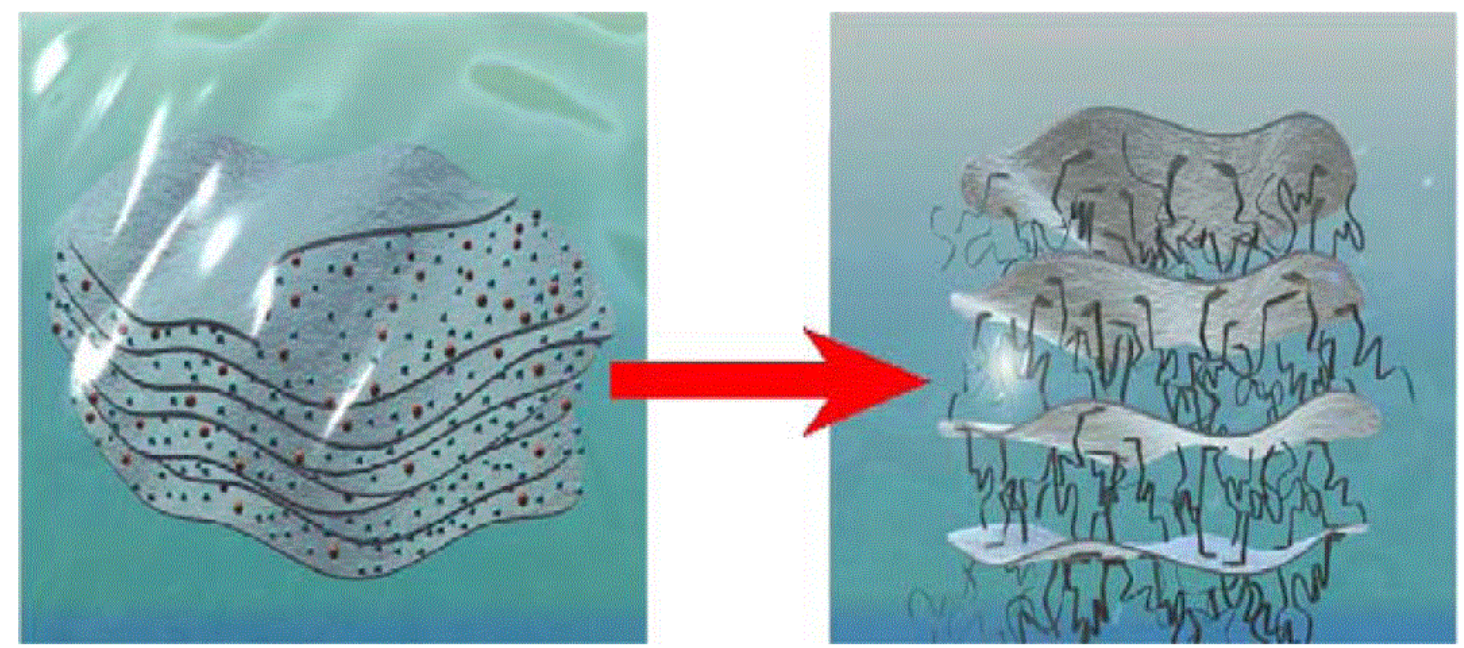

Figura 2.2.2.1 - Figura esquemática de uma troca catiônica (Fischer, 2003)

Pode ser visto na Figura 2.2.2.1 que os íons de sódio são substituídos por volumosos cátions orgânicos. A argila, que antes era hidrofílica, torna-se parcialmente hidrofóbica. Esses cátions orgânicos agem como surfactantes (modificadores de superfície) na troca catiônica, modificando a superfície da argila e permitindo a penetração do polímero.

Após a troca catiônica, as cadeias dos sais podem se localizar de três maneiras diferentes dentro da argila (Xi et al., 2005, 2007). A Figura 2.2.2.2 
mostra um esquema destas três regiões.

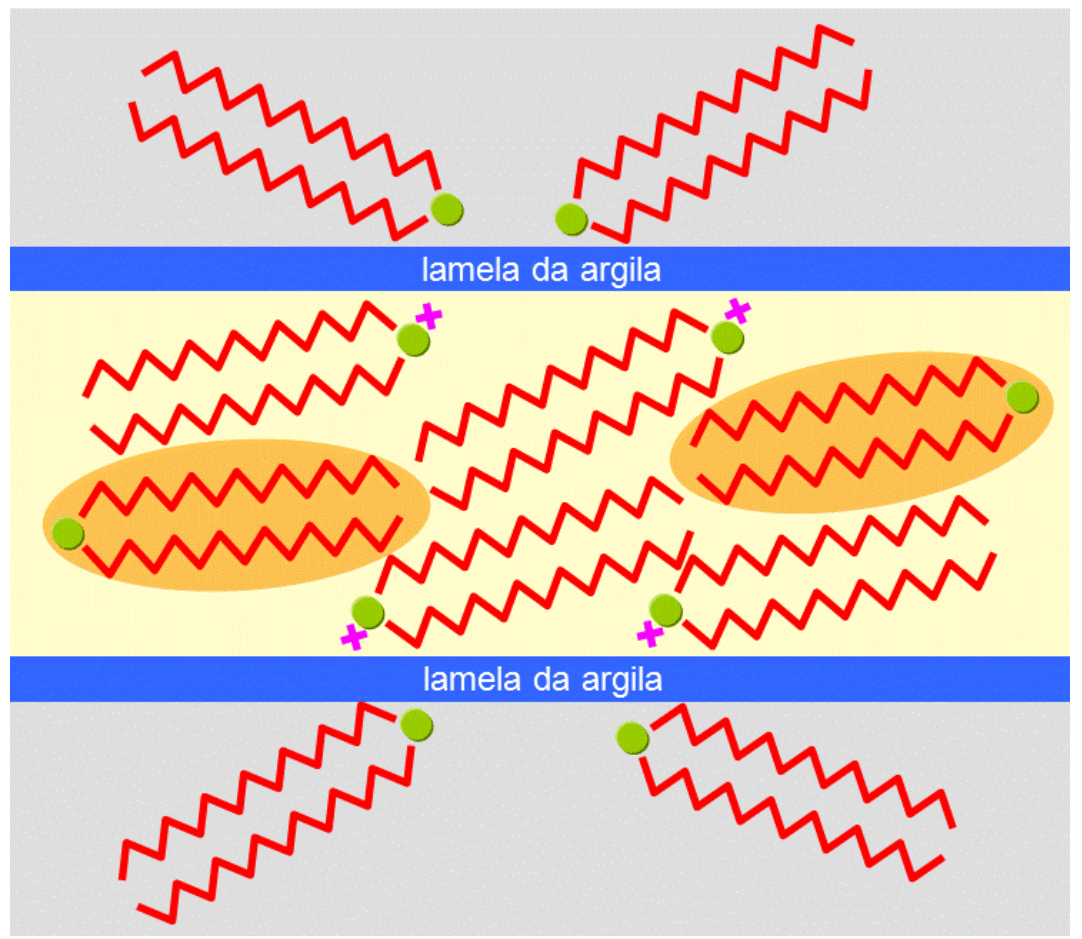

Figura 2.2.2.2 - Descrição das regiões de localização do sal após a troca catiônica (adaptada de Valera et al., 2009)

Os cátions podem (1) ser intercalados nos espaços interlamelares através da troca catiônica e ligados na superfície via interação eletrostática (região amarela); (2) adsorvidos na superfície externa das lamelas (região cinza); ou (3) localizadas dentro dos espaços interlamelares (região laranja) não ligados a superfície das argilas. Estes três tipos de localização do sal organofílico podem explicar a resistência térmica que os nanocompósitos resultantes da mistura das argilas organofílicas e polímeros possuem, como explicado a seguir.

\subsubsection{Estabilidade Térmica da Montmorilonita Modificada Organicamente}

Foi observado que as argilas modificadas preparadas com baixa concentração de sal, abaixo da capacidade de troca catiônica (CTC) da argila exibem melhor estabilidade térmica do que aquelas preparadas com alta concentração (Xie et al., 2001, 2002). Quando alta concentração de sal é 
utilizada, o sal adsorve nas bordas e na superfície das lamelas. Este sal adsorvido nas bordas e na superfície das lamelas resulta em uma menor estabilidade térmica das argilas. Entretanto, esse efeito pode ser minimizado através da lavagem após a troca catiônica para eliminar o sal em excesso.

A estabilidade térmica das argilas modificadas também depende da natureza do sal como mostrado a seguir.

Xie et al. (2001, 2002) estudaram a estabilidade térmica de sais quaternários de amônio e fosfônio. A Figura 2.2.3.1 mostra as derivadas de perda de massa para argilas organofílicas N-4C8 (brometo de tetraoctil amônio) e P-4C8 (brometo de tetraoctil fosfônio).

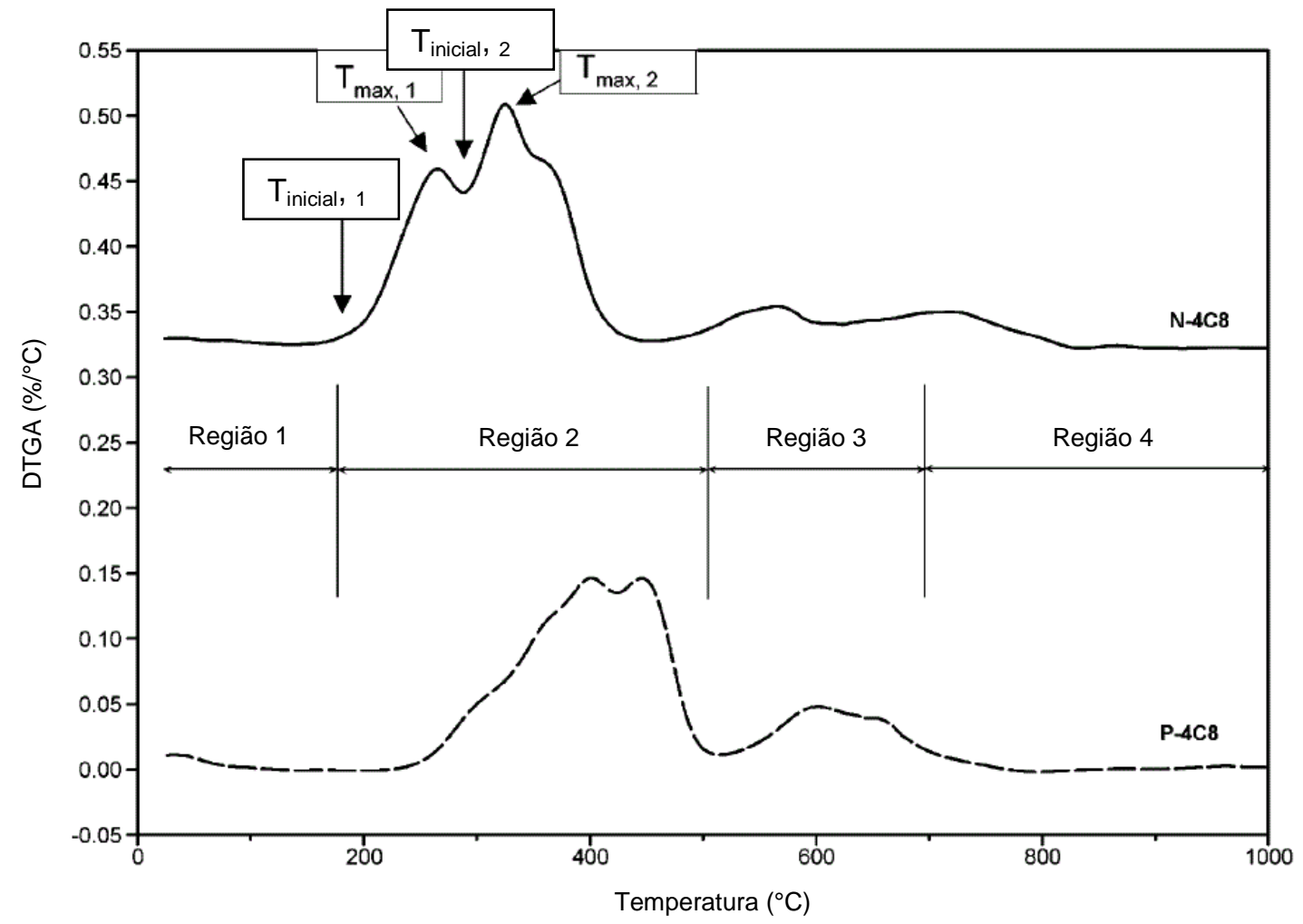

Figura 2.2.3.1 - Derivadas da perda de massa para sal de amônio (N-4C8) e sal de fosfônio (P-4C8) (adaptada de Xie et al., 2002)

Essas curvas podem ser divididas em 4 regiões: (1) perda de água e gases abaixo de $200^{\circ} \mathrm{C}$, (2) perda de substâncias orgânicas entre 200 e $500^{\circ} \mathrm{C}$, (3) desidroxilação da argila entre 500 e $700^{\circ} \mathrm{C}$ e (4) formação de resíduo carbonoso entre 700 e $1000^{\circ} \mathrm{C}$. O primeiro pico exotérmico na região 2 representa o ponto no qual o sal quaternário intercalado começa a decompor. A 
única diferença neste exemplo é o cátion (amônio ou fosfônio). O átomo de fósforo é maior que o átomo de nitrogênio. Essa diferença de arranjo espacial de elétrons faz com que as mesmas reações sejam facilitadas no caso de amônio e dificultadas no caso de fosfônio. Dessa forma, os sais quaternários de fosfônio sofrem suas reações químicas em temperaturas maiores do que os sais quaternários de amônio. Resultados semelhantes foram observados por He et al. (2006); Hedley, Yuan e Theng (2007) e Calderon, Lennox e Kamal (2008).

As diferenças de resistência térmicas dos sais quaternários de amônio e fosfônio podem ser explicadas pelas reações que estes sofrem. Essas reações químicas são mostradas a seguir.

\section{Reações Químicas com Sais Quaternários de Amônio}

A degradação de sais quaternários de amônio a base de cloretos (puros ou com argilas organofílicas) geralmente seguem reações de eliminação ou substituição (Xie et al., 2002; Cui et al., 2008). A Figura 2.2.3.2 mostra um exemplo representativo de uma substituição nucleofílica.

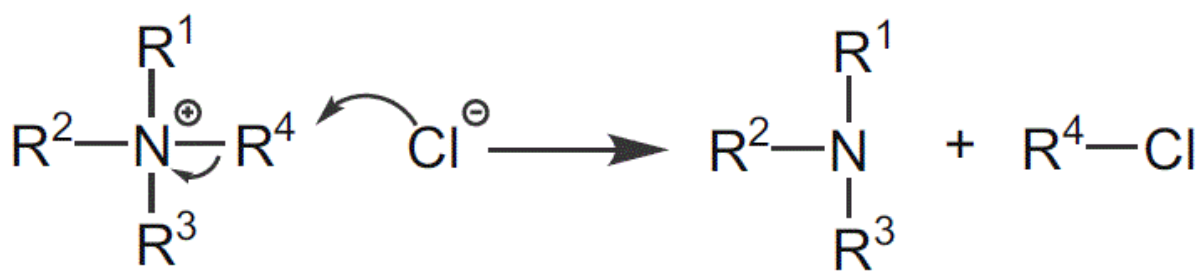

Figura 2.2.3.2 - Substituição nucleofílica conduzindo à decomposição de um surfactante de amônio (Cui et al., 2008)

Pode ser observado neste esquema o ataque nucleofílico ao $\mathrm{R}_{4} \mathrm{~N}^{+}$por um íon cloreto, conduzindo a formação de $\mathrm{RCl}$ e $\mathrm{R}_{3} \mathrm{~N}$, que é a reação reversa da síntese da maioria dos sais quaternários de amônio. O ataque nucleofílico é preferencial para cadeias alquílicas estericamente impedidas, por exemplo, grupo metila ou para cadeias alquílicas eletrofílicas, por exemplo, grupo benzil.

Quando um sal quaternário de amônio é decomposto em uma oleofina e uma amina terciária, sob condições básicas, como por exemplo, água, o processo é chamado reação de eliminação do tipo Hoffmann, como mostrado na Figura 2.2.3.3. 
<smiles>[R]N([R])[N+]([R])=CCC[R]([R])([H])C(CO)CC[N+]([R7])([R])[R]</smiles>

Figura 2.2.3.3 - Reação de eliminação do tipo Hoffmann (Cui et al., 2008)

Entretanto, após a troca catiônica com a montmorilonita, a presença de Si e Al favorecem a reação de eliminação do tipo Hoffmann, como mostrado na Figura 2.2.3.4.<smiles>CN([IH])CCO</smiles>

Figura 2.2.3.4 - Ativação de um grupo hidroxietil com a presença de um Al em uma argila organofilica (Cui et al., 2008)

\section{Reações Químicas com Sais Quaternários de Fosfônio}

Em função do grande tamanho do átomo de fósforo e o fato de que seus orbitais $d$ de baixa camada participam na formação e quebra de ligações químicas, os sais quaternários de fosfônio são capazes de sofrer um grande número de reações e comportam-se de forma diferente do que os sais quaternários de amônio com relação à uma ação de um agente externo de caráter básico.

A Figura 2.2.3.5, esquema 1, mostra os tipos de reações para sais tetraalquil puros ou intercalados na montmorilonita sob determinadas condições básicas (B) e altas temperaturas. Maiores detalhes podem ser encontrados em (Xie et al., 2002). 


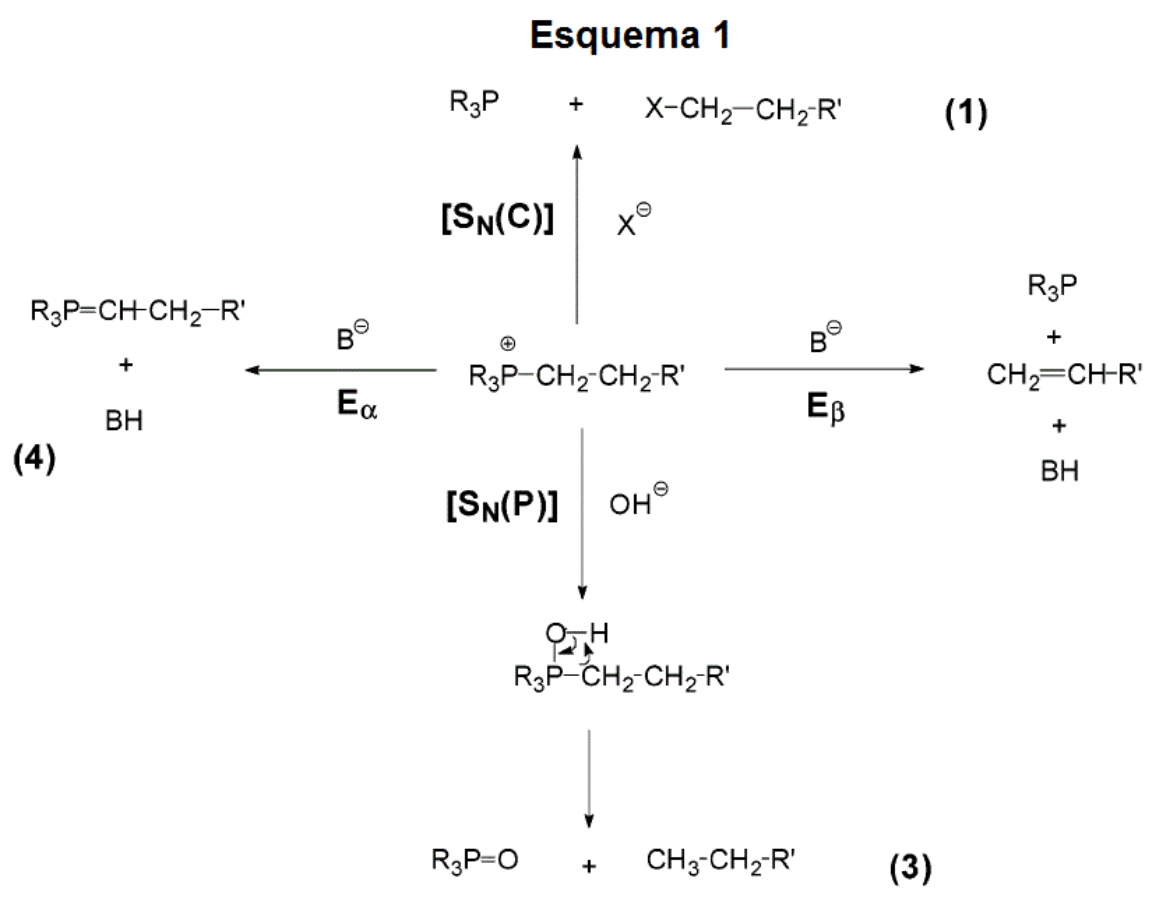

Figura 2.2.3.5 - Reações de degradação para sais tetraalquil fosfônio (adaptada de Xie et al., 2002)

A reação (1) corresponde à reação de substituição nucleofílica no carbono central $\alpha,\left[S_{N}(C)\right]$. Ela é iniciada com o ataque nucleofílico por um halogênio, formando um grupo trifenil fosfina, a qual é a reação inversa de síntese. Durante essa reação, há uma mudança de $\mathrm{P}^{+5}$ para $\mathrm{P}^{+3}$, que é um processo de eliminação redutiva.

A reação (2) corresponde à reação de eliminação- $\beta, E_{\beta}$. No meio básico, o próton- $\beta$ é subtraído pela base com a expulsão do grupo trifenil fosfina do carbono $\alpha$.

A reação (3) corresponde à reação de substituição no fósforo $\left[S_{N}(P)\right]$. A hidroxila ataca o fósforo central para formar um composto intermediário que se separa em um óxido fosfano e um alcano. A força motriz para a reação é a formação da forte ligação fosforil $(P=O)$.

A reação (4) corresponde à reação de eliminação- $\alpha, E_{\alpha}$. Ela só ocorre em presença de base muito forte, na qual o próton- $\alpha$ é subtraído para conversão em compostos carboxila para olefinas. Essa reação é conhecida como reação de Wittig. 
As reações 1, 2 e 3 podem ocorrer tanto para os sais puros como para os sais intercalados na montmorilonita.

A Figura 2.2.3.6 mostra reações para o sal tipo tetrafenil fosfônio.

\section{Esquema 2}

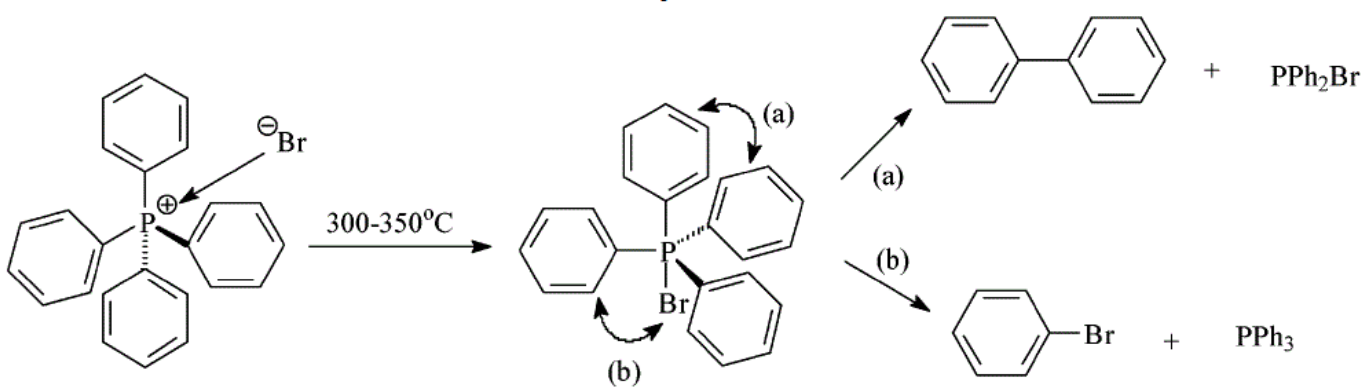

Esquema 3
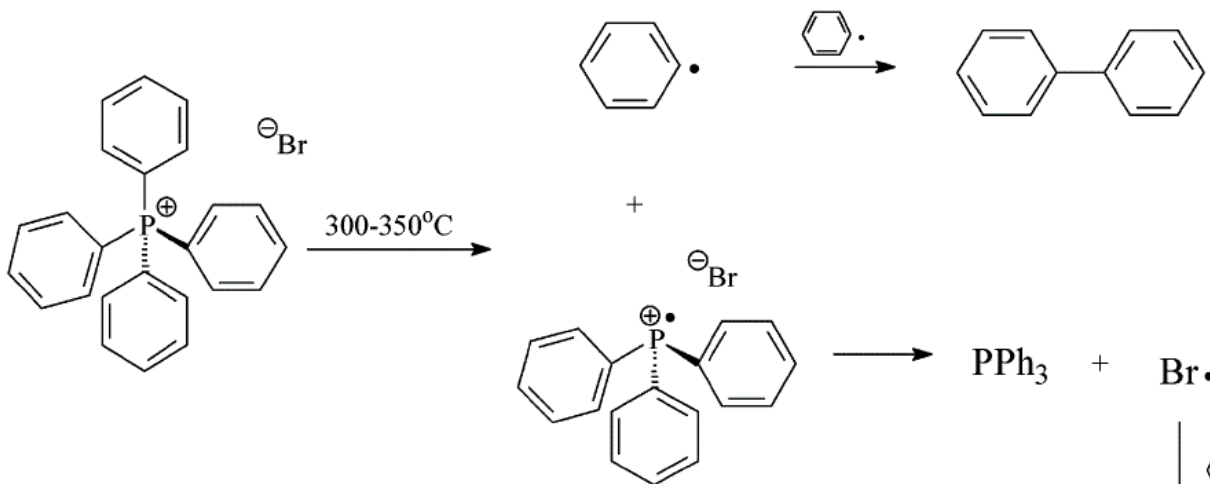

$\longrightarrow \mathrm{PPh}_{3}+\mathrm{Br}$.

Figura 2.2.3.6 - Reações de degradação para sais tetrafenil fosfônio (adaptada de Xie et al., 2002)

Em comparação com as reações anteriores, no caso dos grupos fenil há ausência de hidrogênio- $\alpha$, e dessa forma, não ocorre a eliminação- $\alpha$. Para a ocorrência de eliminação- $\beta$, ela não é favorecida energeticamente para a formação de benzina e requer uma base muito forte.

Dessa forma, duas reações são possíveis. A primeira delas é o esquema 2, na qual ocorre a formação de um composto intermediário bromo tetrafenil fosfano que rapidamente sofre uma eliminação redutiva e forma os compostos representados no esquema 2 por a) e b). Porém, $\mathrm{PPh}_{2} \mathrm{Br}$ é instável e pode se decompor em radical $\mathrm{PPh}_{2}$ e átomo de $\mathrm{Br}$. 
A segunda delas é o esquema 3. Essa reação envolve a formação do radical trifenil fosfônio e do radical fenil através de uma ruptura homolítica da ligação P-fenil. Subseqüentemente, o radical fenil pode se combinar com outro radical e formar um bifenil ou se combinar com um átomo de $\mathrm{Br}$ para formar $\mathrm{PhBr}$. O átomo de $\mathrm{Br}$ é produzido a partir da redução do radical trifenil fosfônio para trifenil fosfina por um agente de $\mathrm{Br}$.

A Figura 2.2.3.7 mostra as reações dos sais de fosfônio tipo tetrafenil fosfônio intercalados na montmorilonita.

\section{Esquema 4}
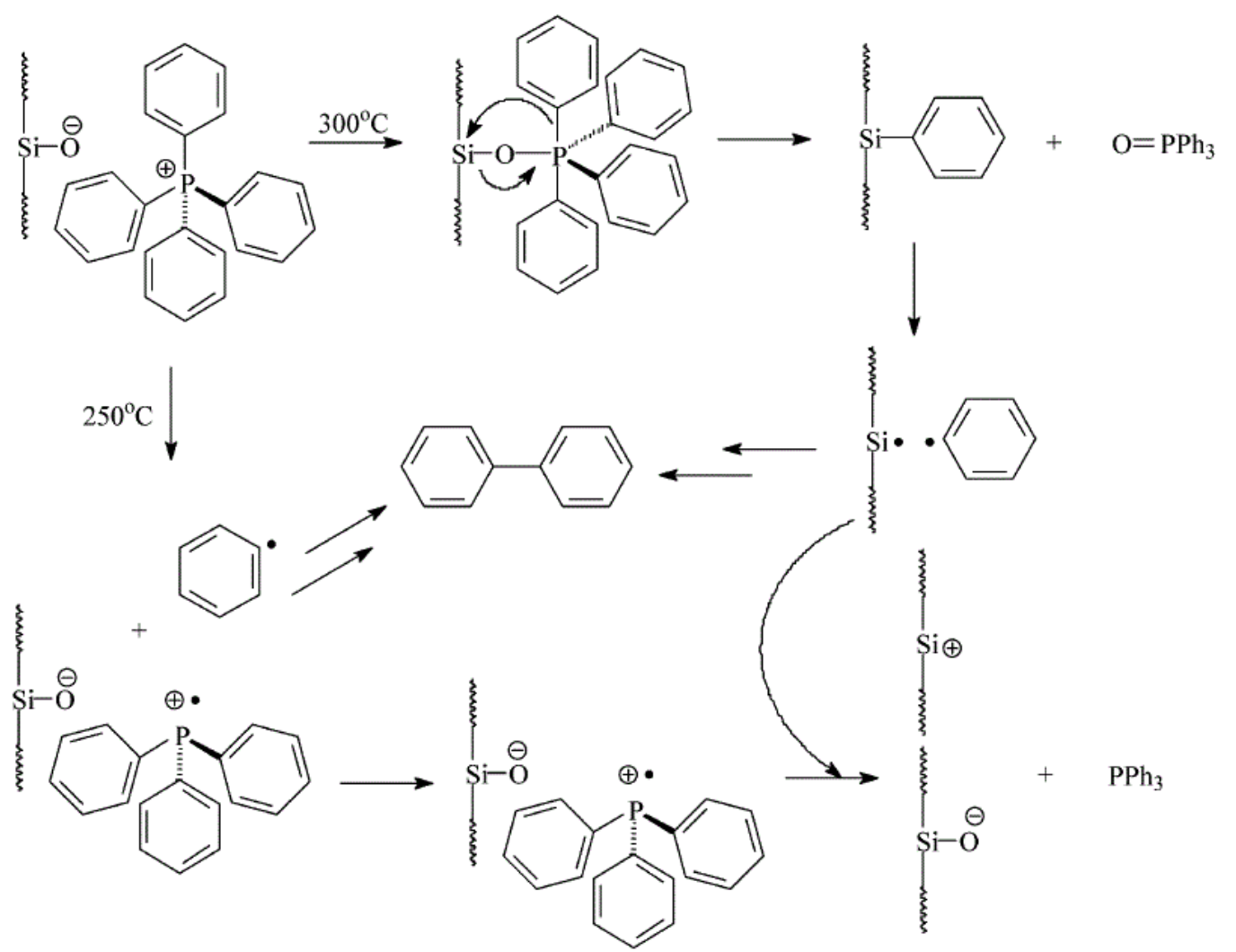

Figura 2.2.3.7 - Reações para sais tetrafenil fosfônio intercalados na montmorilonita (adaptada de Xie et al., 2002)

Estas reações são similares àquelas descritas como $\left[\mathrm{S}_{N}(P)\right]$ para tetralquil fosfônio. Entretanto, a diferença é que o substituinte do fenil migra para o Si-O da argila ou para um defeito de superfície da argila liberando óxido de trifenil. Uma ruptura homolítica de Si-fenil gera um radical fenil e um radical livre de Si na superfície da argila. Uma recombinação de dois radicais fenil resulta em um 
bifenil e este radical remanescente pode favorecer a formação de trifenil fosfina por sua vizinhança com um trifenil fosfônio.

Além do sal quaternário de fosfônio, outros tipos de sais, com boa estabilidade térmica foram utilizados: fosfônio, piridínio, imidazólio, quinolínio, imínio, estibônio, sulfônio, pirrolidínio e ferrocênio. Entretanto, os compostos de fósforo têm sido muito utilizados na indústria de retardantes a chama ou que requerem estabilidade térmica.

Neste trabalho, a fim de melhorar a resistência térmica e a resistência à chama de nanocompósitos de PBT contendo argilas brasileiras, vários sais quaternários de amônio e fosfônio foram utilizados para modificar argilas que foram posteriormente misturadas a PBT objetivando a obtenção de nanocompósitos. O processo de troca catiônica foi avaliado e as argilas, após a troca catiônica, foram testadas quanto às suas propriedades térmicas.

\subsection{Materiais e Métodos}

\subsubsection{Materiais}

Foram utilizados três tipos de argilas MMT comerciais: a argila bruta Brasgel, fornecida pela Bentonita do Nordeste e as argilas comerciais, Cloisite 20A e Cloisite 30B, da Southern Clay.

A argila Brasgel sódica possui uma CTC de 69 meq/100g (Valera et al., 2010) e a sua composição química é mostrada na Tabela 2.3.1.1.

Tabela 2.3.1.1 - Composição Química da Brasgel (Valera et al., 2010)

\begin{tabular}{cc}
\hline Componente & $\begin{array}{c}\text { Porcentagem } \\
\text { (\% massa) }\end{array}$ \\
\hline $\mathrm{SiO}_{2}$ & 53,89 \\
$\mathrm{Al}_{2} \mathrm{O}_{3}$ & 18,17 \\
$\mathrm{Fe}_{2} \mathrm{O}_{3}$ & 9,4 \\
$\mathrm{MgO}$ & 2,89 \\
$\mathrm{CaO}$ & 1,64 \\
$\mathrm{Na}_{2} \mathrm{O}$ & 2 \\
$\mathrm{TiO}_{2}$ & 1,2 \\
$\mathrm{~K}_{2} \mathrm{O}$ & 1,66 \\
Perda ao fogo & 9,64 \\
\hline
\end{tabular}


A argila Brasgel foi modificada utilizando vários sais quaternários. Três sais quaternários de amônio foram utilizados neste trabalho, visando a comparação com trabalhos anteriores do Laboratório de Análise e Processamento de Materiais Poliméricos do Departamento de Engenharia Metalúrgica e de Materiais da Escola Politécnica da Universidade de São Paulo (PMT-EPUSP) (Lins, 2007; Coelho, 2008; Valera et al., 2010). Sais quaternários de fosfônio foram também escolhidos para avaliar a influência da estrutura do sal na argila aliada à sua alta estabilidade térmica na matriz PBT, a qual possui altas temperaturas de processamento. Os sais quaternários utilizados, assim como algumas das suas propriedades, são mostrados na Tabela 2.3.1.2. As estruturas tridimensionais apresentadas nestes trabalhos são apenas ilustrativas e foram desenhadas com auxilio do software (ArgusLab 4.0.1, 2009). 
Tabela 2.3.1.2 - Fórmulas e estruturas dos sais quaternários

Hidrogênio Carbono Nitrogênio $\bigcirc$ Fósforo $\bigcirc$ Cloro Bromo

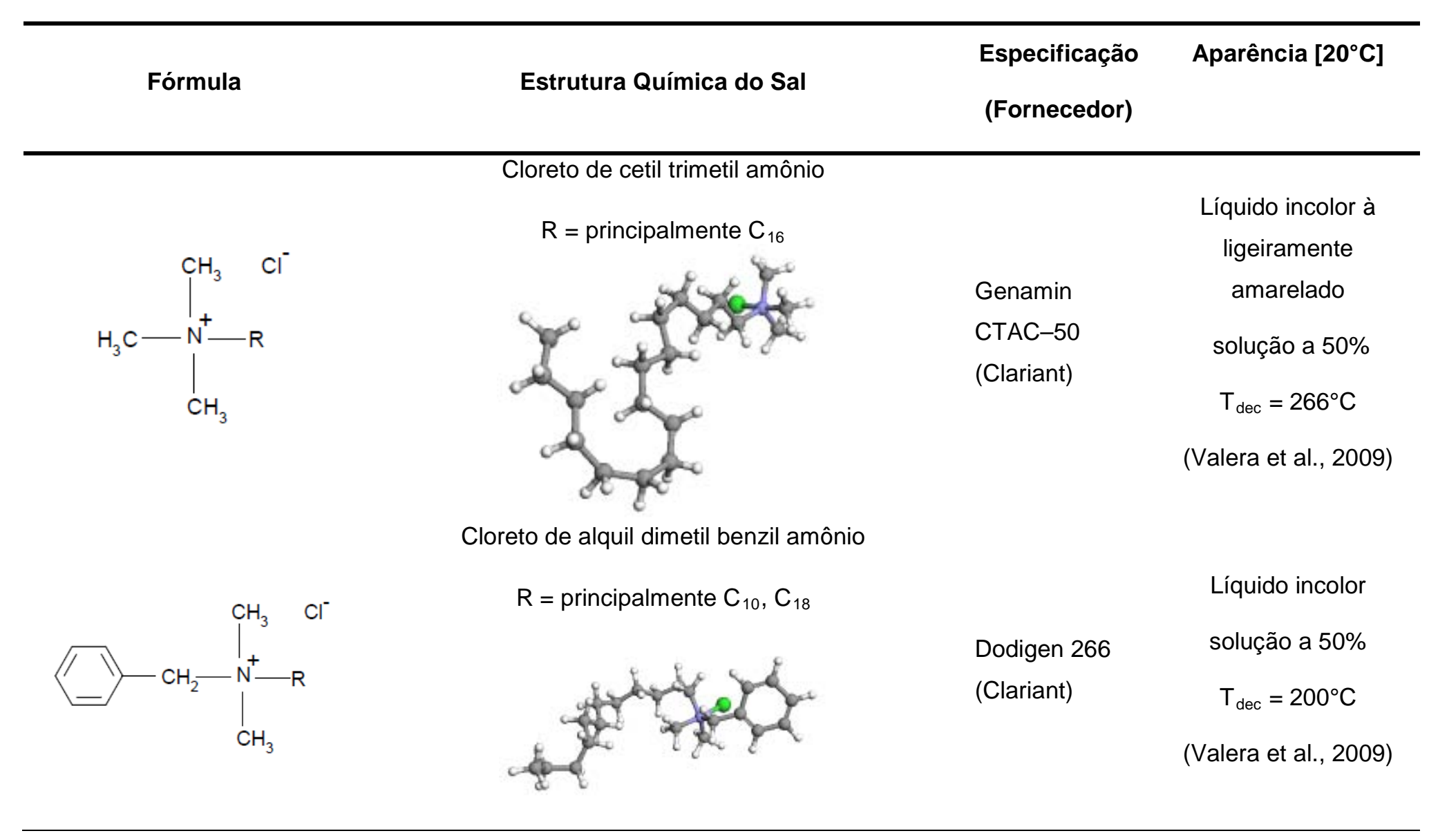


Hidrogênio Carbono Nitrogênio $\bigcirc$ Fósforo $\bigcirc$ Cloro $\bigcirc$ Bromo

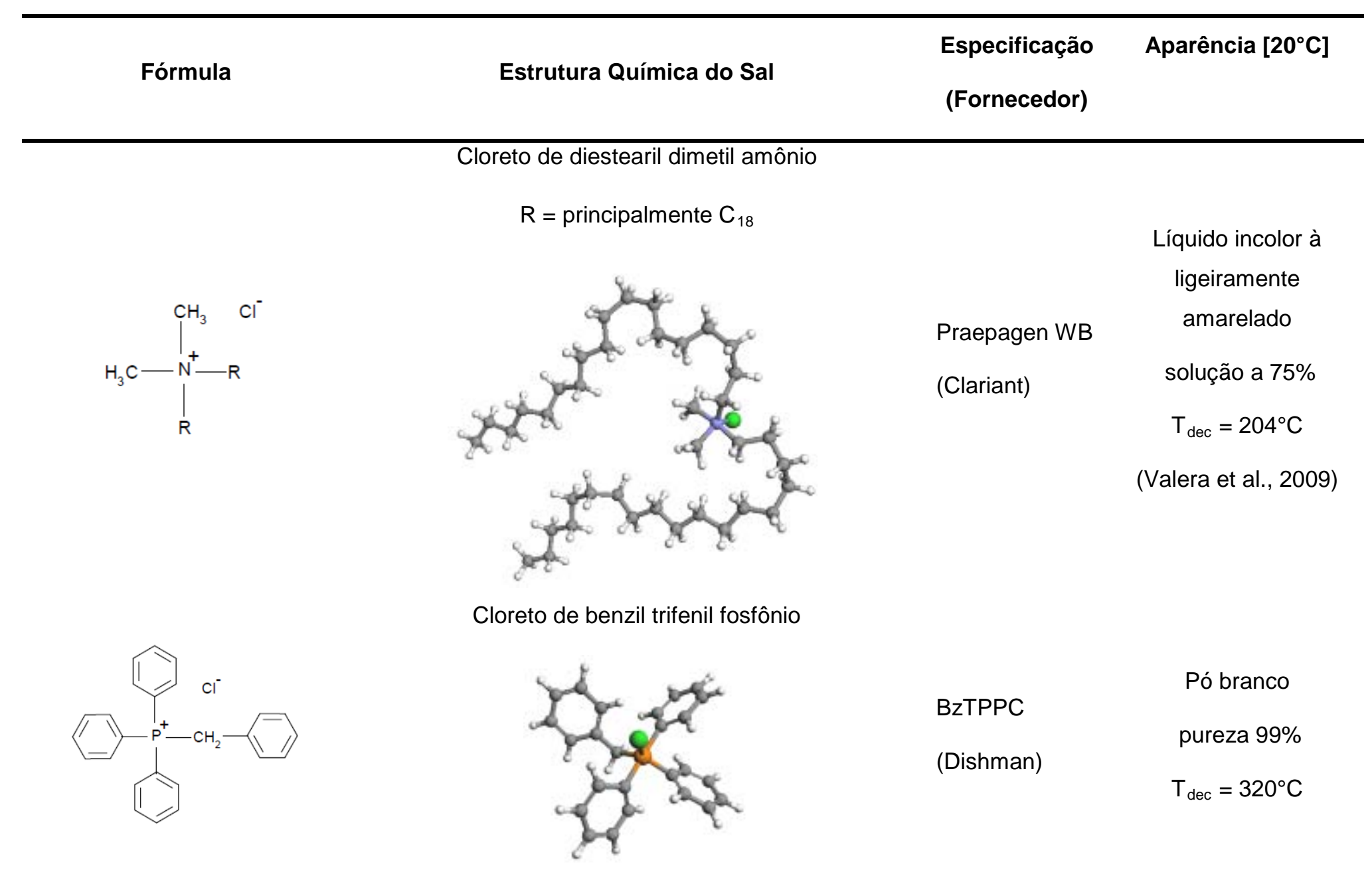


Hidrogênio Carbono Nitrogênio Fósforo Cloro Bromo

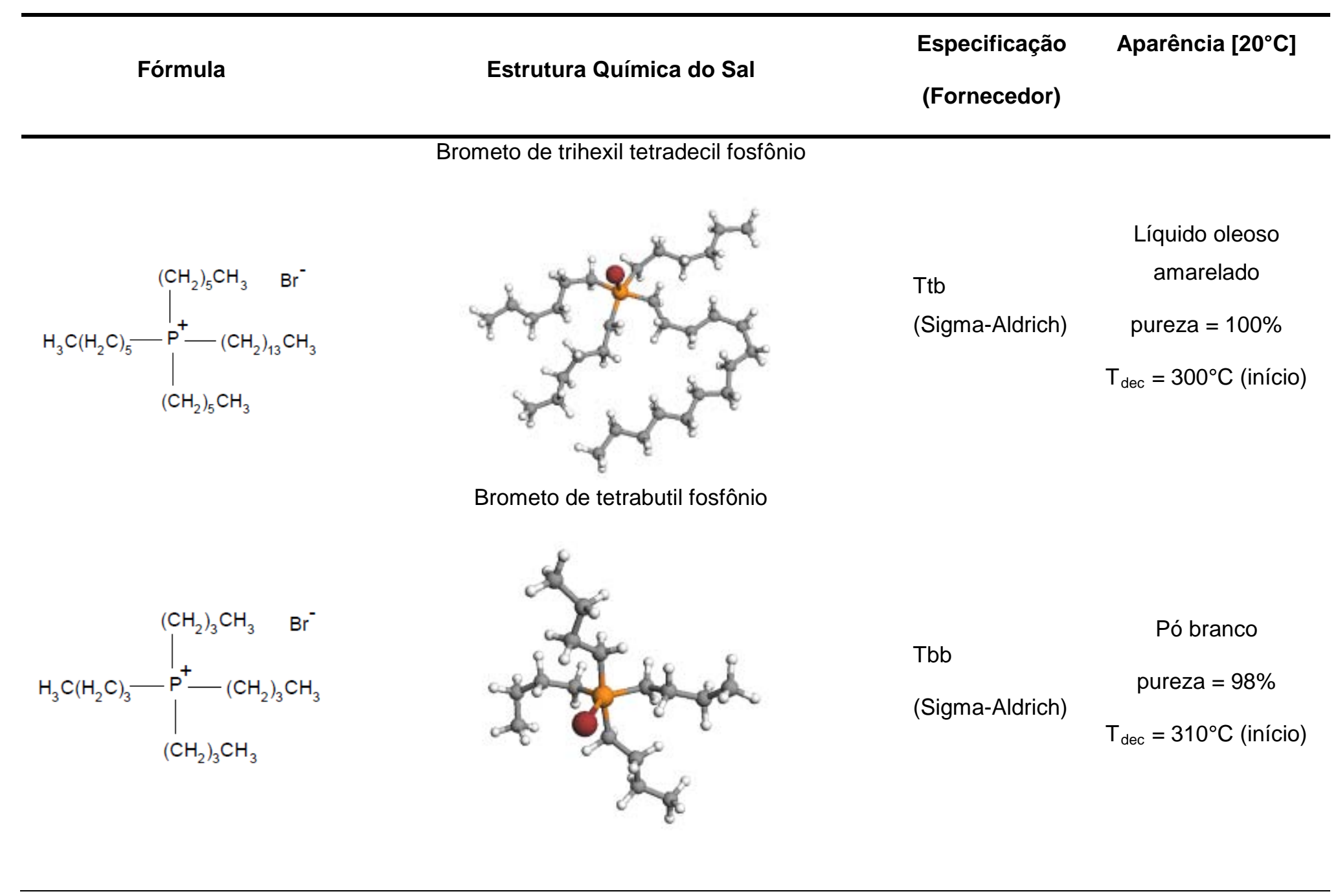


Hidrogênio Carbono $\bigcirc$ Nitrogênio $\bigcirc$ Fósforo $\bigcirc$ Cloro $\bigcirc$ Bromo

$\begin{array}{lll}\text { Fórmula } & \text { Estrutura Química do Sal } & \text { Especificação } \\ \text { (Fornecedor) }\end{array}$


As Cloisites 20A e 30B já são adquiridas modificadas pelos sais Di(alquil de sebo hidrogenado) dimetil amônio (20A) e (alquil de sebo) dihidroxietil metal amônio (30B) como mostrado na Tabela 2.3.1.3.

Tabela 2.3.1.3 - Propriedades das Cloisites 20A e 30B

Hidrogênio Carbono Oxigênio Nitrogênio Cloro

\begin{tabular}{ccc}
\hline $\begin{array}{c}\text { Argila } \\
\text { Comercial }\end{array}$ & Modificador Orgânico & $\begin{array}{c}\text { Concentração } \\
\text { de sal } \\
\text { (meq/100gclay) }\end{array}$
\end{tabular}

Di(alquil de sebo hidrogenado) dimetil amônio

$\mathrm{T}=\sim 65 \% \mathrm{C}_{18} ; \sim 30 \% \mathrm{C}_{16} ; \sim 5 \% \mathrm{C}_{14}$<smiles></smiles>

Cloisite 20A

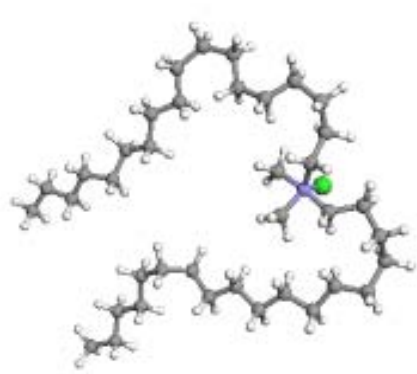

95

2,42

(alquil de sebo) dihidroxietil metal amônio

$$
\mathrm{T}=\sim 65 \% \mathrm{C}_{18} ; \sim 30 \% \mathrm{C}_{16} ; \sim 5 \% \mathrm{C}_{14}
$$

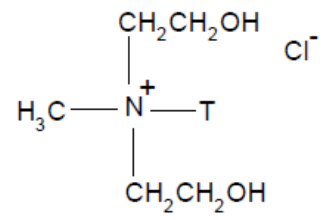

Cloisite 30B

90

1,85

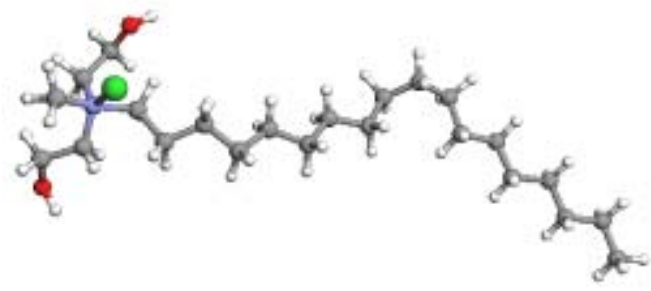




\subsubsection{Métodos}

\subsubsection{Obtenção das Argilas Organofílicas}

A argila MMT, Brasgel sódica, foi modificada organicamente pela reação de troca catiônica com sais quaternários de amônio e fosfônio. Neste trabalho, a troca foi realizada com excesso de sal $(100 \mathrm{meq} / 100 \mathrm{~g})$, de modo a tentar garantir que ocorra troca dos todos os cátions interlamelares pelo sal orgânico (Lins, 2007).

Previamente, a argila foi colocada em um recipiente cilíndrico de $10 \mathrm{~cm}$ de diâmetro e $20 \mathrm{~cm}$ de altura, e esferas de sílica de $2,5 \mathrm{~cm}$ de diâmetro foram adicionadas. O recipiente contendo argila e esferas de sílica foi mantido sob rotação constante durante quatro dias através de um acionador mecânico (tipo calandra). Assim, os aglomerados de argila se chocaram entre as esferas de sílica e com a parede do recipiente, diminuindo a granulometria. Após essa moagem a argila possui classificação granulométrica igual àquela passada em peneira ASTM \#400 (Coelho, 2008).

Para evitar a presença de umidade, a argila foi mantida sob temperatura de $90^{\circ} \mathrm{C}$ por 24 horas à vácuo. Depois para troca catiônica, dois métodos foram utilizados. O método 1 foi proposto por Valenzuela-Diaz (1994) e o método 1 modificado consiste de uma pequena modificação do método 1 . Eles são descritos a seguir:

- Método 1: Durante 30min iniciais, $32 \mathrm{~g}$ de argila com $768 \mathrm{~g}$ de água destilada foram misturadas no agitador mecânico Fisatom (1000rpm). Após esta fase, a mistura foi mantida durante $15 \mathrm{~min}$ sob forte agitação em um dispersor Heidolph Diax 900 a 20000 rpm. Neste ponto, a argila está preparada para a adição do sal quaternário. Assim, foi adicionada uma solução a $25 \%$ do sal quaternário (considerando a pureza de cada sal) e mantidos por 30min sob agitação mecânica (1000rpm).

- Método 1 modificado: Durante 30min iniciais, $32 \mathrm{~g}$ de argila com $768 \mathrm{~g}$ de água destilada foram misturadas no agitador mecânico (1000rpm). Neste ponto, foi adicionada uma solução a $25 \%$ do sal quaternário (considerando a pureza de cada sal) e mantidos por 30min no agitador mecânico (1000rpm). Após esta fase, a mistura é mantida durante 15min 
sob forte agitação em um dispersor (20000rpm).

Na Tabela 2.3.2.1.1 são mostradas os teores teóricos de argila e sal para cada troca. Os sais de amônio foram fornecidos na forma de solução aquosa, e teor de ativos foi relativo à concentração da solução (procedimento descrito em verde a seguir). No caso dos sais de fosfônio, eles foram fornecidos puros e o teor de ativos foi relativo à pureza do sal fornecida pelo fabricante (procedimento descrito em vermelho). Os teores para as argilas comerciais foram calculados de acordo com o teor de sal adicionado, fornecidos pelo fabricante.

Tabela 2.3.2.1.1 - Teor de argila após a troca catiônica, lavagem e secagem

\begin{tabular}{ccccc}
\hline Sal adicionado & $\begin{array}{c}\text { Massa Molar } \\
(\mathbf{g} / \mathbf{m o l})\end{array}$ & $\begin{array}{c}\text { Teor de Ativos } \\
(\%)\end{array}$ & $\begin{array}{c}\text { Teor de Argila } \\
(\%)\end{array}$ & $\begin{array}{c}\text { Teor de Sal } \\
(\%)\end{array}$ \\
\hline Ctac & 320,00 & 50 & 82 & 18 \\
Dod & 364,50 & 50 & 80 & 20 \\
Praep & 575,00 & 75 & 72 & 28 \\
Bz & 388,88 & 99 & 79 & 21 \\
Ttb & 563,76 & 100 & 72 & 28 \\
Tbb & 339,35 & 98 & 81 & 19 \\
Tdc & 435,15 & 95 & 77 & 23 \\
Cloisite 20A & 566,07 & - & 65 & 35 \\
Cloisite 30B & 396,88 & - & 74 & 26 \\
\hline
\end{tabular}


A mistura final passou, então, por um processo de lavagem com água destilada até não conter mais nenhum resíduo de cloreto ou brometo, detectados pela solução de nitrato de prata $\mathrm{AgNO}_{3}$ (caracterizados por uma leve turvação esbranquiçada), sendo seca posteriormente à temperatura $90^{\circ} \mathrm{C}$, moída em almofariz, permanecendo em um formato de pó. Esse procedimento foi aplicado para todos os sais quaternários, exceto o sal Ttb que não é solúvel em água. Neste caso a água foi substituída por álcool etílico puro.

\subsubsection{Caracterização da Argila Modificada}

\subsection{Teor de Argila}

Os teores de argila, após a troca catiônica, foram calculados considerando a massa de sal que reagiu e a massa de sal que deveria ser eliminada na lavagem. Ou seja, foram adicionados $100 \mathrm{meq} / 100 \mathrm{~g}$ de argila e a CTC da argila é $69 \mathrm{meq} / 100 \mathrm{~g}$ de argila. Desta forma, existem $31 \mathrm{meq}$ em excesso e deveriam ser eliminados na lavagem. No caso das argilas comerciais, Cloisites, não existe lavagem após a troca catiônica, segundo o fabricante. Estudos de teor de argila foram conduzidos em mufla Grion com queima a $1000^{\circ} \mathrm{C}$, para avaliação da quantidade real de argila após a troca catiônica. A massa final caracteriza a massa de sólidos e a sua relação com a massa inicial resulta no teor real de argila. Esses teores são apresentados em porcentagens.

\subsection{Inchamento Foster}

A capacidade de inchamento das lamelas das argilas organofílicas foi estudada através de Inchamento Foster em tolueno e em fenol/clorofórmio (60/40). Este último é utilizado como solvente para o PBT. Foram pesadas $0,5 \mathrm{~g}$ de argila modificada com sal e adicionadas em $25 \mathrm{ml}$ de solvente, cuidadosamente, como representado na Figura 2.3.2.2.2.1. Após repouso de 24horas, foi realizada uma primeira leitura do volume $(\mathrm{ml})$ ocupado pela argila modificada que corresponde a s/a (sem agitação), com um desvio padrão médio $\pm 0,4 \mathrm{ml}$. Então, o sistema foi agitado e, novamente, após 24 horas de 
repouso, foi feita uma nova leitura do volume ocupado pela argila modificada, este último é c/a (com agitação). Este método foi adaptado de Valenzuela-Diaz (1994), no qual foi utilizado $1 \mathrm{~g} / 50 \mathrm{ml}$.

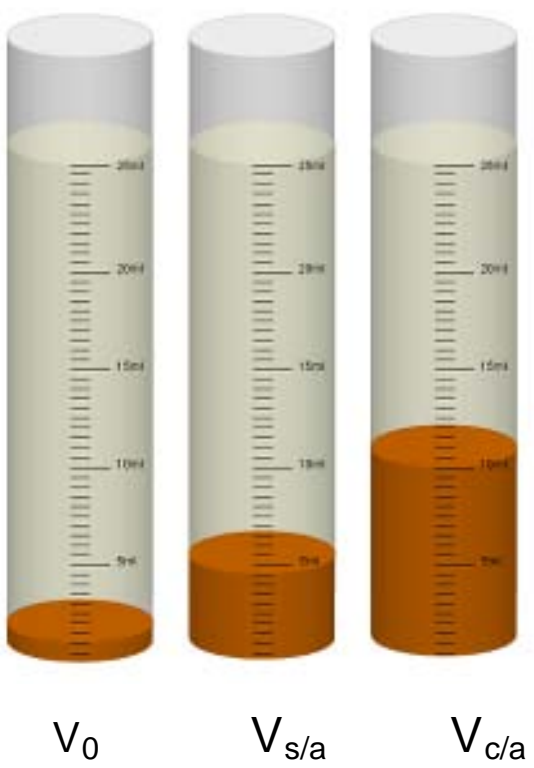

Figura 2.3.2.2.2.1 - Desenho esquemático do inchamento das argilas

\subsection{Difração de Raios - X (XRD)}

A variação da distância entre as lamelas da argila modificada foi avaliada em um difratômetro de Raios - X Rigaku, comprimento de onda 1,54 Å (XRD), disponível no Instituto de Física da USP (IFUSP). As amostras no formato de pó foram secas a $90^{\circ} \mathrm{C}$ por 18 horas sob vácuo. Elas foram dispostas em um plano horizontal para que pudesse ser conduzida a varredura de ângulos de difração. 
Para a determinação do espaçamento basal, foi utilizada a Lei de Bragg:

$$
n \lambda=2 d(\operatorname{sen} \theta)
$$

equação (1)

onde

n é a ordem de difração

$\lambda$ é o comprimento de onda da radiação incidente

d é a distância entre os planos

$\theta$ é o ângulo de difração

\subsection{Análise Termogravimétrica (TGA)}

O comportamento térmico foi avaliado por análise termogravimétrica (TGA, da TA Instruments) disponível na Central Analítica do Instituto de Química da USP (IQUSP). Para as OMMTs, as amostras estavam no formato de pó e foram mantidas em dissecadores para evitar a presença de umidade. A taxa de aquecimento foi de $10^{\circ} \mathrm{C} / \mathrm{mim}$, iniciando em aproximadamente $30^{\circ} \mathrm{C}$ terminando em $1000^{\circ} \mathrm{C}$, sob atmosfera de nitrogênio. 


\subsection{Resultados Obtidos e Discussões}

A seguir são apresentados os resultados das caracterizações das trocas catiônicas. Como apresentado anteriormente, foram utilizados dois métodos de troca iônica para a modificação da argila. Entretanto, os resultados preliminares de microscopia óptica e ensaios mecânicos com PBT não apresentaram diferenças expressivas de resultados com a variação destes parâmetros. Desta forma, os resultados a seguir mostram apenas o método 1 de troca iônica. Os resultados com as demais condições estão apresentados no Apêndice - A.

\subsubsection{Teor Real de Argila}

Os teores de argila, após a troca catiônica, observados pela queima a $1000^{\circ} \mathrm{C}$ são apresentados na Tabela 2.4.1.1. comparados com os valores teoricamente calculados de teor de argila considerando a massa de sal que reagiu e a massa de sal que deveria ser eliminada na lavagem.

Tabela 2.4.1.1 - Quadro comparativo de teores de argila

\begin{tabular}{ccc}
\hline Argila & \multicolumn{2}{c}{ Teores na Troca lônica } \\
Teórico de & Argila (\%) & $\begin{array}{c}\text { Real de } \\
\text { Argila (\%) }\end{array}$ \\
\hline Bra & 100 & 89 \\
Cloisite 20A & 65 & 61 \\
Cloisite 30B & 74 & 68 \\
BraCtac & 82 & 63 \\
BraDod & 80 & 63 \\
BraPraep & 72 & 54 \\
BraBz & 79 & 81 \\
BraTtb & 72 & 51 \\
BraTbb & 81 & 91 \\
BraTdc & 77 & 62 \\
\hline
\end{tabular}

Para a argila bruta Bra, a qual ainda tem caráter hidrofílico, essa perda pode ser atribuída em grande parte pela presença da água. Para as argilas trocadas com sais quaternários que possuem ramificações longas (a maioria dos casos) pode ser observado que o teor de argila real é menor do que o 
aquele teoricamente calculado após a troca iônica considerando a lavagem para a eliminação do sal em excesso. Isto indica que parte do sal quaternário pode ter ficado apenas aderido nas lamelas da argila, sendo fracamente aderido a argila, ou seja, não intercalou e/ou que parte do sal quaternário não foi eliminado durante a lavagem. Entretanto, para os dois sais (Bz e Tbb) o teor de argila foi maior do que o teórico. Isso mostra que parte do sal não reagiu, o que resultou em um pobre espaçamento basal, como será descrito a seguir no item 2.4.3.

\subsubsection{Inchamento Foster}

A Tabela 2.4.2.1 mostra o resultado obtido por Inchamento Foster em tolueno e a Tabela 2.4.2.2 mostra o resultado obtido em fenol/clorofórmio.

Tabela 2.4.2.1 - Inchamento Foster em Tolueno (ml)

\begin{tabular}{lcclcc}
\hline Argila & s/a & cla & Argila & s/a & c/a \\
\hline Bra & 0,5 & 0,5 & BraPraep & 4,5 & 10,0 \\
Cloisite 20A & 11,0 & 15,0 & BraBz & 0,5 & 0,5 \\
Cloisite 30B & 2,0 & 3,1 & BraTtb & 1,6 & 2,0 \\
BraCtac & 5,0 & 6,5 & BraTbb & 1,0 & 1,0 \\
BraDod & 4,8 & 6,5 & BraTdc & 4,0 & 5,8 \\
\hline
\end{tabular}

Tabela 2.4.2.2 - Inchamento Foster em Fenol / Clorofórmio (ml)

\begin{tabular}{llllll}
\hline Argila & s/a & cla & Argila & s/a & c/a \\
\hline Bra & 0,5 & 0,5 & BraPraep & 2,0 & 2,0 \\
Cloisite 20A & 3,2 & 5,8 & BraBz & 1,0 & 1,0 \\
Cloisite 30B & 3,2 & 4,0 & BraTtb & 1,4 & 1,6 \\
BraCtac & 3,0 & 3,0 & BraTbb & 1,0 & 1,0 \\
BraDod & 3,0 & 3,8 & BraTdc & 2,0 & 2,4 \\
\hline
\end{tabular}

Pode ser observado que as argilas modificadas sofreram maior inchamento em tolueno do que em fenol/clorofórmio (60/40). No caso do 
tolueno, os maiores valores foram obtidos para Cloisite 20A e BraPraep. No caso do Praep, ele foi mais expressivo após agitação. Estes resultados com sais de amônio são análogos àqueles obtidos por Lins (2007). As argilas Cloisite 20A e BraPraep possuem o mesmo sal quaternário, o qual dispõe de duas cadeias alquílicas longas. A Cloisite $30 \mathrm{~B}$ apresentou um inchamento menor do que aquele apresentado pela Cloisite 20A. A Cloisite 30B possui hidroxilas em sua estrutura e faz com que ela seja mais hidrofílica do que a Cloisite 20A. O sal quaternário de fosfônio Tdc, o qual possui uma cadeia alquílica grande apresentou um inchamento expressivo. No caso do sal quaternário Ttb, houve um aumento, mas não foi significativo. Uma razão poderia ser que, embora este sal quaternário possua uma cadeia alquílica grande, as demais cadeias são mais "volumosas" do que aquelas do sal quaternário Tdc. Este excesso pode ter impedido a locomoção das moléculas de solventes dentro das lamelas de argila. No caso das BraCtac e BraDod, o inchamento apresentou o mesmo comportamento. Entretanto, no caso do sal quaternário Ctac ele pode ter sido mais influenciado por apresentar cadeias alquílicas maiores $\left(\mathrm{C}_{16}\right)$ do que o $\operatorname{Dod}\left(\mathrm{C}_{10}\right.$ e $\left.\mathrm{C}_{18}\right)$; e no caso do Dod por apresentar um anel aromático com mais afinidade com tolueno.

As argilas organofílicas, OMMTs, modificadas com os sais de fosfônio com estrutura molecular pequena (ramificações) proporcionaram um fraco inchamento nos dois solventes utilizados ou praticamente nenhum inchamento (Bz e Tbb), da mesma forma que a argila bruta Brasgel.

Estes fenômenos podem ser explicados pela termodinâmica do sistema. O confinamento das moléculas do solvente entre as lamelas de argila resultam em decréscimo da entropia destas moléculas. Essa perda entrópica é compensada pelo aumento do grau de liberdade conformacional das cadeias longas dos sais quaternários, o que não acontece com os sais quaternários sem estas cadeias, que foram os casos $\mathrm{Bz}$ e Tbb. Para estes sais, foi favorecida a permanência dos cátions de $\mathrm{Na}^{+}$, que se mantiveram hidratados, caracterizando um caráter hidrofílico, incompatível com solventes orgânicos (hidrofóbico).

Na presença de fenol/clorofórmio (60/40), os valores de inchamento foram menores do que aqueles em tolueno, exceto para a Cloisite 30B e BraBz, 
sendo que para BraBz é desprezível. As hidroxilas presentes na Cloisite 30B podem ter apresentado maior afinidade com aquelas presentes no fenol. Assim como em tolueno, os maiores valores observados foram para a Cloisite 20A. Entretanto, BraPraep que possui o mesmo sal da Cloisite 20A, não apresentou um aumento tão grande quanto aquele apresentado pela Cloisite 20A. Partindo do principio de que a Cloisite 20A seja composta apenas de MMT e sal, a justificativa poderia ser a composição da MMT, uma vez que não temos como garantir que as Cloisites são compostas apenas de argila e sal.

Nas demais OMMTs, ou sejam, BraCtac, BraDod, BraTtb e BraTdc, o comportamento foi similar àquele apresentado em tolueno, apenas com uma ressalva para BraDod, a qual apresentou um inchamento ligeiramente maior do que a BraCtac. Uma diferença estrutural entre os dois sais consiste no anel aromático presente no sal quaternário Dod e que pode ter resultado em uma melhor miscibilidade com fenol.

\subsubsection{Difração de Raios - X (XRD)}

A Tabela 2.4.3.1 mostra os resultados de XRD para os materiais estudados neste trabalho.

Tabela 2.4.3.1 - Difração de Raios - X

\begin{tabular}{lcclcc}
\hline Argila & $\mathbf{2} \boldsymbol{\theta}$ & $\mathbf{d}(\mathbf{n m})$ & Argila & $\mathbf{2} \boldsymbol{\theta}$ & $\mathbf{d}(\mathbf{n m})$ \\
\hline Bra & 9,1 & 0,97 & BraPraep & 2,55 & 3,46 \\
Cloisite 20A & 3,75 & 2,35 & BraBz & 4,85 & 1,82 \\
Cloisite 30B & 5,00 & 1,77 & BraTtb & 3,60 & 2,45 \\
BraCtac & 2,45 & 3,60 & BraTbb & 6,20 & 1,42 \\
BraDod & 3,30 & 2,68 & BraTdc & 3,50 & 2,52 \\
\hline
\end{tabular}

O valor de espaçamento para Bra corrobora aquele obtido por Valera et al. (2010) e corresponde a argila anidra. Para o caso das argilas que foram modificadas com sais quaternários que não possuem cadeias alquílicas 
(BraTbb e BraBz), além de apresentarem um teor de argila maior do que o teórico, e baixo inchamento em solventes (vide resultados acima), também foi observado um pobre espaçamento basal. Isto indica que a troca catiônica com estes sais quaternários realmente não foi bem sucedida, em função do tamanho de suas cadeias. Os resultados obtidos para as Cloisites estão de acordo com aqueles fornecidos pelo fabricante. A Tabela 2.4.3.2 mostra a comparação dos dados obtidos neste trabalho com dados obtidos por outros pesquisadores utilizando a mesma argila. Pode ser visto que dentro do erro experimental os dados obtidos no presente trabalho estão de acordo com os da literatura.

Tabela 2.4.3.2 - Quadro comparativo do espaçamento basal para sais de amônio

\begin{tabular}{cccc}
\hline BraCtac & BraDod & BraPraep & Referência \\
\hline $\mathbf{3 , 6 0}$ & $\mathbf{2 , 6 8}$ & $\mathbf{3 , 4 6}$ & obtidos neste trabalho \\
3,53 & 3,27 & 4,20 & Valera et al. (2010) \\
\hline
\end{tabular}

As pequenas diferenças entre os valores obtidos neste trabalho e aqueles reportados podem ter sido influenciados por equipamentos diferentes ou diversos lotes de sais quaternários. O grande espaçamento observado para BraPraep mostra, mais uma vez, que o tamanho da cadeia alquílica é um fator determinante. Além disso, este sal quaternário apresenta duas cadeias alquílicas, o que aumenta ainda mais o potencial de intercalação nas lamelas da argila. Isso também foi observado para o sal quaternário Ctac, o qual apresenta cadeias alquílicas semelhantes ao do sal quaternário Praep. Por último, segue o sal quaternário Dod. As suas cadeias alquílicas são predominantemente de $\mathrm{C}_{10}$ e $\mathrm{C}_{18}$ (menores em proporção que $\mathrm{C}_{18}$ presentes no Praep e $\mathrm{C}_{16}$ presentes no Ctac), além de apresentar um anel aromático que fornece um impedimento estérico.

Os resultados de XRD das argilas modificadas com sais quaternários de fosfônio (realçados em cor bege) foram comparados com aqueles reportados em literatura para MMT. Embora as argilas utilizadas nestes vários estudos sejam diferentes, os seus valores são apresentados na Tabela 2.4.3.3. 
Tabela 2.4.3.3 - Quadro comparativo do espaçamento basal para sais quaternários de fosfônio

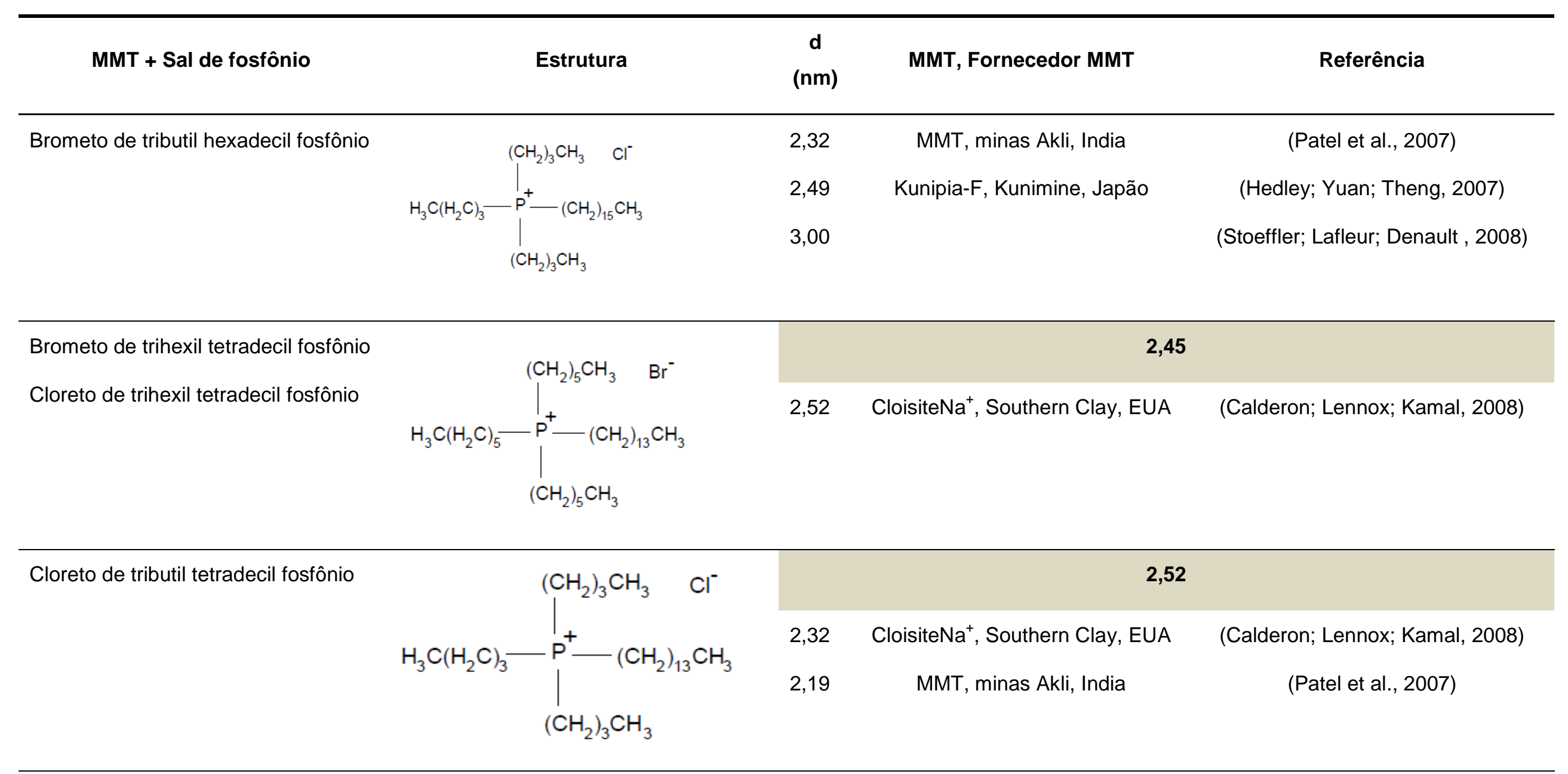




\begin{tabular}{|c|c|c|c|c|}
\hline MMT + Sal de fosfônio & Estrutura & $\begin{array}{c}d \\
(\mathrm{~nm})\end{array}$ & MMT, Fornecedor MMT & Referência \\
\hline Brometo de tetraoctil fosfônio & $\left.\right|_{\left(\mathrm{CH}_{2}\right)_{7} \mathrm{CH}_{3}} ^{\left(\mathrm{CH}_{2}\right)_{7} \mathrm{CH}_{3} \quad \mathrm{Br}^{-}}$ & $\begin{array}{l}2,52 \\
2,12\end{array}$ & $\begin{array}{l}\text { CloisiteNa }{ }^{+}, \text {Southern Clay, EUA } \\
\text { CloisiteNa }{ }^{+}, \text {Southern Clay, EUA }\end{array}$ & $\begin{array}{c}\text { (Calderon; Lennox; Kamal, 2008) } \\
\text { (Avalos et al., 2008) }\end{array}$ \\
\hline Brometo de tetrabutil fosfônio & $8 r$ & \multicolumn{3}{|c|}{1,42} \\
\hline & $\mathrm{P}^{+}-\left(\mathrm{CH}_{2}\right)_{3} \mathrm{CH}_{3}$ & $\begin{array}{l}1,4 \\
1,68\end{array}$ & $\begin{array}{c}\text { MMT, minas Akli, India } \\
\text { Kunipia-F, Kunimine, Japão }\end{array}$ & $\begin{array}{c}\text { (Patel et al., 2007) } \\
\text { (Hedley; Yuan; Theng, 2007) }\end{array}$ \\
\hline Cloreto de tetrabutil fosfônio & $\left(\mathrm{CH}_{2}\right)_{3} \mathrm{CH}_{3}$ & 1,84 & CloisiteNa ${ }^{+}$, Southern Clay, EUA & (Calderon; Lennox; Kamal, 2008) \\
\hline Brometo de trifenil octadecil fosfônio & & 1,87 & CloisiteNa ${ }^{+}$, Southern Clay, EUA & (Patro; Khakhar; Misra, 2009) \\
\hline
\end{tabular}




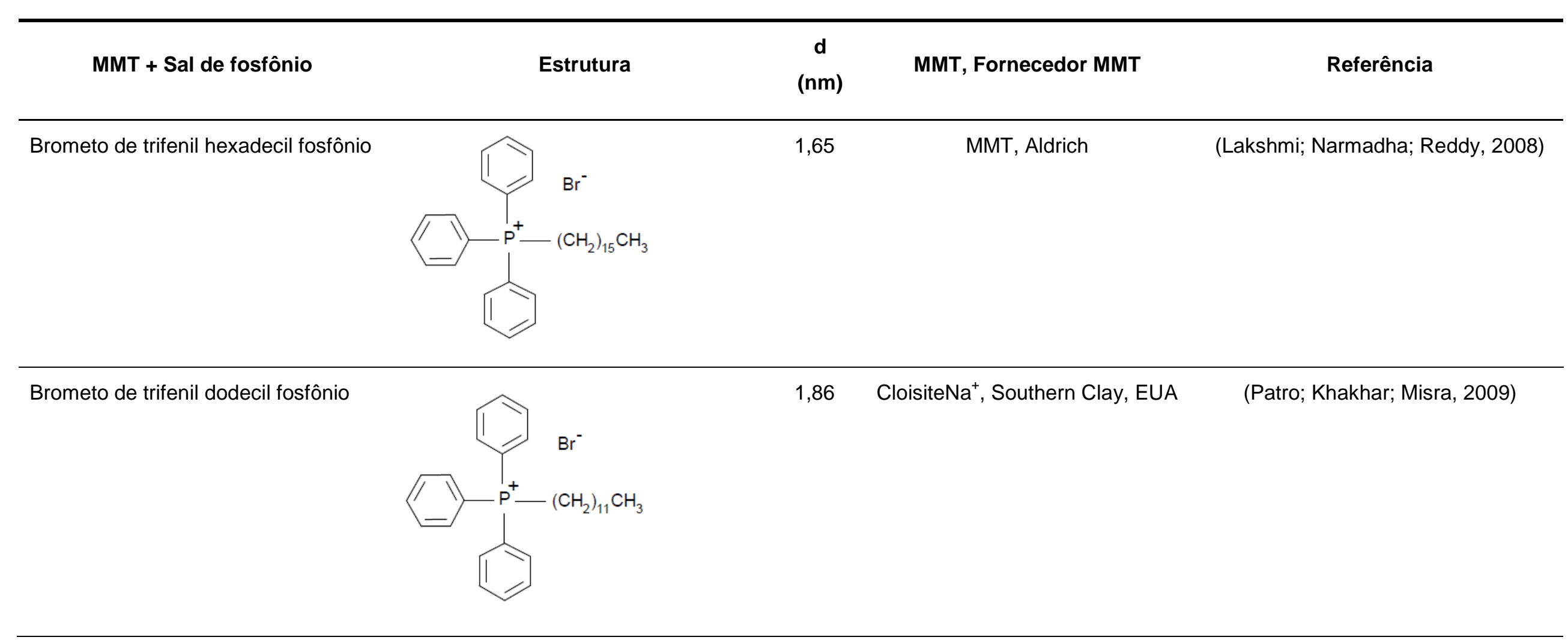




\begin{tabular}{|c|c|c|c|c|}
\hline MMT + Sal de fosfônio & Estrutura & $\begin{array}{c}\text { d } \\
(\mathrm{nm})\end{array}$ & MMT, Fornecedor MMT & Referência \\
\hline Brometo de butil trifenil fosfônio & & 1,77 & Kunipia-F, Kunimine, Japão & (Hedley; Yuan; Theng, 2007) \\
\hline Brometo de propil trifenil fosfônio & & 1,76 & MMT, minas Akli, India & (Patel et al., 2007) \\
\hline
\end{tabular}




\begin{tabular}{|c|c|c|c|c|}
\hline MMT + Sal de fosfônio & Estrutura & $\begin{array}{c}d \\
(n m)\end{array}$ & MMT, Fornecedor MMT & Referência \\
\hline Brometo de etil trifenil fosfônio & & 1,76 & MMT, minas Akli, India & (Patel et al., 2007) \\
\hline Brometo de metil trifenil fosfônio & & 1,76 & MMT, minas Akli, India & (Patel et al., 2007) \\
\hline
\end{tabular}




\begin{tabular}{|c|c|c|c|c|}
\hline MMT + Sal de fosfônio & Estrutura & $\begin{array}{c}d \\
(\mathrm{~nm})\end{array}$ & MMT, Fornecedor MMT & Referência \\
\hline Cloreto de Alil trifenil fosfônio & & 1,85 & MMT-Na, Telekal, Taiwan & (Yei et al., 2007) \\
\hline Brometo de tetrafenil fosfônio & & 1,76 & MMT, minas Akli, India & (Patel et al., 2007) \\
\hline Cloreto de benzil trifenil fosfônio & & \multicolumn{3}{|c|}{1,82} \\
\hline & & 1,85 & CloisiteNa ${ }^{+}$, Southern Clay, EUA & (Patro; Khakhar; Misra, 2009) \\
\hline
\end{tabular}




\begin{tabular}{|c|c|c|c|c|}
\hline MMT + Sal de fosfônio & Estrutura & $\begin{array}{c}d \\
(\mathrm{~nm})\end{array}$ & MMT, Fornecedor MMT & Referência \\
\hline Cloreto de trifenil vinil-benzil fosfônio & & 1,85 & CloisiteNa ${ }^{+}$, Southern Clay, EUA & (Avalos et al., 2008) \\
\hline
\end{tabular}


Pode ser observado que os valores obtidos no presente trabalho são muito similares àqueles reportados por outros pesquisadores. Entretanto, esperou-se que o sal quaternário Ttb proporcionasse um espaçamento basal maior do que os demais sais quaternários de fosfônio por apresentar maiores cadeias alquílicas. Como dito anteriormente, o sal quaternário Ttb não é miscível em água, sendo miscível em álcool e seu aspecto físico é muito oleoso. Isso dificultou o processo de troca iônica e pode ter afetado o resultado.

\subsubsection{Análise Termogravimétrica (TGA)}

A Figura 2.4.4.1 mostra a análise termogravimétrica no caso do sal quaternário Ctac. Comportamento similar foi obtido com os sais quaternários Praep e Tdc. A Figura 2.4.4.2 mostra o caso do sal quaternário Bz. Comportamento similar foi obtido com os sais quaternários Dod, Ttb e Tbb. A diferença entre estes dois grupos consiste que, no primeiro grupo, o primeiro pico de temperatura de degradação do sal quaternário acontece para temperaturas maiores do que o primeiro pico de temperatura de degradação da argila organofílica modificada com o respectivo sal, enquanto que no segundo grupo esse pico acontece para temperaturas menores. As demais curvas são apresentadas no Apêndice-B, assim como os resultados para as Cloisites 20A e 30B e curvas de perda de massa. Os dados apresentados para os sais quaternários Ctac, Dod e Praep foram obtidos por Valera et al. (2009). Os dados apresentados para a argila sem tratamento Bra foram obtidos por Coelho (2008).

Como dito anteriormente, de acordo com Xie et al. (2001, 2002), os eventos térmicos podem ser divididos em 4 regiões: (1) perda de água e gases abaixo de $200^{\circ} \mathrm{C}$, (2) perda de substâncias orgânicas entre 200 e $550^{\circ} \mathrm{C}$, (3) desidroxilação da argila entre 550 e $700^{\circ} \mathrm{C}$ e (4) formação de resíduos carbonosos entre 700 e $1000^{\circ} \mathrm{C}$.

A Tabela 2.4.4.1 mostra a análise de todas as curvas obtidas. Nesta tabela são mostradas as temperaturas e perda de massa (desidratação) na região 1 para as argilas organofílicas, os picos de temperatura para os sais quaternários puros denominados 1 e 2 (em alguns casos foram vistos 2 picos), 
a temperatura inicial de perda para as argilas organofílicas e seus picos de temperatura, picos 1A e 2A (região 2) seguidos das perdas em massa e a perda de cátions orgânicos entre 200 e $850^{\circ} \mathrm{C}$, além do pico de temperatura na região 3. Na região 4 não foram observados picos de temperatura. A perda de massa de água corresponde à perda no pico de temperatura na região 1. As porcentagens de perda de massa dos cátions orgânicos foram estimadas subtraindo a perda de massa da argila bruta, de 200 a $850^{\circ} \mathrm{C}$, devido a desidroxilação, da perda de massa total das argilas organofílicas, de 200 a $850^{\circ} \mathrm{C}$, seguindo os procedimentos de Hedley, Yuan e Theng (2007). 


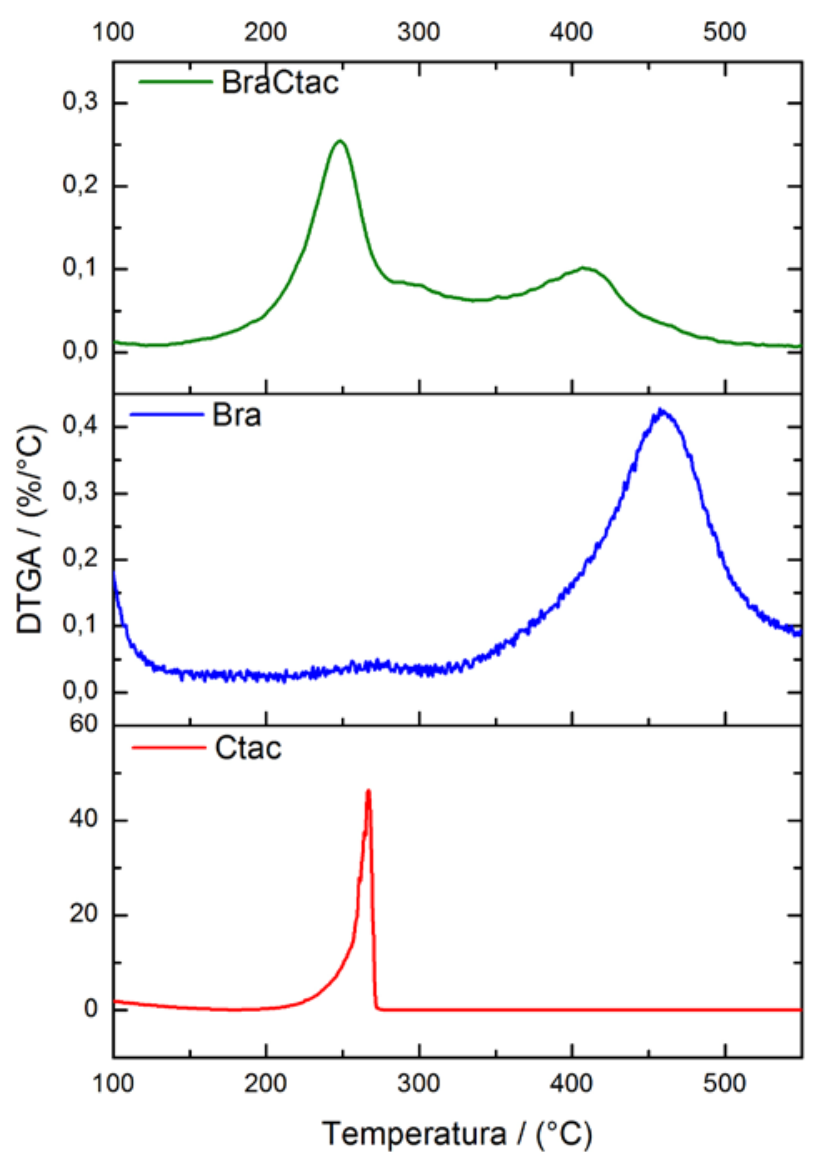

Figura 2.4.4.1 - DTGA para Ctac, Bra e BraCtac

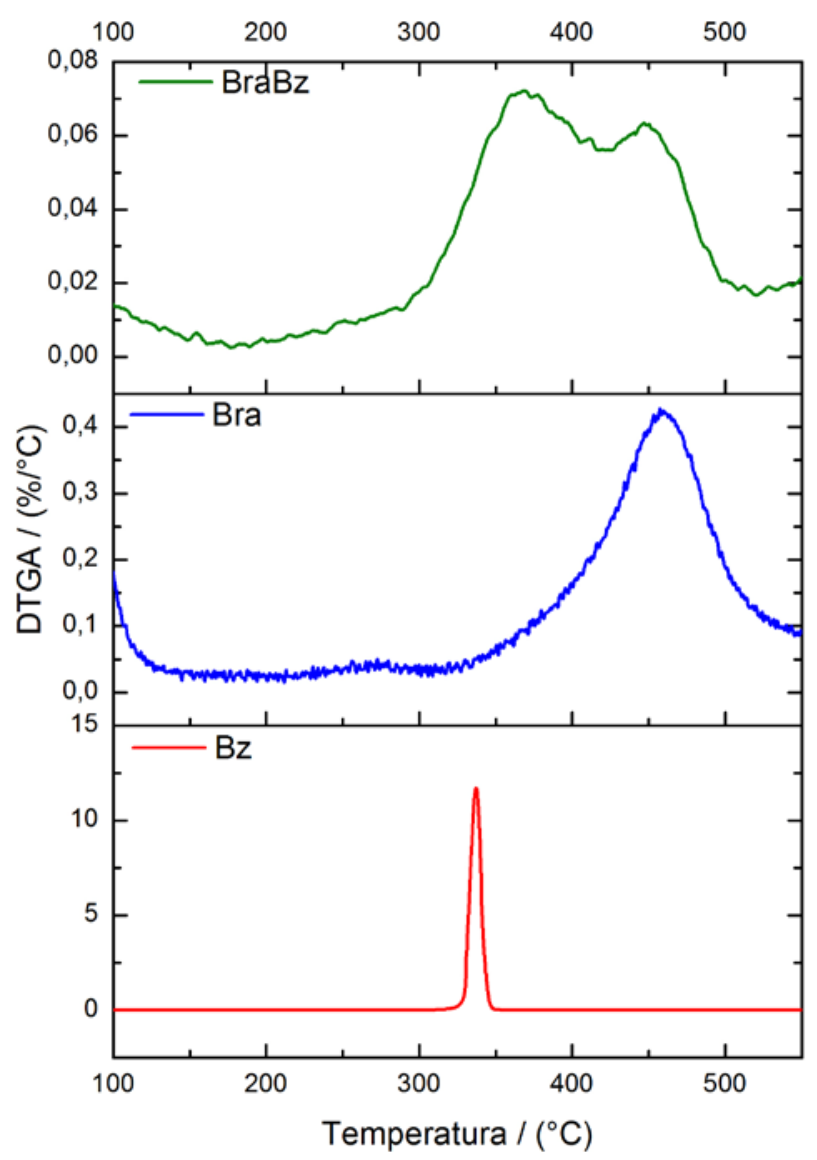

Figura 2.4.4.2 - DTGA para Bz, Bra e BraBz 
Tabela 2.4.4.1 - Temperatura e perda de massa correspondente à desidratação e decomposição do modificador orgânico

\begin{tabular}{|c|c|c|c|c|c|c|c|c|c|c|c|c|c|}
\hline \multirow[b]{2}{*}{ Material } & \multirow[b]{2}{*}{$\begin{array}{c}\text { Temperatura } \\
\left({ }^{\circ} \mathrm{C}\right)\end{array}$} & \multirow{2}{*}{$\begin{array}{l}\text { Região1 } \\
\text { Água } \\
\text { (\%) }\end{array}$} & \multirow[b]{2}{*}{$\begin{array}{c}\text { Perda } \\
\text { até } 200^{\circ} \mathrm{C} \\
(\%)\end{array}$} & \multicolumn{3}{|c|}{ Sais Quaternários Puros } & \multirow[b]{2}{*}{$\begin{array}{c}\text { Temperatura } \\
\text { inicial de perda } \\
\quad\left({ }^{\circ} \mathrm{C}\right)\end{array}$} & \multicolumn{2}{|c|}{ Região 2} & \multirow[b]{2}{*}{$\begin{array}{c}\text { Pico3A } \\
\left({ }^{\circ} \mathrm{C}\right)\end{array}$} & \multirow[b]{2}{*}{$\begin{array}{c}\text { Perda } \\
200-850 \\
\left({ }^{\circ} \mathrm{C}\right)\end{array}$} & \multirow{2}{*}{$\begin{array}{c}\text { Cátions } \\
\text { orgânicos } \\
200-850^{\circ} \mathrm{C} \\
\text { (\%) }\end{array}$} & \multirow{2}{*}{$\begin{array}{c}\text { Região } 3 \\
\text { Pico } \\
\left({ }^{\circ} \mathrm{C}\right)\end{array}$} \\
\hline & & & & $\begin{array}{c}\text { Pico } 1 \\
\left({ }^{\circ} \mathrm{C}\right)\end{array}$ & $\begin{array}{c}\mathrm{Pico} 2 \\
\left({ }^{\circ} \mathrm{C}\right)\end{array}$ & $\begin{array}{c}\text { Perda } \\
\text { até } 200^{\circ} \mathrm{C} \\
(\%)\end{array}$ & & $\begin{array}{c}\text { Pico 1A } \\
\left({ }^{\circ} \mathrm{C}\right)\end{array}$ & $\begin{array}{c}\text { Pico2A } \\
\left({ }^{\circ} \mathrm{C}\right)\end{array}$ & & & & \\
\hline Bra & 71 & 4,4 & 6,9 & - & - & - & 298 & - & 450 & - & 5,6 & - & - \\
\hline BraCtac & 38 & 0,9 & 4,5 & - & 267 & 33,7 & 180 & 248 & 407 & - & 27,6 & 22,0 & - \\
\hline BraDod & 62 & 1,1 & 3,3 & 202 & 221 & 57,5 & 156 & 250 & 403 & - & 25,1 & 19,5 & - \\
\hline BraPraep & 38 & 0,7 & 3,6 & 204 & 365 & 11,8 & 156 & 251 & 300 & 399 & 38,2 & 32,6 & - \\
\hline BraBz & 42 & 1,1 & 3,5 & - & 337 & 0,01 & 236 & 369 & 447 & 611 & 16,1 & 10,5 & 611 \\
\hline BraTbb & 52 & 1,1 & 4,3 & - & 378 & 1,1 & 324 & 465 & - & - & 9,6 & 4,0 & - \\
\hline BraTdc & 58 & 0,4 & 1,5 & - & 367 & 4,1 & 225 & 345 & 491 & - & 28,4 & 22,8 & - \\
\hline
\end{tabular}


Pode ser observado algumas diferenças entre os valores apresentados pelas Tabelas 2.4.1.1 e a 2.4.4.1. Estas diferenças resultam em função do procedimento de ensaio de forma que, são utilizadas pequenas massas nas análises no TGA, as quais são bem menores do que aquelas utilizadas durante as avaliações de perda de massa em mufla.

Com relação aos sais quaternários puros pode ser observado:

$\checkmark$ os sais de amônio apresentam menores temperaturas de decomposição de que os sais de fosfônio.

$\checkmark$ na temperatura de processamento da maioria dos polímeros, em torno de $200^{\circ} \mathrm{C}$, os sais quaternários de amônio já apresentam uma significante perda de massa, o que não é observado para os sais de fosfônio.

A região 1 , que é a perda de massa abaixo de $200^{\circ} \mathrm{C}$, corresponde a água fracamente adsorvida ou água livre que está, na superfície e/ou nas extremidades das lamelas da argila. A perda desta água acontece para temperaturas menores para as argilas organofílicas. Também pode ser visto que a quantidade de água nas argilas organofílicas diminui em relação à Bra. Isto é justificado pelo caráter hidrofóbico da argila após a troca catiônica, ou seja, parte dos cátions que tinham afinidade com água foi removida durante a troca catiônica. Resultados semelhantes foram observados por Hedley, Yuan e Theng (2007) e Calderon, Lennox e Kamal (2008). Na região 2, o primeiro pico exotérmico representa o ponto no qual o sal que está fracamente aderido na superfície das partículas de argila começa a decompor. O segundo pico corresponde à decomposição dos cátions orgânicos intercalados. Como dito anteriormente, no item 2.2.2, quando os cátions orgânicos substituem cátions metálicos presentes em uma argila hidrofílica, eles aderem principalmente na superfície da lamela tetraédrica via interações eletrostáticas. Se a concentração de cátions na argila organofílica aumenta, alguns cátions em excesso ou ficam aderidos na superfície das partículas de argila ou adsorvidos por forças de van der Waals nas cadeias de outros cátions. 
A Figura 2.4.4.3 mostra uma comparação do tamanho dos picos de temperatura para o caso do Ctac, Praep e Tdc, os quais apresentaram maiores perdas de cátions orgânicos para as argilas modificadas com estes sais quaternários.

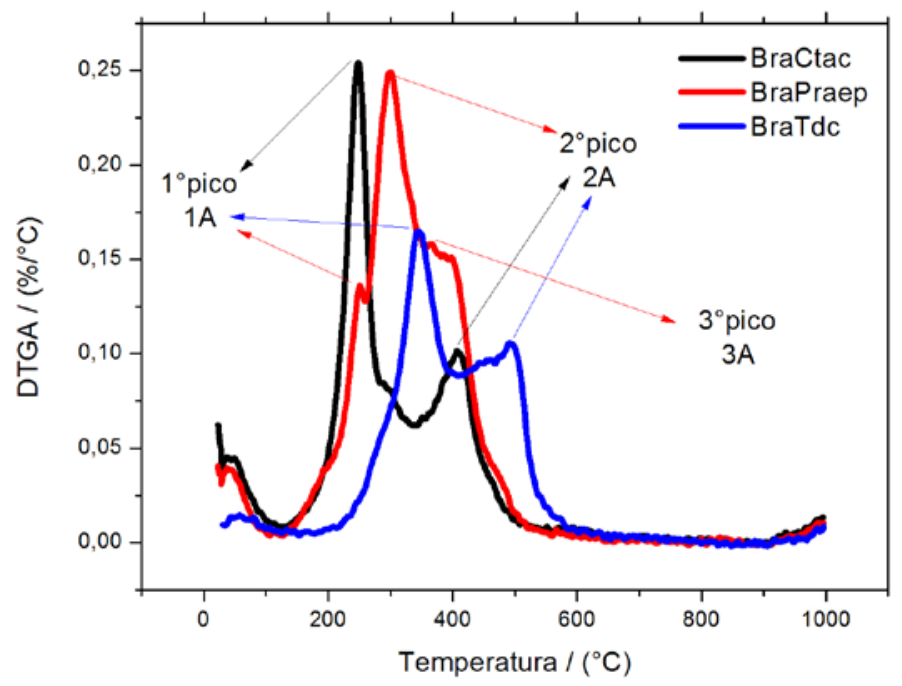

Figura 2.4.4.3 - DTGA para BraCtac, BraPraep e BraTdc

No caso do BraPraep, o pico 1A, representa as perdas iniciais, as quais estão presentes para o sal quaternário puro, $204^{\circ} \mathrm{C}$, como pode ser observado na Figura 2.4.4.4. 


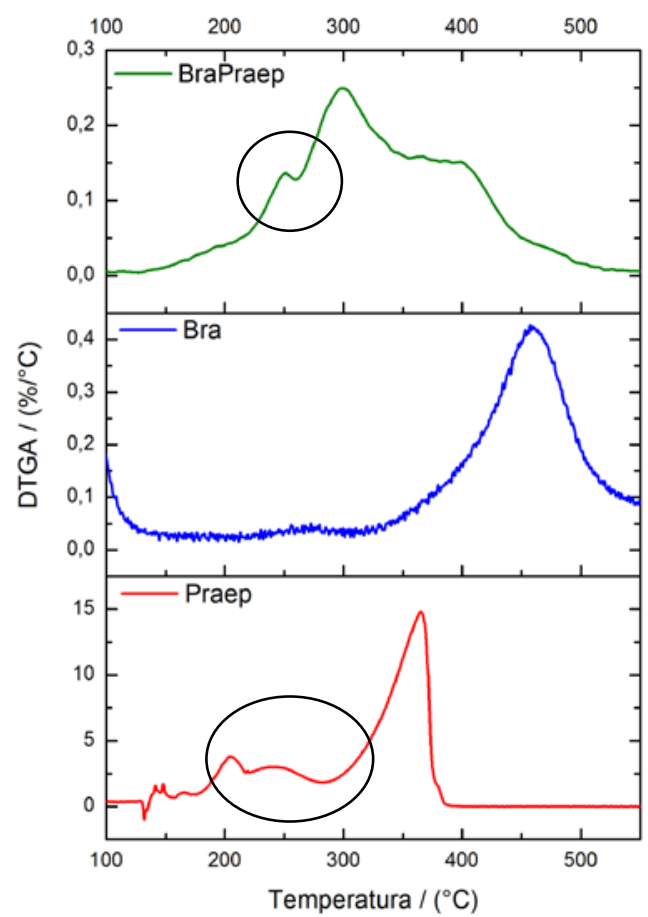

Figura 2.4.4.4 - DTGA para Praep, Bra e BraPraep

O segundo pico, $300^{\circ} \mathrm{C}$, maior em intensidade e menor que o pico para o sal quaternário puro, $365^{\circ} \mathrm{C}$, representa o sal quaternário fracamente adsorvido na superfície das lamelas da argila seguido do terceiro 'pico', $399^{\circ} \mathrm{C}$, maior que o sal quaternário puro, que representa o sal quaternário intercalado.

O pico mais intenso acontecendo a temperaturas de $300^{\circ} \mathrm{C}$ em relação àquele acontecendo a temperaturas de $399^{\circ} \mathrm{C}$ indica que uma fração mais importante de sal Praep não está intercalada, mas localizada nas bordas dos tactóides. Estes resultados estão de acordo com os resultados apresentados na Tabela 2.4.1.1 onde foi mostrado que o teor real de argila para este sal é menor do que o teor teórico e maior perda de cátions orgânicos, Tabela 2.4.4.1.

Neste caso do Praep também foi observado que o espaçamento basal era um dos maiores apesar de uma grande quantidade de sal não se encontrar no espaço interlamelar como mostrado pelos resultados de TGA. Ambos resultados podem indicar uma forte presença de vazios entres as cadeiais de sais presentes entre as placas de argila, explicando o maior inchamento em tolueno para este caso (vide Tabela 2.4.2.1). 
Para os sais Ctac e Tdc, pode ser observado que o primeiro pico da argila organofílica modificada se apresenta em um valor de temperatura menor daquele correspondente ao sal quaternário puro, o que representa cátions orgânicos fracamente adsorvidos na superfície da argila organofílica. E o segundo pico de temperatura se apresenta em temperaturas maiores do que o sal quaternário puro, o que denota sal quaternário intercalado. De forma análoga ao Praep, para estes casos, o segundo pico de temperatura também apresentou menor intensidade do que o primeiro pico de temperatura, mostrando, mais uma vez que, a fração mais importante do sal está localizada nas bordas dos tactóides corroborando os teores reais de argila e inchamento. O Praep possui duas cadeias alquílicas, enquanto que Ctac e Tdc possuem apenas uma cadeia alquílica.

A Figura 2.4.4.5 mostra uma comparação do tamanho dos picos de temperatura para o caso do Dod, Bz, Ttb e Tbb, os quais apresentaram menores perdas de cátions orgânicos para as argilas modificadas com estes sais quaternários.

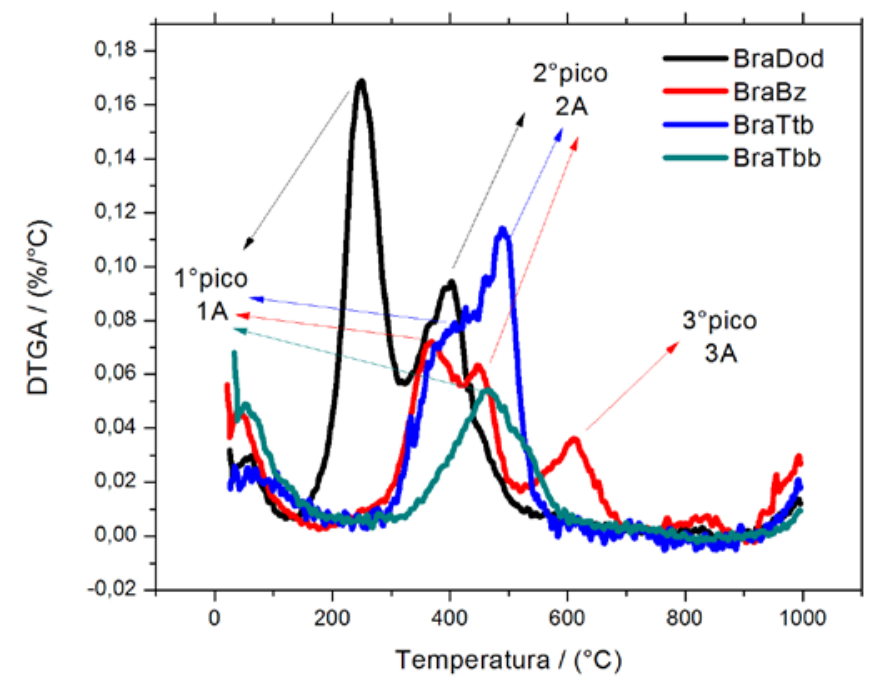

Figura 2.4.4.5 - DTGA para BraDod, BraBz, BraTtb e BraTbb

Para os demais casos, Dod, Bz, Ttb e Tbb, pode ser visto que o primeiro pico de temperatura da argila organofílica (maior em intensidade), aconteceu para temperatura maiores do que o pico de temperatura para o sal quaternário 
puro. Entretanto, o primeiro pico para BraTtb foi indicado aproximadamente em $400^{\circ} \mathrm{C}$, pois o pico não foi bem definido nessa região, mas foi observadas grandes perdas entre $\sim 300-450^{\circ} \mathrm{C}$.

No caso BraBz e BraTbb, como o teor real de argila foi maior que o teórico e a perda de cátions foi uma das menores, isto indica que todo o sal em excesso foi eliminado na lavagem, não restando sal quaternário adsorvido nas lamelas e que todo o sal realmente intercalou, porém resultando em pobre inchamento e baixo espaçamento basal, em função da estrutura destes sais quaternários.

Entretanto, para o caso BraDod e BraTtb, o teor real de argila foi menor que o teórico. Logo, se o sal quaternário em excesso não foi eliminado na lavagem e também não está aderido na superfície das lamelas, a localização mais coerente é dentro dos espaços interlamelares não ligados à superfície das argilas, como descrito na Figura 2.2.2.2. Embora a BraTtb tenha a mesma concentração de sal adicionada que BraPraep, a liberação dos voláteis dos cátions orgânicos necessitou de maior esforço, uma vez que o pico de temperatura da argila organofílica com este sal quaternário foi maior do que o respectivo sal puro.

Pode ser observado através da Tabela 2.4.4.1 que, para as argilas trocadas com sais quaternários e que possuem ramificações longas (a maioria dos casos), a perda de cátions orgânicos foi maior do que aqueles que não possuem ramificações. Isto indica que parte do sal não intercalou e/ou não foi eliminado durante a lavagem, resultando em um aumento não expressivo do espaçamento basal, como foi descrito no item 2.4.3. Entretanto, para os dois sais quaternários (Bz e Tbb) o teor de cátions orgânicos foi menor, ou seja, os melhores resultados de estabilidade térmica foram observados para estes sais, os quais apresentaram menores perdas de massas para seus cátions orgânicos. O impedimento estérico fornecido pelo grupo fenil é uma das principais razões para este efeito que também foi observado por Xie et al. (2001, 2002).

Região 3 e 4: Foi observado apenas picos de temperatura para BraBz, referente a desidroxilação da argila e para 20A e 30B, Apêndice-B, relativos a 
resíduos orgânicos carbonosos.

Portanto, a concentração de sal que é incorporada dentro das lamelas durante a troca catiônica depende não somente da concentração do sal utilizado, mas também da arquitetura destes sais dentro das lamelas da argila, como mostrado pelos resultados de espaçamento basal, inchamento e análise térmica. Resultados similares foram obtidos por Xie et al. $(2001,2002)$ e Delbem et al. (2010). 


\section{Propriedades de Engenharia de PBT/OMMTs sem agente tenacificante}

\subsection{Introdução}

\subsubsection{Generalidades}

A nanotecnologia é uma das ferramentas mais importantes do século 21 e oferece excelentes oportunidades para o desenvolvimento de materiais com características completamente novas ou radicalmente melhoradas, as quais dependem fundamentalmente da micro-(nano) estrutura dos materiais obtidos

Neste trabalho, a microestrutura dos nanocompósitos obtidos foi avaliada através de difração de Raios - X (XRD), microscopia ótica (OM) e microscopia eletrônica de transmissão (TEM). Análises termogravimétricas foram conduzidas e permitiram a compreensão dos fenômenos térmicos e a discussão das propriedades de resistência à chama, obtidos através dos ensaios de flamabilidade. Os materiais também foram avaliados quanto às suas propriedades mecânicas.

\subsubsection{Organização do Capítulo 3}

Neste capitulo, após uma revisão bibliográfica sobre microestrutura, obtenção, propriedades mecânicas e térmicas de nanocompósitos poliméricos, a descrição dos materiais e métodos utilizados para a caracterização e avaliação das propriedades são apresentados. Por fim os resultados obtidos são apresentados com as discussões.

\subsection{Revisão Bibliográfica}

\subsubsection{Estrutura dos Nanocompósitos Poliméricos}

A Figura 3.2.1.1 apresenta esquematicamente três tipos de microestrutura que podem ser obtidos em nanocompósitos poliméricos. 


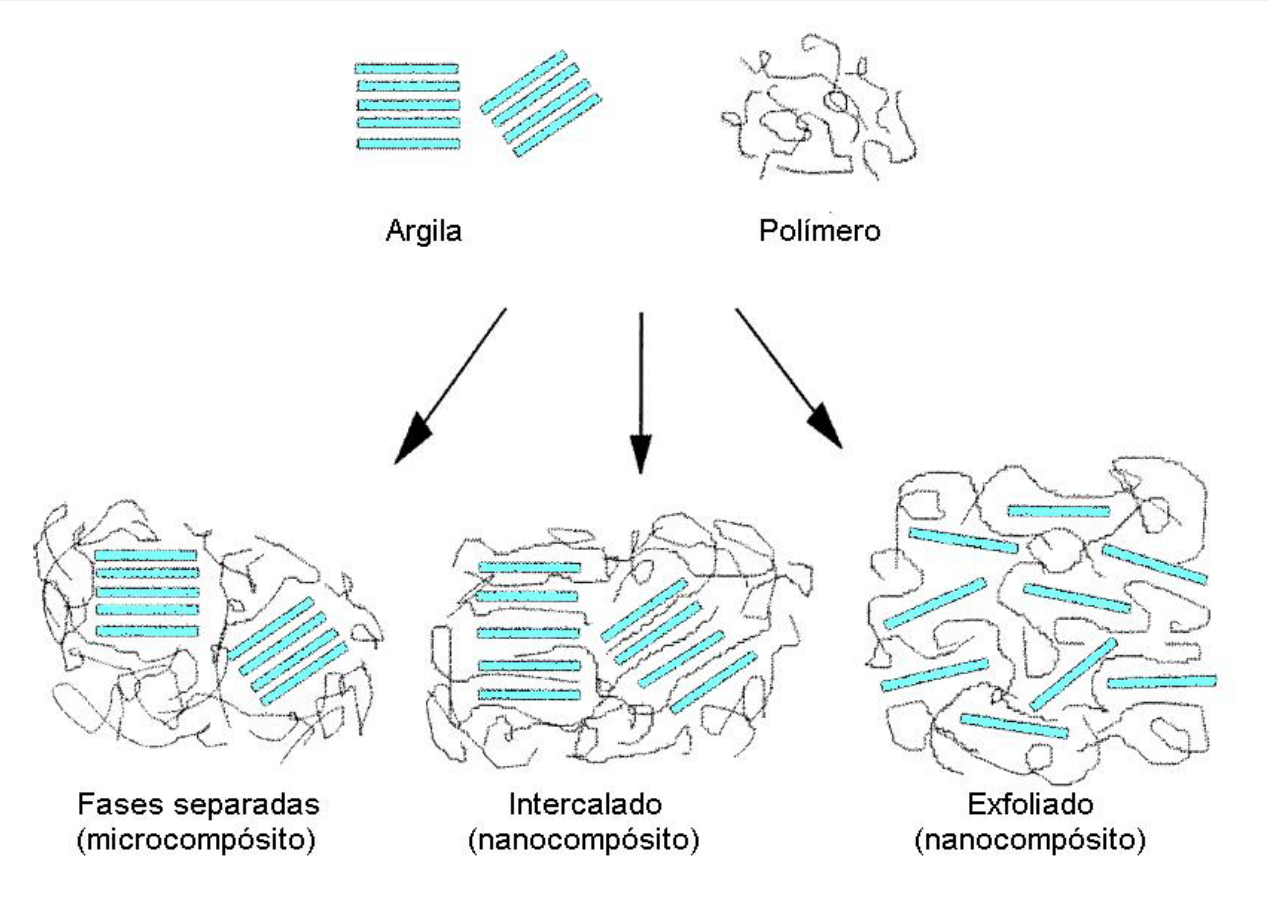

Figura 3.2.1.1 - Estruturas que podem ser obtidas com os nanocompósitos (adaptada de Alexandre e Dubois, 2000)

No primeiro tipo (fases separadas), as partículas da argila (tactóides) existem em seu estado agregado original sem a intercalação da matriz polimérica entre as camadas. Neste estado, as partículas podem, em parte, intensificar as propriedades da matriz. O segundo tipo representa um material intercalado, no qual o polímero está inserido (intercalado) entre as camadas da argila, de uma forma regular e orientada. No último caso, esfoliado, as camadas individuais de aproximadamente $1 \mathrm{~nm}$ de espessura são separadas e dispersas em uma matriz polimérica contínua, com distâncias médias entre as camadas, dependendo da concentração da argila. Geralmente, este tipo de compósito exibe melhores propriedades do que aqueles intercalados de mesma concentração de partículas (Luo e Daniel, 2003). A Figura 3.2.1.2 mostra um esquema de um nanocompósito esfoliado. 


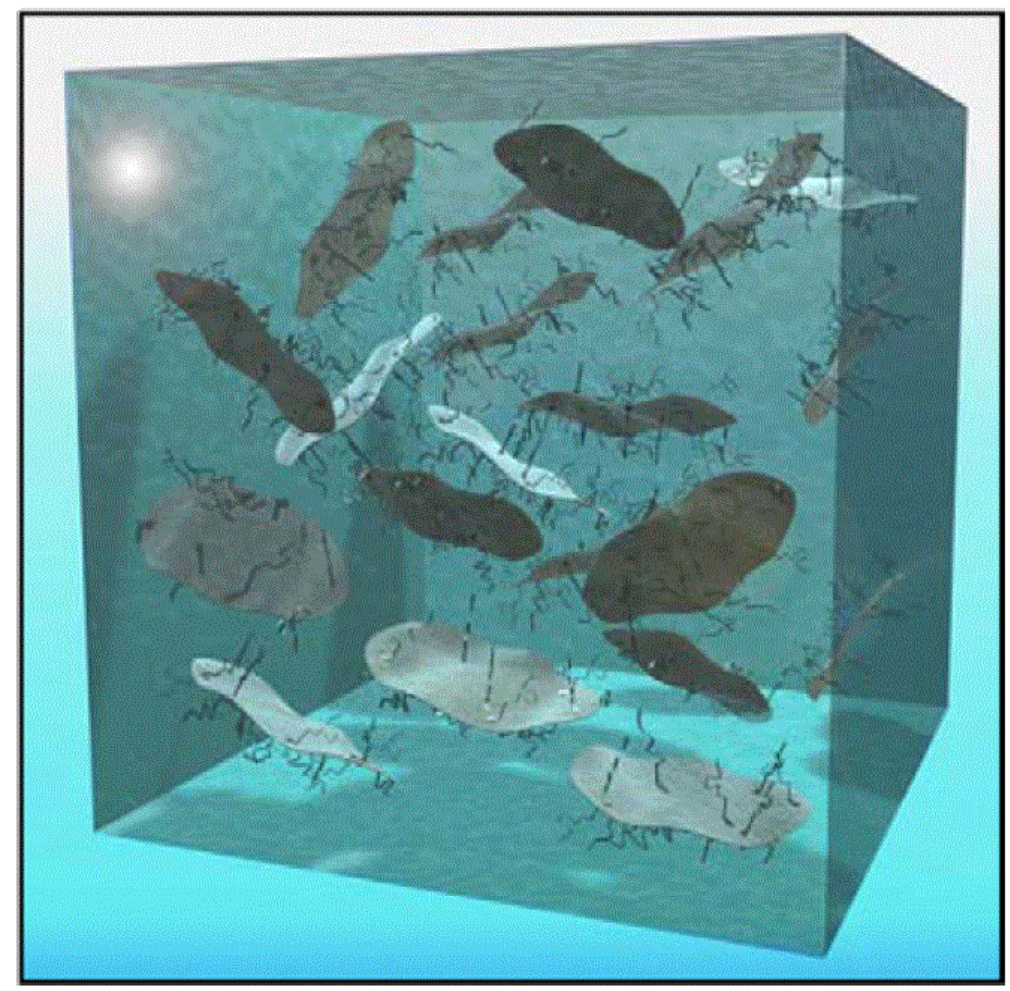

Figura 3.2.1.2 - Esquema de um nanocompósito esfoliado (Fischer, 2003)

Entretanto, o caso mais comum é aquele parcialmente intercalado e esfoliado. Neste caso, as camadas esfoliadas e grupos intercalados estão aleatoriamente distribuídos na matriz polimérica.

A microestrutura de nanocompósitos pode ser estudada por algumas técnicas, a saber, XRD, TEM, TGA e outras, as quais são descritas em Canevarolo (2003).

\subsubsection{Obtenção dos Nanocompósitos Poliméricos}

Existem três procedimentos que são mais utilizados na preparação de nanocompósitos poliméricos. São eles:

Polimerização "in situ": Neste primeiro caso, o método prevê a adsorção do monômero no espaço interlamelar da argila, onde acontece a polimerização. A polimerização pode ser ativada termicamente ou mediante difusão de um iniciador adequado. O resultado em termos de grau de nanoestruturação é fortemente dependente da cinética de polimerização dentro das camadas ou 
entre as camadas. Se a polimerização dentro das camadas é favorecida, a distância entre as camadas da argila cresce com o aumento da conversão, de modo a obter um sistema completamente esfoliado (Turri, 2005).

Solvente: Neste método, a argila modificada é primeiramente inchada em um solvente do polímero, tal como água, clorofórmio ou tolueno. O polímero é também dissolvido. Quando as soluções de polímero e argila são misturadas, as cadeias do polímero intercalam e deslocam o solvente de dentro da camada da argila. Com a remoção do solvente, as estruturas intercaladas remanescentes, resultam em nanocompósitos poliméricos (Sinha Ray e Okamoto, 2003).

Intercalação do fundido: Este método consiste da adição da argila modificada em um polímero fundido. O processo típico emprega equipamentos que fornecem uma ótima dispersão e distribuição de carga no polímero, como extrusora dupla rosca. Este último método de obtenção de nanocompósito é o mais interessante do ponto de vista industrial, pois dispensa a fase de síntese do polímero, e a mistura polímero/argila acontece na ausência de solvente inflamável (Alexandre e Dubois, 2000; Sinha Ray e Okamoto, 2003; Sinha Ray et al., 2003; Turri, 2005b).

Em função do tipo de método utilizado e da interação entre polímero e argila, os nanocompósitos podem apresentar diferentes tipos de microestruturas.

\subsubsection{Propriedades dos Nanocompósitos Poliméricos}

\subsubsection{Propriedades Mecânicas}

As propriedades mecânicas de nanocompósitos poliméricos estão altamente relacionadas com a microestrutura, ou seja, com o nível de dispersão da argila (esfoliado ou não) na matriz polimérica. As maiores diferenças de comportamento entre materiais compósitos convencionais e materiais nanoestruturados resultam do fato de que os últimos têm muito mais área superficial (ou interfacial) por unidade de volume. Uma vez que muitas interações químicas e físicas importantes são governadas pela superfície, um 
material nanoestruturado pode ter diferentes propriedades em função de apresentar uma área interfacial muito maior do que outros materiais de mesma composição. A maior área interfacial das camadas da argila, da ordem de $800 \mathrm{~m}^{2} / \mathrm{g}$ em contato com o polímero promove um maior efeito de reforço ao material. Este resultado é obtido mesmo com pequena concentração de argila (Sinha Ray e Okamoto, 2003; Pavlidou e Papaspyrides, 2008).

A Figura 3.2.3.1.1 mostra um esquema da interação das cadeias poliméricas (cinza) e das camadas de argila (marrom).

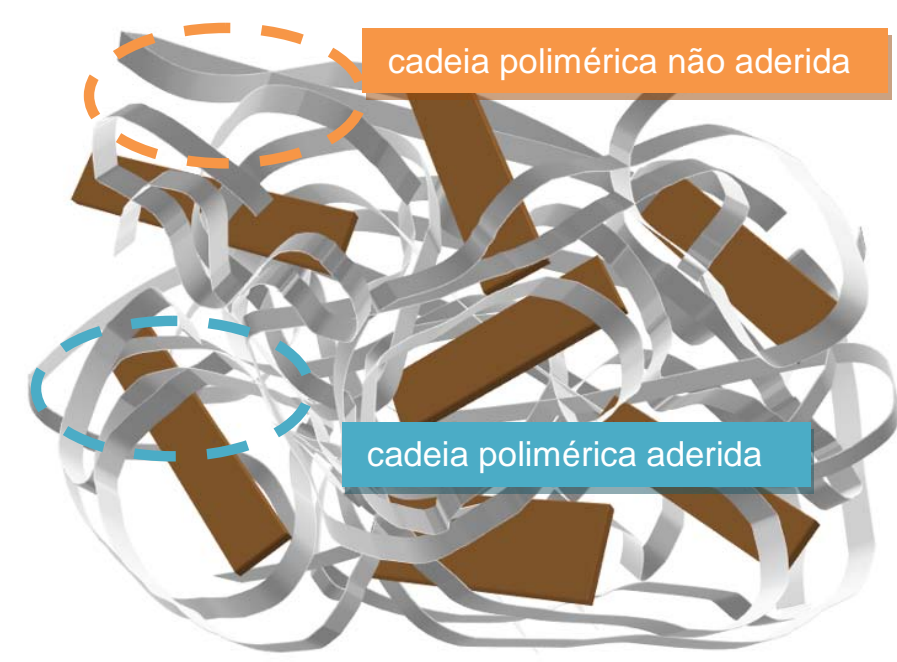

Figura 3.2.3.1.1 - Esquema das camadas de argila e cadeias poliméricas

As cadeias poliméricas que estão aderidas à superfície da argila ficam enrijecidas e têm maiores módulos do que aquelas que não estão em contato. Quanto maior a razão de aspecto, comprimento / espessura, maior é a área superficial da argila e conseqüentemente o módulo exibe maiores aumentos. Desta forma, o módulo de elasticidade, o módulo de armazenamento e a resistência à tração são melhoradas. Entretanto a tenacidade, alongamento na ruptura e a resistência ao impacto diminuem quando comparado com os polímeros puros.

A resistência ao impacto está intimamente ligada à absorção, transferência e dissipação de energia (Tjong, 2006; Pavlidou e Papaspyrides, 2008). Uma vez que a presença da argila modificada faz com que o volume de 
material, para a dissipação da energia torne-se menor, o material rompe de forma rígida e a resistência ao impacto diminui.

\subsubsection{Propriedades Térmicas}

Estabilidade Térmica. Numerosos estudos baseados essencialmente na análise termogravimétrica (TGA) têm demonstrado um melhoramento da estabilidade térmica dos polímeros nanoestruturados com argila quando comparados aos polímeros puros.

Sob efeito da temperatura, ocorre uma combinação de alguns fatores, entre os quais, uma reduzida mobilidade térmica das cadeias macromoleculares confinadas nas camadas da argila, a menor difusão do oxigênio, que é produto de degradações térmicas e pelo efeito de 'labirinto' correlacionado à esfoliação da nanocarga (Turri, 2005c; Pavlidou e Papaspyrides, 2008).

Flamabilidade. A presença de pequena quantidade de argila no polímero funciona como uma barreira protetora pela redução do calor e da transferência de massa entre a chama e o polímero. Após aquecimento, a viscosidade do fundido dos nanocompósitos poliméricos diminue com 0 aumento da temperatura e facilita a migração das camadas de argila para a superfície. A Figura 3.2.3.2.1 mostra um esquema da evolução da queima nas regiões vizinhas às camadas da argila de um estado inicial a) e após a migração para a superfície b).
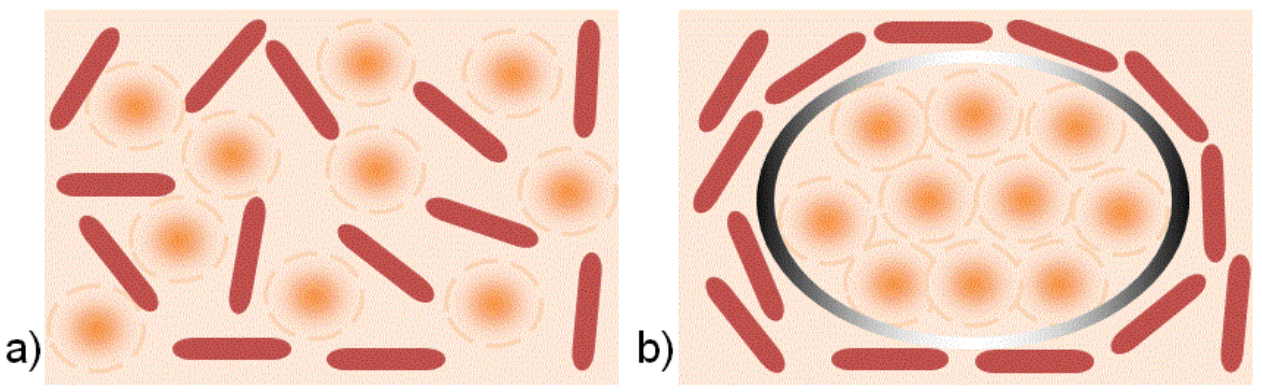

Figura 3.2.3.2.1 - Esquema da evolução da queima nas regiões vizinhas às camadas de argila

A transferência de calor promove o início da decomposição térmica da 
argila organofílica e a criação de sítios fortemente catalíticos, os quais promovem a formação de um resíduo carbonoso representado em preto, na superfície da argila. Este acúmulo de argila na superfície do material age como uma barreira protetora que limita a transferência de calor no material, a volatilização dos produtos de degradação e a difusão do oxigênio no material. Essa migração da argila é beneficiada pela formação de bolhas de gás, iniciada pela decomposição das cadeias poliméricas. Essas bolhas de gás também auxiliam na convecção das camadas de argila na superfície do nanocompósito polimérico (Pavlidou e Papaspyrides, 2008; Laoutid et al., 2009).

\subsubsection{Nanocompósitos Poliméricos de PBT}

Poli (tereftalato de butileno) (PBT) é um importante termoplástico semicristalino que apresenta alta taxa de cristalização, boa resistência à tração, tenacidade, baixa absorção de umidade, boa resistência química, propriedades dielétricas e alta estabilidade térmica. Contudo, o PBT é passível de hidrólise. (Xiao et al., 2005a; Wu et al., 2005a). A estrutura química do PBT é apresentada na Figura 3.2.4.1.

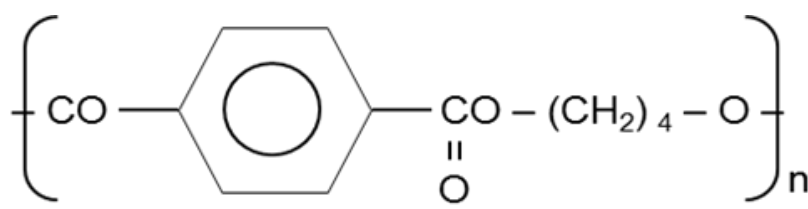

Figura 3.2.4.1 - Estrutura Química do PBT

Como alternativa para obtenção de melhores propriedades, nanocompósitos poliméricos de PBT com argila têm sido estudados. A Tabela 3.2.4.1 apresenta um resumo dos trabalhos reportados em literatura, sobre PBT/MMT. 
Tabela 3.2.4.1 - Resumo dos trabalhos reportados em literatura

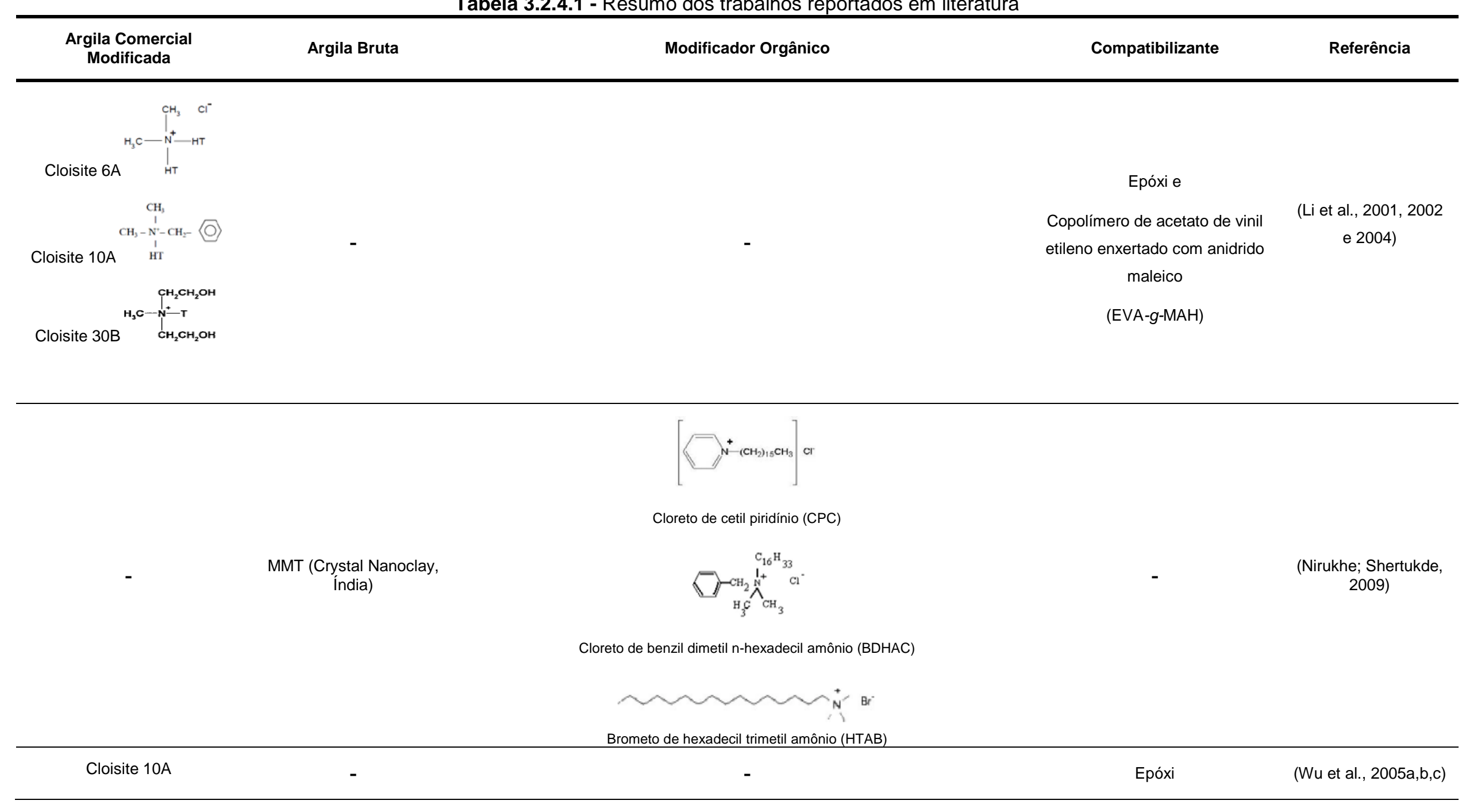




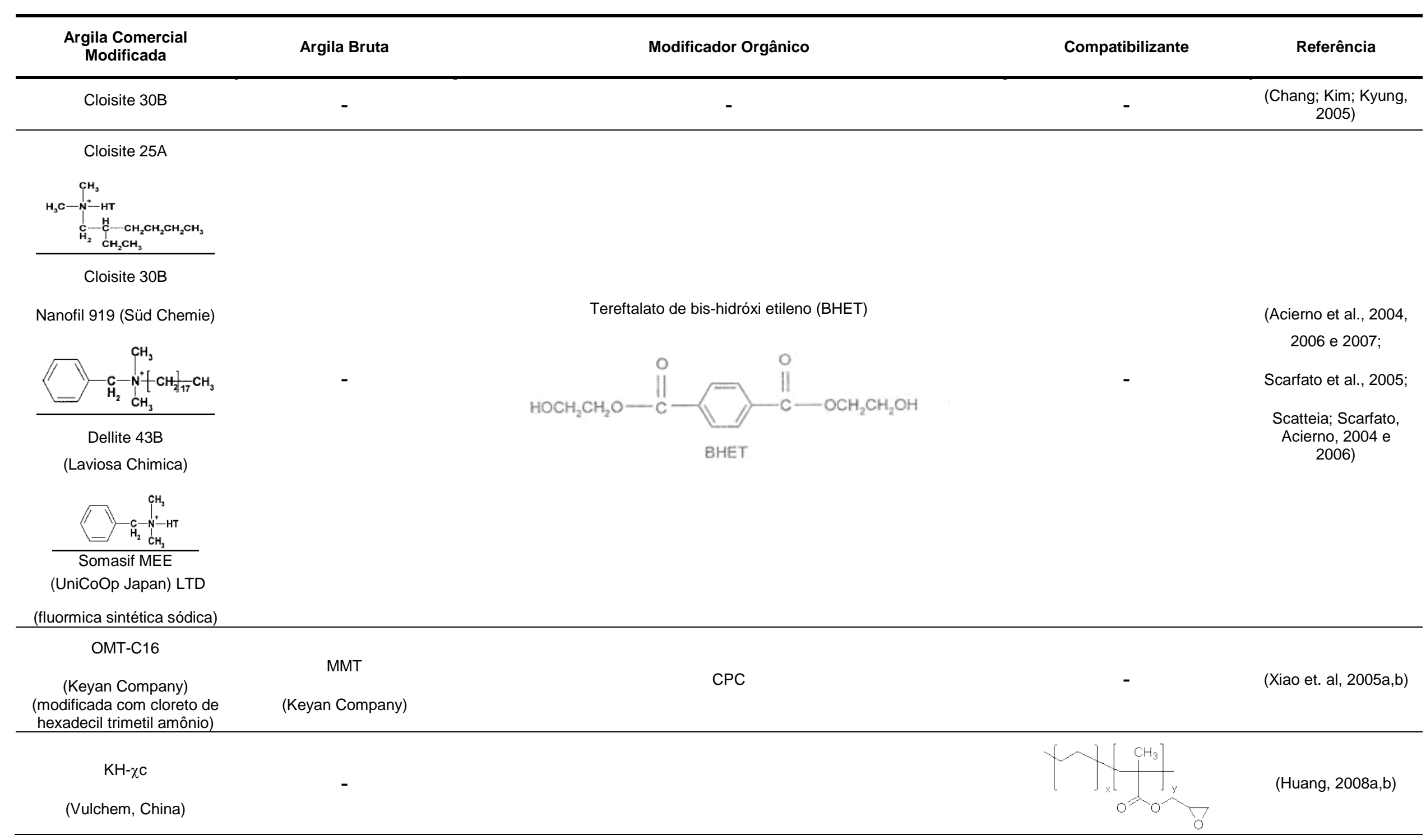




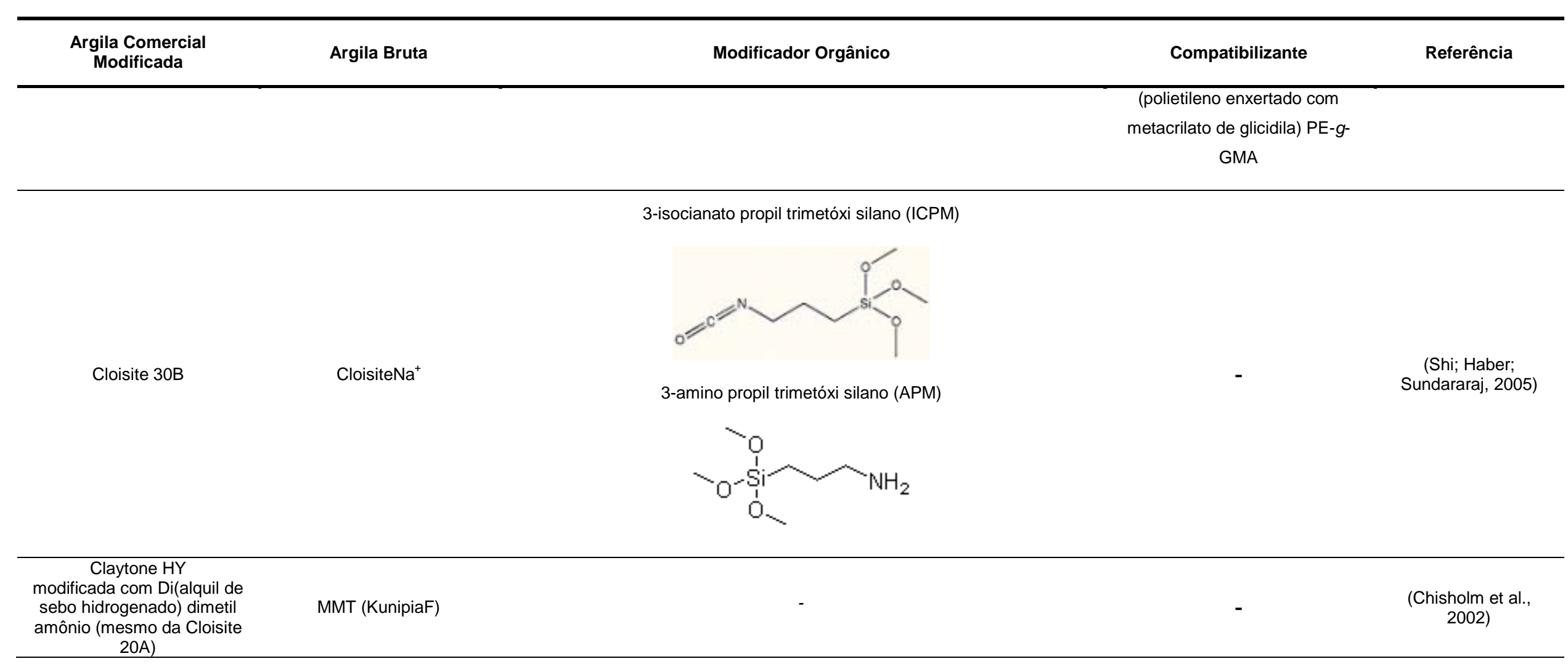


Diversos nanocompósitos de PBT com argilas comerciais e com argilas modificadas com vários sais foram obtidos. A hidrofobicidade da MMT organicamente modificada e as interações polares entre as camadas da argila e o PBT são fundamentais para a formação de um nanocompósito polimérico. A seguir o comportamento obtido para cada uma destas argilas é descrito em relação à sua microestrutura.

A Cloisite 6A possui duas cadeias alquil volumosas e seus cátions amônio são mais hidrofóbicos do que aqueles da 30B, uma vez que esta possui dois grupos hidroxietil, que são mais hidrofílicos, possuindo fortes interações com os grupos carboxila do PBT. A Figura 3.2.4.2 mostra uma micrografia obtida para PBT/6A.

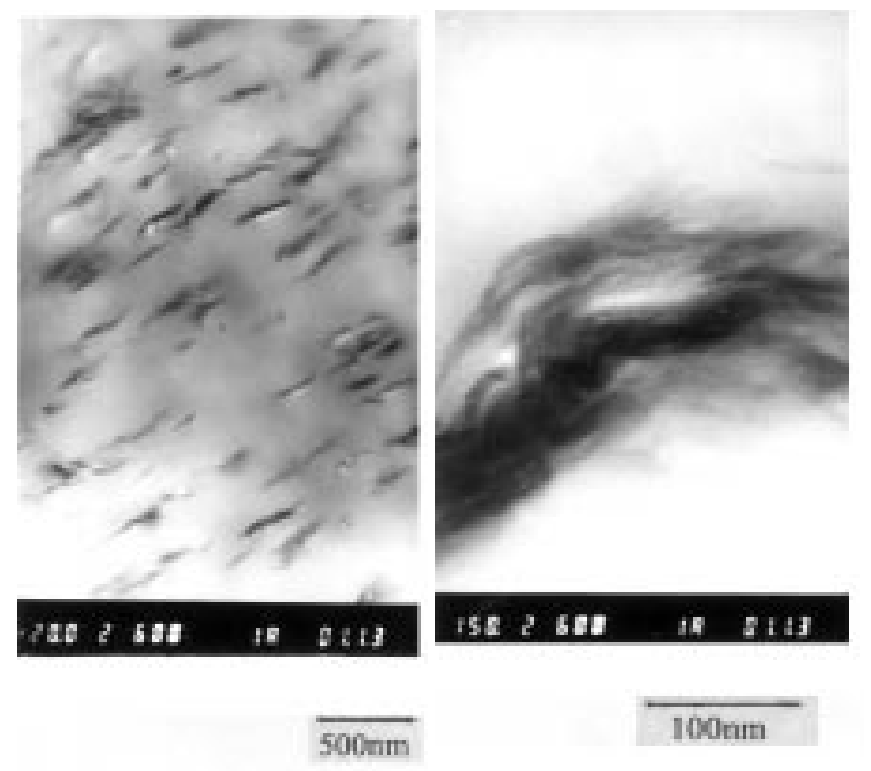

Figura 3.2.4.2 - PBT/6A 3\% (Li et al., 2001)

Pode ser observado que PBT/6A exibiu uma morfologia tradicional de compósitos, com formação de grandes aglomerados, devido a fraca compatibilidade entre o PBT e a argila modificada, de forma que após a adição de PBT, o espaçamento basal praticamente não foi alterado, conforme pode ser visto na Tabela 3.2.4.2 (Li et al., 2001). 
Tabela 3.2.4.2 - Resultados de espaçamento basal para PBT/Cloisite 6A (Li et al., 2001)

\begin{tabular}{cc}
\hline $6 \mathrm{~A}$ & $\mathrm{PBT} / 6 \mathrm{~A} \mathrm{(3 \% )}$ \\
\hline $2,49^{\circ}$ & $2,44^{\circ}$ \\
$3,57 \mathrm{~nm}$ & $\sim 3,6 \mathrm{~nm}$ \\
\hline
\end{tabular}

Em comparação com a Cloisite $6 \mathrm{~A}$, a substituição de um dos grupos parafínicos por um grupo benzil fornece à Cloisite $10 \mathrm{~A}$ um comportamento hidrofóbico e maior compatibilidade com PBT. A Figura 3.2.4.3 mostra uma micrografia obtida para PBT/10A.

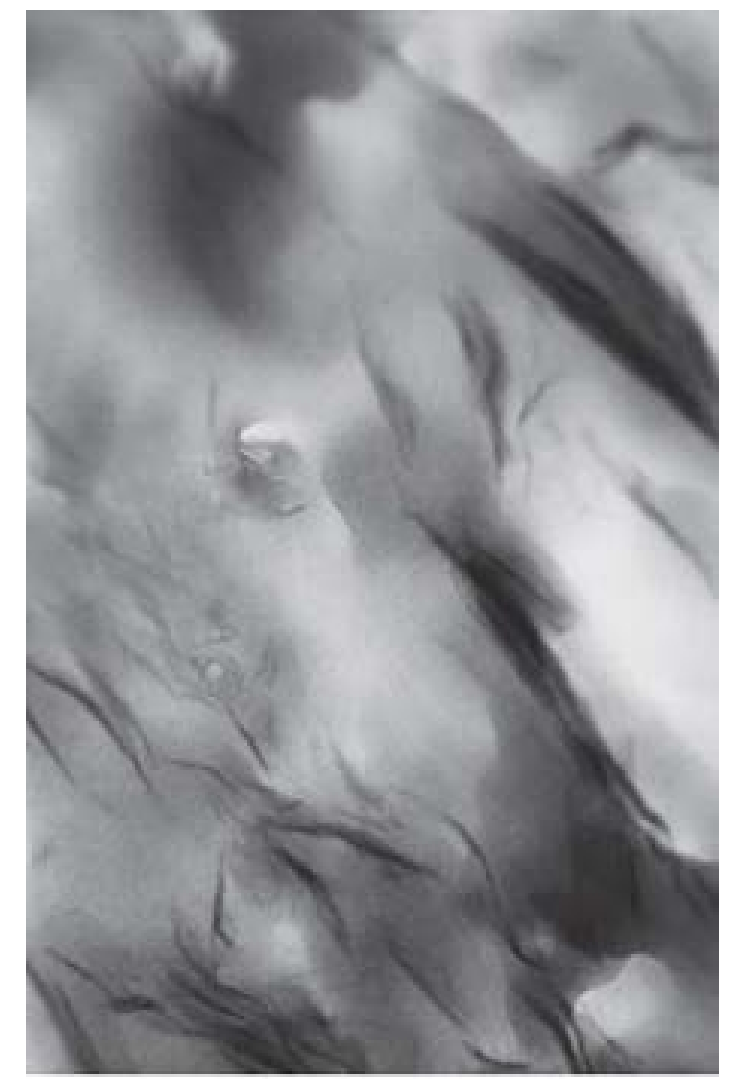

$500 \mathrm{~nm}$

Figura 3.2.4.3 - PBT/10A 4\% (Wu et al., 2005a)

As micrografias mostraram uma estrutura parcialmente intercalada/esfoliada para PBT/10A, (Li et al., 2001; Wu et al., 2005a,b). A Tabela 3.2.4.3 mostra os resultados de espaçamento basal reportados em 
literatura para PBT/10A, variando a concentração.

Tabela 3.2.4.3 - Resultados de espaçamento basal para PBT/Cloisite 10A, variando a concentração

\begin{tabular}{|c|c|c|c|c|c|c|}
\hline \multirow{2}{*}{ Cloisite 10A } & PBT/10A (3\%) & PBT/10A (4\%) & $\begin{array}{c}\mathrm{PBT} / 10 \mathrm{~A} \\
(2 \%)\end{array}$ & $\begin{array}{c}\text { PBT/10A } \\
(4 \%)\end{array}$ & $\begin{array}{c}\text { PBT/10A } \\
(6 \%)\end{array}$ & $\begin{array}{c}\text { PBT/10A } \\
(8 \%)\end{array}$ \\
\hline & Li et al. (2001) & Wu et al. (2005a) & \multicolumn{4}{|c|}{ Wu et al. (2005b) } \\
\hline \multicolumn{7}{|l|}{$2,00 \mathrm{~nm}$} \\
\hline Li et al, 2001 & $2,35^{\circ}$ & $2,60^{\circ}$ & $2,58^{\circ}$ & $2,24^{\circ}$ & $2,44^{\circ}$ & $2,40^{\circ}$ \\
\hline $1,98 \mathrm{~nm}$ & - & $3,42 \mathrm{~nm}$ & $3,42 \mathrm{~nm}$ & $3,94 \mathrm{~nm}$ & $3,62 \mathrm{~nm}$ & $3,68 \mathrm{~nm}$ \\
\hline Wu et al, $2005 a$ & & & & & & \\
\hline
\end{tabular}

- não reportado

Pode ser observado que, à medida que a concentração de 10A aumentou, o espaçamento basal aumentou, em relação ao espaçamento da argila pura com o maior espaçamento para 4\% em massa de argila. Nesta concentração, a intensidade do pico que caracteriza o espaçamento basal foi menor com relação às outras concentrações. Os autores sugerem que algumas camadas de silicato podem estar esfoliadas. O excesso de argila pode obstruir a difusão das cadeias (Wu et al., 2005b).

No caso da Cloisite 30B, Li et al. (2001) observaram que a Cloisite 30B pode formar estruturas intercaladas com o PBT, devido às fortes interações entre o cátion de amônio e as camadas da argila, ou seja, devido ao seu caráter hidrofílico. Entretanto, estruturas intercaladas/esfoliadas foram observadas por Scarfato et al. (2005), Scatteia, Scarfato e Acierno (2006) e Chang, Kim e Kyung (2005). As estruturas esfoliadas obtidas com Cloisite 30B foram observadas quando foi utilizado um PBT de alta viscosidade (Chang; Kim; Kyung, 2005). Neste caso, os autores denominaram o polímero de menor viscosidade como PBT-A e o de maior viscosidade como PBT-B. A Figura 3.2.4.4 mostra uma micrografia obtida para PBT-A/30B e PBT-B/30B. 

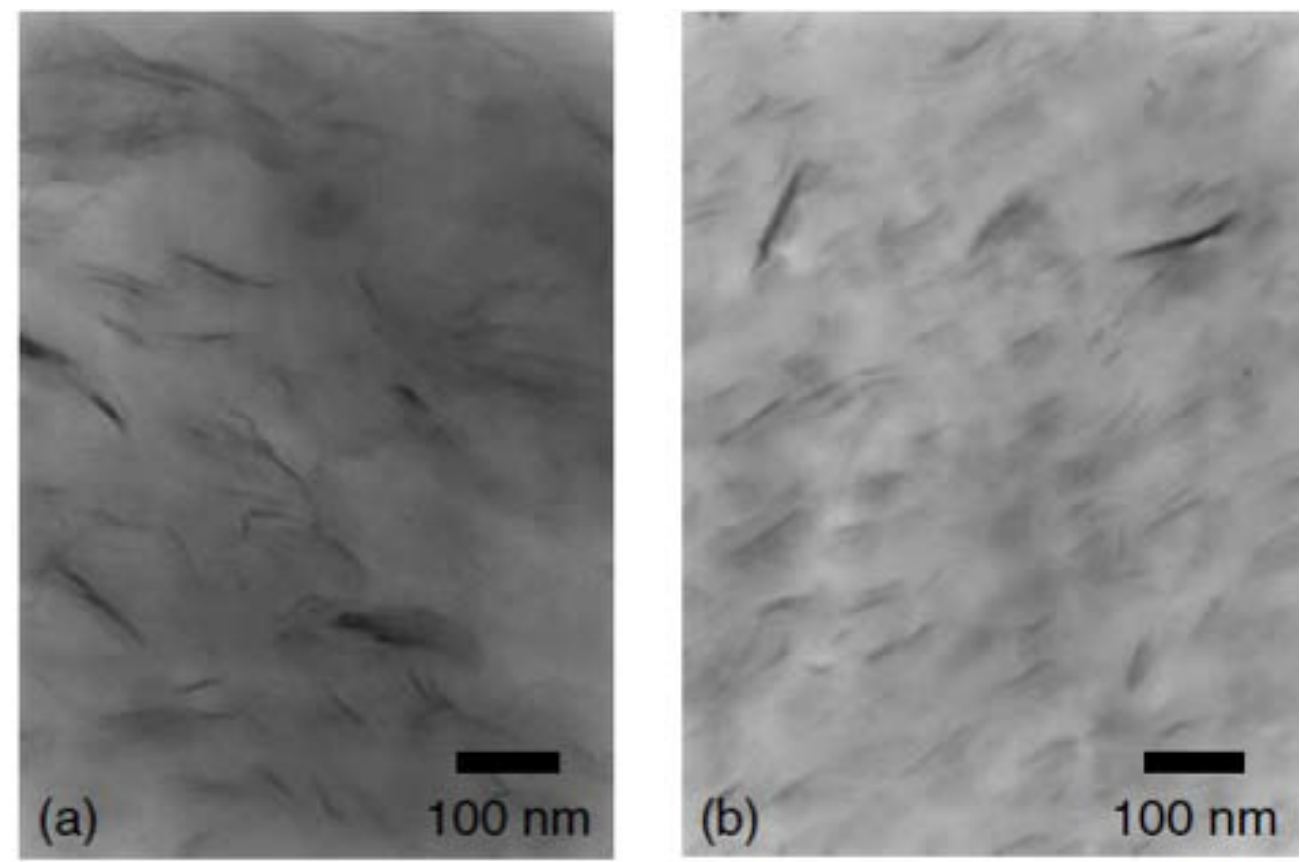

Figura 3.2.4.4 - a) PBT-A/30B; b) PBT-B/30B (Chang; Kim; Kyung, 2005)

Pode ser observado pelas micrografias que o PBT-B / argila apresentou camadas finas de argila dispersas uniformemente na matriz, enquanto que o PBT-A / argila apresenta alguns aglomerados e camadas mais grossas. A Tabela 3.2.4.4 mostra os valores de espaçamento basal reportados em literatura obtidos para PBT/30B.

Tabela 3.2.4.4 - Resultados de espaçamento basal para PBT/Cloisite 30B variando o tipo de polímero

\begin{tabular}{cccc}
\hline \multirow{2}{*}{ 30B } & PBT/30B (3\%) & PBT-A/30B (5\%) & PBT-B/30B (5\%) \\
\cline { 2 - 3 } & Li et al (2001) & Chang, Kim e Kyung (2005) \\
\hline 1,88nm & & & \\
Li et al, 2001 & $2,44^{\circ}$ & $2,80^{\circ}$ & $2,10^{\circ}$ \\
$4.8^{\circ}$ & $-3,6 \mathrm{~nm}$ & - & - \\
Chang et al., 2005 & & & \\
\hline
\end{tabular}

- não reportado

Os resultados obtidos por Li et al., 2001 mostram que para uma 
concentração de 5\% em massa de argila, o pico de difração para os dois tipos de PBT com argila aparecem em um ângulo menor do que aquele da argila pura, mostrando que o PBT intercalou na argila devido às fortes interações dos grupos carboxila presentes no PBT e os grupos hidroxilas existentes na argila. Entre os dois PBT, o de maior viscosidade (PBT-B) apresentou menor ângulo de difração. Isto mostrou que o PBT-B/argila tinha um grau de esfoliação muito maior do que o PBT-A/argila. Estas observações sugeriram que a tensão de cisalhamento é um fator importante para a esfoliação da argila. Este comportamento foi muito mais evidente no polímero de maior viscosidade, como mostraram os resultados, uma vez que favoreceu ao deslizamento entre as camadas e, conseqüentemente, à sua separação, facilitando o processo de esfoliação.

Acierno e outros autores (Acierno et al., 2004, 2006, 2007; Scarfato et al., 2005; Scatteia; Scarfato; Acierno, 2004, 2006) conduziram um estudo sistemático com nanocompósitos de PBT com CloisiteNa ${ }^{+}, \mathrm{CloisiteNa}^{+}-\mathrm{BHET}$, Cloisite 25A e 30B, Nanofil 919, Somasif MEE e Dellite 43B.

A Figura 3.2.4.5 mostra um difratograma e a Figura 3.2.4.6 mostra uma micrografia de PBT/25A, 9\% em massa.

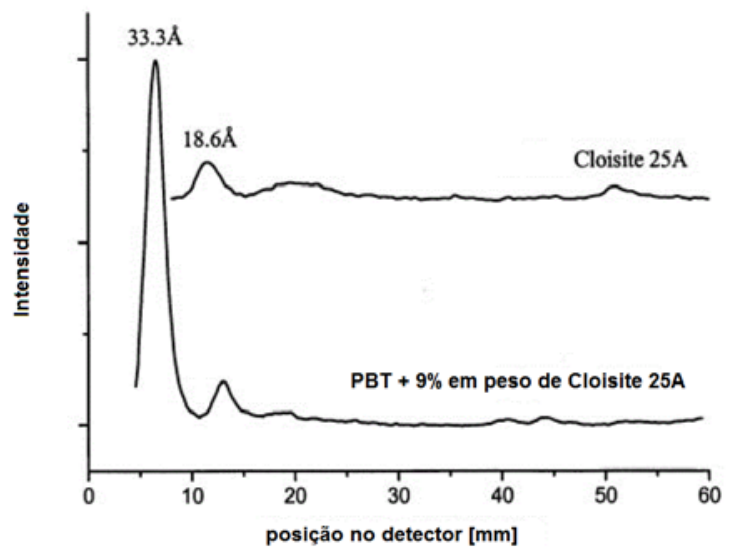

Figura 3.2.4.5 - XRD para Cloisite 25A e PBT/25A, 9\% (adaptada de Scatteia; Scarfato; Acierno, 2004)

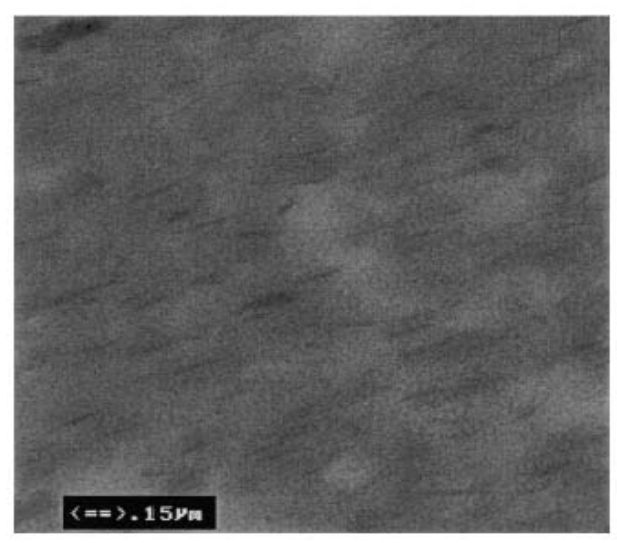

Figura 3.2.4.6 - MET para PBT/25A, 9\% (Scatteia; Scarfato; Acierno, 2004) 
Pode ser observado que o espaçamento basal aumenta após a adição de PBT e também visto por TEM. A Figura 3.2.4.7 mostra uma comparação com os difratogramas da Cloisite 25A e Nanofil 919 e seus respectivos com PBT (9\%) e a Figura 3.2.4.8 mostra esta comparação com a Dellite 43B. (Lembrando que as estruturas destas argilas são apresentadas na Tabela 3.2.4.1).

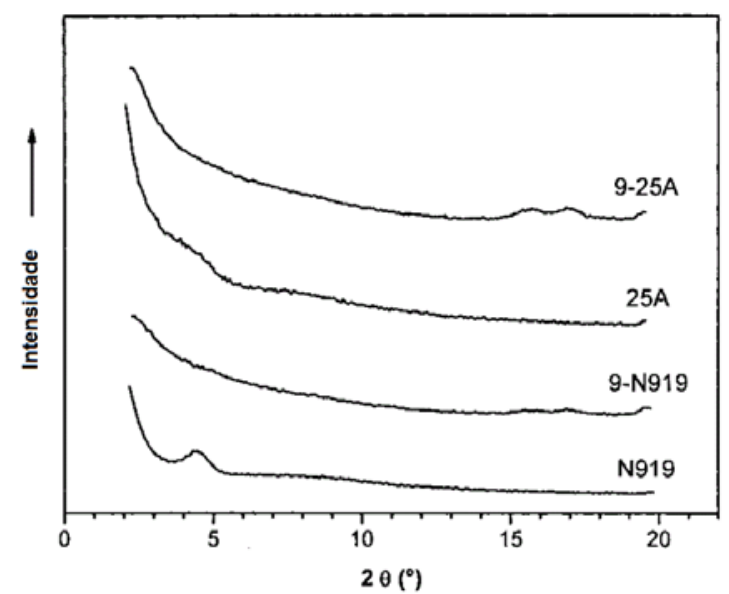

Figura 3.2.4.7 - XRD para Cloisite 25A e Nanofil 919, 9\% (adaptada de Scarfato et al., 2005)

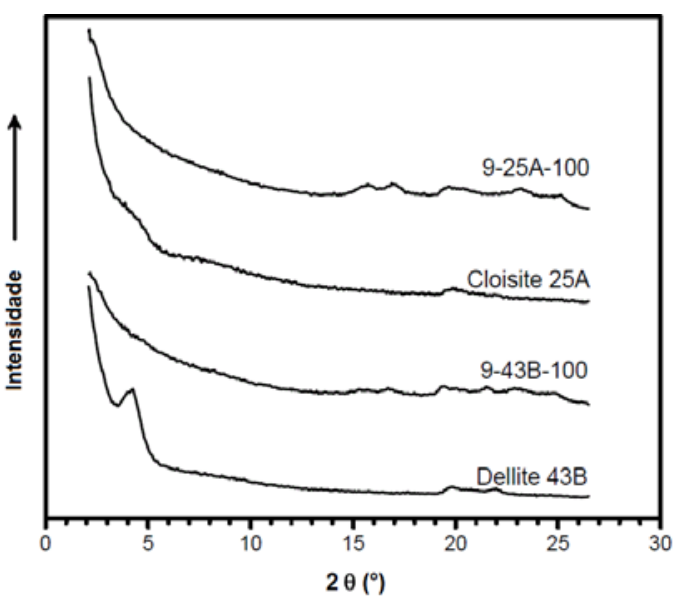

Figura 3.2.4.8 - XRD para 25A e 43B, 9\% (adaptada de Scatteia; Scarfato; Acierno, 2006)

Todos os materiais obtidos apresentaram um aumento no espaçamento basal com uma morfologia intercalada / esfoliada, havendo um pico de intercalação mais nítido com a 43B. Um menor grau de esfoliação foi obtido com N919 muito mais do que a 25A, e revelou que esta última tem maior afinidade com o PBT, facilitando a sua intercalação, à composição e processamento fixos. A qualidade da esfoliação aumentou com o aumento da taxa de extrusão para pequenas quantidades de argila.

Também foi estudada a adição de outra argila comercial, OMT-C16, modificada com cloreto de hexadecil trimetil amônio. Com a adição de PBT, o espaçamento basal aumentou de 2,37nm para 3,22nm, com uma morfologia intercalada (Xiao et al., 2005a).

Foi observado, também, que a argila não tratada MMT apresenta baixo espaçamento basal após a adição do polímero, como mostrado na Tabela 3.2.4.5. 
Tabela 3.2.4.5 - Resultados de espaçamento basal para PBT/MMT não tratada

\begin{tabular}{|c|c|c|}
\hline \multirow{2}{*}{ MMT } & \multirow{2}{*}{$\begin{array}{c}\text { PBT/MMT (3\%) } \\
\text { (Xiao et al., 2005a,b) }\end{array}$} & \multirow{2}{*}{$\begin{array}{c}\text { PBT/MMT (1, } 3 \text { e } 5 \%) \\
\text { (Nirukhe; Shertukde, 2009) }\end{array}$} \\
\hline & & \\
\hline \multicolumn{3}{|l|}{$1,51 \mathrm{~nm}$} \\
\hline \multicolumn{3}{|l|}{ Xiao et al, 2005a } \\
\hline $1,216 \mathrm{~nm}$ & $1,51 \mathrm{~nm}$ & sem picos de difração \\
\hline \multicolumn{3}{|l|}{ (Nirukhe; } \\
\hline Shertukde, 2009) & & \\
\hline
\end{tabular}

Pode ser visto que a adição de argila não modificada não apresenta nenhum aumento no espaçamento basal, indicando que o PBT não intercalou as camadas da argila sem a adição de um agente modificador para a argila.

A Figura 3.2.4.9 mostra os resultados para o caso da adição de BHET para a modificação da MMT.

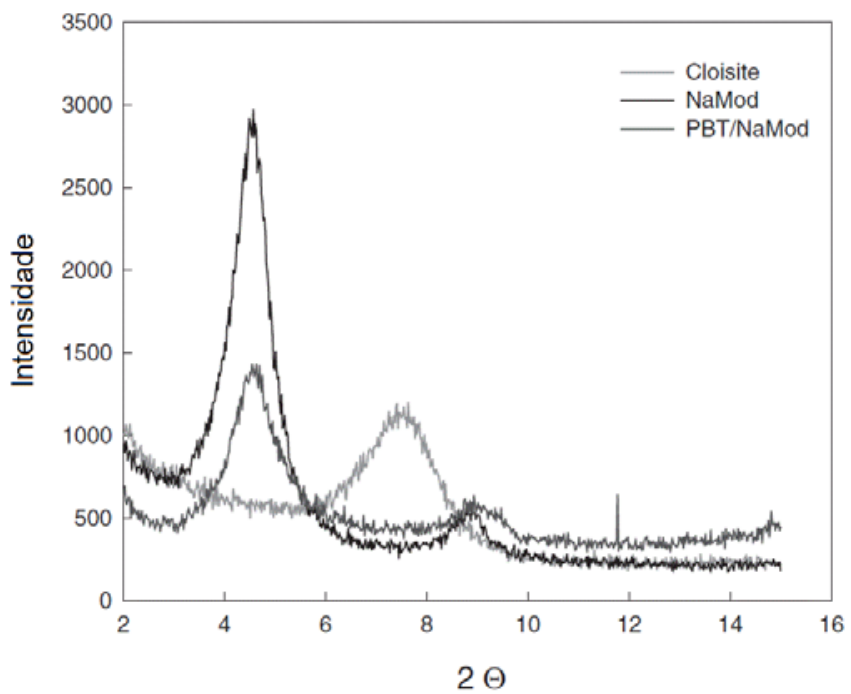

\begin{tabular}{lc}
\hline & Raios - $\mathbf{X}$ \\
\hline Amostra & $\mathrm{d}(\AA)$ \\
\hline Na-MMT & 11,58 \\
NaMod & 19,31 \\
PBT-NaMod & 19,39 \\
PBT-MEE & 16 \\
\hline
\end{tabular}

Figura 3.2.4.9 - Adição de BHET, 6\% NaMod. (adaptada de Acierno et al., 2007) (Os autores denominaram a CloisiteNa ${ }^{+}$como NaMMT, CloisiteNa ${ }^{+}-\mathrm{BHET}$ como NaMod., Somasif MEE de MEE e Cloisite25A como Cloisite)

As análises mostraram que PBT / 25A e PBT / Cloisite $\mathrm{Na}^{+}$exibiram uma 
morfologia intercalada. PBT / CloisiteNa ${ }^{+}$-BHET exibiu uma morfologia parcialmente esfoliada. Isto foi conseqüência da penetração do BHET nas camadas da argila.

CPC foi utilizado como agente modificador da montmorilonita na preparação de nanocompósitos de PBT (Xiao et al., 2005a,b; Nirukhe; Shertukde, 2009). Um resumo destes dados é apresentado na Tabela 3.2.4.6.

Tabela 3.2.4.6 - Resultados de espaçamento basal para PBT/MMT-CPC

\begin{tabular}{|c|c|c|c|}
\hline \multirow{3}{*}{ МMT/CPC } & $\begin{array}{c}\text { PBT/MMT/CPC } \\
\text { (1\% de MMT/CPC) }\end{array}$ & $\begin{array}{c}\text { PBT/MMT/CPC } \\
\text { (3 e } 5 \% \text { de }\end{array}$ & $\begin{array}{c}\text { PВT/MMT/CPC (3\% } \\
\text { de MMT/CPC) }\end{array}$ \\
\hline & & $\mathrm{MMT/CPC)}$ & \\
\hline & \multicolumn{2}{|c|}{ (Nirukhe; Shertukde, 2009) } & (Xiao et al., 2005a) \\
\hline \multicolumn{4}{|l|}{$2,264 \mathrm{~nm}$} \\
\hline $\begin{array}{c}\text { (Nirukhe; } \\
\text { Shertukde, 2009) }\end{array}$ & \multirow{2}{*}{$\begin{array}{c}2,48^{\circ} \\
3,56 \mathrm{~nm}\end{array}$} & $\begin{array}{l}\text { Os autores não } \\
\text { reportaram }\end{array}$ & $3,27 \mathrm{~nm}$ \\
\hline $2,38 \mathrm{~nm}$ & & $2 \theta<5^{\circ}$ & \\
\hline (Xiao et al, 2005a) & & & \\
\hline
\end{tabular}

\begin{tabular}{cccc}
\hline $\begin{array}{c}\text { PBT/MMT/CPC } \\
(3 \% \text { de MMT 0,5\% } \\
\text { de CPC })\end{array}$ & $\begin{array}{c}\text { PBT/MMT/CPC } \\
\text { (3\% de MMT 1\% } \\
\text { de CPC) }\end{array}$ & $\begin{array}{c}\text { PBT/MMT/CPC } \\
(3 \% \text { de MMT 2\% } \\
\text { de CPC) }\end{array}$ & $\begin{array}{c}\text { PBT/MMT/CPC (3\% } \\
\text { de MMT 3\% de } \\
\text { CPC) }\end{array}$ \\
\hline (Xiao et al., 2005b) \\
\hline $3,37 \mathrm{~nm}$
\end{tabular}

Pode ser observado que o espaçamento basal aumentou após a adição de argila modificada com CPC. Quando a concentração de CPC adicionada aumentou, o espaçamento basal também aumentou até um máximo de $2 \%$ e depois voltou a diminuir, indicando que o excesso de CPC favoreceu a formação de aglomerados. Este comportamento foi comprovado por micrografias. A Figura 3.2.4.10 mostra exemplos PBT/MMTCPC. 

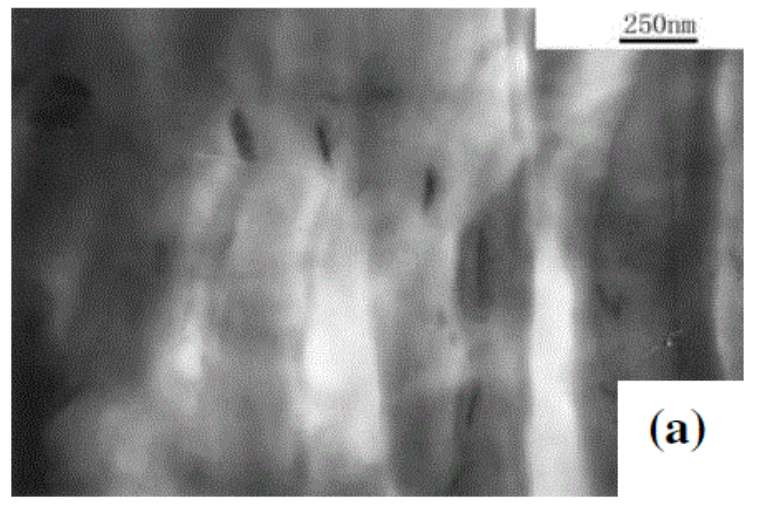

(a)

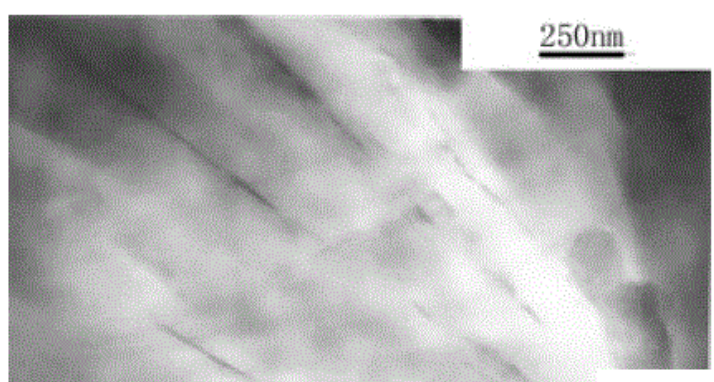

(b)

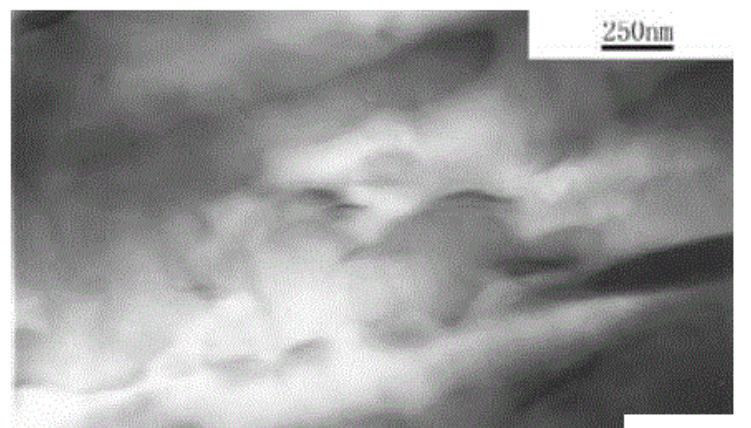

(c)

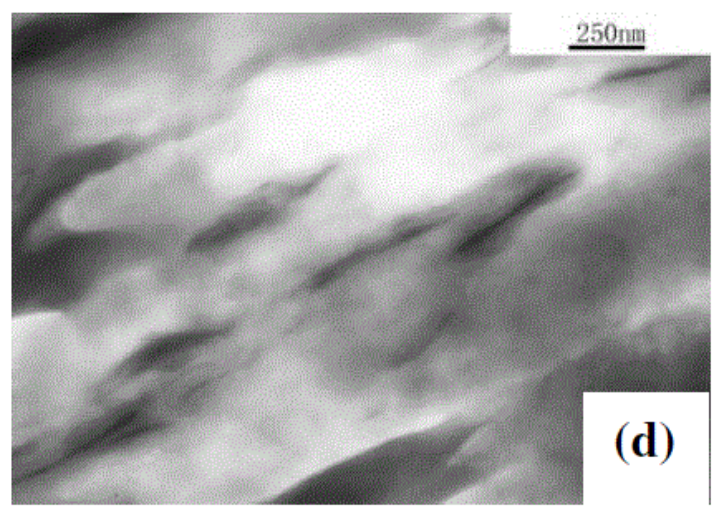

Figura 3.2.4.10 - (a) PBT+ (3 \% MMT+ 0,5\% CPC); (b) PBT+ (3\% MMT+ 1\% CPC); (c) PBT+ (3 \% MMT+ 2\% CPC), e (d) PBT+ (3\% MMT+ 3\% CPC) (Xiao et al., 2005b)

Pode ser observado que o espaçamento basal aumentou após a adição de argila modificada com CPC. Nos estudos de Xiao et al., (2005a,b), os quais variaram a concentração de CPC, as estruturas estão parcialmente intercaladas e esfoliadas. CPC contém grupos de anéis aromáticos os quais são similares aos grupos fenil do PBT. Entretanto o espaçamento basal aumentou até uma concentração de $2 \%$ de CPC, para uma concentração fixa de argila de 3\%. Com 3\% de CPC, este espaçamento diminuiu, mostrando que a capacidade de intercalação atingiu um limite. Com uma concentração de 0,5\% de CPC, as micrografias apresentaram tactóides intercalados contendo muitas camadas de silicato paralelas e grandes partículas da ordem de micra. Quando a concentração aumenta para 1\%, as camadas paralelas estão mais ordenadas e as grandes partículas não são observadas. Para a concentração de 2\%, há uma boa dispersão da argila, mas com tactóides intercalados maiores do que para 1\%. E com 3\% de CPC, começam a surgir os aglomerados de tactóides, confirmando os resultados de XRD. Estes 
resultados sugerem uma possível mudança de orientação de CPC na superfície da argila, a qual altera a interação interfacial entre a argila e as cadeias de PBT, para as concentrações de 2 e 3\% de CPC. Segundo os autores, Xiao et al. (2005a,b), isso se deve ao fato de que concentrações de 2 e 3 \% de sal representam um excesso em relação a capacidade de troca iônica da argila.

PE-g-MA também foi utilizado como agente modificador da MMT. A Figura 3.2.4.11 mostra os difratogramas deste estudo e a Figura 3.2.4.12 mostra uma micrografia para PBT/PE-g-MA/MMT.

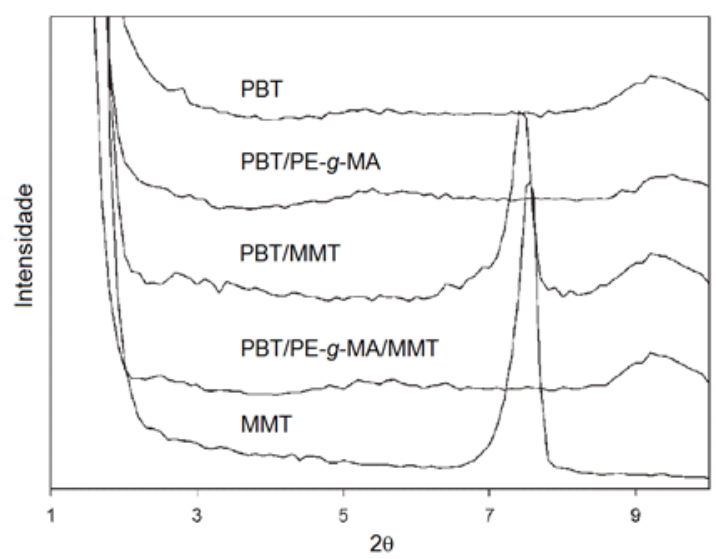

Figura 3.2.4.11 - Difratogramas de PBT, PBT/PE-g-MA, PBT/MMT, PBT/PE- $g$ MA/MMT e MMT (adaptada de Huang, 2008b)

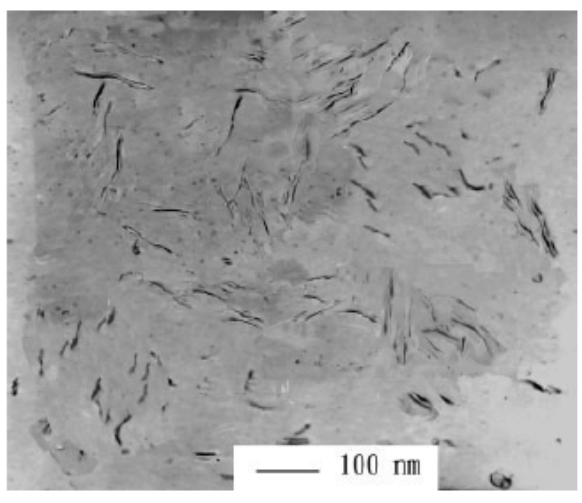

Figura 3.2.4.12 - Micrografia de PBT/PE-gMA/MMT (Huang, 2008b)

Pode ser observado que após a adição de PBT, o espaçamento basal não aumentou significativamente, indicando que sem modificação a argila não permite a penetração do PBT. Entretanto, os autores afirmam que com a presença de PE-g-MA o espaçamento basal aumentou acima de 80nm, uma vez que não foram observados picos de difração e foi observada uma estrutura esfoliada. Esse alto grau de esfoliação foi atribuído às reações químicas entre PBT e PE-g-MA, favorecendo a miscibilidade entre os materiais.

Com a adição de BDHAC e HTAB na MMT, foram observados aumentos do espaçamento basal: 2,904nm para MMT/BDHAC e 2,323nm para 
HTAB/MMT. Com a adição de PBT, esse aumento foi de 3,503nm para 1 e 3\% de BDHAC, mas os autores não reportaram o valor do espaçamento basal para HTAB, embora eles aumentaram e, também, não estudaram morfologia (Nirukhe; Shertukde, 2009).

Outros estudos foram conduzidos com a adição de resina epóxi. Devido à existência de grupo polar epóxi, as resinas epóxi podem facilmente intercalar entre as camadas da argila organicamente modificada. Além disso, as resinas epóxi são miscíveis com PBT a temperaturas acima de $210^{\circ} \mathrm{C}$, com alta agitação.

A partir destas considerações, Li et al. $(2001,2004)$ puderam observar após a adição da resina epóxi, que as partículas de Cloisite 6A ficaram separadas da matriz PBT e o espaçamento basal praticamente não foi alterado. No caso da Cloisite 10A, a presença de epóxi diminui a intercalação e a esfoliação. As partículas parcialmente esfoliadas são maiores e estão pouco dispersas quando comparado com os nanocompósitos na ausência de epóxi. Desta forma, a Cloisite 10A pode ser intercalada e parcialmente esfoliada na matriz PBT, devido ao seu caráter hidrofóbico e compatibilidade com o PBT. Por outro lado, a adição de epóxi no caso da Cloisite 30B mostrou-se efetiva. A Figura 3.2.4.13 mostra o difratograma para $\mathrm{PBT/30B}$ na presença de resina epóxi. 


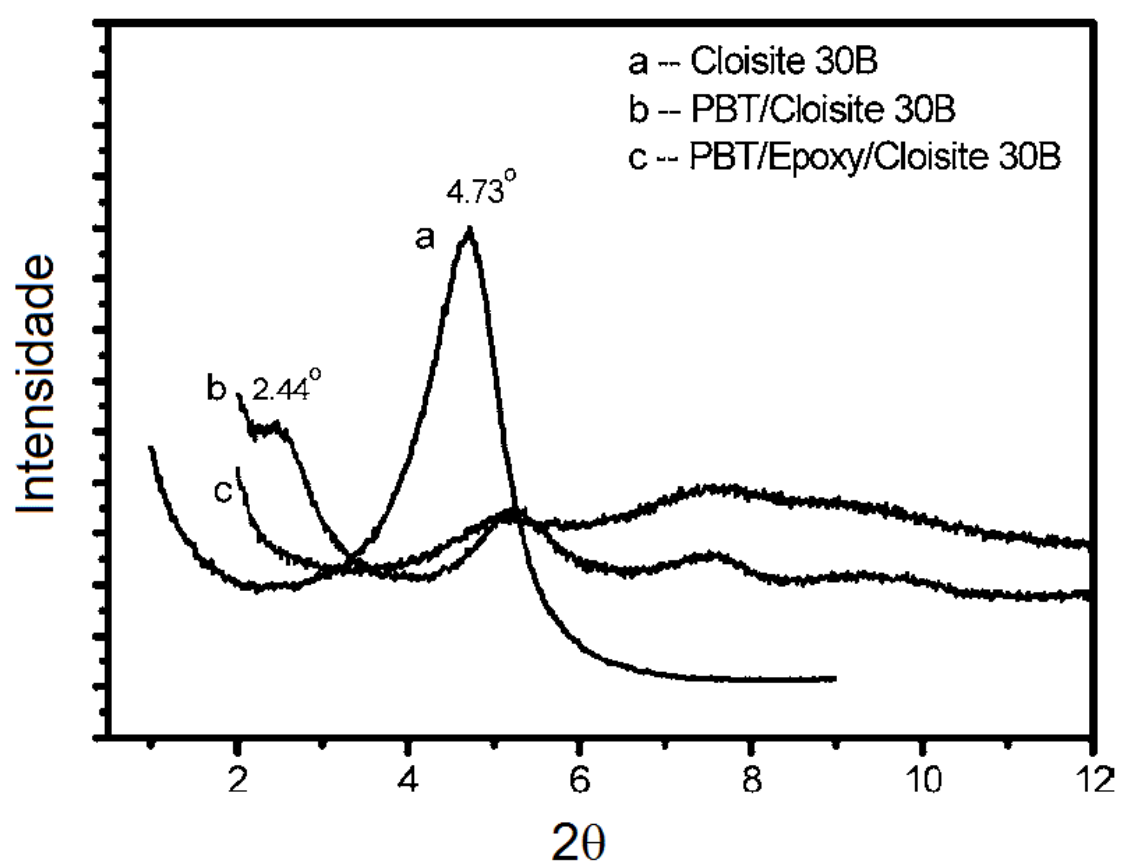

Figura 3.2.4.13 - Difratograma para PBT/30B com e sem adição de epóxi (adaptada de Li et al., 2004)

Pode ser observado que o pico característico da estrutura intercalada desapareceu nas curvas XRD, mostrando que houve um alto grau de intercalação e esfoliação. Isto é justificado em função da forte interação e possíveis reações entre o epóxi e a argila modificada, e a compatibilidade entre o epóxi e o PBT.

Em outros dois trabalhos, Li et al. (2002, 2004) os autores estudaram compostos ternários de PBT/EVA-g-MAH/30B com a presença de epóxi, variando os procedimentos de mistura. Os autores concluíram que a seqüência de adição dos materiais na mistura influencia na morfologia e no estado de dispersão da argila na matriz polimérica. Numa primeira etapa, os três materiais foram adicionados juntos no misturador. Foi observada uma morfologia de domínios grandes e irregulares de EVA-g-MAH. A Cloisite 30B se dispersou nas duas fases, mas principalmente em EVA-g-MAH e próximo da área interfacial, o que sugere que a interação polar entre Cloisite 30B e EVA-gMAH foi mais forte do que aquela entre PBT e Cloisite 30B e apresentou uma morfologia intercalada e esfoliada. Na segunda etapa, (PBT/30B) foi misturado com EVA-g-MAH. Foi observado que algumas partículas de Cloisite 30B se 
dividiram em várias camadas na matriz PBT. A Figura 3.2.4.14 mostra o difratograma desta segunda seqüência.

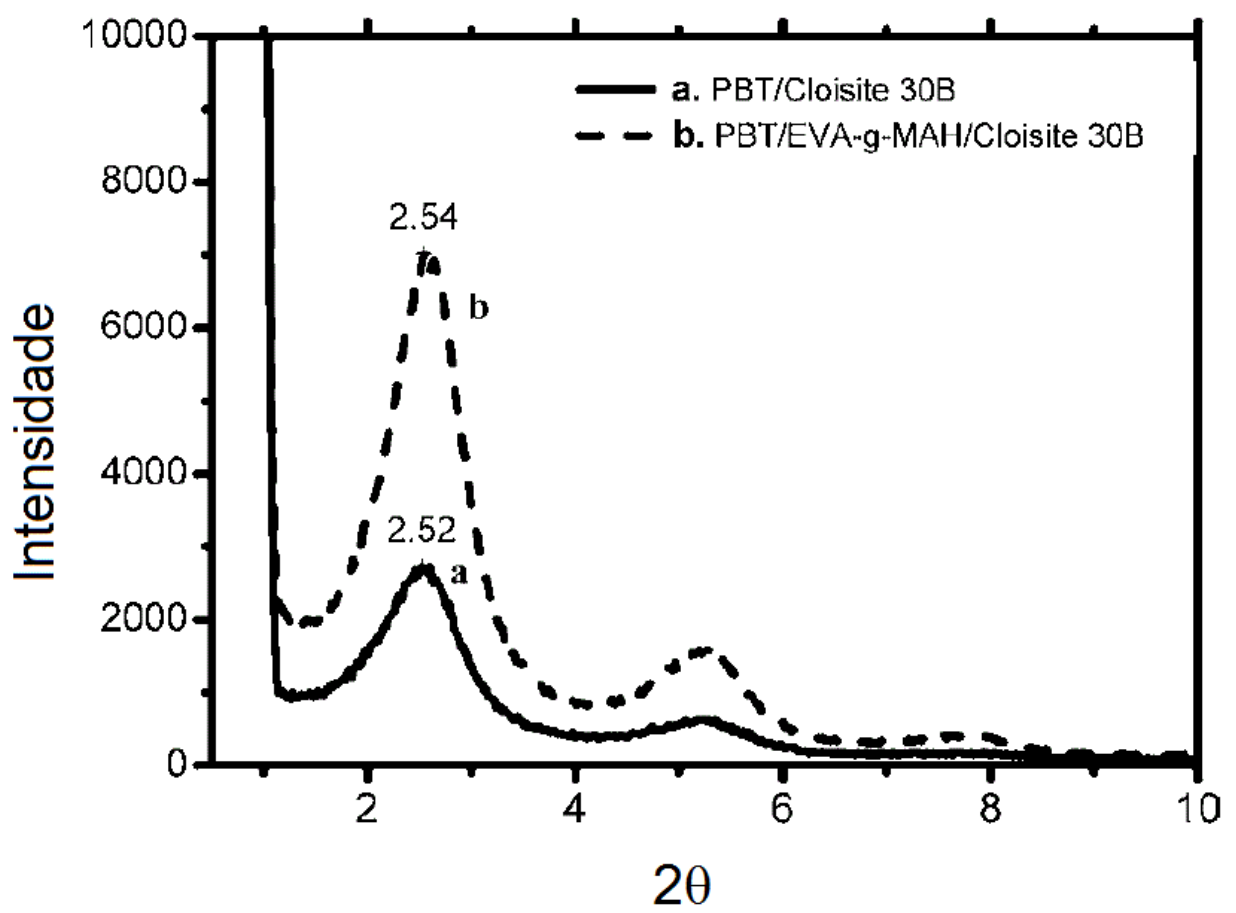

Figura 3.2.4.14 - Difratograma para PBT/30B e PBT/EVA-g-MAH/30B, com epóxi (adaptada de Li et al., 2004)

Porém, como não houve modificação no pico de intercalação por difração, eles acreditam que não ocorreu intercalação nesta segunda parte da mistura, confirmado por TEM. Também foi observado que nesta segunda fase, nenhuma partícula de Cloisite 30B migrou para a fase de EVA-g-MAH. Isto pode ter ocorrido devido à forte interação das ligações de hidrogênio entre os grupos hidroxila da 30B e a matriz PBT, as quais mantêm as camadas da argila na matriz PBT evitando a sua migração para a fase EVA-g-MAH. Na terceira etapa, (EVA-g-MAH/30B) foi misturado com PBT. Embora a morfologia tenha apresentado grandes partículas de Cloisite 30B (principalmente na fase EVA-g$\mathrm{MAH}$ ), uma estrutura parcialmente esfoliada e parcialmente intercalada foi obtida. Além disso, a dispersão de (EVA-g-MAH/30B) em PBT é irregular. Na quarta etapa, (PBT/EVA-g-MAH) foi misturado com Cloisite 30B. Grandes domínios de EVA-g-MAH foram observados na matriz de PBT. A adição de 
Cloisite 30B caracterizou uma morfologia como aquela vista na primeira etapa, com muitas camadas de argilas localizadas na área interfacial. Nos compósitos de PBT/epóxi/30B os autores observaram que o pico de difração característico da Cloisite 30B em PBT/30B desapareceu após a adição de epóxi, caracterizando um alto grau de esfoliação e intercalação. As razões desse resultado é que os grupos polares epóxi facilitam a intercalação nas camadas da argila, além de sua miscibilidade com PBT.

Entretanto, o epóxi em excesso pode dificultar a difusão das cadeias poliméricas, uma vez que o epóxi em excesso pode se agrupar na superfície da argila e envolver os tactóides (Wu et al., 2005c).

\section{ANÁLISE TÉRMICA}

De uma forma geral todos os estudos térmicos sobre nanocompósitos de PBT/OMMTs reportados na literatura apresentaram melhor estabilidade térmica, quando comparada a do PBT puro. Li et al. (2004) observaram que a presença de EVA-g-MAH/MMT melhorou a estabilidade térmica em relação ao PBT puro, como mostrada na Figura 3.2.4.15.

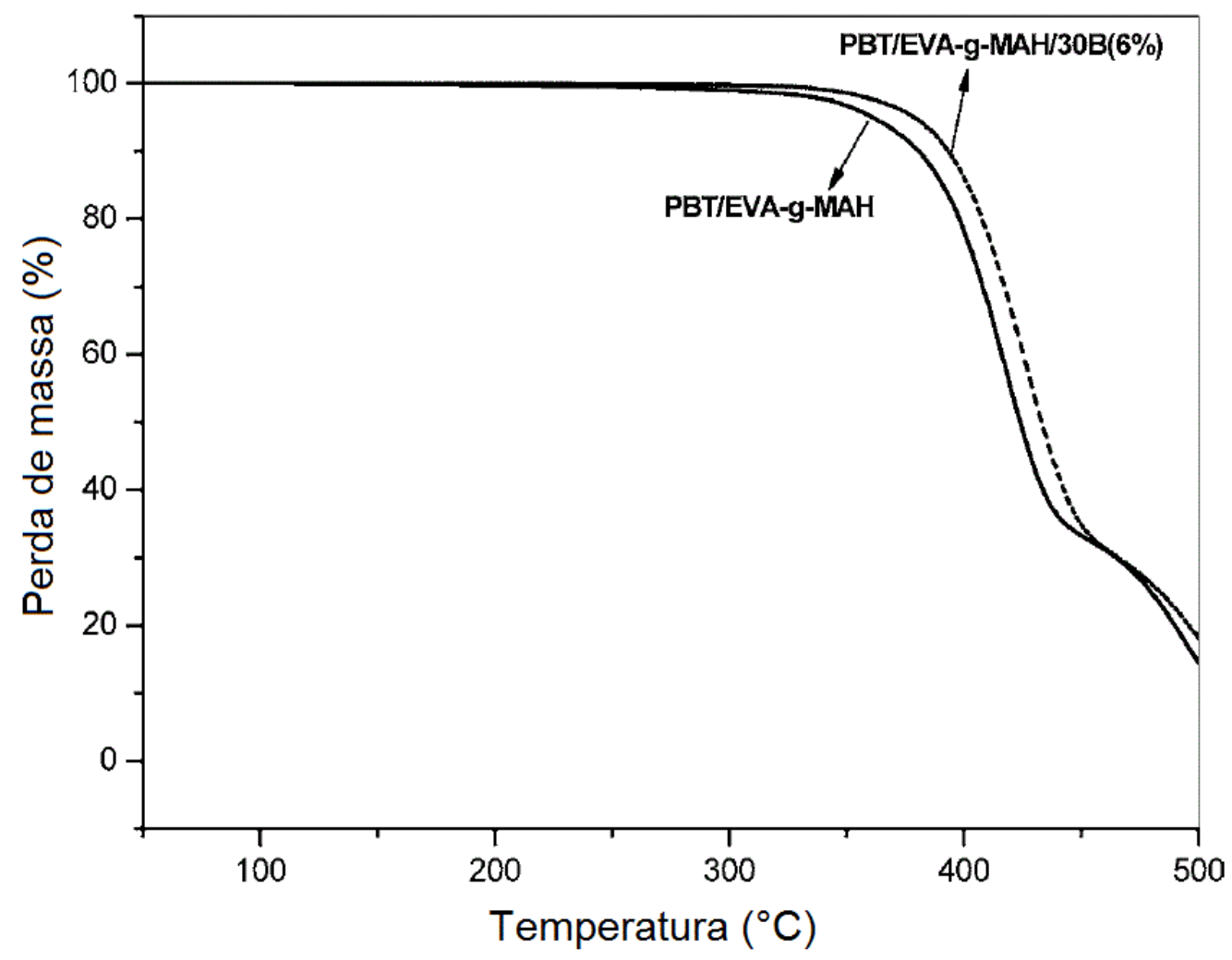

Figura 3.2.4.15 - TGA de PBT/EVA-g-MAH e PBT/EVA-g-MAH/30B (6\%)

(adaptada de Li et al., 2004) 
Esse comportamento foi associado às camadas da argila que limitaram a mobilidade das pequenas moléculas produzidas durante a decomposição térmica.

As análises de Shi; Haber, Sundararaj (2005) mostraram que as argilas modificadas (APM-MMT e ICPM-MMT) mantidas durante duas horas a $110^{\circ} \mathrm{C}$ foram mais estáveis durante uma análise termogravimétrica do que aquelas mantidas a $65^{\circ} \mathrm{C}$ no mesmo tempo, em função do favorecimento da formação de ligações químicas entre os agentes modificadores e a argila sob altas temperaturas.

Na presença de CPC, uma maior estabilidade térmica foi observada, pois houve pouca perda de massa uma vez que os anéis aromáticos dos cátions piridínio têm melhor estabilidade térmica do que os cátions amônio (Xiao et al., 2005a; Nirukhe; Shertukde, 2009).

Com a presença de BHET, a temperatura de degradação da MMT-BHET foi maior do que com Cloisite 25A e MEE. A perda de massa inicial foi atribuída à condensação do BHET. A Tabela 3.2.4.7 mostra um resumo destes dados.

Tabela 3.2.4.7 - Resultados de TGA para PBT, PBT/NaMod, PBT/MEE e PBT/25A (adaptada de Acierno et al., 2007)

\begin{tabular}{lccc}
\hline Amostra & Resíduo $(\%)$ & $\mathrm{T}_{\text {inicial }}\left({ }^{\circ} \mathrm{C}\right)$ & $\mathrm{T}_{\max }\left({ }^{\circ} \mathrm{C}\right)$ \\
\hline PBT & 4.2 & 369 & 389 \\
PBT/NaMod & 5.4 & 370 & 388 \\
PBT/MEE & 9.2 & 373 & 392 \\
PBT/C25A & 8.6 & 359 & 390 \\
\hline
\end{tabular}

A estabilidade térmica do PBT/MMT-BHET não aumentou consideravelmente comparada ao PBT puro, sendo melhor do que a PBT/25A, uma vez que a presença de sais de alquil amônio favoreceu a queima a temperatura mais baixa (Acierno et al., 2006, 2007).

Após a adição do epóxi, as análises térmicas mostraram que a adição de epóxi não foi eficiente para PBT/10A. Na Tabela 3.2.4.8, os nanocompósitos foram descritos como PCNxy, onde x é a concentração em massa de epóxi e y é concentração em massa de Cloisite 10A. 
Tabela 3.2.4.8 - Resultados de TGA para PBT/10A com e sem epóxi (adaptada de Wu et al., 2005a)

\begin{tabular}{lllll}
\hline Amostras & $\mathrm{T}_{5 \%}\left({ }^{\circ} \mathrm{C}\right)$ & $\mathrm{T}_{10 \%}\left({ }^{\circ} \mathrm{C}\right)$ & $\mathrm{T}_{\max }\left({ }^{\circ} \mathrm{C}\right)$ & $\begin{array}{l}\% \text { Residual a } \\
700^{\circ} \mathrm{C}\end{array}$ \\
\hline PBT & 383 & 391 & 432 & 1.3 \\
PCN04 & 411 & 424 & 472 & 3.2 \\
PCN24 & 413 & 426 & 468 & 4.1 \\
PCN44 & 413 & 425 & 466 & 4.7 \\
PCN64 & 408 & 421 & 462 & 3.8 \\
PCN84 & 406 & 419 & 463 & 5.3 \\
\hline
\end{tabular}

Com a adição de argila e epóxi a estabilidade térmica melhorou com relação ao PBT puro. Mas os melhores resultados foram obtidos com e 2 e 4\% de epóxi. Nestes compostos, há muito mais tactóides de argila do que aqueles sem epóxi, os quais estavam bem dispersos na matriz. Acima de 6\%, a degradação do excesso de epóxi disperso na matriz fez com que a estabilidade térmica diminuísse, mas que ainda foi maior do que o PBT puro. Com base nesses resultados, os autores concluíram que a concentração ideal de epóxi é 4\% em massa (Wu et al., 2005a).

Para a compreensão dos fenômenos que ocorrem durante estas avaliações foram descritos, no item 2.2.1, os mecanismos de reação de decomposição para sais de amônio e fosfônio.

\section{PROPRIEDADES MECÂNICAS}

Chisholm et al. (2002) avaliaram que a adição de argila modificada em PBT forneceu um maior aumento no módulo elástico do que a adição de argila não modificada, quando comparado ao PBT puro, uma vez que a argila modificada apresenta partículas de menor tamanho. Eles trabalharam com nanocompósitos sulfonados. O aumento da concentração de grupos $-\mathrm{SO}_{3} \mathrm{Na}$ também ocasionou um aumento no módulo de elasticidade.

A Tabela 3.2.4.9 mostra os resultados obtidos por Li et al. (2004), os quais estudaram blendas de PBT/EVA-g-MAH/30B. 
Tabela 3.2.4.9 - Propriedades mecânicas obtidas por (adaptada de Li et. al, 2004)

\begin{tabular}{lcccc}
\hline Amostras & $\begin{array}{l}\text { Resistência à } \\
\text { tração } \\
(\mathrm{MPa})\end{array}$ & $\begin{array}{l}\text { Alongamento } \\
\text { na ruptura } \\
(\%)\end{array}$ & $\begin{array}{l}\text { Módulo de } \\
\text { elasticidade } \\
(\mathrm{MPa})\end{array}$ & $\begin{array}{l}\text { Resistência } \\
\text { ao impacto } \\
(\mathrm{J} / \mathrm{m})\end{array}$ \\
\hline PBT & 56.4 & 42.8 & 370 & 24.7 \\
PBT/EVA-g-MAH & 38.6 & 72.3 & 268 & 90.6 \\
PBT/EVA-g-MAH/ & 42.4 & 45.6 & 325 & 65.4 \\
30B (3\% peso) & & & 362 & 64.8 \\
PBT/EVA-g-MAH/ & 44.1 & 43.7 & & \\
30B (6\% peso) & & & 362 & \\
\hline
\end{tabular}

Os autores observaram que a resistência a tração e módulo de elasticidade de PBT/EVA-g-MAH aumentaram com a adição de argila e com o aumento da concentração de argila, que estão associados com a forte interação entre argila e polímero, mas foram menores que o PBT. Também quando os autores variaram a ordem de adição dos materiais durante o processamento, eles observaram que os valores de resistência ao impacto de todos os compostos com Cloisite 30B estiveram entre os valores de PBT e PBT/EVA-g-MAH. Assim, os autores concluíram que a presença de EVA-gMAH foi fundamental para as melhores propriedades de impacto.

Acierno et al. (2004) observaram que as propriedades mecânicas das amostras extrusadas sob alta rotação são maiores do que aquelas processadas a baixa rotação, de forma que os híbridos apresentaram maior rigidez e uma ductibilidade reduzida em relação ao PBT puro.

No caso do estudo de Chang, Kim e Kyung (2005), PBT/30B, pode ser observado que o módulo aumentou com o aumento da concentração da argila e este efeito de maior rigidez é mais acentuado no PBT-B/argila do que no PBT-A/argila, o que pode estar correlacionado com uma dispersão mais fina das camadas da argila na matriz (mais esfoliado). A Figura 3.2.4.16 mostra o alongamento na ruptura para estes estudos. 


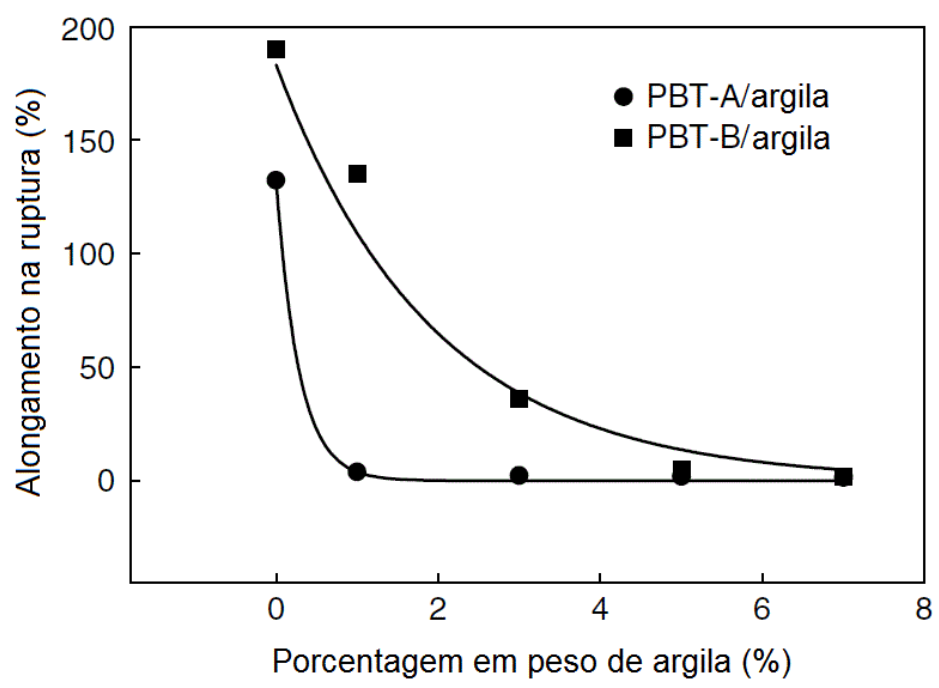

Figura 3.2.4.16 - Efeito da quantidade de argila modificada no alongamento na ruptura para PBT/OMMTs (adaptada de Chang, Kim, Kyung, 2005)

Quando comparado ao PBT puro, os híbridos mostraram uma clara redução no alongamento na ruptura após a adição da argila, mas com comportamentos diferentes. O composto PBT-A/argila com uma concentração de somente $1 \%$ em massa de argila mostrou uma brusca redução do alongamento na ruptura com relação ao PBT puro. Enquanto que o PBTB/argila teve uma redução mais suave até $3 \%$ de adição de argila, comprovando que o grau de dispersão também influiu nesta propriedade

Nirukhe; Shertukde (2009) associaram o aumento das propriedades mecânicas com a degradabilidade dos sais adicionados. A adição de CPC resultou em um aumento maior da resistência a tração do que os demais em função de que o CPC possui menor degradabilidade na temperatura de processamento do PBT. Além disso, os autores observaram que acima de 5\% de adição de argila as propriedades mecânicas foram menores do que em concentrações abaixo de deste valor.

\section{FLAMABILIDADE}

Do nosso conhecimento, apenas um trabalho estudou a flamabilidade de nanocompósitos de PBT/OMMT (Xiao et al., 2005b). Eles estudaram PBT com MMT modificada com CPC. A Figura 3.2.4.17 mostra os resultados de flamabilidade obtidos para PBT/MMT-CPC. 


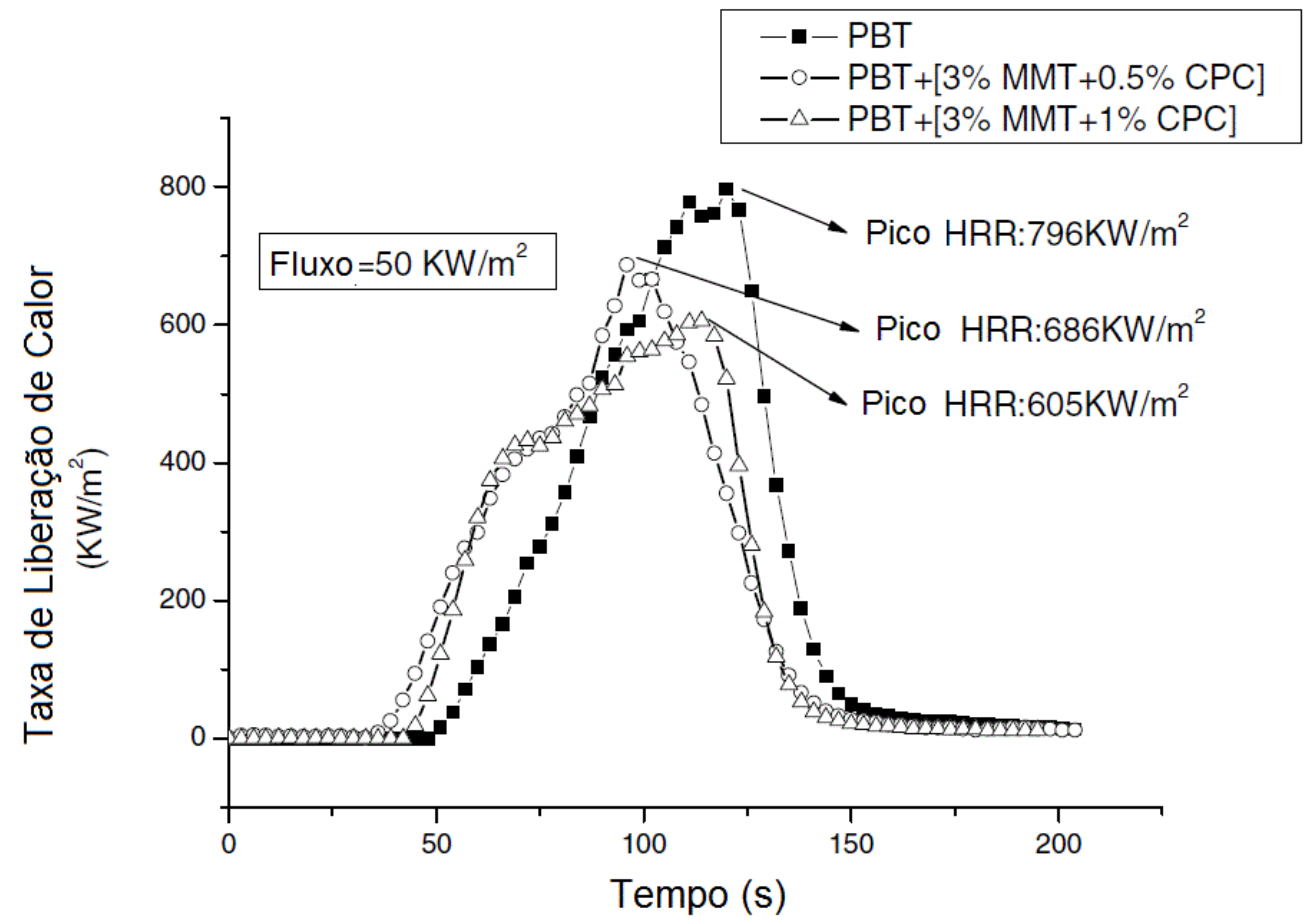

Figura 3.2.4.17 - Taxa de liberação de calor (HRR) para PBT,

PBT+[3\%MMT+0,5\%CPC] e PBT+[3\%MMT+1\%CPC] (adaptada de Xiao et al., 2005b)

Segundo os autores, pode ser observada uma taxa de diminuição de 14\% na presença de 0,5\% de CPC e de 24\% na presença de $1 \%$ quando comparado ao PBT puro, uma vez que CPC melhorou a capacidade de dispersão da argila no PBT. Entretanto, o tempo de ignição é maior para PBT, em função de que a decomposição térmica do CPC resulta da formação de voláteis rapidamente percebidos durante o ensaio.

\subsection{Materiais e Métodos}

\subsubsection{Materiais}

O PBT utilizado neste trabalho foi fornecido pela Sabic Innovative Plastics, sob a especificação Valox 325. Algumas de suas propriedades são apresentadas na Tabela 3.3.1.1 e foram fornecidas pelo fabricante. 
Tabela 3.3.1.1 - Propriedades do PBT

\begin{tabular}{|c|c|c|}
\hline Propriedade & Valor & Unidade \\
\hline Absorção de água, 24 horas & 0,08 & $\%$ \\
\hline Alongamento na ruptura (tração) $50 \mathrm{~mm} / \mathrm{min}$ & 200 & $\%$ \\
\hline Flamabilidade $(94 \mathrm{HB})^{*}$ & HB & - \\
\hline Impacto Izod (sem entalhe) & 1602 & $\mathrm{~J} / \mathrm{m}$ \\
\hline Temperatura de processamento & $230-260$ & ${ }^{\circ} \mathrm{C}$ \\
\hline Temperatura de secagem para injeção & 120 & ${ }^{\circ} \mathrm{C}$ \\
\hline Tempo de secagem para injeção & 12 & $\mathrm{~h}$ \\
\hline Resistência à tração no escoamento, 50 mm/min & 51 & $\mathrm{MPa}$ \\
\hline Módulo de Elasticidade, 1mm/min & 2,4 & GPa \\
\hline Volume específico & 0,76 & $\mathrm{~cm}^{3} / \mathrm{g}$ \\
\hline
\end{tabular}

* O material é classificado ou não classificado como resistente à chama avaliado através da norma $94 \mathrm{HB}$.

Para efeitos de comparação durante os ensaios de flamabilidade, um retardante a chama comercial (Exolit OP1312), fornecido pela Clariant foi utilizado apenas para estes ensaios. Ele é baseado em fosfinatos orgânicos, a base de zinco, como mostrado na Figura 3.3.1.1, onde $R_{1}$ e $R_{2}$ são cadeias orgânicas e M é um metal, como por exemplo, o zinco. Ao longo do texto ele foi denominado com RT.

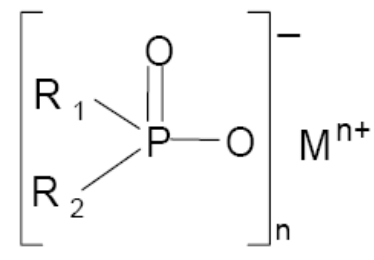

Figura 3.3.1.1 - Estrutura de um fosfinato 


\subsubsection{Métodos}

\subsubsection{Obtenção de PBT/OMMTs e PBT/Sal}

No sentido de avaliar a influência de cada um dos materiais nas propriedades de flamabilidade do PBT, foram obtidas as misturas de PBT/OMMT e PBT/Sal Orgânico, além PBT/RT para efeitos de comparação.

PBT/OMMTs: A argila modificada e o PBT foram secos à vácuo por pelo menos 18 horas antes de sua utilização. A argila modificada foi mantida sob uma temperatura de $70^{\circ} \mathrm{C}$ e o PBT sob uma temperatura de $120^{\circ} \mathrm{C}$. A concentração de argila modificada ou retardante a chama foi 5\% em massa.

PBT/Sal Orgânico: Por se apresentarem na forma de solução, os sais orgânicos de amônio foram secos à vácuo por 48 horas a $90^{\circ} \mathrm{C}$ para eliminação da água. Os sais orgânicos de fosfônio foram secos por pelo menos 18 horas a $90^{\circ} \mathrm{C}$. Para cada sal, a massa adicionada foi proporcional à massa presente na troca iônica.

Os materiais foram misturados utilizando uma extrusora dupla rosca acoplada a um reômetro de torque Haake, relação comprimento/diâmetro L / D $=40$, sob velocidade rotacional de $75 \mathrm{rpm}$ e $150 \mathrm{rpm}$. A temperatura foi $235^{\circ} \mathrm{C}$ desde a zona de alimentação ao orifício de saída do material, o que garante uma temperatura de $250^{\circ} \mathrm{C}$ no material fundido, de acordo com o sistema de controle do reômetro. O material extrusado foi resfriado em água, granulado e seco.

As amostras foram injetadas em três formatos diferentes: (1) tração (ASTM D638), impacto (D 4812) e discos de $2,5 \mathrm{~cm}$ de diâmetro $\times 2 \mathrm{~mm}$ de altura para a realização de análises de XRD. A injetora utilizada foi Demag Ergotech Pro $35-115$. O perfil de temperatura foi $240-245-250-255^{\circ} \mathrm{C}$ e a temperatura do molde foi $70-80^{\circ} \mathrm{C}$. A pressão de injeção foi 30bar. 


\subsubsection{Caracterização e Propriedades dos Materiais}

\subsection{Teor de Argila}

Para avaliação da real quantidade de argila modificada presente na mistura, prévios estudos de teor de argila foram conduzidos em mufla Grion com queima a $1000^{\circ} \mathrm{C}$.

\subsection{Difração de Raios - X (XRD)}

O procedimento foi o mesmo utilizado para as argilas modificadas, mas no caso das PBT/OMMTs, as amostras foram injetadas no formato de discos e secadas.

\subsection{Microscopia}

A dispersão da argila nas amostras de PBT/OMMTs foi primeiramente avaliada por microscopia óptica acoplado, Olympus BX50, em um estágio a quente através dos pequenos discos no formato de filme disponível no Laboratório de Reologia do PMT-EPUSP. As observações por microscopia óptica forneceram uma breve informação da dispersão das argilas na matriz polimérica de uma forma grosseira e foi um ensaio realizado a altas temperaturas, $235^{\circ} \mathrm{C}$.

A qualidade das camadas foi avaliada por um microscópio eletrônico de transmissão (TEM). Para a observação no TEM, foram obtidas amostras com aproximadamente $70 \mathrm{~nm}$ de espessura com a utilização de um ultra-micrótomo (Leica) a baixas temperaturas, disponível no Laboratório de Reologia do PMTEPUSP. Após a obtenção destas amostras, elas foram dispostas em redes de cobre seguidas da observação no TEM, JEOL $2100200 k \mathrm{k}$, disponível no Laboratório Nacional de Luz Síncrotron, LNLS. As observações por TEM nos forneceram o comportamento das camadas da argila dentro da matriz polimérica.

Assim, os materiais devem ser observados de várias magnitudes para serem estudados de forma mais aprofundada e completa. 


\subsection{Análise Termogravimétrica (TGA)}

O comportamento térmico foi avaliado por análise termogravimétrica, TGA 2950 Hi-Res Modulated, TA Instruments, disponível na Braskem. Para as OMMTs, as amostras estavam no formato de grão (extrusado). A taxa de aquecimento foi de $10^{\circ} \mathrm{C} / \mathrm{mim}$, iniciando em aproximadamente $30^{\circ} \mathrm{C}$ terminando em $1000^{\circ} \mathrm{C}$, sob atmosfera de nitrogênio.

\subsection{Propriedades Mecânicas}

As propriedades mecânicas foram avaliadas através de ensaios de tração (Kratos K 2000MP) disponível no PMT-EPUSP e impacto (Tinius Olsen IT 504) disponível na Universidade Mackenzie, ambos em temperatura ambiente. Para os ensaios de tração foram realizadas duas etapas. Na primeira etapa, a amostra foi tracionada até $0,50 \mathrm{~mm}$ para que pudessem ser avaliados os módulos de elasticidade, a uma velocidade de $1 \mathrm{~mm} / \mathrm{min}$. Depois a amostra foi tracionada até a ruptura a uma velocidade de $20 \mathrm{~mm} / \mathrm{min}$. Os ensaios de impacto, Izod, foram realizados sem entalhe, à temperatura ambiente. Para cada ensaio, foram utilizadas 5 amostras de cada material.

\subsection{Flamabilidade}

Os ensaios de flamabilidade foram conduzidos dentro da norma UL 94HB (Underwriters Laboratories Horizontal Burning, Tests for Flammability of Plastic Materials for Parts in Devices and Applications - USA), disponível na Sabic Innovative Plastics. Os corpos de prova possuíam dimensões de $125 \mathrm{~mm}+/$ - 5 $\mathrm{mm}$ de comprimento por $13,0 \mathrm{~mm}+/-0,5 \mathrm{~mm}$ de largura. O procedimento consistiu em avaliar a taxa de queima, $\mathrm{mm} / \mathrm{min}$, de um corpo de prova no qual foram delimitadas duas marcas entre as quais havia um comprimento de $75 \mathrm{~mm}$. Uma chama de aproximadamente $20 \mathrm{~mm}$ de altura, inclinada de $45^{\circ}$, foi aplicada durante 30 s e depois retirada. Para amostras com espessura maior que $3 \mathrm{~mm}$, o material é qualificado como adequado se essa taxa de queima é menor que $40 \mathrm{~mm} / \mathrm{min}$, e para materiais com menos de $3 \mathrm{~mm}$ de espessura a taxa de queima deve ser abaixo de $75 \mathrm{~mm} / \mathrm{min}$. As amostras estudadas neste 
trabalho possuíam dimensões de 3,2mm. A Figura 3.3.2.2.6.1 mostra um esquema deste ensaio de flamabilidade. Para cada ensaio, foram utilizadas 5 amostras de cada material.

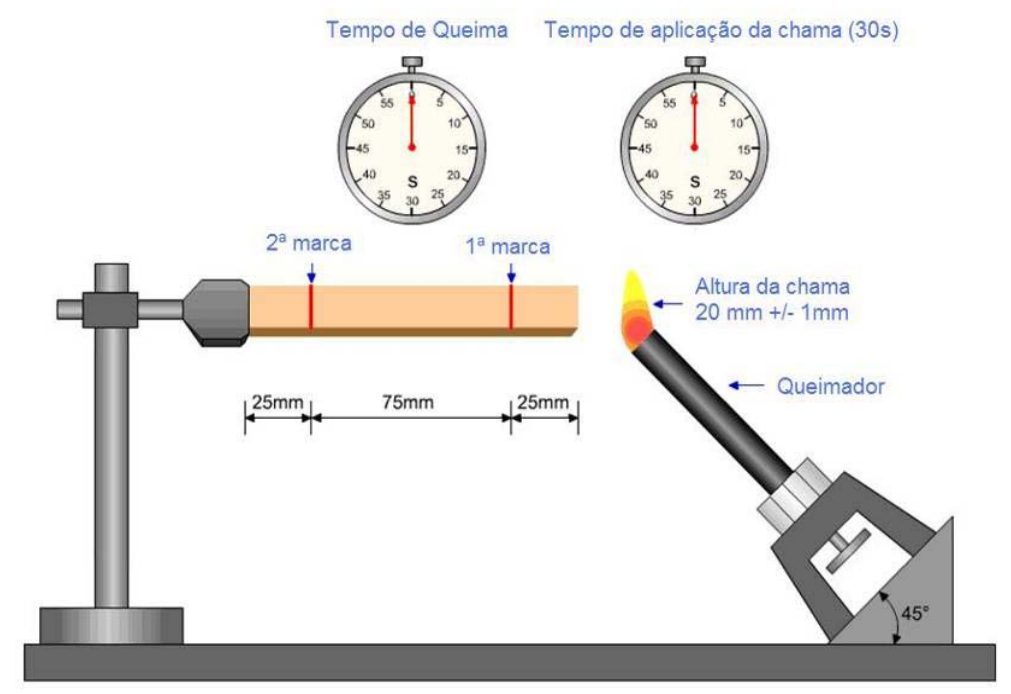

Figura 3.3.2.2.6.1 - Esquema de um ensaio de flamabilidade pela norma UL94 HB ${ }^{1}$

\footnotetext{
${ }^{1}$ http://www.ttc.bayermaterialscience.com/bpo/bpo ttc.nsf/id/Flammability UL 94 HB em 17/06/2009
} 


\subsection{Resultados e Discussões}

A seguir são apresentados os resultados das caracterizações e propriedades dos nanocompósitos estudados neste trabalho. Foram propostas duas condições de processamento. Entretanto, em função das diferenças não significativas, como dito anteriormente, os estudos foram aprofundados apenas com o processamento a 150rpm. Esses dados foram apresentados no Apêndice - A.

\subsubsection{Teor de Argila}

O teor de argila modificada presente no polímero. Estes teores são apresentados na Tabela 3.4.1.1, a partir dos dados apresentados no capítulo 2.

Tabela 3.4.1.1 - Quadro comparativo de teores de argila

\begin{tabular}{ccccc}
\hline \multirow{2}{*}{ Argila } & \multicolumn{2}{c}{ Teores na Troca lônica } & \multicolumn{2}{c}{$\begin{array}{c}\text { Teores no } \\
\text { Processamento }\end{array}$} \\
& $\begin{array}{c}\text { Teórico de } \\
\text { Argila (\%) }\end{array}$ & $\begin{array}{c}\text { Real de } \\
\text { Argila (\%) }\end{array}$ & $\begin{array}{c}\text { Adicionado } \\
\text { de Argila (\%) }\end{array}$ & $\begin{array}{c}\text { Real de } \\
\text { Argila (\%) }\end{array}$ \\
\hline Bra & 100 & 66 & 3,3 & 2,0 \\
Cloisite 20A & 65 & 61 & 3,0 & 3,2 \\
Cloisite 30B & 74 & 68 & 3,4 & 3,5 \\
BraCtac & 82 & 63 & 3,1 & 3,2 \\
BraDod & 80 & 63 & 3,1 & 3,2 \\
BraPraep & 72 & 54 & 2,7 & 3,2 \\
BraBz & 79 & 81 & 4,1 & 3,2 \\
BraTtb & 72 & 51 & 2,5 & 2,0 \\
BraTbb & 81 & 91 & 4,6 & 4,3 \\
BraTdc & 77 & 62 & 3,1 & 3,1 \\
\hline
\end{tabular}

Pode ser observado que o teor real de argila apresenta um valor muito próximo ao valor adicionado. As pequenas diferenças, positivas ou negativas, são funções da não homogeneidade da amostra, que pode variar ao longo do processamento. 


\subsubsection{Difração de Raios - X (XRD)}

A Figura 3.4.2.1 mostra o difratograma para o PBT/BraPraep. Demais difratogramas estão no Apêndice - C. A Tabela 3.4.2.1 mostra os resultados de espaçamento basal e a diferença do espaçamento basal após a adição ao PBT.

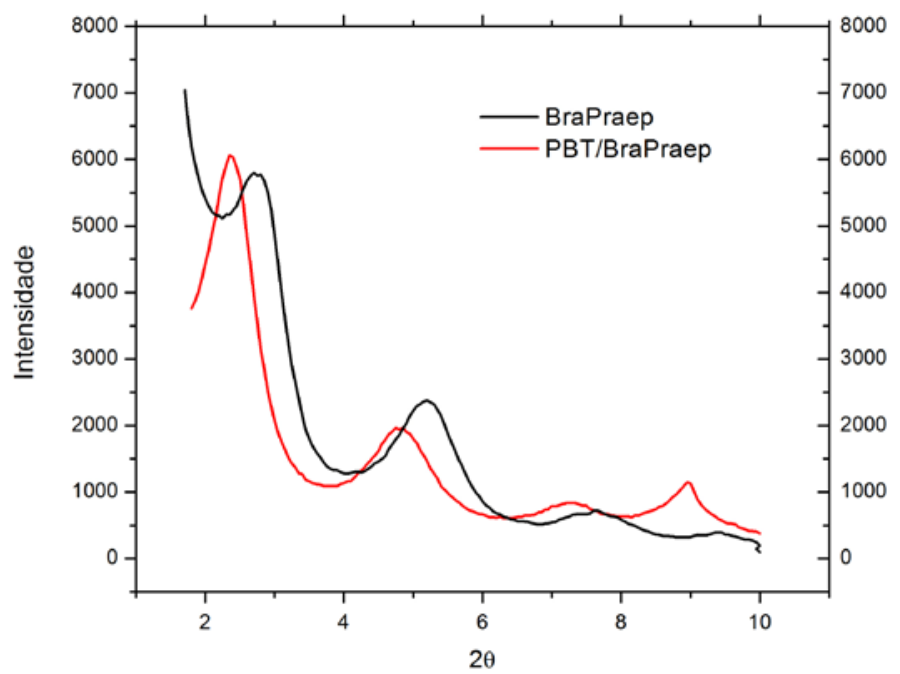

Figura 3.4.2.1 - Difratogramas para PBT/Praep

Tabela 3.4.2.1 - Quadro comparativo de espaçamento basal após a adição ao PBT

\begin{tabular}{lccccc}
\hline & $\mathbf{2} \boldsymbol{\theta}$ & $\mathbf{d}^{\mathrm{a}}(\mathbf{n m})$ & $\mathbf{2} \boldsymbol{\theta}$ & $\mathbf{d}^{\mathrm{b}}(\mathbf{n m})$ & $\boldsymbol{\Delta d}$ \\
\hline Bra & 9,10 & 0,97 & 8,90 & 0,99 & 0,02 \\
Cloisite 20A & 3,75 & 2,35 & 2,65 & 3,33 & 0,98 \\
Cloisite 30B & 5,00 & 1,77 & 2,55 & 3,46 & 1,69 \\
BraCtac & 2,45 & 3,60 & 2,40 & 3,68 & 0,08 \\
BraDod & 3,30 & 2,68 & 2,60 & 3,40 & 0,72 \\
BraPraep & 2,55 & 3,46 & 2,35 & 3,76 & 0,30 \\
BraBz & 4,85 & 1,82 & 4,85 & 1,82 & 0,00 \\
BraTtb & 3,60 & 2,45 & 3,30 & 2,68 & 0,23 \\
BraTbb & 6,20 & 1,42 & 5,80 & 1,52 & 0,10 \\
BraTdc & 3,50 & 2,52 & 3,20 & 2,76 & 0,24 \\
\hline
\end{tabular}

$\mathrm{d}^{\mathrm{a}}=$ espaçamento basal obtido na troca iônica; $\mathrm{d}^{\mathrm{b}}=$ espaçamento basal obtido após adição ao PBT 
Pode ser observado que o espaçamento basal não sofreu grandes alterações após a adição ao polímero, também observado por Li et al. (2001). Isso mostra que a modificação química da estrutura da argila é muito mais eficiente no aumento do espaçamento basal de que a penetração das cadeias poliméricas entre as camadas da argila, ou seja, o polímero apenas ocupa esse espaço aumentado na troca iônica.

\subsubsection{Microscopia eletrônica de transmissão (TEM)}

A Figura 3.4.3.1 mostra uma micrografia para o caso de PBT/BraPraep. Micrografias de outras amostras podem ser vistas em Apêndice - C.
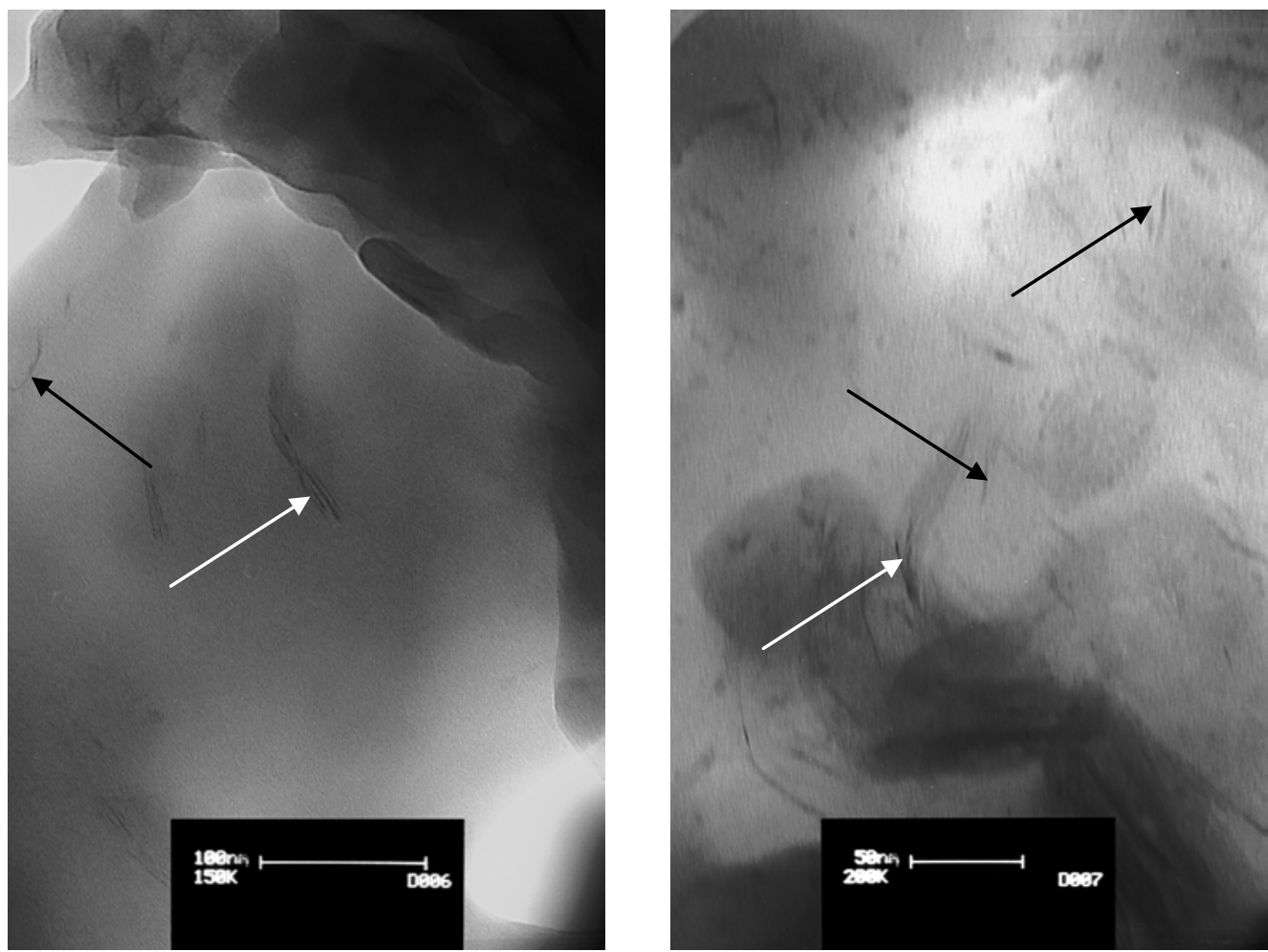

Figura 3.4.3.1 - Microscopia eletrônica de transmissão para PBT/BraPraep

As imagens sugerem que as lamelas da argila estão intercaladas (setas brancas) e esfoliadas (setas pretas), o que corroboram os dados de XRD.

A diferença mais expressiva após a adição ao PBT foi com a Cloisite 30B, 
ou seja, o espaçamento obtido após a adição ao PBT foi muito grande, de 1,77 para 3,46. Esse comportamento tem sido explorado por outros autores (Li et al., 2001; Chang et al., 2005). Devido à existência dos grupos hidroxila, o cátion (alquil de sebo) dihidroxietil metil amônio presente na argila 30B tem forte interação com os grupos carboxila presentes no PBT, favorecendo a intercalação das cadeias poliméricas dentro das camadas da argila. Por outro lado, esses grupos hidroxila polares também podem manter forte interação com a superfície da argila. Isso pode trazer como conseqüência a formação de uma intensa intercalação e potencial esfoliação. No caso do BraDod, o espaçamento também aumentou de 2,68 para 3,40, após a adição de PBT, que pode ter sido favorecido pela presença do anel benzênico o qual possui afinidade com PBT, uma vez que os dados de TGA apresentados para BraDod sugerem a presença de sal dentro das lamelas de argila, assim como com a BraTtb, embora esta última não tenha apresentado um aumento basal expressivo após a adição de PBT, 2,45 para 2,68. Mas, como dito anteriormente, a arquitetura do sal quaternário Ttb pode ser originado um impedimento estérico e dificultou a penetração das cadeias de PBT. Para a 20A, o espaçamento basal aumentou de 2,35 para 3,33. A ausência de sal em excesso na 20A favoreceu o efeito contrário que foi a penetração do PBT, aumentando o espaçamento basal. Este comportamento não foi observado para BraPraep, a qual apresenta o mesmo sal quaternário, mas o espaçamento aumentou de 3,46 para 3,76. Mas como discutido no Capítulo 2, BraPraep tem sal em excesso e a fração mais importante de sal Praep não esta intercalada, mas localizada nas bordas dos tactóides. Isto pode ter impedido a entrada das cadeias de PBT dentro das lamelas da argila, também observado para BraCtac e BraTdc, os quais aumentaram de 3,60 para 3,68 e 2,52 para 2,76, respectivamente. 


\subsubsection{Microscopia Ótica (OM)}

A Figura 3.4.4.1 mostra uma micrografia para PBT/20A, que representa a morfologia obtida para as argilas comerciais e a Figura 3.4.4.2 mostra uma micrografia para PBT/BraPraep, que representa a morfologia obtida para as argilas brasileiras organofílicas, com teores de argila de $5 \%$ em peso. Demais micrografias estão no Apêndice - C.

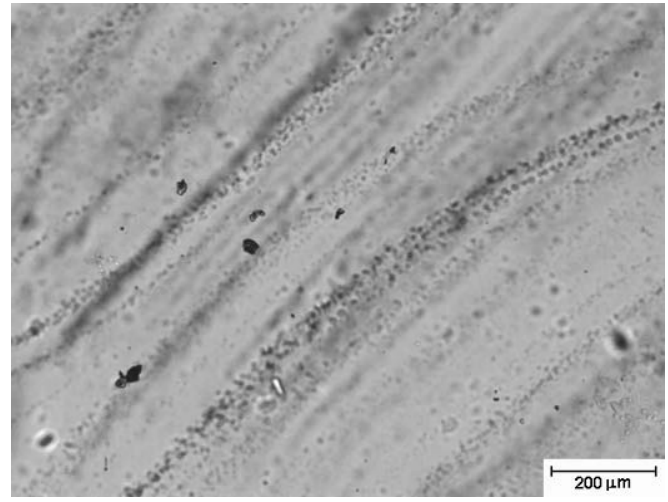

Figura 3.4.4.1 - PBT / 20A

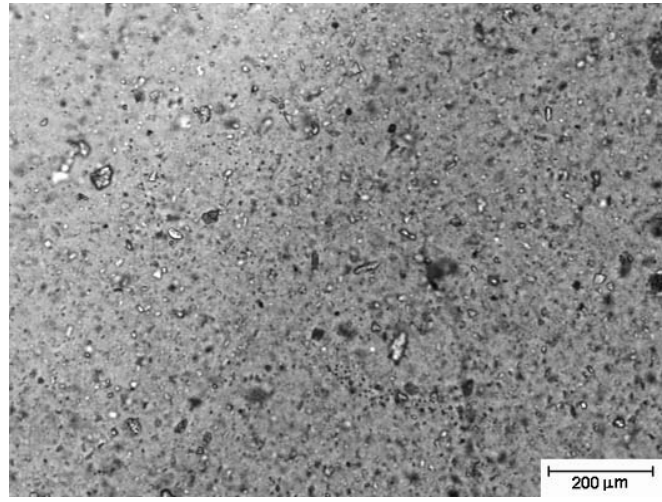

Figura 3.4.4.2 - PBT / BraPraep

Pode ser observado que existem aglomerados de argila, principalmente com a argila Bra, o que caracteriza a obtenção de compósitos. De acordo com Cárdenas et al. (2008), o tamanho de partícula tem influência nas propriedades mecânicas, uma vez que o tamanho de partícula é uma das variáveis que determinam a dispersão da argila e sua interação com a matriz polimérica. Estes resultados são descritos a seguir.

\subsubsection{Propriedades Mecânicas}

A Figura 3.4.5.1 mostra as curvas de tensão versus deformação para PBT, PBT/Bra, PBT/20A e PBT/30B. 


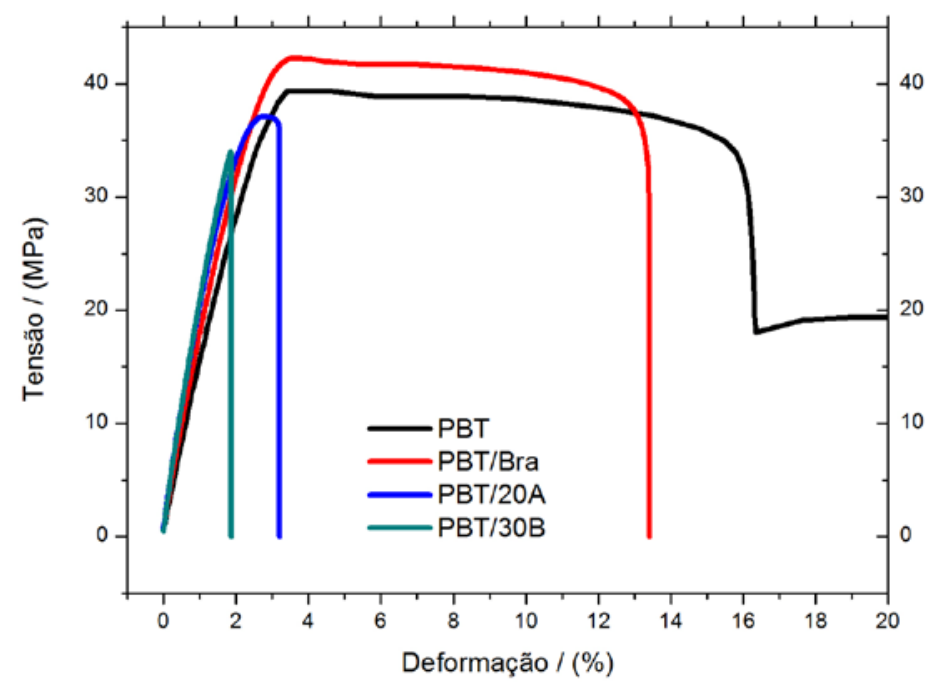

Figura 3.4.5.1 - Tensão x Deformação para o PBT, $\mathrm{PBT} / \mathrm{Bra}$, PBT/20A e PBT/30B

A Figura 3.4.5.2 mostra as curvas de tensão versus deformação para PBT, PBT/BraCtac, PBT/BraDod e PBT/BraPraep.

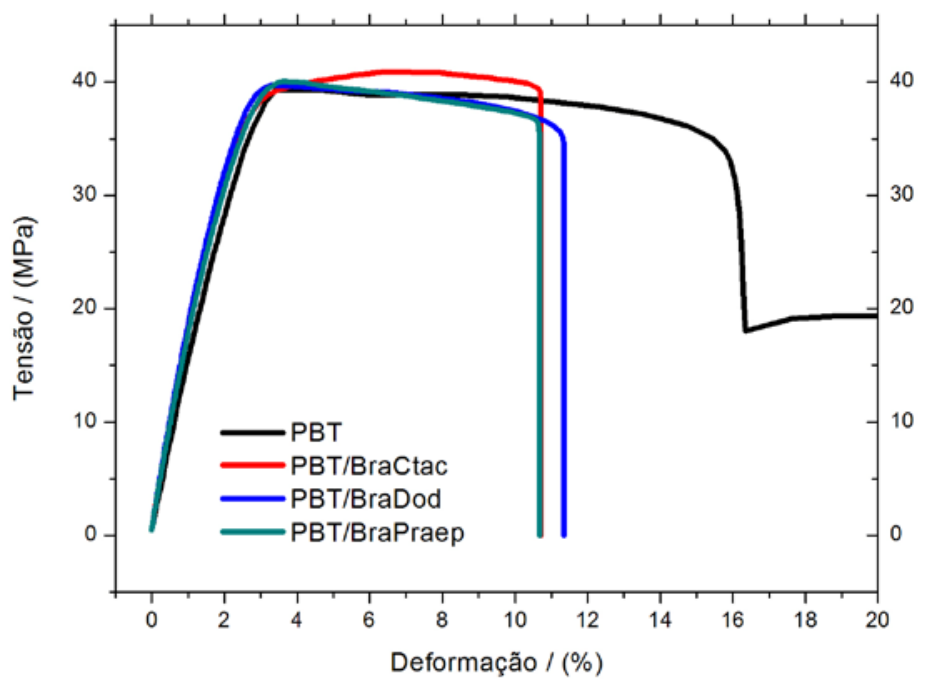

Figura 3.4.5.2 - Tensão x Deformação para PBT, PBT/BraCtac, PBT/BraDod e PBT/BraPraep

A Figura 3.4.5.3 mostra as curvas de tensão versus deformação para PBT, PBT/BraPraep, PBT/BraBz, PBT/BraTtb, PBT/BraTbb, PBT/BraTdc e PBT/RT. 


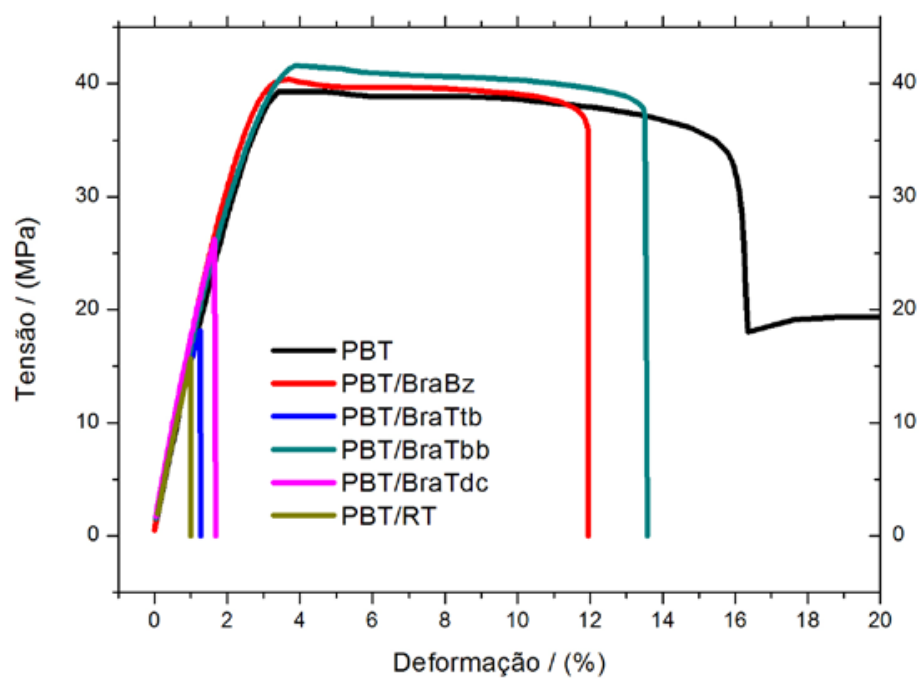

Figura 3.4.5.3 - Tensão x Deformação para PBT, PBT/BraBz, PBT/BraTtb, PBT/BraTbb, PBT/BraTdc e PBT/RT

A Figura 3.4.5.4 mostra os resultados para a resistência ao impacto para PBT/OMMTs.

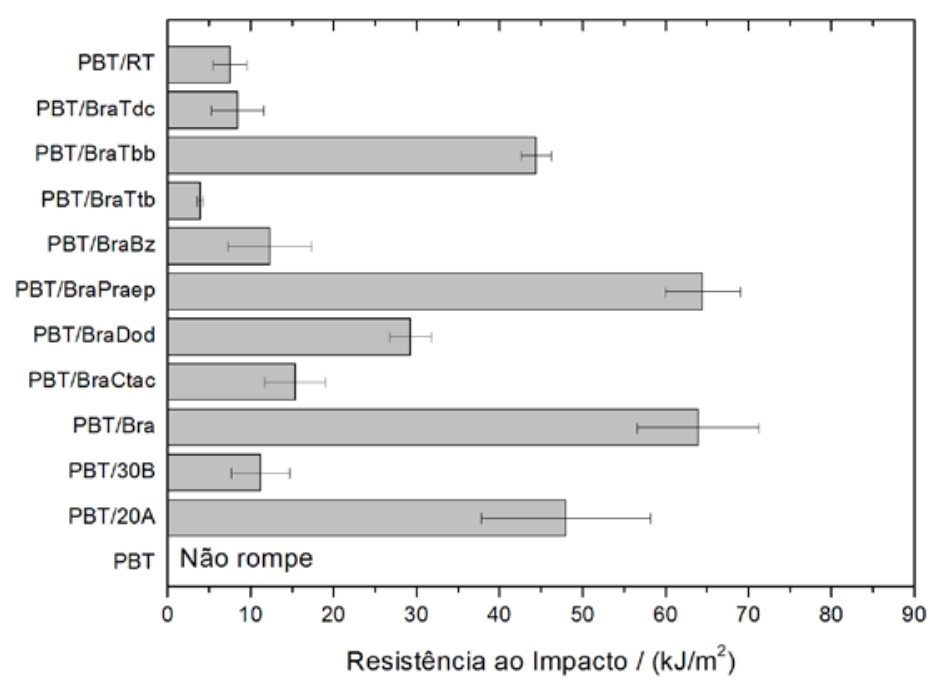

Figura 3.4.5.4 - Resistência ao impacto para PBT/OMMTs (amostras não entalhadas)

A Tabela 3.4.5.1 mostra uma comparação dos valores de módulo de elasticidade, resistência máxima a tração e alongamento na ruptura comparados com dados da literatura. Entretanto, em função do grande desvio 
padrão para medidas de resistência ao impacto, além da grande diversidade dos tipos de ensaios de resistência ao impacto, estes dados não foram comparados com dados reportados em literatura. 
Tabela 3.4.5.1 - Módulo de Elasticidade, Resistência Tração e Alongamento na Ruptura para PBT, PBT/OMMTs e PBT/RT

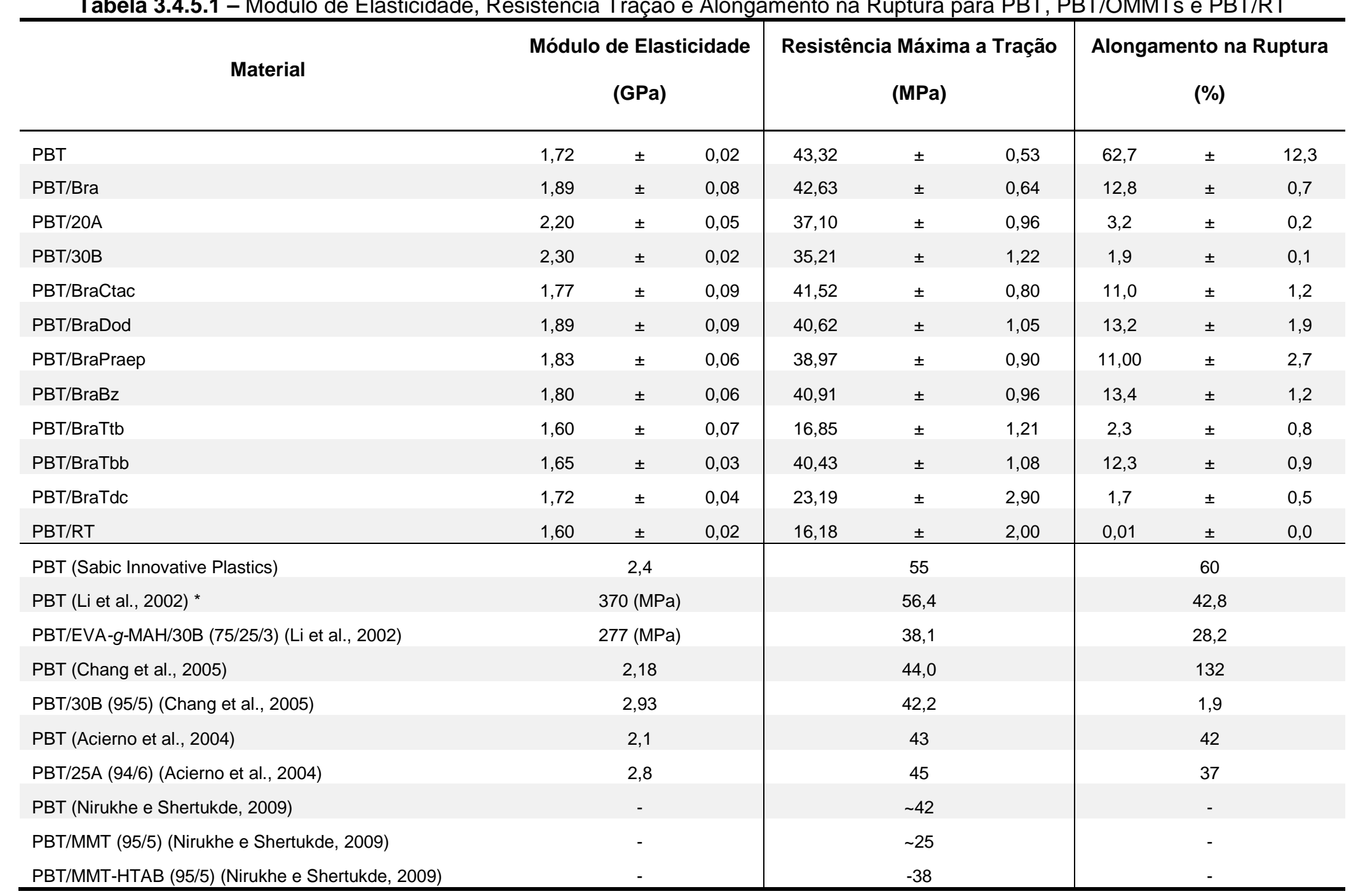

*Foi utilizado um misturador interno para a obtenção das misturas. Os demais utilizaram extrusora dupla rosca. 
Pode ser observado que o alongamento diminuiu drasticamente nos PBT/OMMTs e PBT/RT com relação ao PBT. Esse comportamento é devido ao fato de que a adição das argilas, modificadas ou não, ou o retardante a chama, resulta na presença de uma fase descontínua na matriz polimérica. Dessa forma, o alongamento sofre uma redução. Esta redução é mais acentuada com a presença das argilas comerciais, Cloisites. Como visto através das micrografias no item 3.4.4, essas argilas possuem uma granulometria mais fina do que aquelas modificadas em laboratório (observadas pela microscopia óptica), o que poderia explicar a maior redução no alongamento, uma vez que a área interfacial da argila é maior nesses compósitos. Resultados semelhantes foram obtidos por Cárdenas et al. (2008).

Chisholm et al. (2002) e Li et al. (2002, 2004) também associaram esse efeito ao tamanho da partícula, uma vez uma área superficial maior favorece a um número maior de interações entre polímero e argila, resultando na necessidade de maiores tensões para causar uma deformação elástica destes materiais. Entretanto, PBT/BraTdc também apresentou um alongamento muito pequeno embora esse material não tenha apresentado uma granulometria tão fina quanto as argilas comerciais. Chang et al. (2005) também observaram uma nítida redução no alongamento na ruptura após a adição da argila, devido ao efeito de enrijecimento das camadas da argila.

Também pode ser observado que os nanocompósitos que mostraram menor espaçamento basal (adição de BraBz e BraTbb, ou seja, onde o espaçamento basal foi mais próximo do valor para a argila não modificada Bra), apresentaram maiores valores do alongamento na ruptura do que os demais PBT/OMMTs.

Ao contrário do alongamento, os PBT/OMMTs com as Cloisites apresentaram maiores valores para o módulo de elasticidade do que as demais argilas. No caso de PBT/OMMTs com argila Bra, os valores de módulo de elasticidade são similares. A resistência máxima à tração diminuiu após a adição de argila. Nirukhe; Shertukde (2009) também observaram essa diminuição e associaram esse efeito com a degradação da argila modificada durante o processamento. A argila dispersa na matriz polimérica a torna uma fase descontínua, dificultando o desdobramento / estiramento das cadeias 
poliméricas. Entretanto, como dito anteriormente, por sua granulometria menor, esse estiramento é menos afetado no caso das argilas comerciais. Acierno et al. (2004) também observaram uma redução do alongamento na ruptura para os materiais que apresentaram maiores módulos. Segundo os autores, esse efeito era esperado, porém indesejado. Cho e Paul (2001), ao estudarem nanocompósitos de poliamida, observaram que o alongamento na ruptura é influenciado pela velocidade da tração e é uma propriedade sensível a falhas. Os autores também concluíram que a ductibilidade de nanocompósitos é fortemente dependente do tipo argila modificada.

No caso de resistência ao impacto, pode ser observado que os resultados obtidos foram variados, entretanto a presença das argilas e do retardante a chama tornou os materiais mais susceptíveis à fratura por representarem pontos de acúmulo de tensão, ou seja, tornando-se um agravante na propagação das fraturas, também observado por Li et al. (2002, 2004). Como dito anteriormente, os nanocompósitos poliméricos mostram um aumento no módulo de elasticidade seguido de uma perda na resistência ao impacto, em relação ao PBT puro. 


\subsubsection{Análise Termogravimétrica (TGA)}

A Figura 3.4.6.1 apresenta a perda de massa em função da temperatura e o gráfico em detalhe mostra estes picos de temperatura. A Tabela 3.4.6.1 apresenta os valores de temperatura, para perdas em massa de 5 e 50\%, os picos de temperatura e a massa residual em $850^{\circ} \mathrm{C}$.

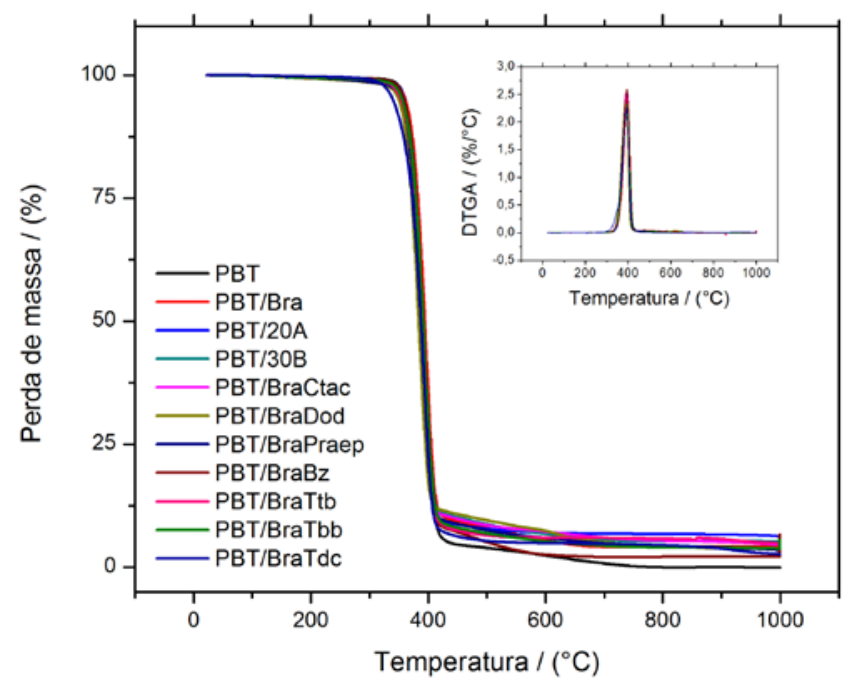

Figura 3.4.6.1 - Perda de massa em função da temperatura para PBT e PBT/OMMTs

Tabela 3.4.6.1 - Análise térmica para PBT e PBT/OMMTs

\begin{tabular}{lllll}
\hline \multirow{2}{*}{ Material } & \multicolumn{2}{c}{ Perda de massa } & Pico & Resíduo a 850 \\
& $\mathbf{5 \%}$ & $\mathbf{5 0 \%}$ & & \\
\cline { 2 - 5 } & & ${ }^{\circ} \mathbf{C}$ & & $\mathbf{( \% )}$ \\
\hline PBT & 361 & 393 & 396 & 0,0 \\
PBT/Bra & 361 & 394 & 397 & 4,2 \\
PBT/20A & 360 & 391 & 393 & 6,7 \\
PBT/30B & 359 & 391 & 393 & 5,4 \\
PBT/BraCtac & 356 & 389 & 389 & 5,3 \\
PBT/BraDod & 350 & 383 & 385 & 4,0 \\
PBT/BraPraep & 355 & 388 & 391 & 4,1 \\
PBT/BraBz & 359 & 390 & 393 & 2,2 \\
PBT/BraTtb & 354 & 391 & 395 & 5,6 \\
PBT/BraTbb & 356 & 391 & 395 & 4,0 \\
PBT/BraTdc & 340 & 388 & 392 & 4,2 \\
\hline
\end{tabular}


Pode ser observado que o PBT apresenta valores maiores de temperatura de decomposição de que os compósitos, sendo menor apenas que PBT/Bra. Acierno et al. (2004) também observaram uma diminuição destes picos de temperaturas na presença de argila organofílica. Os autores associaram esse comportamento à presença de susbtâncias voláteis dos sais quaternários. Aumentando a quantidade de aditivos voláteis, a temperatura máxima de decomposição do nanocompósito diminui (Xiao et al., 2005b). Acierno et al. $(2006,2007)$ também concluíram que a presença de sais do tipo alquil também favorece a maior perda de massa. Neste trabalho os resultados obtidos mostram que para ambos tipos de sal de amônio e fosfônio a temperatura de decomposição é menor para os compósitos do que para o polímero puro.

Entretanto, Wu et al. (2005a) e Li et al. (2004) defendem a existência do efeito de barreira das camadas de argila na superfície do material, ou seja, as camadas da argila limitam a mobilidade das pequenas moléculas produzidas durante a decomposição térmica. Dessa forma, as temperaturas de degradação para os materiais com argila são maiores do que a matriz polimérica pura, resultado que não foi observado aqui.

Em comparação com os valores teóricos de argila e com o teor residual de argila obtido por queima em mufla, pode ser observada uma diferença não desprezível. Entretanto, para os ensaios em mufla foram adicionadas maiores massas e não houve o controle da taxa de aquecimento.

\subsubsection{Flamabilidade}

Durante os ensaios de flamabilidade foram observados 6 aspectos de queima, como mostrados pelas Figuras 3.4.7.1 a 3.4.7.6. 


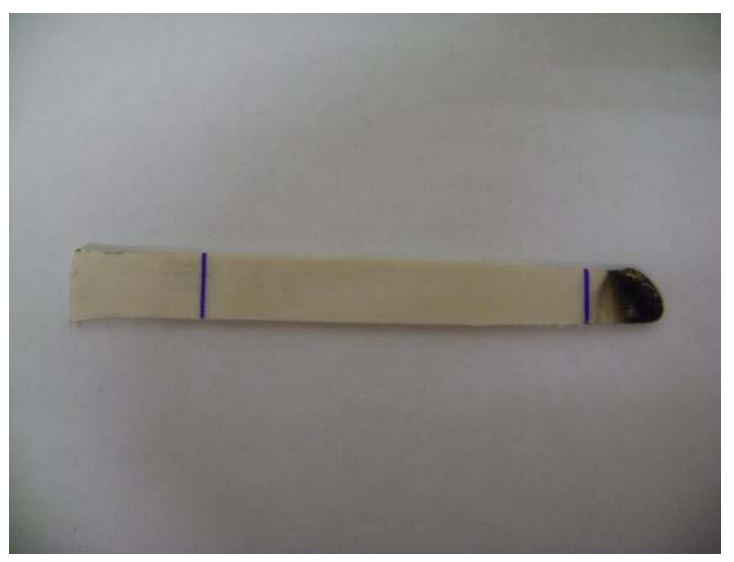

Figura 3.4.7.1 - Aspecto da queima 1

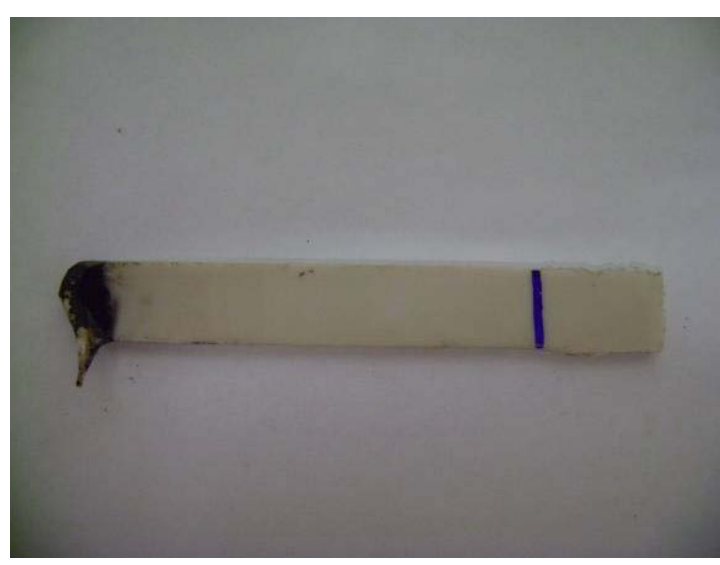

Figura 3.4.7.3 - Aspecto da queima 3

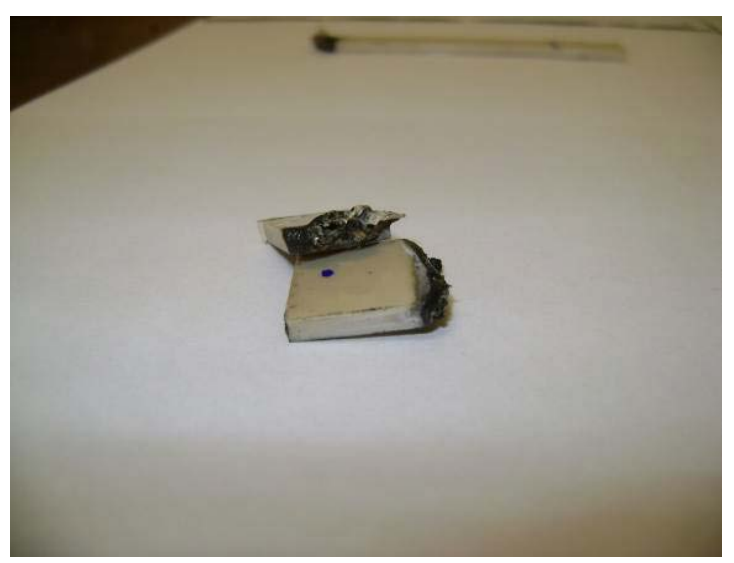

Figura 3.4.7.5 - Aspecto da queima 5

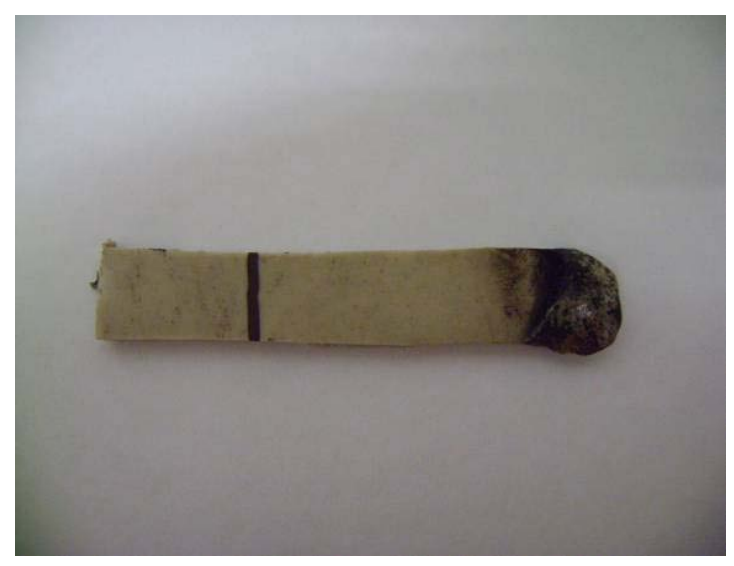

Figura 3.4.7.2 - Aspecto da queima 2

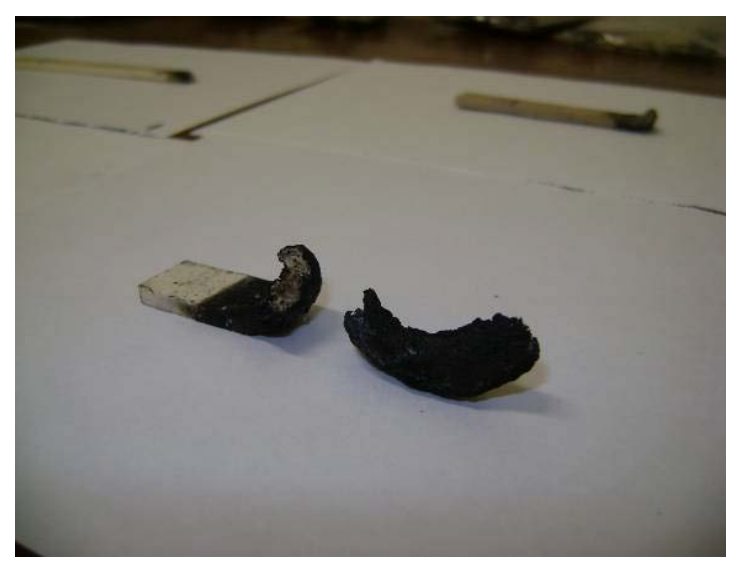

Figura 3.4.7.4 - Aspecto da queima 4

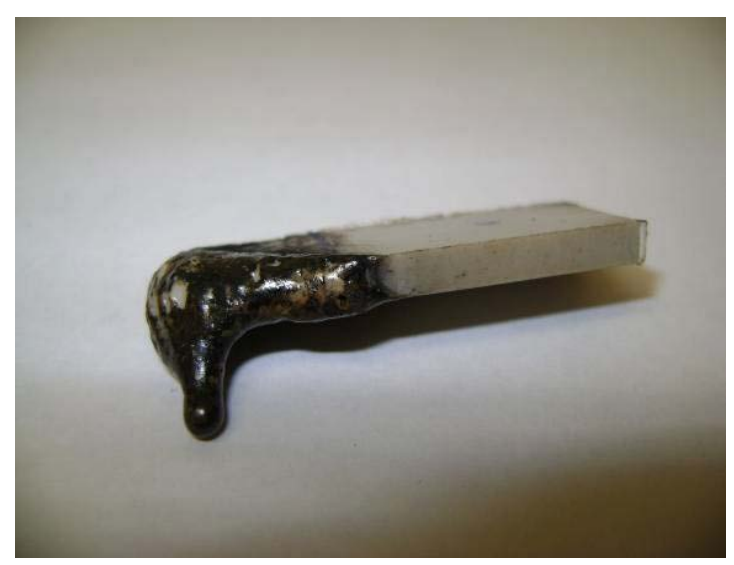

Figura 3.4.7.6 - Aspecto da queima 6 
As observações para cada aspecto de queima são apresentados na Tabela 3.4.7.1.

Tabela 3.4.7.1 - Classificação de flamabilidade observada para PBT/OMMT e PBT/RT

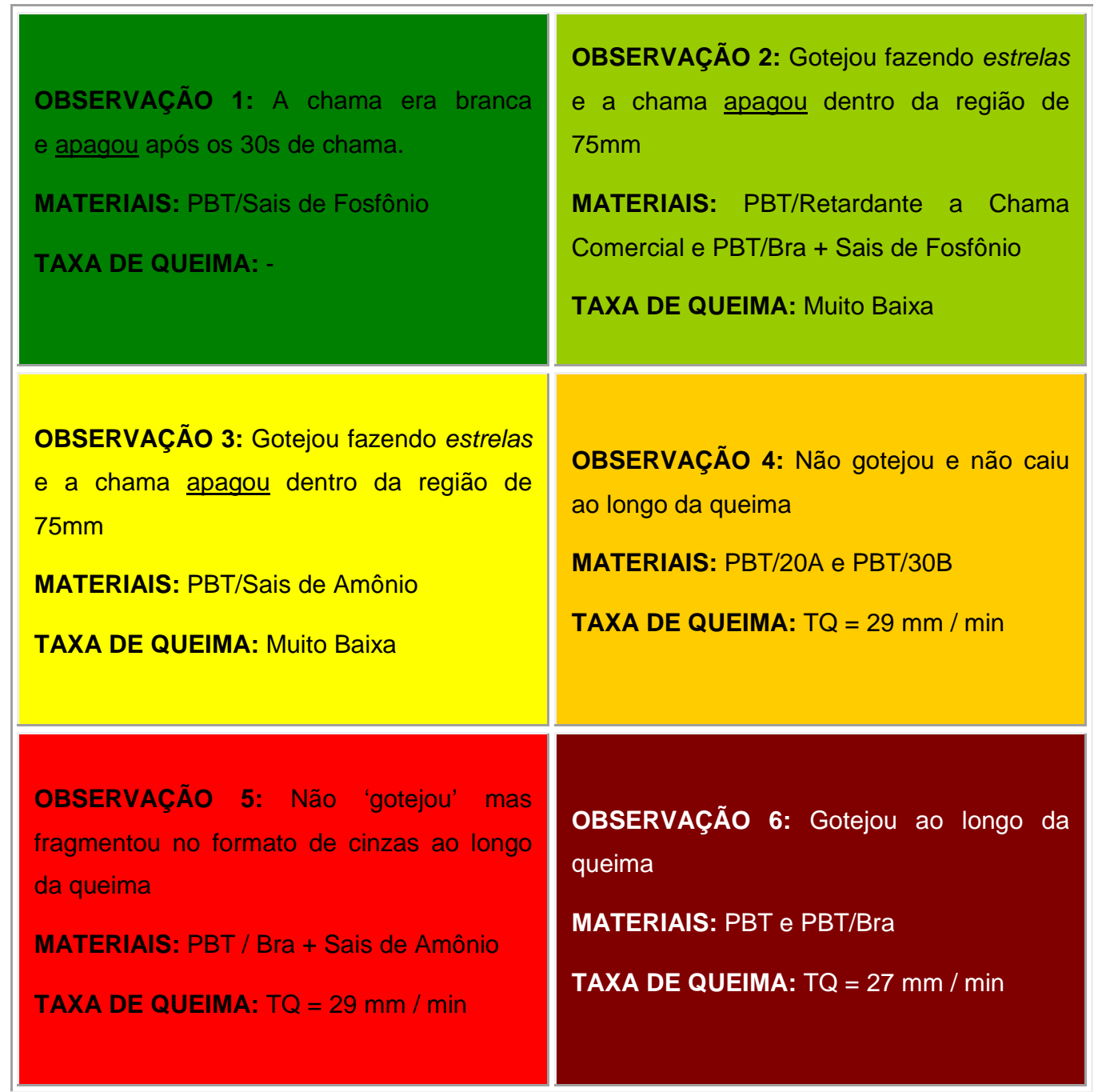

O grupo verde escuro é composto apenas de PBT com sais de fosfônio (sem argila). No inicio do ensaio, após a aproximação da chama, mantida por 30s, a chama se extinguia e não propagava pela amostra. A chama apresentou uma cor clara, brilhante.

O grupo verde claro é composto pelo PBT com Retardante a Chama e pelos PBT com Bra/Sais de Fosfônio. Após a aproximação da chama por 30s, as amostras queimaram e a chama se extinguiu antes de atingir a marca de 75 $\mathrm{mm}$ e apresentaram um aspecto viscoso. A chama tinha uma coloração 
alaranjada.

O grupo amarelo é composto apenas de PBT com sais de amônio (sem argila). Após a aproximação da chama por 30s, as amostras queimaram e gotejaram com um aspecto muito fluido; a chama se extinguiu antes de atingir a marca de $75 \mathrm{~mm}$. A chama tinha uma coloração alaranjada.

O grupo laranja é composto apenas de PBT com argilas comerciais. A chama percorreu toda a marca dos $75 \mathrm{~mm}$. As amostras não gotejaram e apresentaram um aspecto "carbonizado" sólido. A chama tinha uma coloração alaranjada.

O grupo vermelho é composto de PBT com Bra/Sais de amônio. A queima percorreu toda a marca dos $75 \mathrm{~mm}$. As amostras se fragmentavam no formato de cinzas e apresentaram um aspecto mais viscoso que o grupo verde claro. A chama tinha uma coloração alaranjada.

O grupo cor-de-vinho é composto de PBT e PBT/Bra. A chama percorreu toda a marca dos $75 \mathrm{~mm}$. As amostras gotejaram ao longo da queima e apresentaram um aspecto menos fluido que o grupo amarelo. A chama tinha uma coloração alaranjada.

De acordo com essas observações e com a norma, a Figura 3.4.7.7 mostra o esquema da evolução da resistência à chama. 


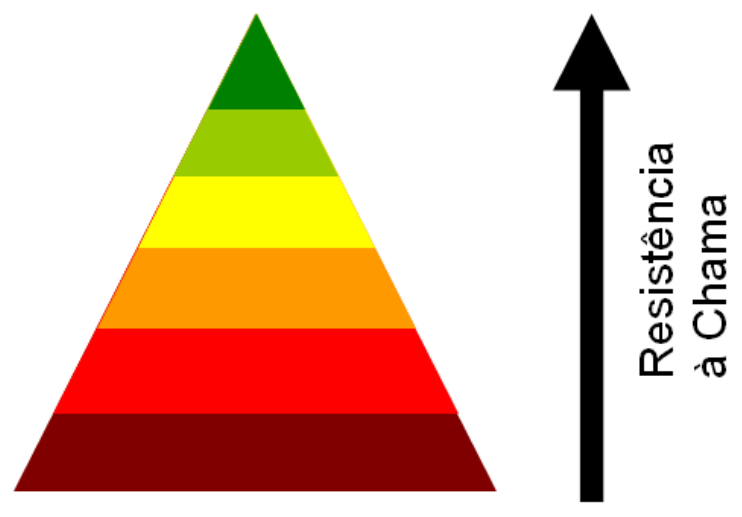

Figura 3.4.7.7 - Esquema da evolução da resistência à chama

Juntamente com as reações apresentadas no item 2.2.3 foi comprovado que os materiais a base de sais quaternários apresentam melhores propriedades perante o fogo. Entretanto, esses materiais não apresentam nenhum aspecto favorável quanto às suas propriedades mecânicas. O PBT, embora seja classificado como material HB (resistente à chama) teve sua retardância a chama aprimorada após a adição de argila organofílica, principalmente a base de sais de fosfônio. A principal diferença em relação ao $\mathrm{PBT}$ e $\mathrm{PBT} / \mathrm{Bra}$ foi o fato de que estes materiais gotejaram de forma muito fluida. Após a adição de argila esse gotejamento diminuiu e se tornou muito mais viscoso. E no caso de PBT com Bra/Sais de amônio ou fosfônio, a chama se extinguiu, porém o material foi mais fluido quando da presença de sais de amônio.

No sentido de aprofundar a compreensão destes resultados, alguns materiais, a saber, PBT/20A, PBT/BraPraep e PBT/BraTdc, foram selecionados para a adição de um agente tenacificante de modo a recuperar a tenacidade do material, mantendo a boas propriedades de flamabilidade obtidas com a adição de argila brasileira modificada. O método de seleção baseou-se em 3 aspectos: 1. Uma argila brasileira modificada com sal de amônio, uma argila brasileira modificada com sal de fosfônio e uma argila comercial. Os PBT/20A e PBT/BraPraep apresentam o mesmo sal, além de bons valores de módulo de elasticidade e resistência ao impacto, quando comparados ao PBT puro. $O$ 
Freitas, C. A.

PBT/BraTdc, embora não tenha apresentado expressivo valor de resistência ao impacto, não perdeu em módulo de elasticidade, quando comparada ao PBT puro. Estes estudos são mostrados no Capítulo 4. 


\section{Propriedades de Engenharia de PBT/OMMTs com agente tenacificante}

\subsection{Introdução}

\subsubsection{Generalidades}

Os poliésteres, de uma forma geral são materiais rígidos, têm boas resistência térmica e estabilidade dimensional, mas são passíveis de hidrólise e são muito sensíveis a entalhes e fissuras. No sentido de melhorar estas propriedades, a adição de nanopartículas, tais como a argila organofílica, se mostra como uma alternativa na obtenção de matrizes poliméricas com melhores propriedades. Entretanto, essa aplicação dos nanocompósitos poliméricos como novos materiais ainda é parcialmente dificultada em função da qualidade da dispersão destas partículas na matriz polimérica. Foi apresentado no Capítulo 3 que a adição de nanopartículas não resultou na obtenção de propriedades mecânicas aprimoradas, principalmente na resistência ao impacto, onde foi visto uma diminuição severa em seus valores em relação ao matriz polimérica pura PBT. Entretanto, a matriz polimérica PBT teve a sua propriedade de retardância à chama melhorada após a adição das nanopartículas. No sentido de resgatar as propriedades mecânicas, optou-se por tenacificar o PBT na presença de argila organofílica.

Inúmeros copolímeros são adicionados como agentes modificadores de impacto atuando como tenacificantes. No caso de PBT e PET, agentes tenacificantes contendo grupo funcional epóxi são muito eficazes. O grupo funcional epóxi apresenta boa reatividade com a carboxila e a hidroxila presentes na estrutura do PBT, o que permite uma compatibilização reativa e boa adesão entre as fases. Deste modo, eles atuam na obtenção de materiais com boa adesão interfacial, morfologia mais fina e, conseqüentemente, melhores propriedades mecânicas.

Neste trabalho, o terpolímero etileno/acrilato de metila/metacrilato de glicidila $\mathrm{P}$ (E-co-MA-co-GMA), foi adicionado como agente tenacificante para o PBT na presença de argila organofílica. 


\subsubsection{Organização do Capítulo 4}

Neste capítulo, após uma revisão bibliográfica sobre misturas poliméricas, tenacificação de polímeros e nanocompósitos contendo P(E-co-MA-co-GMA), a descrição dos materiais, condições de processamento, métodos utilizados para a caracterização e avaliação das propriedades são apresentados. Por fim os resultados obtidos são apresentados com as discussões.

\subsection{Revisão Bibliográfica}

\subsubsection{Misturas Poliméricas}

A pesquisa em misturas poliméricas representa o caminho mais eficaz para a obtenção de novos materiais sem a síntese total de novos materiais. Este interesse surge a partir do potencial em atingir, em uma mistura, propriedades que não são alcançáveis com um simples homopolímero ou copolímero. As propriedades finais da mistura polimérica são fortemente influenciadas pela escala de tamanho de uma microestrutura, fazendo da relação entre processo e desenvolvimento da sua microestrutura um tópico de intensa pesquisa. Como a maioria dos polímeros formadores de uma mistura polimérica é imiscível e esses formam sistemas multifásicos heterogêneos, freqüentemente resultam em propriedades de materiais que são fortemente dependentes das condições de processamento, morfologia e interações entre as fases. Contudo, tais sistemas tipicamente têm uma morfologia matriz-fase dispersa com fases dispersas relativamente grandes e fraca adesão interfacial, a qual, em muitos casos, resulta em pobres propriedades mecânicas para as misturas poliméricas resultantes. Uma alternativa comum para aliviar este problema envolve a adição (ou a formação in situ) de um agente ativo interfacialmente, ou então chamado compatibilizante, para a mistura polimérica Neste trabalho, foi utilizado um agente tenacificante que tem afinidade química com o PBT, de forma que na interface entre estas duas fases há a formação de um copolímero que atua como agente compatibilizante. Uma descrição de polímeros tenacificados é apresentada a seguir. 


\subsubsection{Tenacificação de Polímeros}

A adição de agente tenacificante tem como objetivo atuar como um concentrador de tensão. Dessa forma, o material pode absorver energia de impacto, impedindo ou atrasando falhas graves. De acordo com Valera (2005) e Bezzan (2006), existem dois mecanismos de tenacificação:

Microfibrilações da matriz: Em um material, sob tensão ou impacto, é originada a propagação de microfissuras na matriz polimérica, como ilustrado na Figura 4.2.1.1.1.

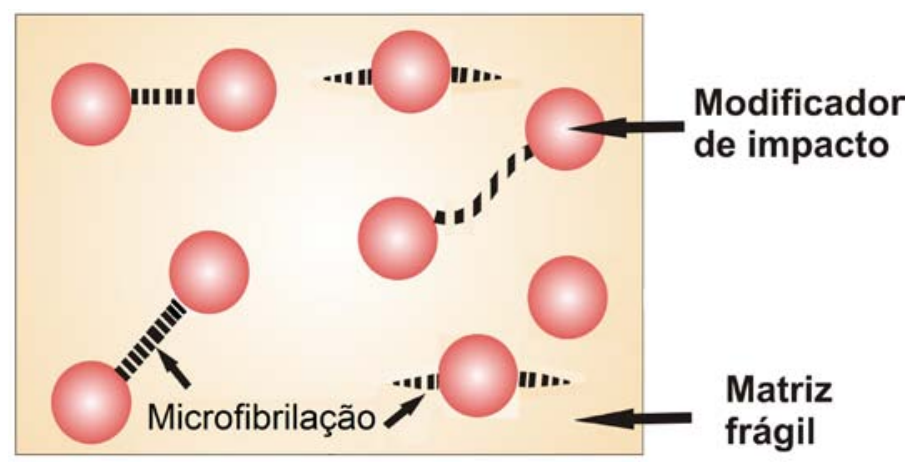

Figura 4.2.1.1.1 - Tenacificação por microfibrilações ${ }^{2}$

As partículas do agente tenacificante controlam essa propagação crescimento, o qual se propaga perpendicularmente à direção da aplicação da tensão e próximo ao equador destas partículas, até encontrar outra partícula do agente tenacificante, onde termina esta propagação. O resultado final é a formação de grande quantidade de pequenas fibrilas, em comparação com o pequeno número de grandes fibrilas no material sem agente tenacificante. Uma vez que parte do volume das fissuras é vazio, ocorre o fenômeno de embranquecimento do material. Essa região formada por esse volume vazio é responsável pela dissipação de energia e responsável pelo aumento de volume no material.

$\checkmark$ Escoamento sob cisalhamento da matriz: Este mecanismo corresponde a fenômenos de deformações plásticas da matriz em nível molecular. Estes pontos são denominados "bandas de cisalhamento". Geralmente, estão

\footnotetext{
${ }^{2}$ http://www.specialchem4polymers.com/tc/polymeric-impact-modifiers/index.aspx?id=work em 14/05/2010
} 
defasadas $45^{\circ}$ em relação à direção da tensão aplicada, sendo exatamente a tensão de cisalhamento máxima. A deformação plástica é irreversível, e estas bandas de cisalhamento atuam como barreiras à propagação de trincas. Além disso, as partículas do agente tenacificante apresentam o fenômeno de cavitação. Quando a matriz está sob tensão geralmente também são formadas cavidades vazias ao redor das partículas do agente tenacificante, como ilustrado na Figura 4.2.1.1.2.

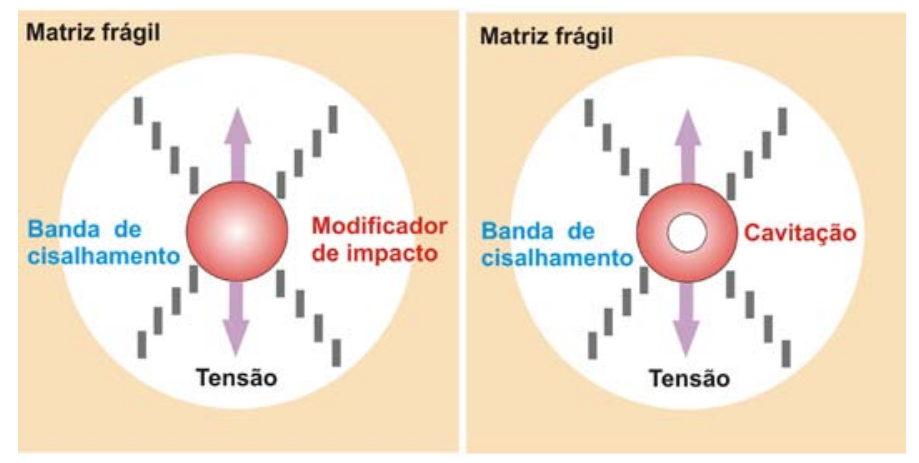

Figura 4.2.1.1.2 - Tenacificação por escoamento ${ }^{3}$

Este deslocamento acarreta a formação de espaços vazios, os quais são capazes de liberar as pressões, geradas pela dificuldade de acomodação das partículas, sofrendo um aumento de volume. Dessa forma, estas cavidades auxiliam na absorção da energia de impacto.

Cada partícula possui influência ao longo do seu equador e será dependente do tipo de mecanismo de deformação apresentado pelo material. Assim, a dispersão destas partículas é fundamental, a qual pode ser estudada pela distância interpartícula. De acordo com Wu (1985), esta distância entre partículas é o principal parâmetro para avaliar a tenacificação de matrizes poliméricas pela adição de um agente tenacificante. Essa distância deve ser menor do que uma distância crítica que é uma propriedade intrínseca do material da matriz, sendo independente da fração em volume do agente tenacificante e do tamanho da partícula.

De acordo com Valera (2005), sob efeito de impacto, ocorre o fenômeno de

\footnotetext{
${ }^{3}$ http://www.specialchem4polymers.com/tc/polymeric-impact-modifiers/index.aspx?id=work em 14/05/2010
} 
cavitação (formação de lacunas), para aliviar as tensões e promover o escoamento. Dependendo da distância entre partículas, pode ocorrer uma interação entre os campos de tensão de partículas vizinhas, de acordo com a Figura 4.2.1.1.3.
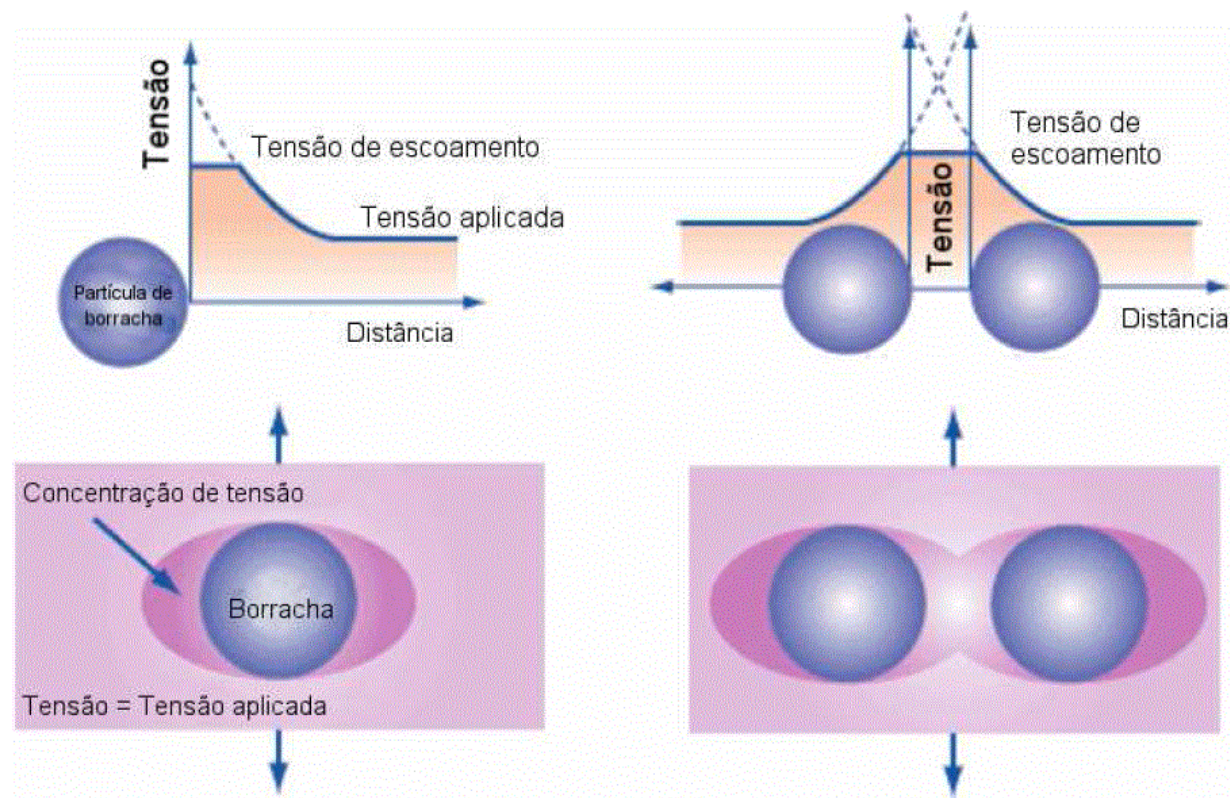

Figura 4.2.1.1.3 - Efeito da distância entre partículas do agente tenacificante (Bezzan, 2006)

Ou seja:

1) se a distância entre partículas é menor do que a distância crítica, os campos de tensão interagem, aumentando o escoamento e tenacificando a matriz.

2) se a distância entre partículas é maior que a distância crítica, os campos de tensão não interagem, não propagando o escoamento e a matriz falha de maneira frágil.

\subsubsection{Misturas Poliméricas de PBT I P(E-co-MA-co-GMA)}

A estrutura do tenacificante $\mathrm{P}(\mathrm{E}-\mathrm{co}-\mathrm{MA}-\mathrm{co}-\mathrm{GMA})$ é apresentada na Figura 4.2.1.2.1. 


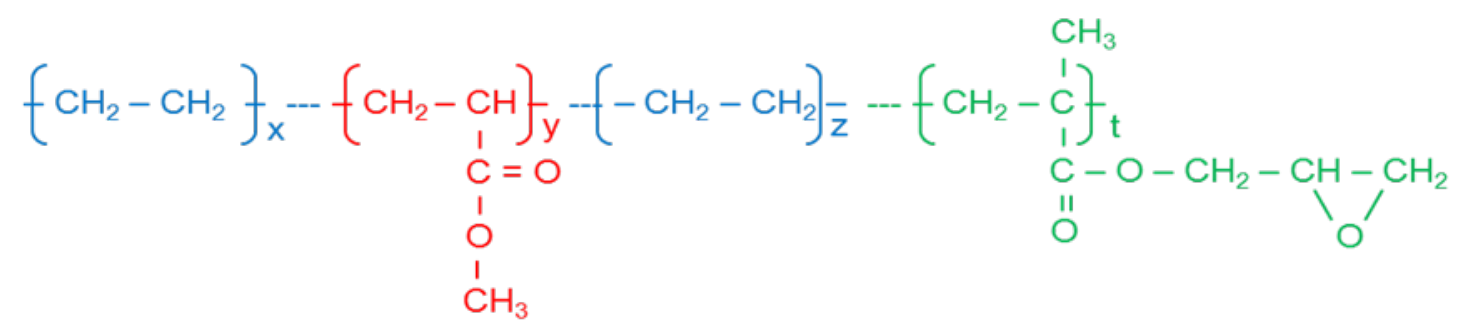

Figura 4.2.1.2.1 - Estrutura do tenacificante, copolímero P(E-co-MA-co-GMA)

O comportamento elastomérico surge em função da existência de um monômero (MA), de $T_{g}$ abaixo da $T_{a m b}$, ligado com 2 monômeros $(E)$, de $T_{g}$ acima da $T_{\text {amb. }}$. Quando na temperatura ambiente, o $P(E-c o-M A-c o-G M A)$ se comporta como um elastômero, ou seja, um termoplástico elastomérico. Além disso, esta fase confere ao polímero uma alta estabilidade térmica durante o processamento. A absorção de energia durante o impacto e a alta flexibilidade são favorecidas quanto maior for a concentração desta fase. O monômero GMA, em verde, apresenta alta reatividade com grupos funcionais tais como, $-\mathrm{OH},-\mathrm{COOH}$ e $\mathrm{NH}_{2}$, o que conduz a uma ótima dispersão durante a mistura com PET e PBT, por exemplo.

Misturas poliméricas de PBT / P(E-co-MA-co-GMA) exibem uma reatividade muito complexa (Sun et al., 1996; Hale; Keskkuda; Paul, 1999; Martin et al., 2001, 2003, 2004a,b,c; Yow et al., 2002; van Duin et al., 2003; Yu et al., 2004; Barhoumi et al., 2008; Zhang et al., 2009). Existem dois conjuntos de reações competitivas entre si, que acontecem simultaneamente durante o processo de mistura:

i. compatibilização como resultado das reações interfaciais entre os grupos terminais carboxila e hidroxila do PBT e o grupo epóxi do tenacificante P(E-co-MAco-GMA), resultando na formação de copolímeros enxertados PBT / P(E-co-MA-coGMA), como apresentado na Figura 4.2.1.2.2. As reações 1 e 2 representam reações interfaciais entre os grupos epóxi das cadeias do tenacificante e os grupos terminais carboxila e hidroxila do PBT, respectivamente, em função da abertura do anel epóxi. 
1)<smiles>CCCCCC(C)(CC)C(C)(C)CCOCC1CO1</smiles>

$+\quad$ PBT

$\mathrm{COOH}$

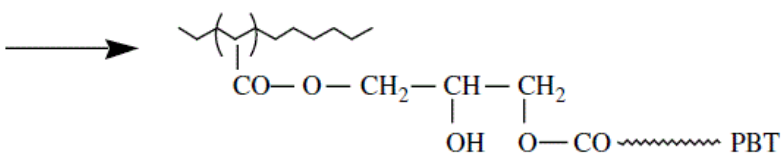

2)<smiles>CCCCCC(C)C(C)CCOCC1CO1</smiles>

PBT

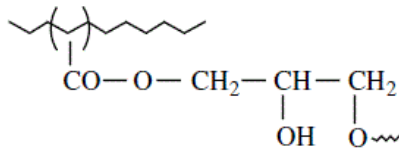
PBT

Figura 4.2.1.2.2 - Reações entre PBT e P(E-co-MA-co-GMA) (Martin et al., 2001)

Como conseqüência, novos e secundários grupo hidroxila são formados. A reação 1 acontece de forma mais lenta do que a reação 2. A eficiência de conversão de ambas as reações depende da concentração das espécies reativas e é influenciada pela concentração de grupos epóxi do tenacificante $\mathrm{P}(\mathrm{E}-\mathrm{CO}-\mathrm{MA}-\mathrm{co}-$ GMA).

ii. rápida reticulação da fase $\mathrm{MA}$, como resultado da conseqüente reação entre os grupos epóxi nas cadeias de P(E-co-MA-co-GMA) desencadeada pelos grupos hidroxila formados. A Figura 4.2.1.2.3 mostra as reações de reticulação das cadeias do tenacificante em função destes grupos hidroxila formados (3) e em função das funcionalidades das cadeias de PBT (4).

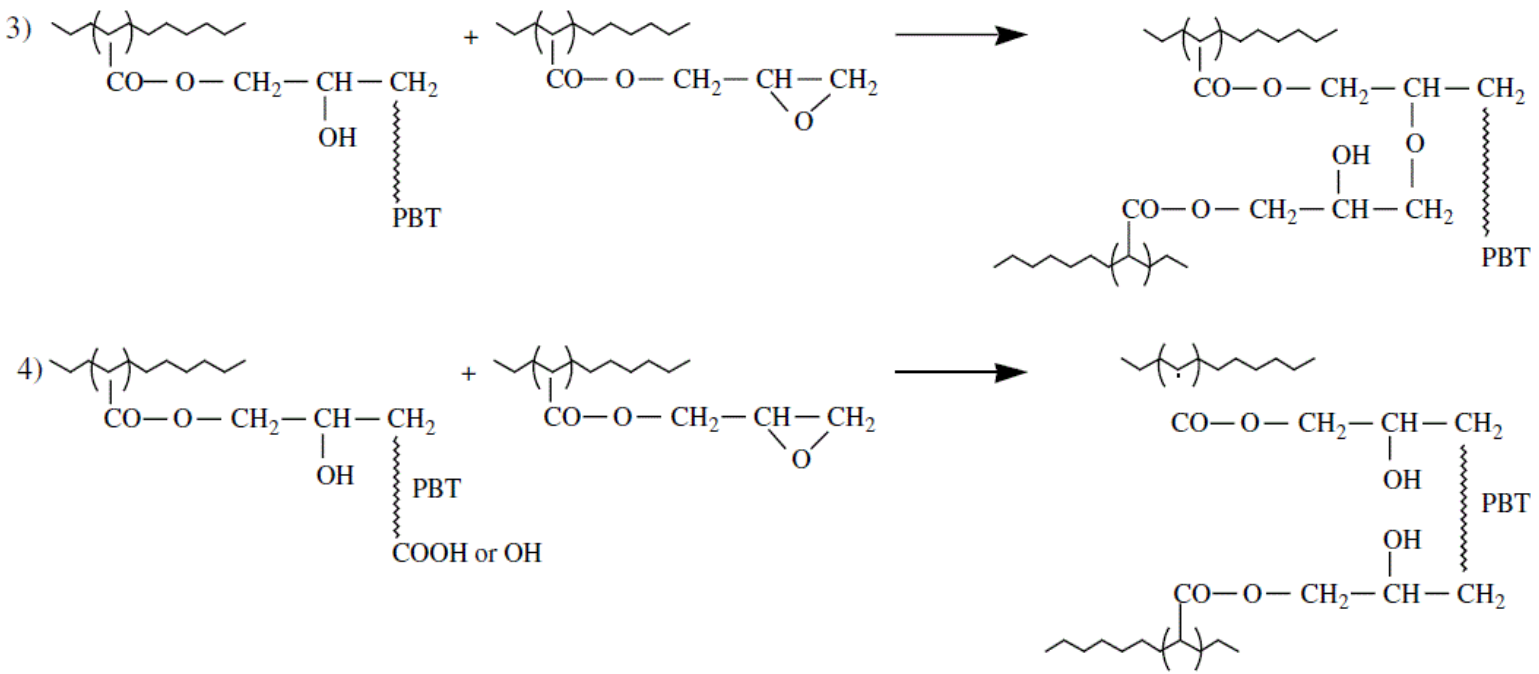

Figura 4.2.1.2.3 - Reações de reticulação do P(E-co-MA-co-GMA) (Martin et al., 2001)

Em função da formação de grupos hidroxila secundários, reação 3, as cadeias 
de $\mathrm{P}(\mathrm{E}-\mathrm{Co}-\mathrm{MA}-\mathrm{Co}-\mathrm{GMA})$ podem reagir e formar uma estrutura em rede. Da mesma forma, reação 4, as cadeias de PBT podem atuar como agentes reticuladores entre as cadeias de $P(E-c o-M A-c o-G M A)$. Isto é uma conseqüência direta da presença dos grupos terminais carboxila e hidroxila, os quais são fortemente reativos.

As reações 1 e 2 acontecem na interface da mistura polimérica. A reação 3 acontece no tenacificante. A reação 4 acontece principalmente na interface e é mais lenta do que a reação 3.

Martin et al. (2001, 2003, 2004a,b,c) e van Duin et al. (2003) fizeram um intenso estudo da compatibilização de PBT / P(E-co-MA-co-GMA). Eles avaliaram os fenômenos envolvidos durante a mistura das fases e quando estes fenômenos ocorrem. Para as misturas poliméricas de PBT / P(E-Co-MA-Co-GMA), nos primeiros estágios da mistura, polímeros enxertados são formados, PBT-g-P(E-co-MA-coGMA) os quais geram grupos hidroxila secundários nas cadeias do tenacificante próximo da interface. Conseqüentemente, a reticulação começa e procede partindo da interface para o núcleo das partículas da fase dispersa. Os autores observaram uma morfologia mais fina a partir da formação do copolímero enxertado PBT-g-P(Eco-MA-co-GMA) na interface da mistura polimérica devido à reação entre os grupos terminais carboxila do PBT e as funções epóxi do tenacificante, durante o processamento.

Como dito anteriormente, nos estágios iniciais da mistura, ou seja, tempos de mistura muito curtos, a morfologia da mistura polimérica é essencialmente governada por fatores físicos tais como a viscosidade de ambas as fases, a composição da mistura polimérica, a taxa de cisalhamento e a tensão interfacial. Este é o regime físico controlado (zona 1). A medida que o tempo de mistura aumenta, a reação química (regime químico) assume lugar progressivamente, conduzindo a um refinamento da morfologia e sua subseqüente estabilização (zona 2). Em outras palavras, o sistema muda de regime fisicamente controlado para um regime quimicamente controlado. No último passo, a evolução do tamanho é governada pela cinética relativa entre a reação de compatibilização e a reticulação do tenacificante. A transição entre as duas fases não é nítida e está intimamente relacionada com a cinética das reações químicas e as condições de processamento.

Martin et al. (2003, 2004a) estudaram misturas poliméricas de PBT / P(E-co- 
MA-co-GMA) e avaliaram a influência de alguns parâmetros, como velocidade de rotação, temperatura de processamento, viscosidade da matriz polimérica na compatibilização entre estes materiais. A Figura 4.2.1.2.4 mostra um esquema da influência destes parâmetros.

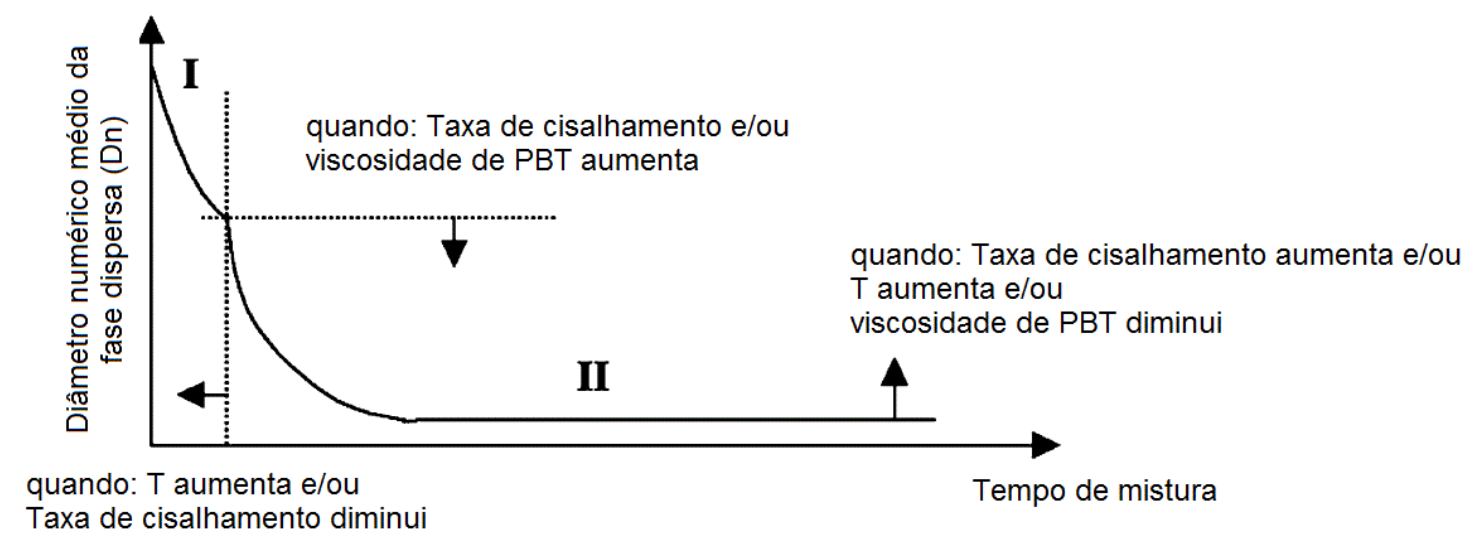

Figura 4.2.1.2.4 - Influência dos parâmetros na compatibilização de PBT / P(E-co-MA-co-GMA) (adaptada de Martin et.al., 2003)

Em taxas de cisalhamento suficientemente altas, $90 \mathrm{rpm}$, os processos físicos de dispersão e coalescência podem, mesmo em um período longo de tempo, superar os efeitos devido às reações químicas. Em outras palavras, as forças dispersivas são tão importantes que a diferença na densidade de reticulação do tenacificante existente em estágios iniciais da mistura não modificam a dispersão da fase borrachosa. Muitas partículas pequenas são então geradas e rapidamente estabilizadas através do acoplamento interfacial entre PBT e P(E-co-MA-co-GMA).

No caso da temperatura de processamento, aumentando de $250^{\circ} \mathrm{C}$ para $280^{\circ} \mathrm{C}$ os autores observaram, juntamente com a diminuição da viscosidade, um aumento na relação $\eta_{d} / \eta_{m}$. Eles avaliaram que as forças dispersivas para a quebra de partícula são conseqüentemente diminuídas o que favorece a formação de maiores partículas da fase dispersa pelo aumento da temperatura de processamento nos estágios iniciais da mistura. Também, uma vez que a temperatura é aumentada, o acoplamento interfacial e a reticulação do tenacificante aconteceram mais rapidamente. Em outras palavras, a transição do regime fisicamente controlado para o regime quimicamente controlado foi alterado para tempos de mistura mais curtos. 
Com o aumento da temperatura os autores observaram que a quantidade de cadeias livres do tenacificante diminuiu e a concentração interfacial do copolímero aumentou. A compatibilização mais rápida foi favorável para a dispersão do tenacificante, enquanto a reticulação mais rápida do tenacificante conduziu a um aumento da elasticidade da fase borrachosa, enquanto que não foi favorável para a quebra de gota e coalescência.

$\mathrm{Na}$ influência da viscosidade da matriz, o PBT com maior peso molecular apresentou morfologia mais fina. Nos primeiros estágios da mistura, a morfologia foi governada por processos físicos de quebra e coalescência (fase 1), progressivamente, as reações químicas, ou seja, compatibilização e reação de reticulação, se desenvolveram, conduzindo a uma redução do tamanho da partícula da fase dispersa e a estabilização da interface. A partir de considerações geométricas, quanto menores foram as partículas da fase dispersa (então maior o peso molecular do PBT), mais rápido foi o consumo de grupos epóxi que estavam disponíveis, devido a reticulação. A quantidade de PBT enxertado esteve intimamente relacionada com a massa molar do PBT e ao tamanho da fase dispersa. Uma maior cobertura interfacial de copolímero foi obtida para maiores partículas de tenacificante em função do menor consumo dos grupos epóxi disponíveis pela reação de reticulação.

A Figura 4.2.1.2.5 mostra um exemplo da morfologia obtida por Yu et al. (2004) para misturas poliméricas de PBT / P(E-co-MA-co-GMA) (90/10, 80/20, 70/30), em massa. A fase dispersa foi removida pela dissolução seletiva com xileno. 

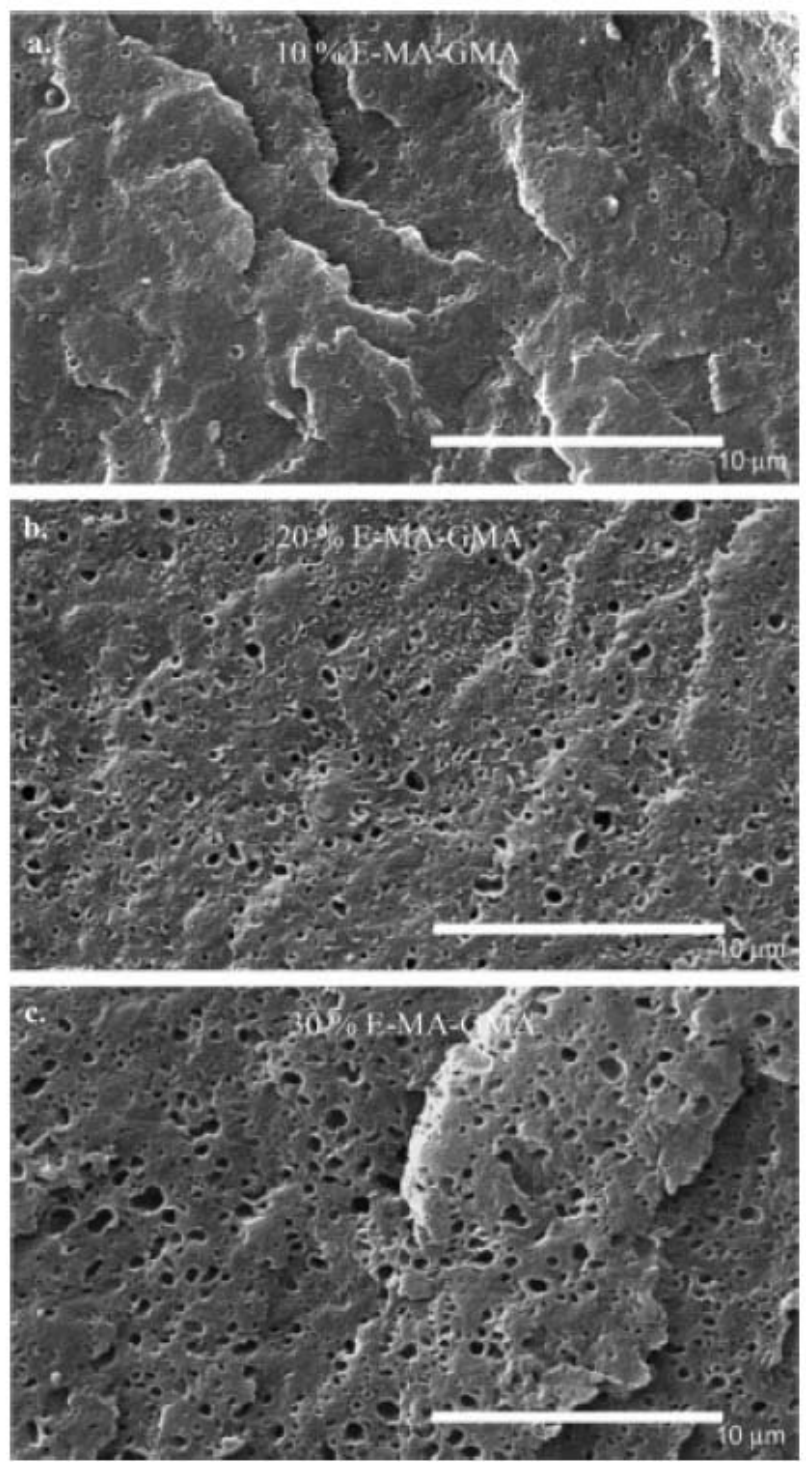

Figura 4.2.1.2.5 - Micrografia por SEM para PBT / P(E-co-MA-co-GMA) a) (90/10) b) (80/20 c) (70/30), em massa (Yu et al., 2004)

Pode ser observado que o tamanho de partículas aumenta com o aumento da concentração de $\mathrm{P}(\mathrm{E}-\mathrm{co}-\mathrm{MA}-\mathrm{co}-\mathrm{GMA})$, mas ainda é muito pequeno. De acordo com os autores, a maior quantidade de P(E-Co-MA-Co-GMA) favorece a um maior numero de reações de reticulação, aumentando a viscosidade da fase dispersa, dificultando a dispersão.

De uma forma geral, o módulo de elasticidade diminui e esta diminuição foi mais acentuada com o aumento da concentração de P(E-co-MA-co-GMA), assim como a resistência a tração. Entretanto, a resistência ao impacto aumentou com o aumento da concentração de P(E-co-MA-co-GMA) (Yow et al., 2002; Yu et al., 2004; 
Barhoumi et al., 2008).

Através de uma escolha adequada de condições de processamento, é possível favorecer a ocorrência de um fenômeno em relação a outro. A compreensão destes parâmetros em função da variação do processamento se torna importante na compreensão das propriedades finais. Assim, no caso de nanocompósitos de misturas poliméricas de PBT / P(E-co-MA-co-GMA), a presença de um terceiro componente sólido pode afetar estes fenômenos.

\subsubsection{Nanocompósitos de Misturas Poliméricas}

A dispersão de partículas nanométricas em misturas poliméricas tem sido estudada por vários autores na literatura. As argilas organofílicas podem atuar como agente compatibilizante, reduzindo o tamanho da fase dispersa, melhorando a adesão interfacial entre os polímeros, prevenindo a coalescência, estabilizando a morfologia e reduzindo a tensão interfacial (Arcus, 2009). De acordo com Sinha Ray et.al. (2004, 2007) a adição de Cloisite 20A em misturas poliméricas de PP/PS e PP-g-MA/PS permitiu a diminuição da tensão interfacial entre os componentes da mistura. Além disso, também foi observado um aumento no espaçamento basal, sendo mais pronunciado no caso da mistura PP-g-MA/PS/20A, para a qual não foi observada pico de difração, indicando que a estrutura foi esfoliada. Assim, as misturas poliméricas agregam vantagens nas propriedades dos componentes individuais, bem como no sinergismo entre eles.

É possível dar dois enfoques ao estudo de misturas poliméricas envolvendo nanocompósitos:

$\checkmark \quad$ O uso de nanopartículas para melhorar as propriedades de uma blenda polimérica,

$\checkmark \quad$ A adição de um segundo componente polimérico para melhorar as propriedades de um nanocompósito.

Como exemplo do primeiro caso podemos citar o uso de um nanocompósito como fase de reforço para um determinado polímero utilizado como matriz. Liao et al. (2001) utilizaram um nanocompósito de copolímero em bloco de polietileno e poli(etileno glicol) com montmorilonita sódica como reforço para polietileno. Os 
resultados obtidos mostram um aumento no valor da resistência mecânica se comparado com o PE puro com argila, indicando que este nanocompósito é um ótimo material para ser utilizado como reforço de PE. As nanopartículas podem ser também utilizadas como reforço de blendas totalmente miscíveis, como é o caso da blenda de poli(óxido de etileno) e poli (metacrilato de metila) estudada por Lim et al. (1994). Neste trabalho os autores determinaram os parâmetros de interação de Flory-Huggins para a mistura PEO/PMMA/MMT. Os resultados mostraram que a argila tem afinidade com o PMMA. Entretanto, para qualquer concentração de PEO a presença de argila melhora significativamente as propriedades mecânicas da mistura polimérica.

De acordo com o segundo enfoque - de melhoria das propriedades de nanocompósitos pelo uso de misturas poliméricas - podemos citar como exemplo o uso da adição de uma segunda fase polimérica ao nanocompósito para melhorar a sua resistência ao impacto. Apesar de em muitos casos a tenacidade de um polímero não ser significativamente afetada pela adição de nanopartículas, em certos casos há uma perda considerável de resistência ao impacto. Este problema pode ser compensado pela adição de polímeros que agem como tenacificadores, como, por exemplo, elastômeros ou polímeros mais dúcteis como PE ou PP (Sperling, 1997). Liu et al. (2001) estudaram o efeito da adição de polipropileno enxertado com anidrido maleico (PP-g-MA) como agente tenacificador de nanocompósitos de poliamida 6 com argila. Os resultados obtidos mostraram que com a adição de apenas 10\% de PP-g-MA ao nanocompósito o valor de resistência ao impacto original da PA-6 pura foi superado. A adição de PP-g-MA também reduziu muito a absorção de água do material, fator crítico para poliamidas.

\subsubsection{Nanocompósitos de Misturas Poliméricas contendo P(E-co-MA-co-GMA)}

$\mathrm{Na}$ literatura apenas dois estudos sobre obtenção de nanocompósitos contendo P(E-Co-MA-co-GMA) foram realizados. Em particular, Yilmazer e Alyamac $(2007 a, b)$ estudaram o efeito da adição do agente tenacificante P(E-Co-MA-co-GMA) em PET/25A, sob várias seqüências de processamento: PI-A, PA-I, IA-P e TUDO, onde $\mathrm{P}=\mathrm{PET}, \mathrm{I}=$ modificador de impacto $\mathrm{P}(\mathrm{E}-\mathrm{co}-\mathrm{MA}-\mathrm{co}-\mathrm{GMA})$ e $\mathrm{A}=$ argila. As duas 
primeiras letras indicam um primeiro processamento e, em seguida, num segundo processamento, adicionado o terceiro componente. Ambos os processamentos foram conduzidos em extrusora dupla rosca, 350rpm, $270^{\circ} \mathrm{C}$. Além do processamento, os autores também variaram a composição. A Figura 4.2.3.1 mostra os resultados de XRD obtidos pelos autores.

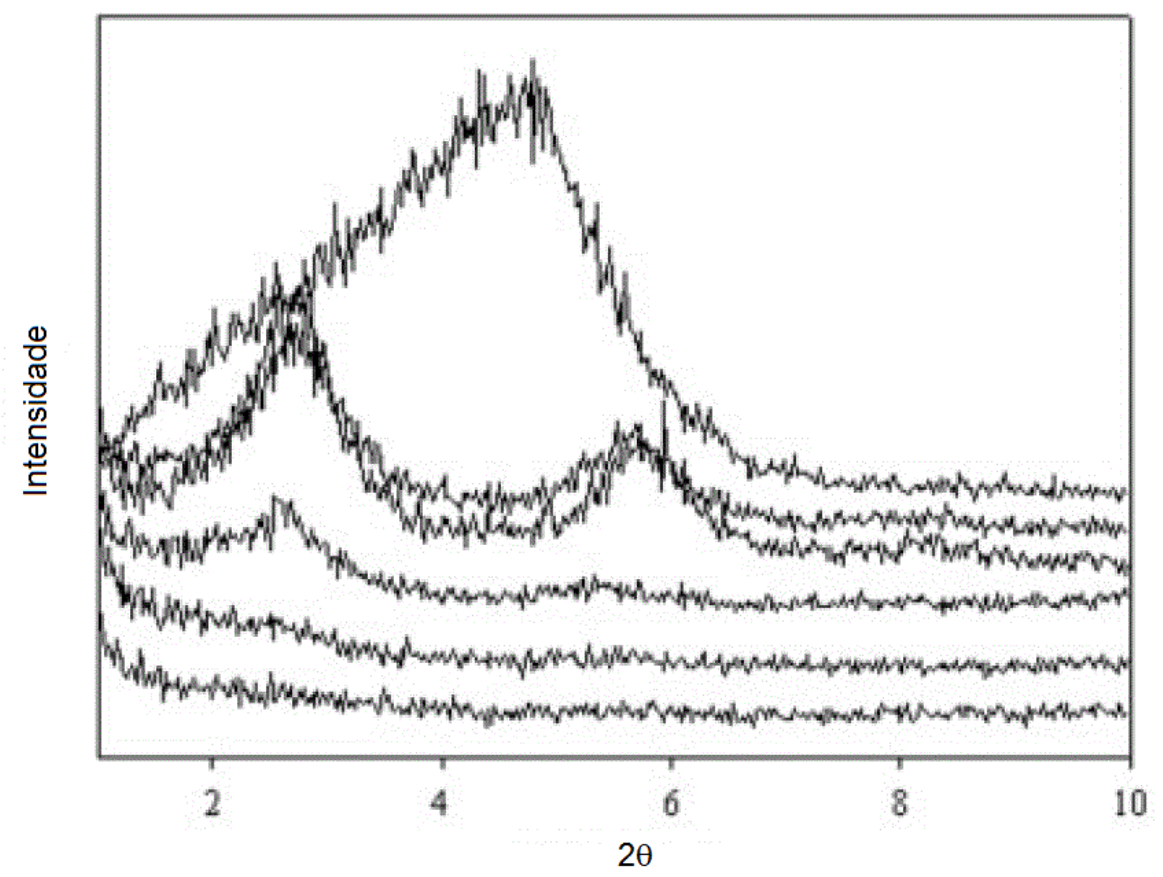

Figura 4.2.3.1 - Difratrogramas dos nanocompósitos contendo $3 \%$ em peso de argila (de cima para baixo: Cloisite 25A, PA-I, PA, TUDO, IA-P e PI-A) (adaptada de Yilmazer e Alyamac, 2007b)

Os autores concluíram que PI-A, IA-P e TUDO esfoliaram, pois o pico de difração não foi observado. A Figura 4.2.3.2 apresenta os resultados para o módulo de elasticidade e resistência à tração em função da concentração de argila, para as vários de seqüência de processamento de PET / P(E-co-MA-co-GMA) / 25A, obtidos por (Yilmazer e Alyamac, 2007b). O aumento na concentração de argila resultou num aumento do módulo de elasticidade, principalmente no caso do processamento PI-A, mas numa diminuição da resistência ao impacto. A adição de P(E-Co-MA-coGMA) resultou em materiais mais dúcteis, aumentando o alongamento na ruptura. $A$ resistência ao impacto aumentou para os materiais com P(E-co-MA-co-GMA), mas diminuiu com $5 \%$ em peso de argila, uma vez que estes materiais apresentaram um 
grande número de aglomerados de argila.
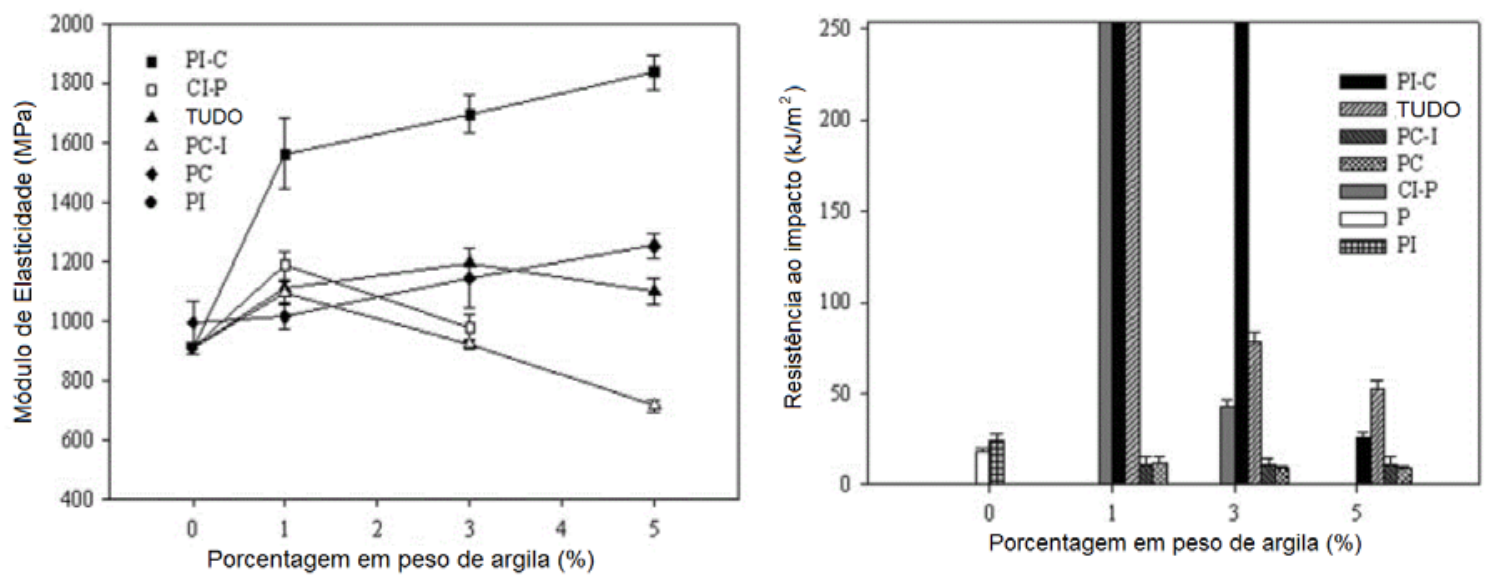

Figura 4.2.3.2 - Módulo de Elasticidade e resistência à tração em função da concentração de argila para as várias seqüências de processamento (adaptadas de Yilmazer e Alyamac, 2007b)

Os autores concluíram que a melhor seqüência de processamento foi PI-A, com 5\% em peso de $\mathrm{P}(\mathrm{E}-\mathrm{co}-\mathrm{MA}-\mathrm{Co}-\mathrm{GMA})$ e $5 \%$ em peso de argila, pois o módulo de elasticidade aumentou 225\%. O alongamento aumentou 300\% em relação ao PET puro, com 1\% de argila. Neste caso a matriz polimérica PET/ P(E-co-MA-co-GMA), obtida no primeiro processamento, possui maior viscosidade no fundido do que o PET puro, o que pode ter gerado maiores tensões entre as partículas de argila, adicionadas no segundo processamento, esfoliando as lamelas de argila, resultando em melhores propriedades mecânicas.

\subsection{Materiais e Métodos}

\subsubsection{Materiais}

$O$ agente tenacificante, $P(E-c o-M A-c o-G M A)$, utilizado neste trabalho foi fornecido pela Arkema sob a especificação de AX8900. Ele contem $24 \%$ em peso de acrilato de metila e $8 \%$ em peso de metacrilato de glicidila, com um índice de fluidez de 6g/10min. Os outros materiais já foram apresentados no Capítulo 3. 


\subsubsection{Métodos}

\subsubsection{Obtenção de PBT/ P(E-co-MA-co-GMA)/OMMTs}

Em uma primeira fase otimizou-se a seqüência de mistura, para isto utilizou-se uma composição (79/17/4). Essa otimização foi realizada com argila BraPraep. Quatro diferentes seqüências de processamento, SP, foram utilizadas para a obtenção dos materiais com agente tenacificante, utilizando uma combinação das etapas descritas acima. Estes métodos são descritos a seguir, onde $\mathrm{P}=\mathrm{PBT} ; \mathrm{I}=$ $\mathrm{P}$ (E-co-MA-co-GMA) (modificador de impacto) e $\mathrm{A}=\mathrm{OMMT}$, obtidas no misturador (M) e/ou na extrusora (E). Uma vez que a condição de processamento foi otimizada, foram adotadas três linhas de pesquisa, como descrito a seguir. 


\section{Otimização da sequência de processamento \\ SP \\ TUDO \\ PI-A \\ PA-I \\ IA-P \\ Etapa 1 \\ $P+I+A(E)$ \\ $P+I(E)$ \\ $P+A(E)$ \\ I + A (M) \\ Etapa 2 \\ $\mathrm{PI}+\mathrm{A}(\mathrm{E})$ \\ $P A+I(E)$ \\ $I A+P(E)$}

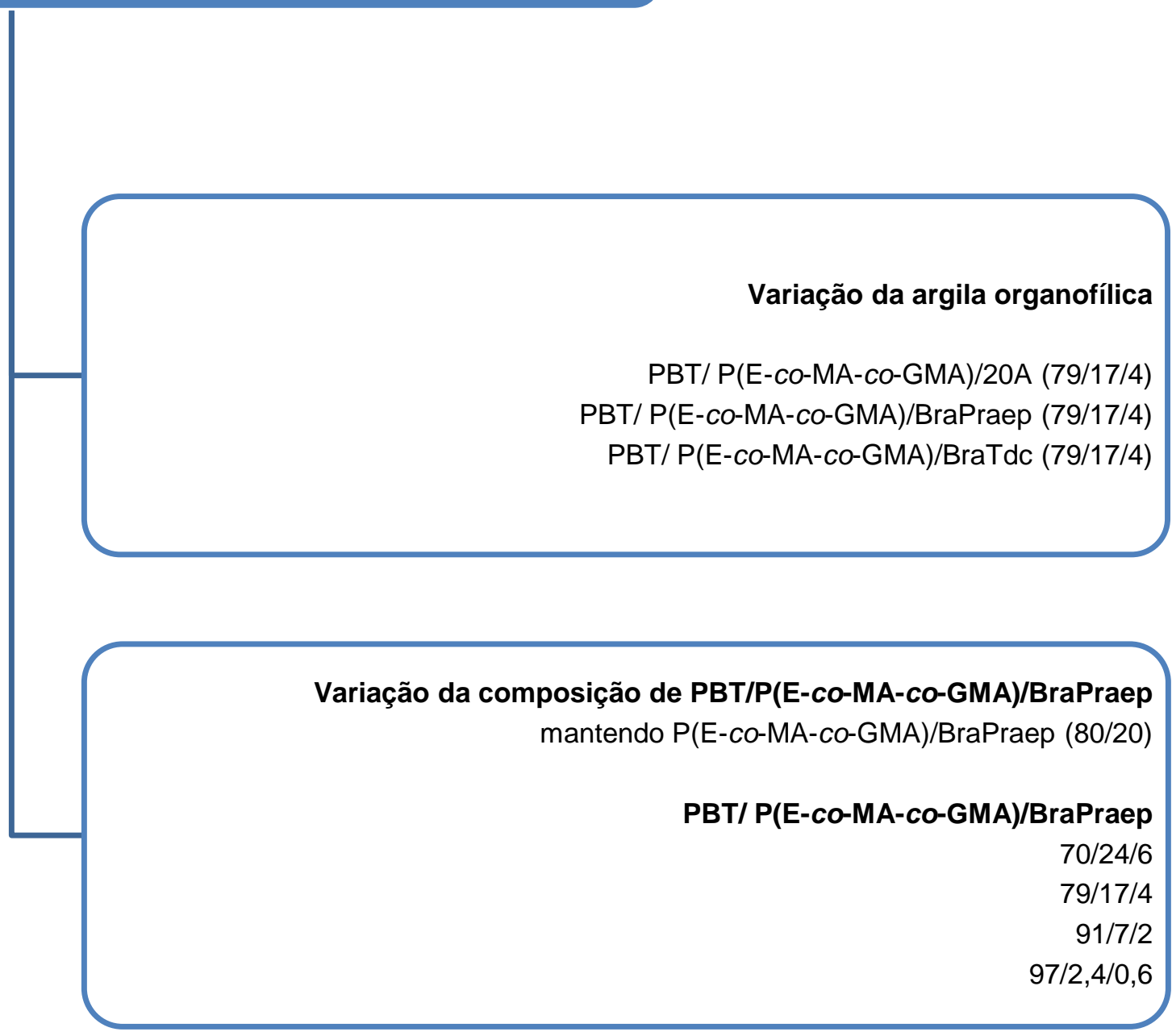

A argila modificada e o PBT foram secos à vácuo por pelo menos 18 horas antes de sua utilização. A argila modificada foi mantida sob uma temperatura de $70^{\circ} \mathrm{C}$, PBT sob uma temperatura de $120^{\circ} \mathrm{C}$ e $\mathrm{P}(\mathrm{E}-\mathrm{Co}-\mathrm{MA}-\mathrm{Co}-\mathrm{GMA}) / \mathrm{OMMT}$ sob uma temperatura de $45^{\circ} \mathrm{C}$.

A obtenção dos materiais seguiu uma ou duas etapas como mostrado no quadrado azul escuro. As condições de mistura no misturador (M) e na extrusora (E) 
são descritas a seguir:

Extrusora (E): Os materiais foram misturados utilizando uma extrusora dupla rosca acoplada a um reômetro de torque Haake, relação comprimento/diâmetro L / $\mathrm{D}=40$, a uma velocidade rotacional de $150 \mathrm{rpm}$. A temperatura foi de $235^{\circ} \mathrm{C}$ desde a zona de alimentação ao orifício de saída do material, o que garante uma temperatura de $250^{\circ} \mathrm{C}$ no material fundido, de acordo com o sistema de controle do reômetro de torque. O material extrusado foi resfriado em água, granulado e seco.

Misturador (M): Misturas de P(E-co-MA-co-GMA)/OMMT foram obtidas a $150^{\circ} \mathrm{C}$, 20min e 50rpm. P(E-co-MA-Co-GMA) sem OMMT e P(E-co-MA-Co-GMA)/Bra foram preparadas para apresentar mesmo histórico de processamento. A mistura final é moída e seca.

As amostras foram injetadas em dois formatos: (1) tração (ASTM D638), impacto (D 4812). A injetora utilizada foi Demag Ergotech Pro 35-115. O perfil de temperatura foi $240-245-250-255^{\circ} \mathrm{C}$ e a temperatura do molde foi $70-80^{\circ} \mathrm{C}$. A pressão de injeção foi 40bar.

Assim como proposto por Yilmazer e Alyamac (2007a,b), todas as etapas foram realizadas na extrusora. Entretanto, a etapa 1 da seqüência $I A-P$, ou seja $I+A$ pela extrusora, se tornou inviável sem a adição de estearato de zinco, em função da alta viscosidade de P(E-co-MA-co-GMA). Assim esta etapa foi obtida através do misturador. Como as demais misturas, com e sem a adição de P(E-co-MA-co-GMA), foram obtidas sem a adição de estearato de zinco, optou-se pela não obtenção da seqüência IA-P pela extrusora.

\subsubsection{Caracterização e Propriedades dos Materiais}

Os materiais foram caracterizados e suas propriedades mecânicas e flamabilidade foram estudadas, assim como descritos no Capítulo 3. Entretanto, para alguns ensaios de resistência ao impacto, as amostras foram entalhadas, à temperatura ambiente, na entalhadora automática Tinius Olsen, modelo 899, disponível na Universidade Mackenzie. 


\subsection{Microscopia Eletrônica de Varredura (SEM)}

As amostras foram mantidas em nitrogênio líquido, por uma hora, para fratura criogênica. Para melhor visualização das fases, efetuou-se a dissolução da fase dispersa, $\mathrm{P}(\mathrm{E}-\mathrm{co}-\mathrm{MA}-\mathrm{co}-\mathrm{GMA})$, em xileno, a $70^{\circ} \mathrm{C}$ por 24 horas. Os materiais foram então morfologicamente caracterizados por microscopia eletrônica de varredura disponível no PMT-EPUSP. Este equipamento é da marca Philips, modelo XL 30, tensão de $15 \mathrm{kV}$. Para melhorar a condutividade elétrica das amostras, as faces fraturadas foram recobertas com ouro utilizando um sputter coater, Balzers, SCD50.

\subsection{Difração de Raios - X (XRD)}

A variação da distância entre as lamelas da argila modificada foi avaliada em um difratômetro de Raios - X PANalytical, modelo X'Pert PRO com detector $X$ 'Celerator, disponível no Departamento de Engenharia de Minas e de Petróleo (PMI) da EPUSP. As amostras foram obtidas injetadas no formato de discos e secadas.

\subsection{Espectrometria no Infravermelho com Transformada de Fourier (FTIR)}

A avaliação dos grupos funcionais das estruturas dos materiais foi estudada em Espectrofotômetro Nicolet modelo Magna 560, disponível no PMT-EPUSP. As amostras foram obtidas no formato de filme, utilizando um estágio à quente acoplado ao microscópio ótico. 


\subsection{Resultados e Discussões}

A seguir são apresentadas as propriedades mecânicas dos nanocompósitos estudados neste trabalho após a adição do agente tenacificante $\mathrm{P}(\mathrm{E}-\mathrm{CO}-\mathrm{MA}-\mathrm{co}$ GMA). A composição (70/24/6) não foi aprofundada em função de seu processamento ter sido dificultado pela alta viscosidade do tenacificante sob a alta temperatura de processamento do PBT. Os resultados foram divididos em três partes:

$\checkmark$ Otimização do processamento: TUDO, PI-A, PA-I, IA-P

$\checkmark$ Variação do tipo de argila organofílica: 20A, BraPraep e BraTdc

$\checkmark$ Variação da composição da mistura polimérica PBT/P(E-co-MA-coGMA)/BraPraep): (79/17/4), (91/7/2) e (97/2,4/0,6)

\subsubsection{Otimização do processamento}

A Figura 4.4.1.1 mostra a curva de torque no processamento de PBT com PBT e $\mathrm{P}$ (E-co-MA-co-GMA), na composição (79/21). O P(E-co-MA-co-GMA) foi adicionado após 4 min.

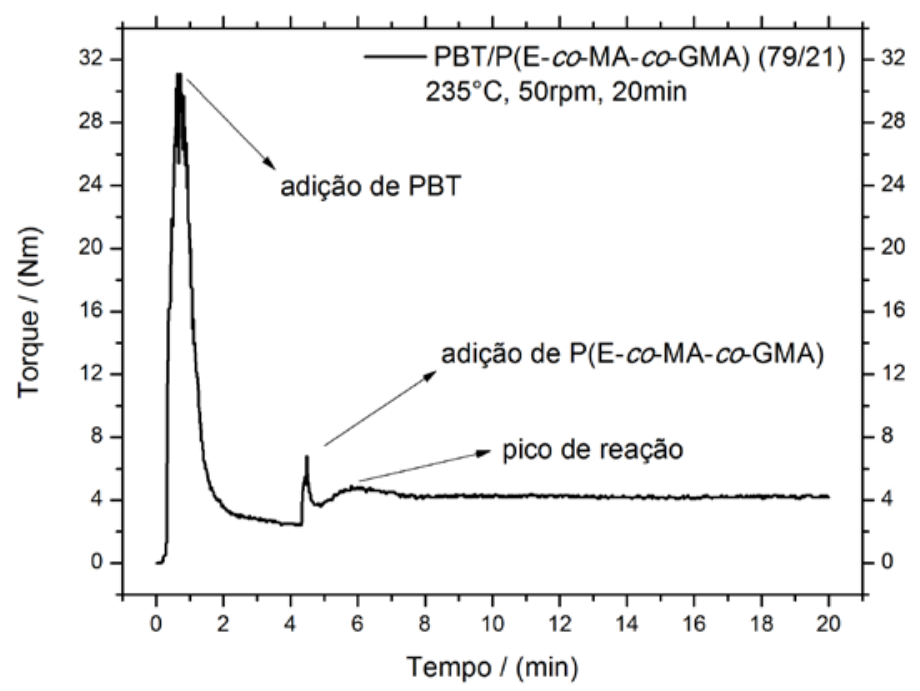

Figura 4.4.1.1 - Torque no misturador para PBT / P(E-co-MA-co-GMA) (79/21)

Pode ser observado que após a adição P(E-co-MA-co-GMA) a curva de torque 
apresenta um pico de reação. Resultados semelhantes foram obtidos por Carvalho e Sousa (2009) quando estudaram a reação entre PET e P(E-co-MA-co-GMA).

A Figura 4.4.1.2 mostra os espectros obtidos por FTIR para avaliação dos grupos terminais dos polímeros PBT e P(E-co-MA-co-GMA). 

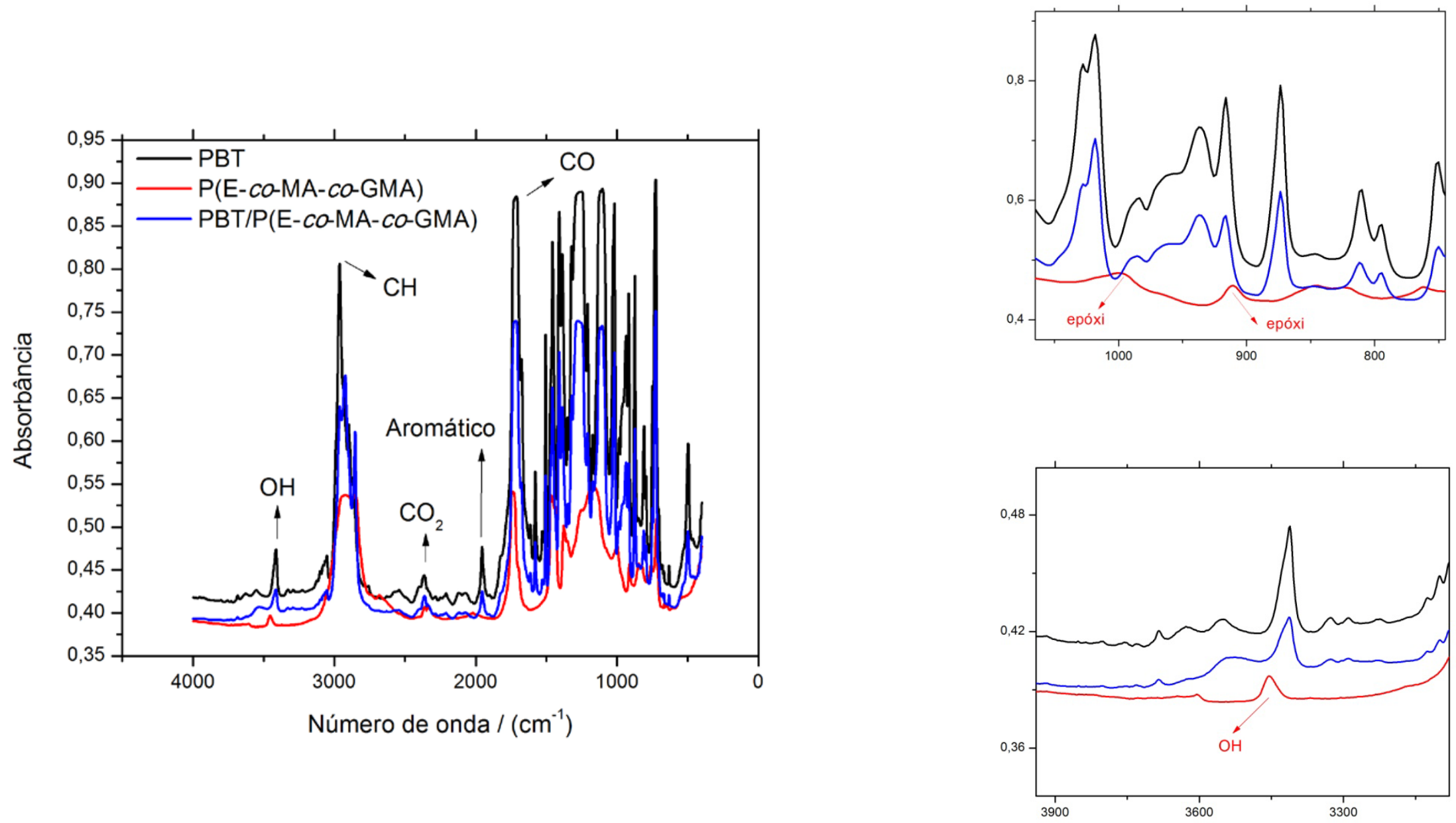

Figura 4.4.1.2 - Espectros por FTIR para PBT, P(E-co-MA-co-GMA) e PBT/P(E-co-MA-co-GMA) (79/21) 
Pode ser observado que o pico relativo ao epóxi, presente no espectro de P(Eco-MA-co-GMA), não aparece no espectro da mistura polimérica PBT/P(E-co-MAco-GMA). Isto indica que o grupo epóxi pode ter sido todo consumido durante as reações com PBT ou reticulação. A Figura 4.4.1.3 mostra em detalhes a região de epóxi no espectro para os vários tipos de seqüência de processamento de PBT/P(Eco-MA-co-GMA)/BraPraep.

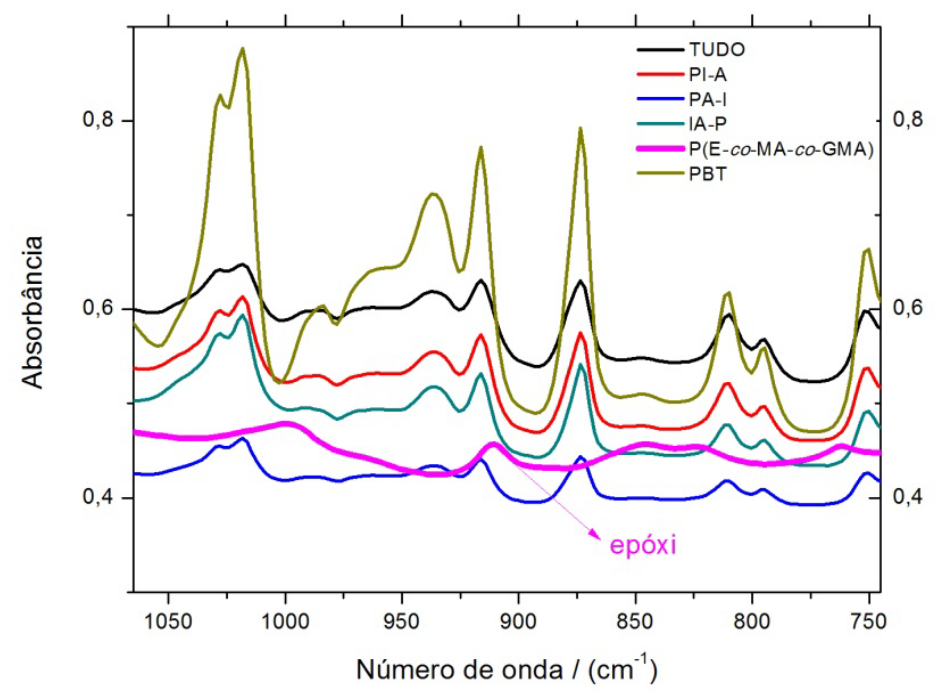

Figura 4.4.1.3 - Espectros por FTIR para PBT, P(E-co-MA-co-GMA) e PBT/P(E-co-MA-coGMA)/BraPraep para as várias seqüências de processamento

Pode ser visto em todos os processamentos que o pico do epóxi desapareceu, indicando, mais uma vez, que o grupo epóxi pode ter sido todo consumido durante as reações com PBT ou reticulação, independente do tipo de seqüência de processamento utilizado. Isto indica que a compatibilização reativa foi bem conduzida, favorecendo a boa adesão interfacial. Entretanto, as propriedades mecânicas (que são mostradas mais adiante) não foram tão parecidas entre as diversas seqüências de processamento, indicando que embora a reação entre as fases tenha ocorrido, as propriedades foram dependentes da seqüência de processamento, as quais são influenciadas pela taxa de cisalhamento, tempo de residência e viscosidade.

A Figura 4.4.1.4 mostra os difratogramas para as várias seqüências de 
processamento. A intensidade de BraPraep e PBT/BraPraep foi menor e está representada pela escala à esquerda; as demais, com P(E-co-MA-co-GMA) à direita. Essa diferença de intensidade se deve ao fato de que foram avaliadas em equipamentos diferentes. 


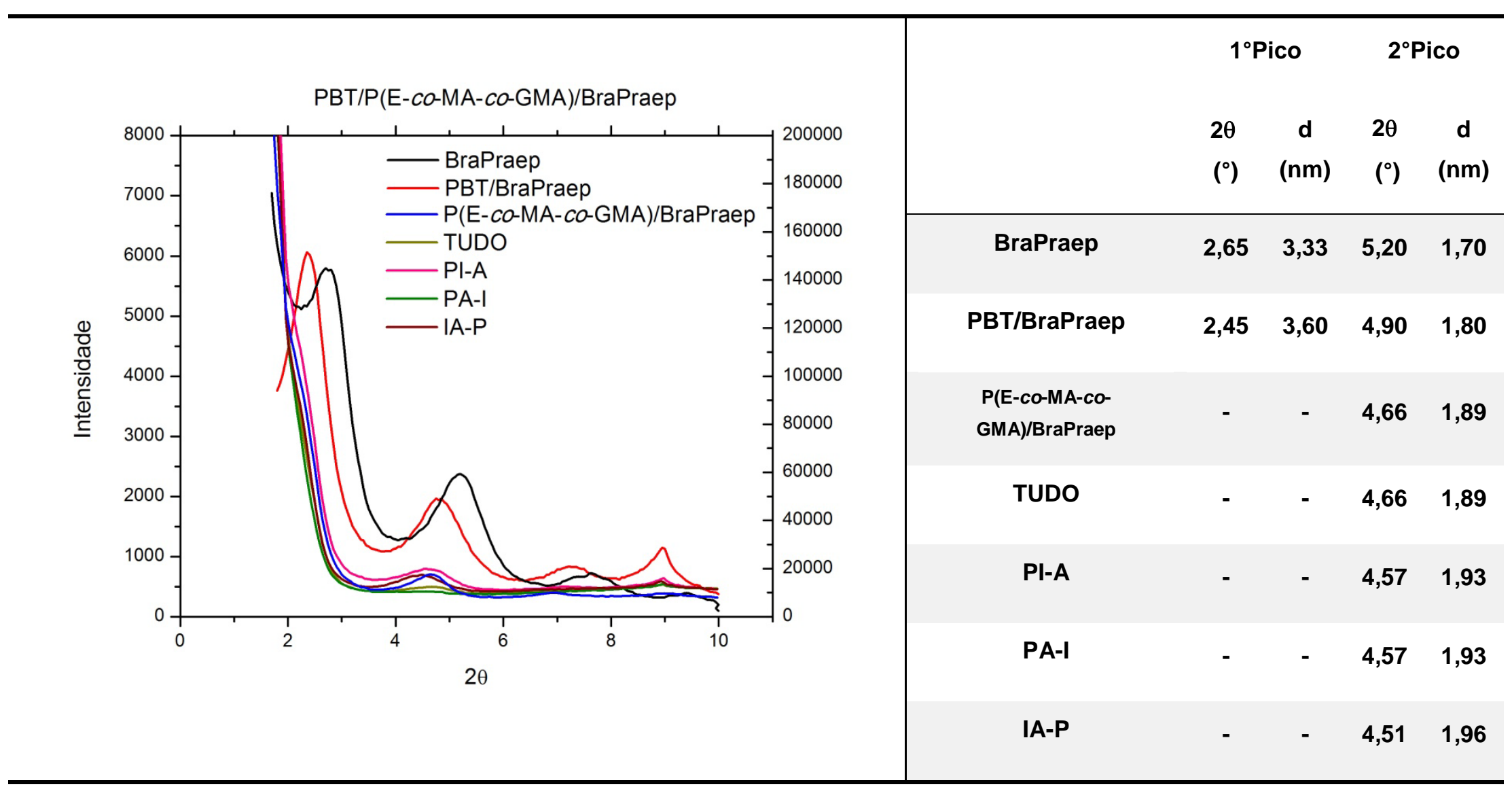

Figura 4.4.1.4 - Difratogramas para as diversas seqüências de processamento 
Pode ser observado que as diversas seqüências não apresentaram grandes diferenças entre si. Entretanto, como o primeiro pico de difração, entre 2 e $3^{\circ}$, não se apresentou de forma nítida e clara, as suas diferenças podem ser comparadas pelo segundo pico de difração, entre 4 e $6^{\circ}$. Estes últimos mostram que maior espaçamento basal foi obtido para a seqüência de adição IA-P. O primeiro pico de difração, para esta seqüência de processamento (curva cor-de-vinho) apresenta um sutil deslocamento para a esquerda (menores ângulos) o que caracteriza maior espaçamento. Na primeira etapa deste processamento, ou seja, a mistura P(E-coMA-co-GMA)/BraPraep obtida no misturador, já indica um grande espaçamento basal. Esse valor tende a ser maior do que aquele observado apenas para PBT/BraPraep, que foram obtidos na extrusora. Este resultado pode ter sido favorecido pela alta viscosidade do $\mathrm{P}(\mathrm{E}-\mathrm{Co}-\mathrm{MA}-\mathrm{Co}-\mathrm{GMA})$ durante o longo do tempo de mistura no misturador, em comparação com o curto tempo de residência de PBT/BraPraep na extrusora. Além disso, este tipo de processamento também apresentou uma das morfologias mais finas, como apresentado a seguir.

As Figuras 4.4.1.5 a 4.4.1.8 mostram as morfologias obtidas por SEM, após fratura criogênica, para os vários tipos de seqüências de processamentos utilizados na obtenção de PBT/ P(E-co-MA-co-GMA)/BraPraep (79/17/4).

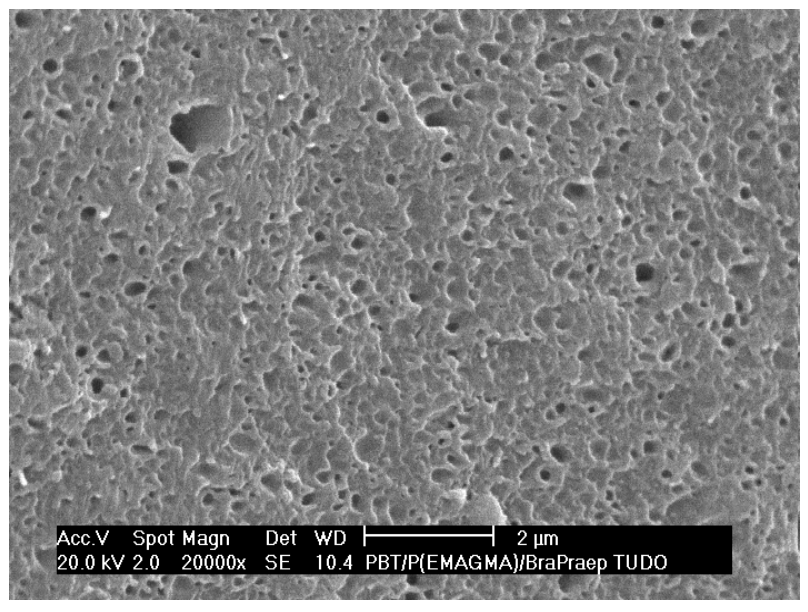

Figura 4.4.1.5 - Processamento Tudo

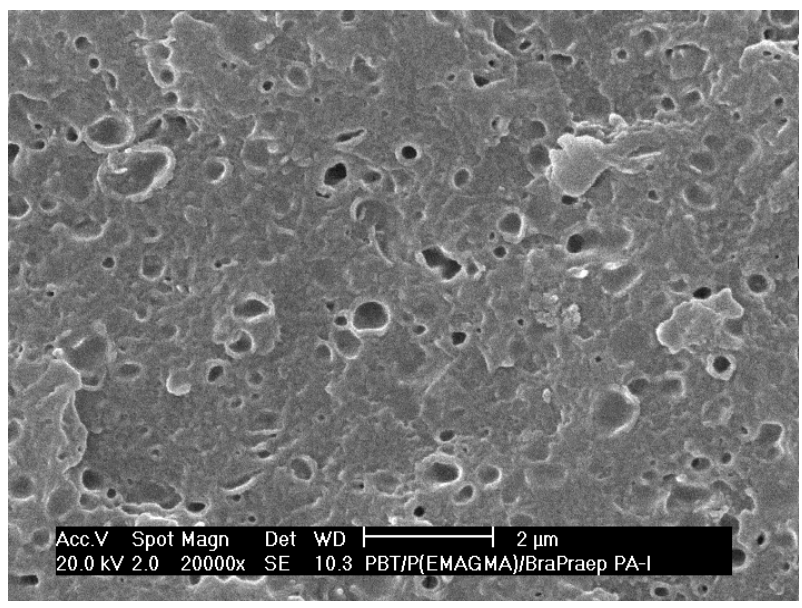

Figura 4.4.1.6 - Processamento PA-I 


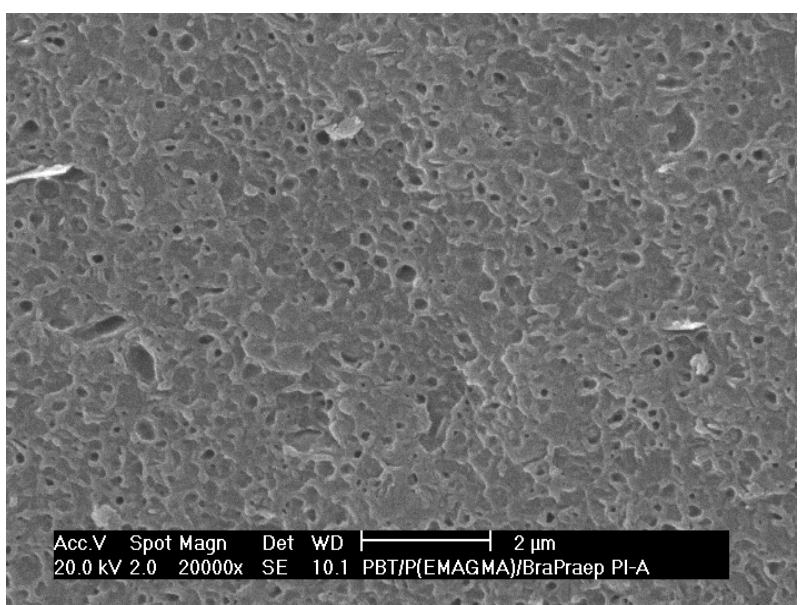

Figura 4.4.1.7 - Processamento PI-A

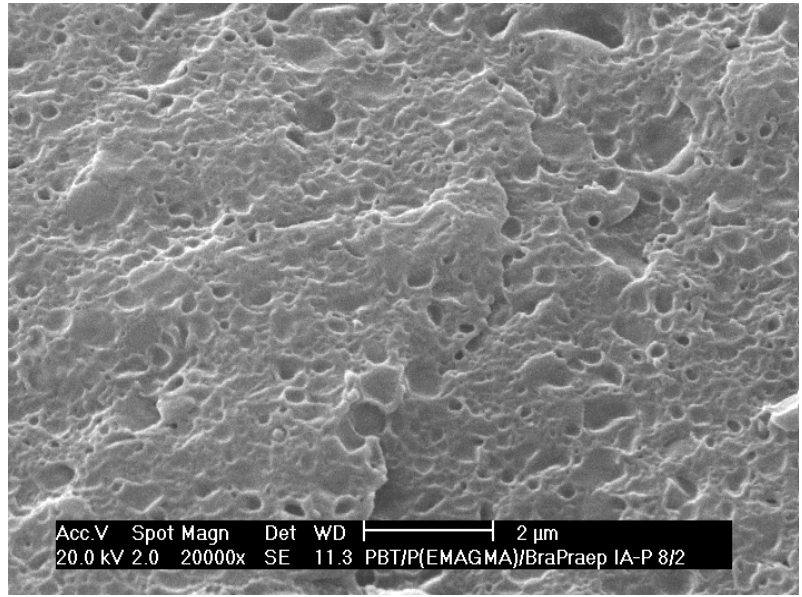

Figura 4.4.1.8 - Processamento IA-P

Pode ser observado que as morfologias com a fase dispersa apresentadas em tamanhos menores foram obtidas para os processamentos TUDO, PI-A e IA-P. No caso de TUDO, a quebra em tamanho menor pode ter sido influenciada pela viscosidade desta mistura na presença de argila, uma vez que todos os materiais foram adicionados ao mesmo tempo. No caso de PI-A e IA-P, o agente modificador de impacto, já esteve presente desde o primeiro processamento. Estes resultados indicam que, uma vez que $\mathrm{P}(\mathrm{E}-\mathrm{Co}-\mathrm{MA}-\mathrm{Co}-\mathrm{GMA})$ esteve mais tempo submetido ao cisalhamento, as suas gotas podem ter sido rompidas em tamanhos menores. No caso de PI-A, também houve maior tempo de contato entre PBT/P(E-co-MA-coGMA), favorecendo a reação entre os grupos terminais destes dois componentes. No caso de PA-I, a distância entre partículas foi bem maior do que nos demais casos, não favorecendo aos mecanismos de tenacificação, sejam por microfibrilações ou por escoamento.

A Figura 4.4.1.9 mostra as curvas de tensão versus deformação e Figura 4.4.1.10 mostra o módulo de elasticidade, resistência a tração e alongamento para as várias condições de processamento utilizadas no processamento de PBT/P(E-coMA-co-GMA)/BraPraep (79/17/4), com média de pelo menos 5 ensaios. Todas as amostras não fraturaram durante o ensaio de resistência ao impacto sem entalhe e fraturaram parcialmente quando foram entalhadas. 


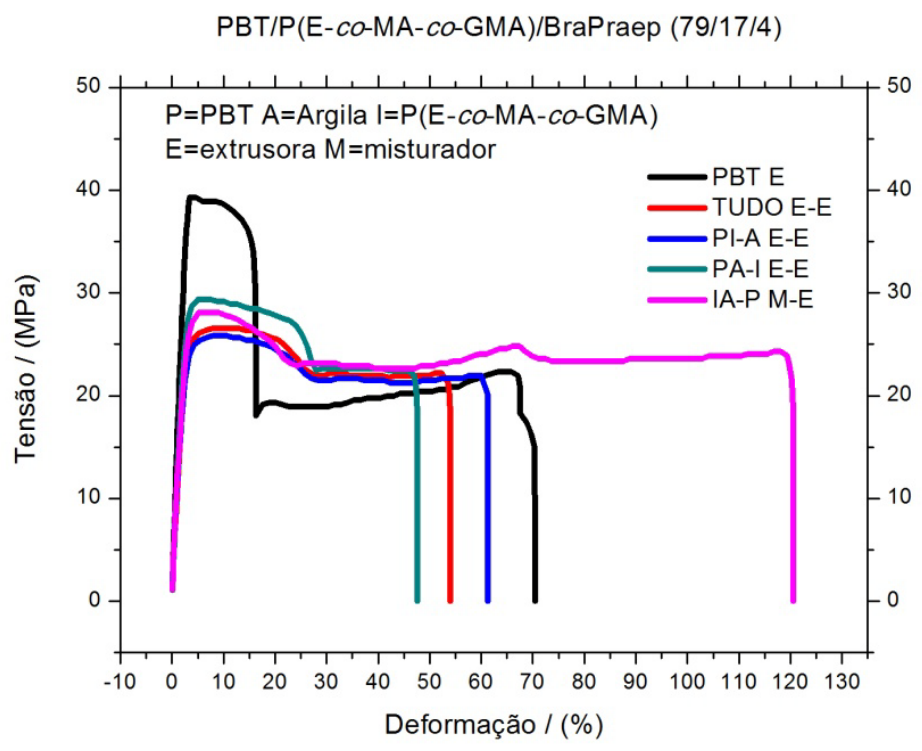

Figura 4.4.1.9 - Tensão x Deformação para as várias condições de processamentos utilizadas para a obtenção de PBT/P(E-co-MA-co-GMA)/BraPraep 

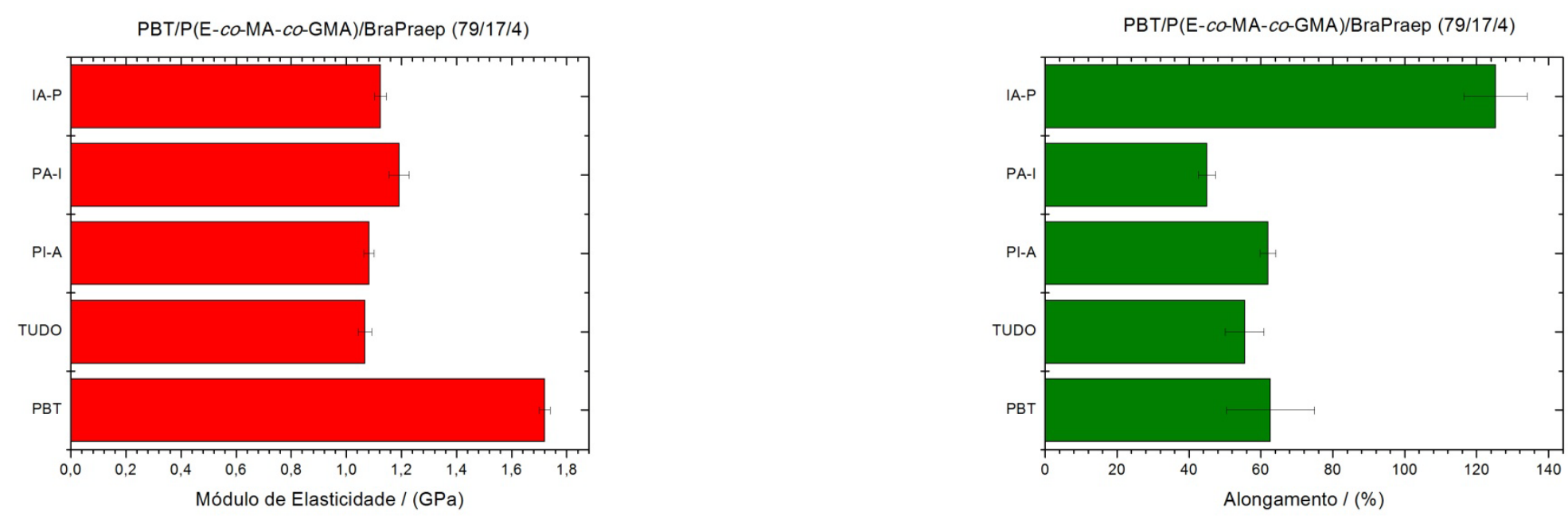

PBT/P(E-co-MA-co-GMA)/BraPraep (79/17/4)

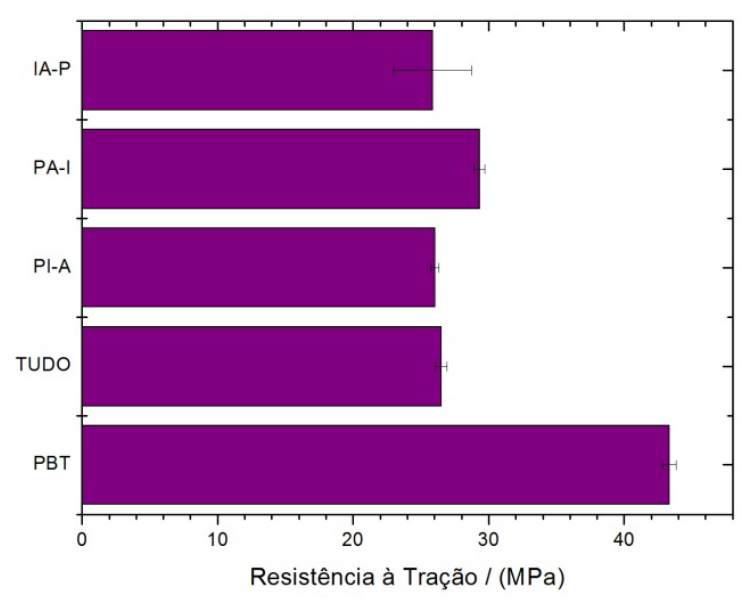

Figura 4.4.1.10 - Módulo de Elasticidade, resistência à tração e alongamento para as várias seqüências de processamento utilizadas para a obtenção de PBT/P(E-co-MA-co-GMA)/BraPraep (79/17/4) 
Pode ser observado que a seqüência de processamento IA-P, ou seja, de $P(E-$ co-MA-co-GMA) com BraPraep no misturador e adicionados ao PBT na extrusora, conduziu aos melhores resultados de alongamento. O módulo de elasticidade reduziu em relação ao PBT puro e não houve variação deste valor em relação ao tipo de seqüência de processamento utilizado, da mesma forma que a resistência à tração, sendo que as amostras não romperam durante os ensaios de resistência ao impacto (sem entalhe).

Como dito anteriormente, o maior de tempo de residência durante o processamento no misturador em comparação com os pequenos tempos de mistura na extrusora podem ter sido a razão principal desta diferença de morfologia. Isto indica que a obtenção de P(E-co-MA-co-GMA) com BraPraep no misturador foi fundamental na obtenção destas propriedades e a seqüência de processamento IA$P$ foi utilizado como processamento otimizado nos dois estudos a seguir.

\subsubsection{Variação da Argila Organofílica}

A Figura 4.4.2.1 mostra a curva de torque no processamento de P(E-Co-MAco-GMA) com 20A, Bra, BraPraep e BraTdc, na composição (80/20). Os materiais foram previamente misturados manualmente e adicionados juntos ao misturador.

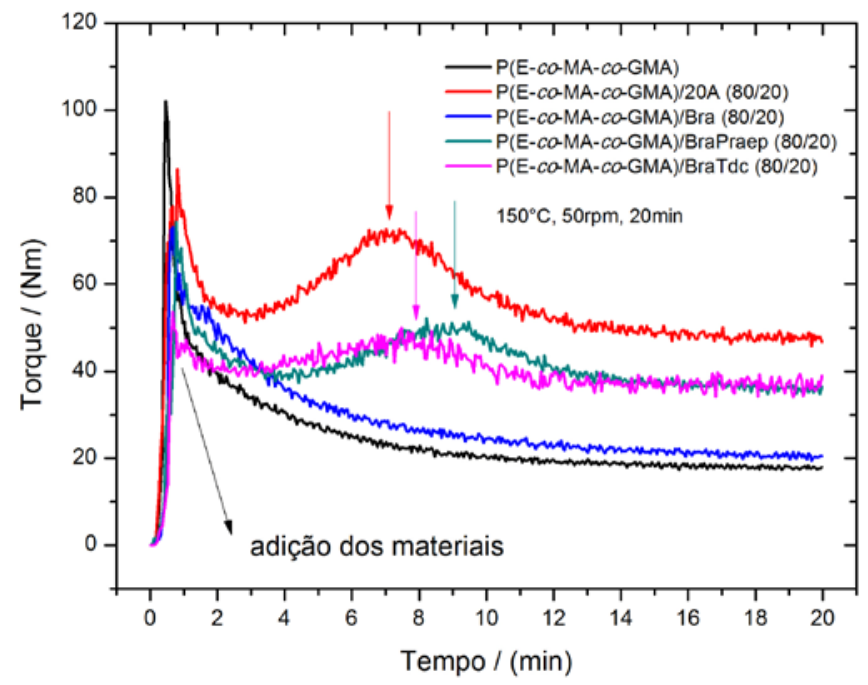

Figura 4.4.2.1 - Torque no misturador para $P(E-c o-M A-c o-G M A), P(E-c o-M A-c o-G M A) / 20 A, P(E-c o-$ MA-co-GMA)/Bra, P(E-co-MA-co-GMA)/BraPraep e P(E-co-MA-co-GMA)/BraTdc, na composição $(80 / 20)$ 
Pode ser observado que o torque, na presença de argila organofílica apresenta um pico, indicados pelas setas, o que sugere que o $\mathrm{P}(\mathrm{E}-\mathrm{Co}-\mathrm{MA}-\mathrm{Co}-\mathrm{GMA})$ reagiu com os sais quaternários presentes na argila. Como dito anteriormente, o tenacificante possui afinidade com grupos $\mathrm{NH}_{2}$, os quais estão presentes nos sais de amônio, ou seja, nas argilas 20A e BraPraep. Todavia, estes picos de reação não foram observados no processamento de $\mathrm{P}(\mathrm{E}-\mathrm{co}-\mathrm{MA}-\mathrm{co}-\mathrm{GMA})$ com os sais quaternários puros, como observado pela Figura 4.4.2.2. Além disso, $P(E-c o-M A-c o-G M A)$ é solúvel em xileno, mas $\mathrm{P}(\mathrm{E}-\mathrm{co}-\mathrm{MA}-\mathrm{co}-\mathrm{GMA}) / O M M T$ foi parcialmente solúvel, o que sugere alguma afinidade química entre as duas fases ou grande intercalação das lamelas da argila, como foi visto por XRD.

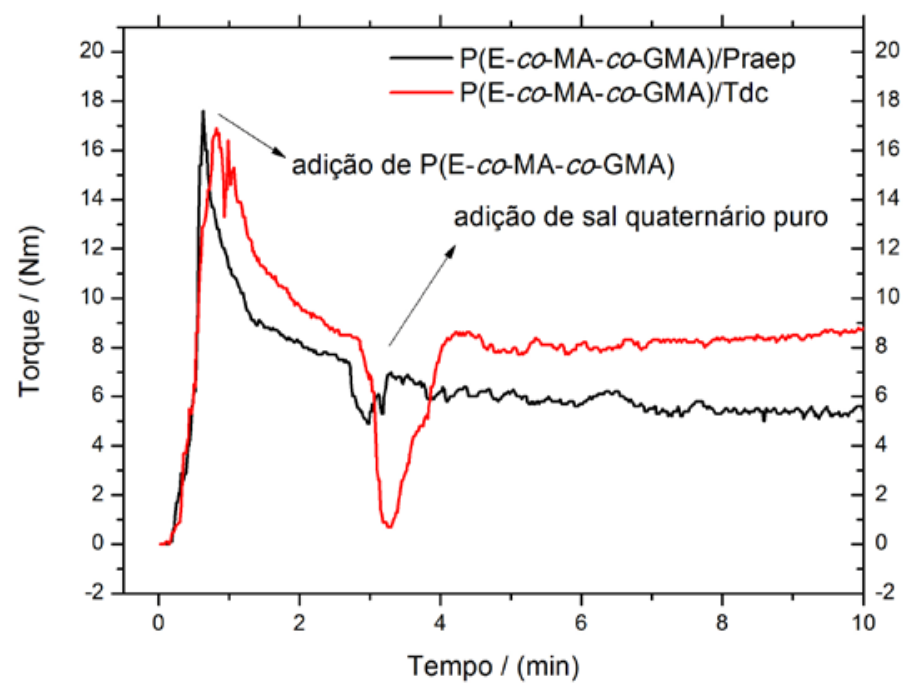

Figura 4.4.2.2 - Torque no misturador para $\mathrm{P}(\mathrm{E}-\mathrm{co}-\mathrm{MA}-\mathrm{co}-\mathrm{GMA}) / \mathrm{Praep}$ e $\mathrm{P}(\mathrm{E}-\mathrm{co}-\mathrm{MA}-\mathrm{co}-\mathrm{GMA}) / \mathrm{Tdc}$

A Figura 4.4.2.3 mostra os difratogramas para PBT/P(E-co-MA-co-GMA)/20A, a Figura 4.4.2.4 mostra os difratogramas para PBT/P(E-Co-MA-Co-GMA)/BraPraep e a Figura 4.4.2.5 mostra os difratogramas para PBT/P(E-co-MA-co-GMA)/BraTdc, todos na composição (79/17/4). 


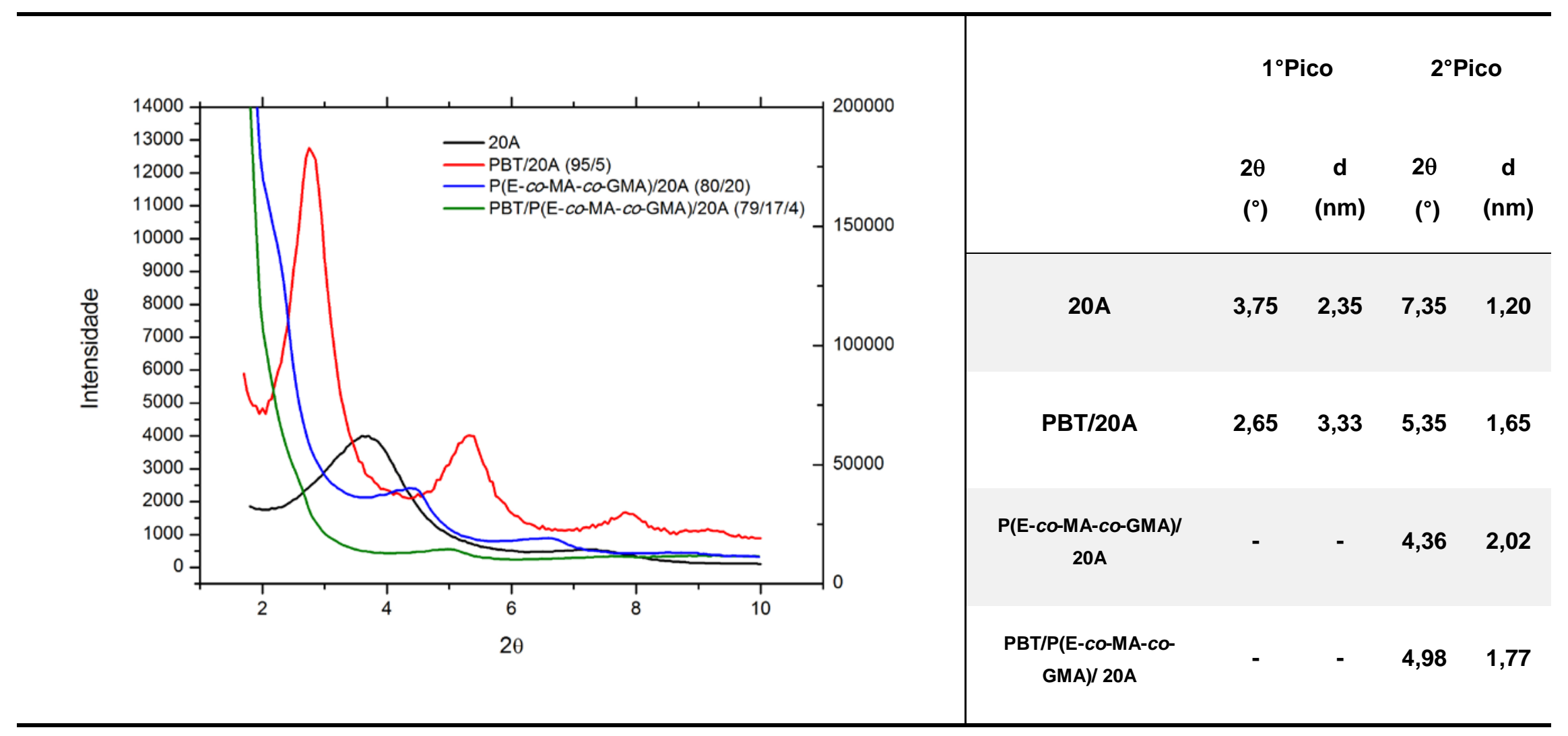

Figura 4.4.2.3 - Difratogramas para 20A, PBT/20A (95/5), P(E-co-MA-co-GMA)/20A (80/20) e PBT/P(E-co-MA-co-GMA)/20A (79/17/4) 


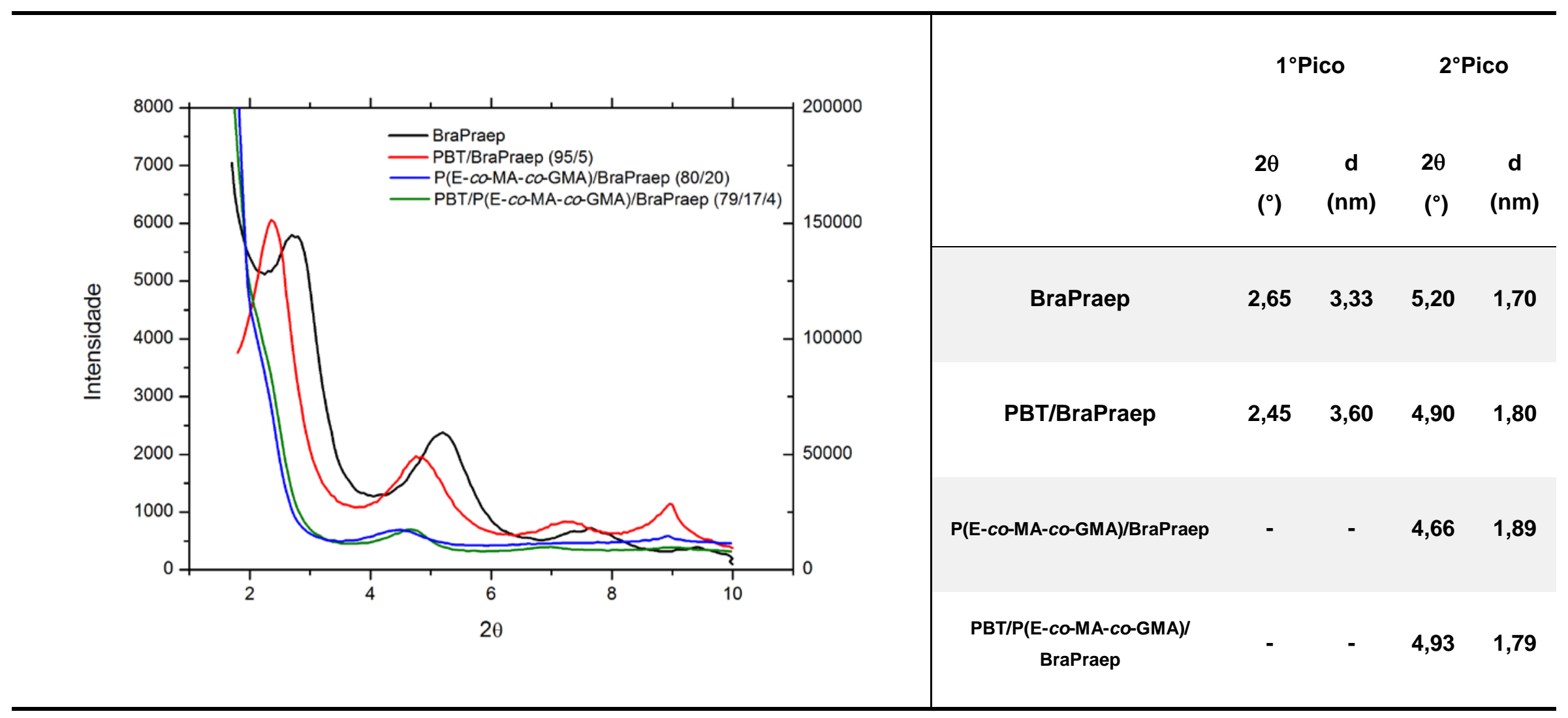

Figura 4.4.2.4 - Difratogramas para BraPraep, PBT/BraPraep (95/5), P(E-co-MA-co-GMA)/BraPraep (80/20) e PBT/P(E-co-MA-co-GMA)/BraPraep (79/17/4) 


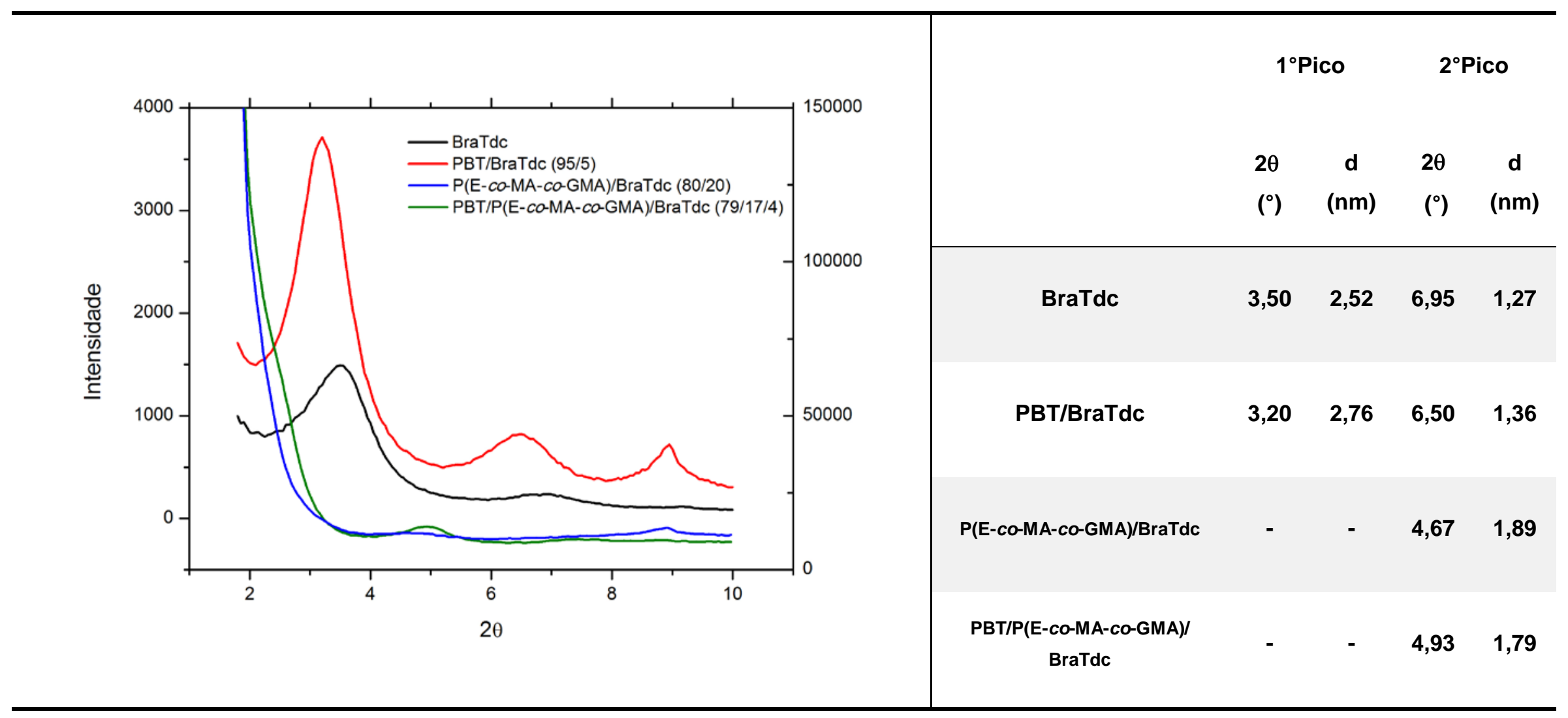

Figura 4.4.2.5 - Difratogramas para BraTdc, PBT/BraTdc (95/5), P(E-co-MA-co-GMA)/BraTdc (80/20) e PBT/P(E-co-MA-co-GMA)/BraTdc (79/17/4) 
Da mesma forma que no caso BraPraep, pode ser observado, neste dois casos, um deslocamento na curva entre 2 e $3^{\circ}$, indicando um espaçamento de aproximadamente $4 \mathrm{~nm}$. Estes resultados de XRD sugerem que as lamelas de argila nestes materiais podem estar esfoliadas. Em comparação com BraPraep, os espaçamentos basais foram ligeiramente menores nos casos de 20A e BraTdc.

A Figura 4.4.2.6 apresenta a morfologia obtida, após fratura criogênica, para e PBT/ P(E-Co-MA-co-GMA)/20A,, a Figura 4.4.2.7 apresenta para PBT/ P(E-Co-MAco-GMA)/BraPraep e a Figura 4.4.2.8 apresenta para PBT/ P(E-co-MA-coGMA)/BraTdc, todos na composição (79/17/4), obtidas por SEM.

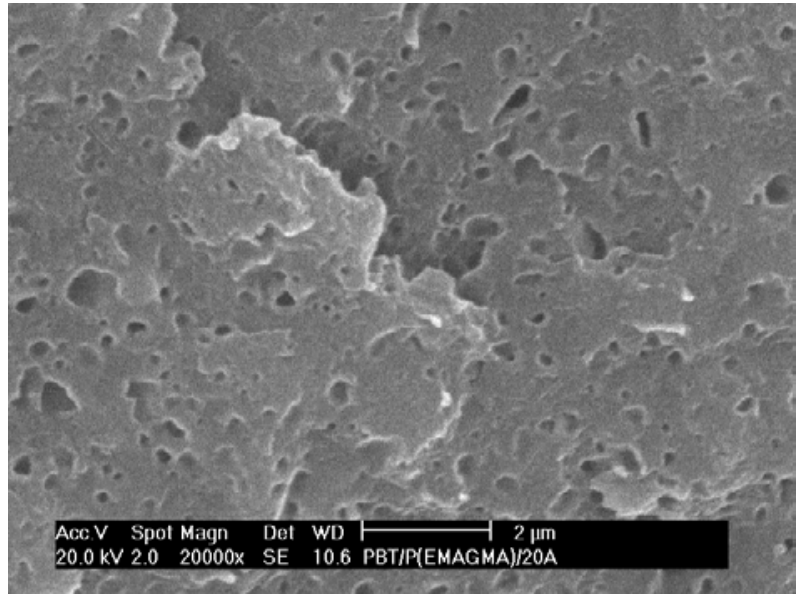

Figura 4.4.2.6 - PBT/ P(E-co-MA-co-GMA)/20A

$(79 / 17 / 4)$

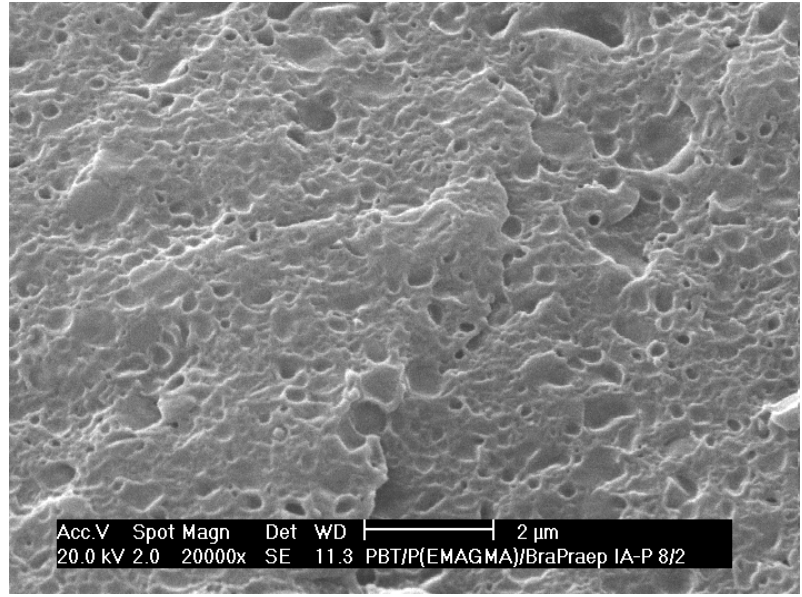

Figura 4.4.2.7 - PBT/ P(E-CO-MA-COGMA)/BraPraep (79/17/4)

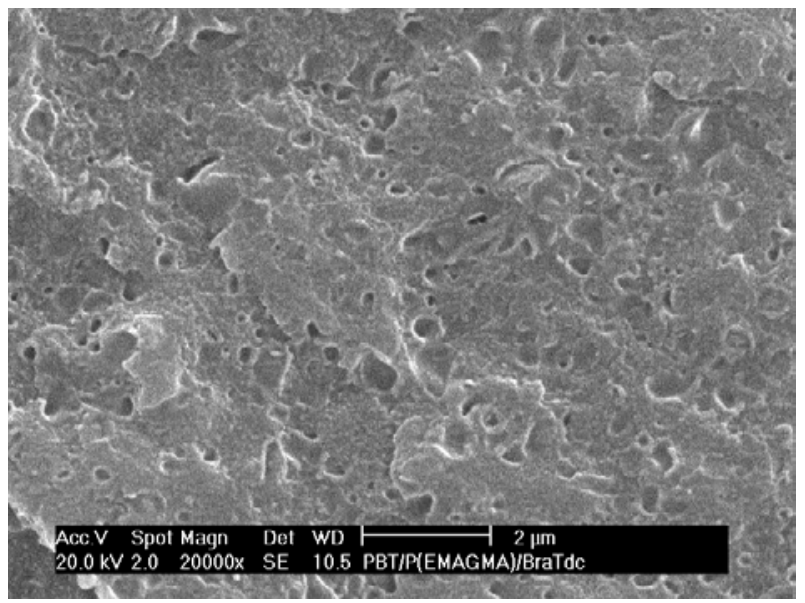

Figura 4.4.2.8 - PBT/ P(E-co-MA-co-GMA)/BraTdc (79/17/4) 
Pode ser visto que a distância entre partículas nos casos de 20A e BraTdc foram maiores do que no caso BraPraep. A quantificação do diâmetro médio destas partículas foi impossibilitada uma vez que nem todas as gotas estavam na forma esférica. Como dito anteriormente, os mecanismos de tenacificação dependem desta distância. No caso BraPraep os mecanismos de tenacificação podem ter sido favorecidos, uma vez que a morfologia está mais homogênea e a distância entre partículas se aproxima bem do valor dos diâmetros das gotas, o que favorece ao campo de tensões de escoamento.

A Figura 4.4.2.9 mostra as curvas de tensão versus deformação para PBT, PBT/P(E-co-MA-co-GMA), PBT/P(E-co-MA-co-GMA)/20A e PBT/P(E-co-MA-coGMA)/BraPraep, PBT/P(E-co-MA-co-GMA)/BraTdc em comparação com os respectivos materiais sem a presença de $\mathrm{P}(\mathrm{E}-\mathrm{co}-\mathrm{MA}-\mathrm{Co}-\mathrm{GMA})$, seguida da Figura 4.4.2.10 que mostra módulo de elasticidade, resistência a tração, alongamento e resistência ao impacto (sem entalhe).

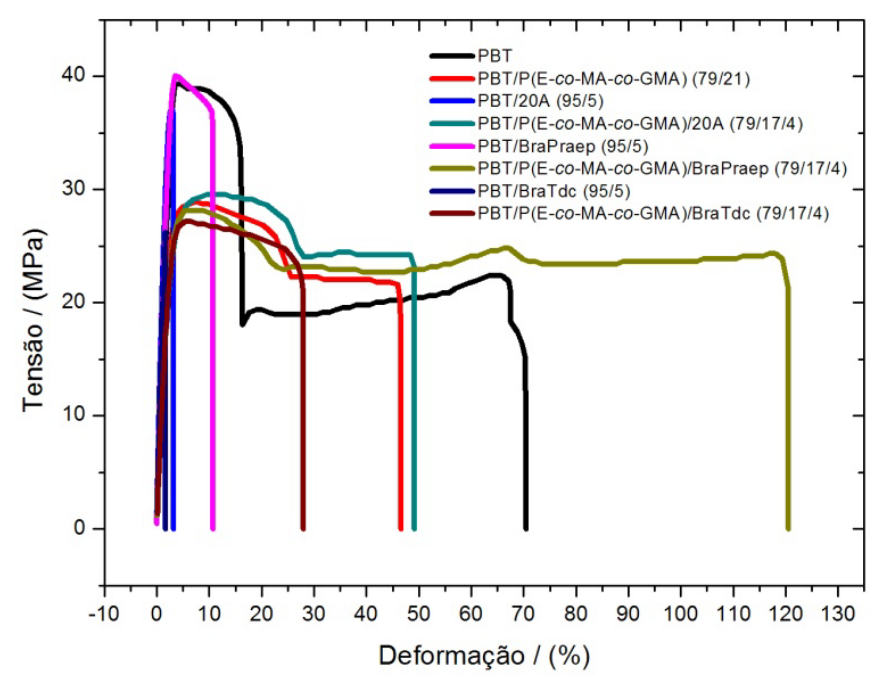

Figura 4.4.2.9 - Tensão x Deformação para o PBT, PBT/20A e PBT/BraPraep, PBT/BraTdc com e sem adição de $P(E-c o-M A-c o-G M A)$ 

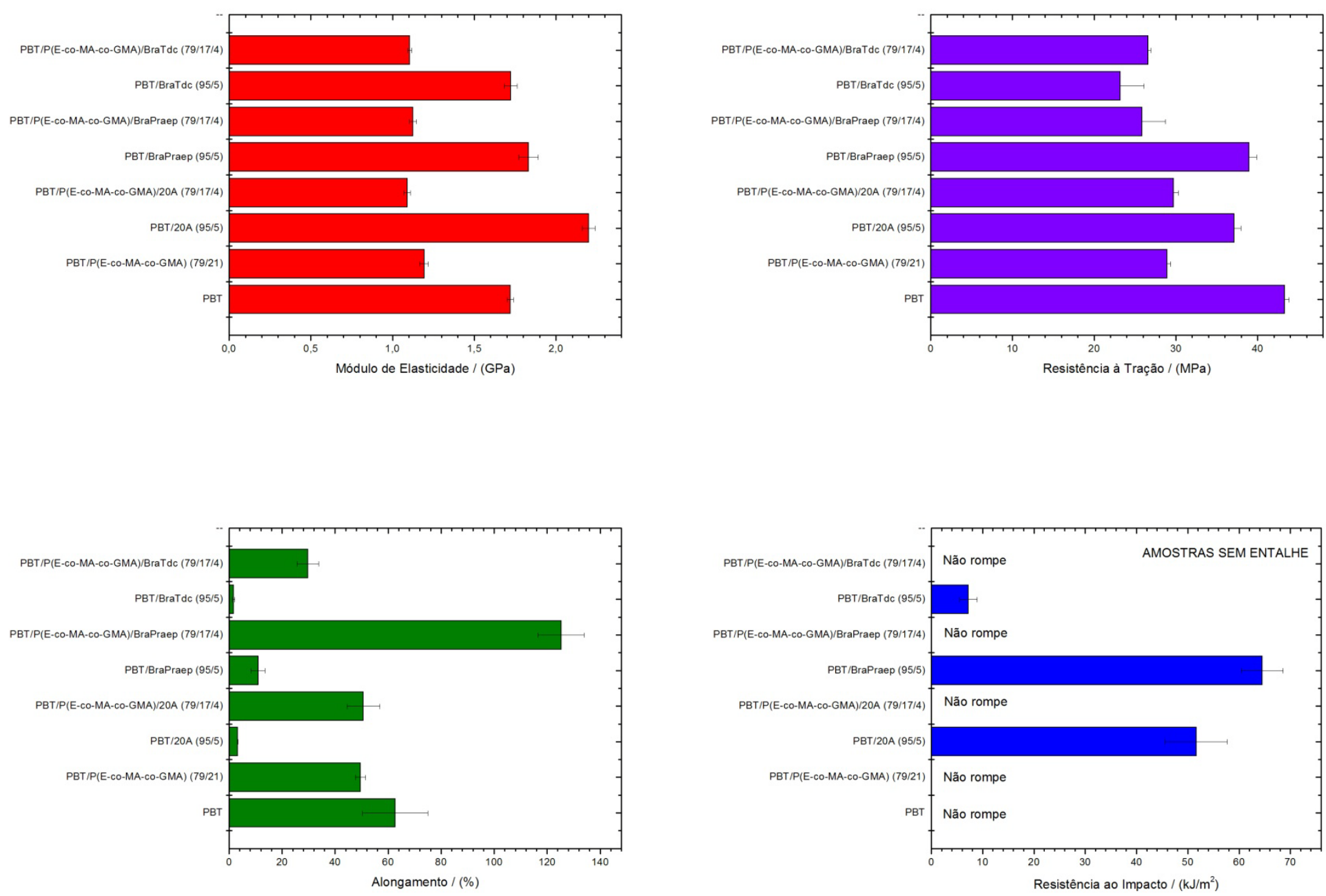

Figura 4.4.2.10 - Módulo de Elasticidade, resistência à tração, alongamento e resistência ao impacto para PBT, PBT/20A e PBT/BraPraep, PBT/BraTdc com e sem adição de $\mathrm{P}(\mathrm{E}-\mathrm{co}-\mathrm{MA}-\mathrm{Co}-\mathrm{GMA})$ 
Pode ser observado que a presença do tenacificante, em relação ao PBT:

$\checkmark$ diminuiu o módulo de elasticidade;

$\checkmark$ aumentou a resistência ao impacto;

$\checkmark$ diminuiu a resistência a tração;

$\checkmark$ aumentou o alongamento, sendo maior que o PBT puro, no caso da adição de Praep

A Figura 4.4.2.11 apresenta a perda de massa em função da temperatura e o gráfico em detalhe mostra estes picos de temperatura. A Tabela 4.4.2.1 apresenta os valores de temperatura, para perdas em massa de 5 e $50 \%$, os picos de temperatura e a massa residual em $850^{\circ} \mathrm{C}$.

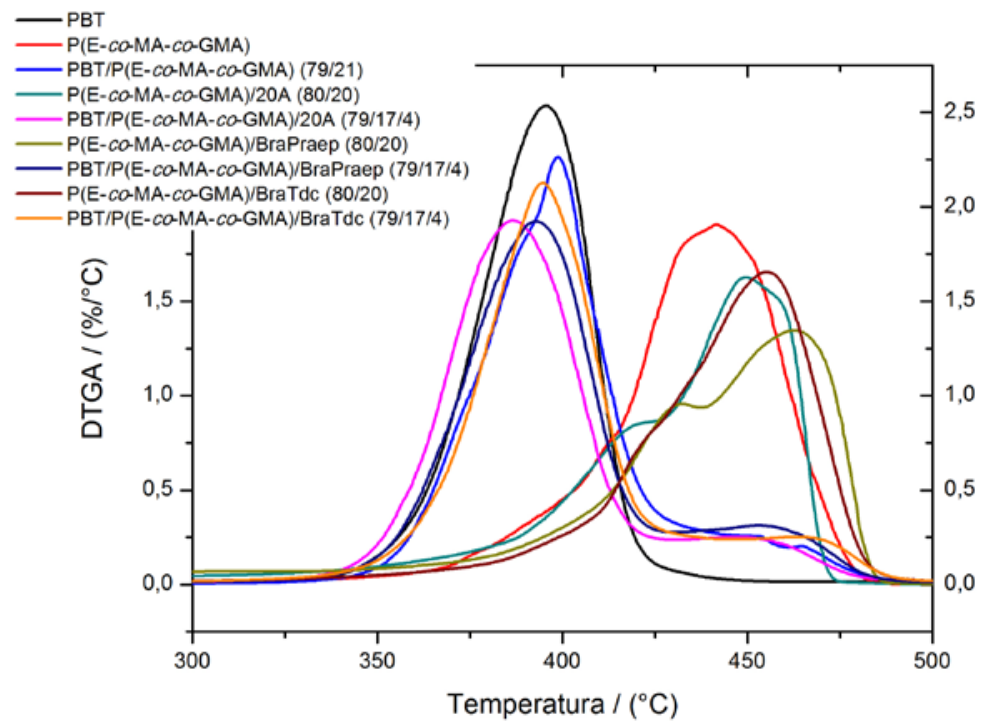

Figura 4.4.2.11 - DTGA em função da temperatura para PBT, PBT/P(E-co-MA-co-GMA) e PBT/P(E-co-MAco-GMA) com 20A, BraPraep e BraTdc 
Tabela 4.4.2.1 - Análise térmica para PBT, PBT/P(E-co-MA-co-GMA) e PBT/P(E-co-MA-co-GMA) com 20A, BraPraep e BraTdc

\begin{tabular}{|c|c|c|c|c|c|}
\hline \multirow{2}{*}{ Material } & \multicolumn{2}{|c|}{ Perda de } & \multirow{2}{*}{ Pico1 } & \multirow{2}{*}{ Pico2 } & \multirow{2}{*}{$\begin{array}{c}\text { Resíduo a } \\
850^{\circ} \mathrm{C} \\
(\%)\end{array}$} \\
\hline & $5 \%$ & $50 \%$ & & & \\
\hline PBT & 361 & 393 & 396 & - & 0,0 \\
\hline$P(E-c o-M A-c o-G M A)$ & 383 & 437 & - & 442 & 0,0 \\
\hline PBT/P(E-co-MA-co-GMA) & 364 & 398 & 399 & 464 & 1,9 \\
\hline $\mathrm{P}(\mathrm{E}-\mathrm{co}-\mathrm{MA}-\mathrm{co}-\mathrm{GMA}) / 20 \mathrm{~A}(80 / 20)$ & 351 & 445 & $\sim 415$ & 450 & 11,3 \\
\hline PBT/P(E-co-MA-co-GMA)/20A (79/17/4) & 356 & 390 & 387 & 446 & 3,3 \\
\hline P(E-co-MA-co-GMA)/BraPraep (80/20) & 311 & 448 & 432 & 462 & 11,1 \\
\hline PBT/P(E-co-MA-co-GMA)/BraPraep (79/17/4) & 359 & 395 & 393 & 453 & 4,1 \\
\hline $\mathrm{P}(\mathrm{E}-\mathrm{co}-\mathrm{MA}$-co-GMA)/BraTdc $(80 / 20)$ & 375 & 450 & $\sim 415$ & 450 & 12,8 \\
\hline PBT/P(E-co-MA-co-GMA)/BraTdc (79/17/4) & 361 & 398 & 395 & 465 & 3,0 \\
\hline
\end{tabular}

Pode ser observado que as misturas de P(E-co-MA-co-GMA) com OMMT apresentam dois picos. O primeiro pico (Pico1) é menor do que o pico do $\mathrm{P}$ (E-coMA-co-GMA) puro e o segundo pico (Pico2) é maior do que o pico do $\mathrm{P}(\mathrm{E}-\mathrm{Co}-\mathrm{MA}$ co-GMA). Além disso, o Pico2 tem maior intensidade do que o Pico1. Isto indica que este $\mathrm{P}(\mathrm{E}-\mathrm{co}-\mathrm{MA}$-co-GMA) esta intercalado entre as lamelas de OMMT, uma vez que foi dificultado a sua decomposição durante os ensaios de TGA. O PBT puro apresenta apenas um pico de temperatura. Após a adição de P(E-co-MA-co-GMA) IOMMT ao PBT, a mistura final apresenta dois picos, sendo o segundo pico relativo ao $\mathrm{P}$ (E-co-MA-co-GMA). Maiores valores de temperatura foram obtidos na presença de Tdc, em função da alta estabilidade térmica deste sal quaternário.

Durante os ensaios de flamabilidade foram observados três comportamentos diferentes. Eles são esquematizados na Tabela 4.4.2.2. 
Tabela 4.4.2.2 - Classificação de flamabilidade observada para PBT/P(E-co-MA-co-GMA)/OMMT

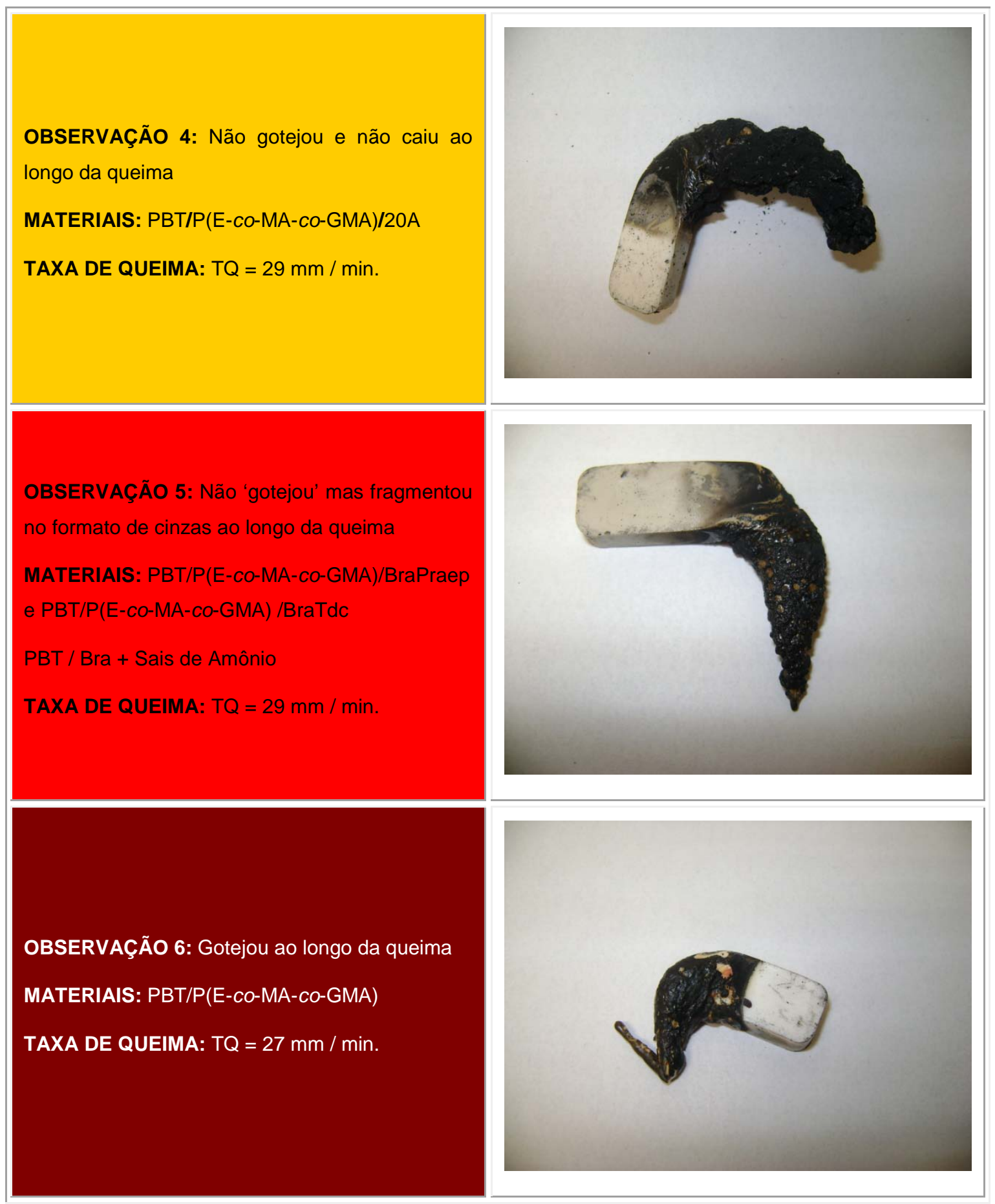


Pode ser observado que os aspectos das queimas foram os mesmos do que aqueles sem a presença de $\mathrm{P}($ E-co-MA-co-GMA). Embora a adição do agente tenacificante tenha contribuído para melhores propriedades mecânicas, a sua presença não afetou as propriedades térmicas, independente do sal quaternário utilizado. Assim, o estudo foi mantido com BraPraep, variando a composição das fases das misturas e nanocompósitos, como descrito a seguir.

\subsubsection{Variação da Composição da Mistura Polimérica PBTI (P(E-co-MA-co-GMA)/BraPraep)}

A Figura 4.4.3.1 apresenta a morfologia obtida, após fratura criogênica para e PBT/ P(E-Co-MA-Co-GMA)/BraPraep (79/17/4), a Figura 4.4.3.2 apresenta para PBT/ $\mathrm{P}(\mathrm{E}-\mathrm{co}-\mathrm{MA}$-co-GMA)/BraPraep (91/7/2) e Figura 4.4.3.3 apresenta para PBT/ $\mathrm{P}(\mathrm{E}-$ co-MA-co-GMA)/BraPraep $(97 / 2,4 / 0,6)$, obtidas por SEM.

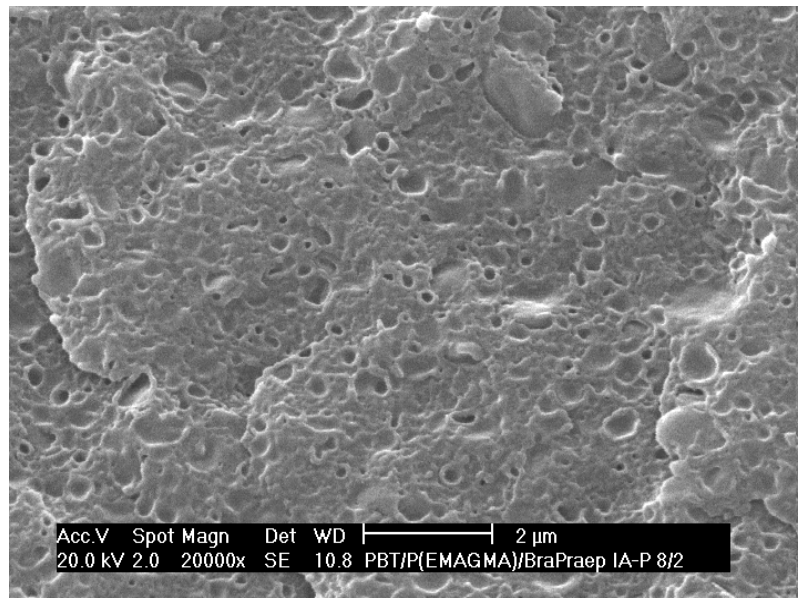

Figura 4.4.3.1 - PBT/ P(E-co-MA-coGMA)/BraPraep (79/17/4)

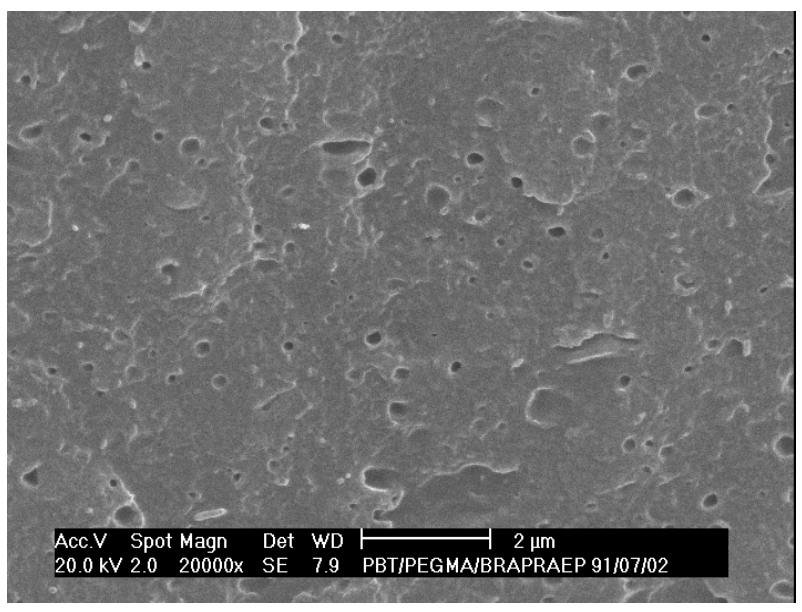

Figura 4.4.3.2 - PBT/ P(E-CO-MA-COGMA)/BraPraep (91/7/2) 


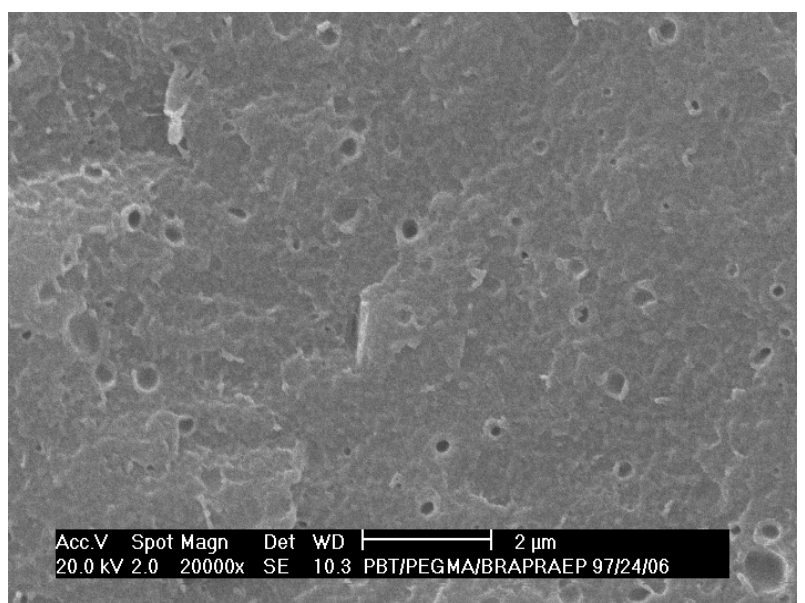

Figura 4.4.3.3 - PBT/ P(E-co-MA-co-GMA)/BraPraep $(97 / 2,4 / 0,6)$

Pode ser observado que a quantidade de gotas da fase dispersa nestas foi proporcional à quantidade adicionada. Dessa forma, a distância entre partículas aumentou à medida que a quantidade de $\mathrm{P}(\mathrm{E}-\mathrm{co}-\mathrm{MA}-\mathrm{Co}-\mathrm{GMA})$ diminui. A distância muito grande entre as partículas do tenacificante não favorece aos mecanismos de tenacificação. Por outro lado, teores de P(E-co-MA-co-GMA) maiores do que aqueles da composição (79/17/4) não foram obtidos uma vez que aumentando o teor de $\mathrm{P}(\mathrm{E}-\mathrm{co}-\mathrm{MA}-\mathrm{co}-\mathrm{GMA})$, o número de reações de reticulação e a viscosidade da fase dispersa também aumentam, dificultando a quebra em 'gotas' menores e, conseqüentemente, o processamento da mistura que se tornou impossível.

A Figura 4.4.3.4 mostra as curvas de tensão versus deformação para PBT/P(Eco-MA-co-GMA)/BraPraep (79/21/0), (79/17/4), (91/7/2) e $(97 / 2,4 / 0,6)$, seguida da Figura 4.4.3.5 que mostra módulo de elasticidade, resistência a tração, alongamento e resistência ao impacto (com entalhe). 


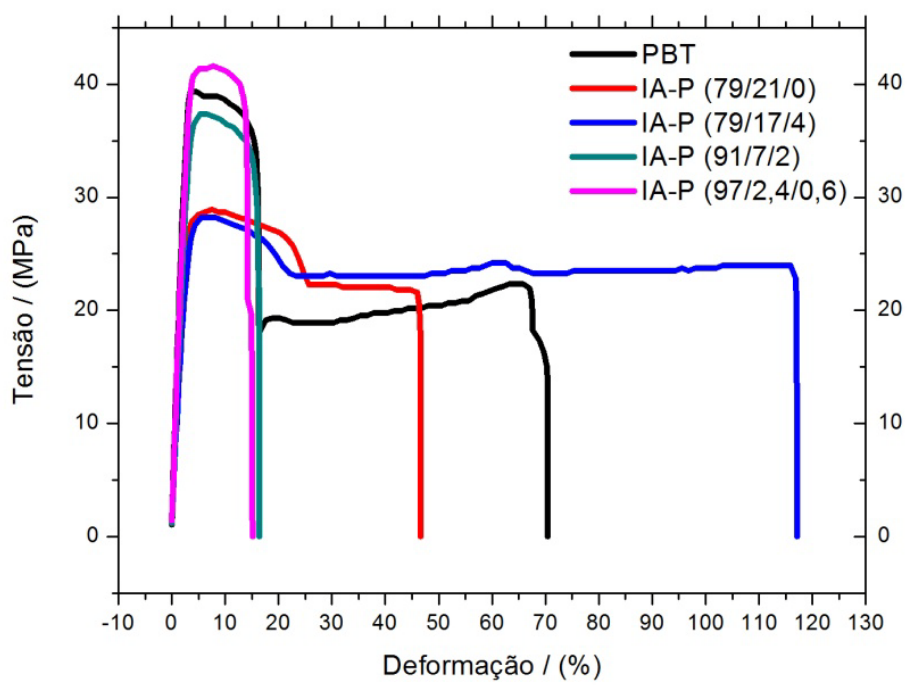

Figura 4.4.3.4 - Tensão x Deformação para PBT e PBT/P(E-co-MA-co-GMA)/BraPraep (79/21/0), (79/17/4), (91/7/2) e $(97 / 2,4 / 0,6)$ 

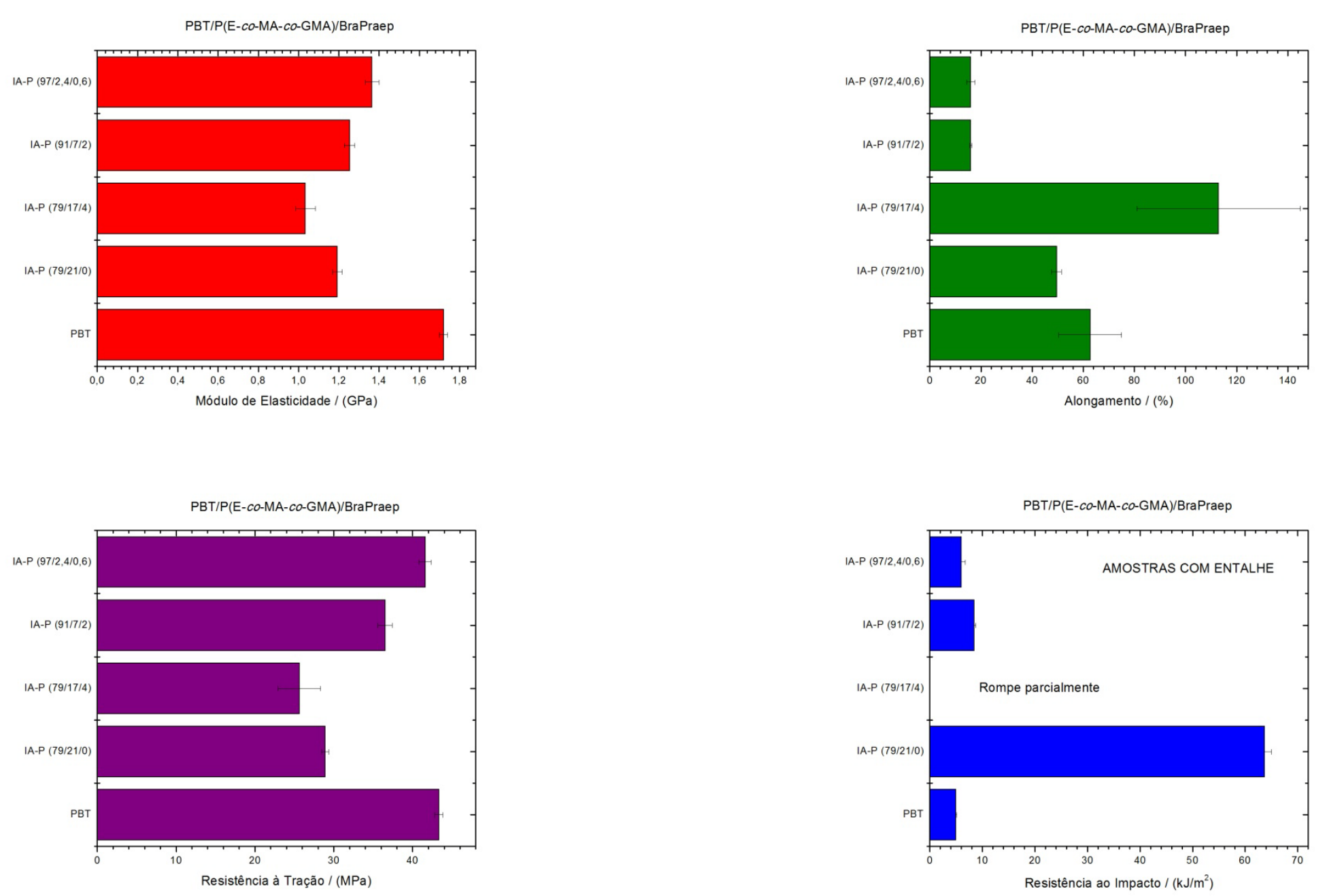

Figura 4.4.3.5 - Módulo de Elasticidade, resistência à tração, alongamento e resistência a tração para PBT e PBT/P(E-co-MA-co-GMA)/BraPraep (79/21/0), (79/17/4), (91/7/2) e $(97 / 2,4 / 0,6)$ 
Pode ser visto que a quantidade de P(E-co-MA-Co-GMA) foi determinante nas propriedades mecânicas. Embora os resultados de resistência a tração e módulo de elasticidade tenham sido menores em função da grande quantidade de P(E-co-MAco-GMA), o alongamento e resistência ao impacto foram maiores na composição (79/17/4) em relação às demais composições. As composições (91/7/2) e $(97 / 2,4 / 0,6)$ apresentaram a mesma tendência do PBT puro, mas perderam em tenacidade. Isso se deve ao fato de que os mecanismos de tenacificação foram prejudicados nestas composições como visto pelas morfologias. Um quadro mais completo de comparação teria sido obtido com maiores concentrações de $\mathrm{P}(\mathrm{E}-\mathrm{co}$ MA-co-GMA). Porém, o processamento de PBT com P(E-co-MA-co-GMA) se torna dificultado à medida que se aumenta a quantidade de P(E-Co-MA-co-GMA), em função da alta viscosidade do tenacificante e da grande reatividade entre esses materiais. Dessa forma, a composição (79/17/4) de P(E-co-MA-co-GMA)/BraPraep foi estabelecida como composição limite. 


\section{Considerações Gerais}

\subsection{Argilas Organofílicas}

$\checkmark$ O processo de lavagem, após a troca catiônica, não foi eficiente na eliminação do sal em excesso.

$\checkmark$ Sais quaternários sem cadeias alquil não proporcionam bom aumento no espaçamento basal, ainda que sejam volumosos.

$\checkmark$ O grande espaçamento basal obtido para BraPraep mostra que além do tamanho, a quantidade de cadeias alquílicas também foi importante para o aumento do espaçamento basal.

$\checkmark$ Com relação à estabilidade térmica, os sais quaternários de amônio apresentam menores temperaturas de decomposição de que os sais quaternário de fosfônio.

$\checkmark \mathrm{Na}$ temperatura de processamento da maioria dos polímeros, em torno de $200^{\circ} \mathrm{C}$, os sais quaternários de amônio já apresentam uma significante perda de massa, o que não é observado para os sais de fosfônio.

\subsection{PBT/OMMT sem agente tenacificante}

$\checkmark$ Após a adição ao PBT, o espaçamento não sofreu grandes alterações, indicando que o processo de troca é quase auto-suficiente no aumento do espaçamento basal e que o polímero apenas ocupa este espaço aumentado após a troca catiônica. Entretanto, um aumento expressivo foi obtido após a adição de 30B, o que é justificado pela grande afinidade entre os grupos funcionais do PBT e as hidroxilas da 30B.

$\checkmark$ O excesso de sal quaternário, que não foi eliminado durante a lavagem, proporcionou a liberação de voláteis, diminuindo a temperatura de decomposição em relação ao polímero puro.

$\checkmark$ As propriedades mecânicas não foram aprimoradas após a adição de argila organofílica, principalmente a tenacidade. Muito se deve ao tamanho de partículas e dispersão das mesmas.

$\checkmark$ Por outro lado, o gotejamento durante ensaios de flamabilidade foi eliminado, favorecendo a um tempo maior de queima e, em alguns casos, a extinção da 
chama.

\subsection{PBT/OMMT com agente tenacificante}

$\checkmark$ A adição do agente tenacificante recuperou as propriedades mecânicas. A reatividade entre os grupos funcionais do PBT e P(E-Co-MA-Co-GMA) torna esta mistura compatível.

$\checkmark$ As melhores propriedades mecânicas foram obtidas com grande quantidade de tenacificante. Entretanto, o excesso de compatibilizante não favorece ao processamento em função da alta viscosidade de $P(E-c o-M A-c o-G M A)$ na temperatura de processamento do PBT.

$\checkmark$ As propriedades de flamabilidade foram mantidas, independente do sal quaternário utilizado. 


\section{Conclusões}

O objetivo deste trabalho foi a obtenção de nanocompósitos de PBT com argila brasileira modificada organicamente com sais quaternários de fosfônio e amônio com aprimoradas propriedades antichama, conservando as propriedades mecânicas.

Dentro das condições utilizadas nesta pesquisa, este objetivo foi alcançado, porém, com algumas observações:

$\checkmark$ Se o objetivo de aplicação do PBT é propriedade mecânica, a adição de argila organofílica não é indicada.

$\checkmark$ Se o objetivo de aplicação do PBT é propriedade antichama, apenas a adição de sal quaternário de fosfônio é indicada (sem argila).

$\checkmark$ Se o objetivo de aplicação do PBT é propriedade mecânica e antichama, a adição de argila organofílica é indicada, entretanto, na presença de agente tenacificante. 
Freitas, C. A.

\section{Contribuições ao Conhecimento}

A partir das condições utilizadas nesta pesquisa, os resultados obtidos mostraram que a adição de nanopartículas em materiais de alto desempenho, como é o PBT, pode ser aplicada mas depende da propriedade a qual se deseja melhorar. Neste estudo, as propriedades antichama foram aprimoradas após a adição de nanopartículas, mas as propriedades mecânicas foram afetadas, principalmente quanto à tenacidade do PBT. As propriedades mecânicas e antichama apenas foram mantidas na presença de um agente tenacificante. 


\section{Sugestões de Trabalhos Futuros}

Diante do que foi estudado neste trabalho, seguem algumas sugestões de pesquisas futuras.

a. Continuação da avaliação da morfologia por microscopia eletrônica de transmissão.

b. Estudo do efeito da concentração de argila na mistura polimérica $P(E-$ co-MA-co-GMA)/BraPraep (80/20).

c. Estudo da cristalinidade do PBT após a adição de argilas organofílicas.

d. Evolução da morfologia durante as etapas de processamento.

e. Estudo das propriedades mecânicas dos nanocompósitos de PBT obtidos em extrusora e/ou misturadores de perfis diferentes.

f. Avaliação da aplicação de nanocompósitos de PBT em peças industriais, as quais requerem resistências térmica e mecânica.

g. Obtenção de fibras poliméricas de nanocompósitos de PBT, para a indústria têxtil. 


\section{REFERÊNCIAS}

Acierno, D.; Amendola, E.; Callegaro, G.; Napolitano, G. "Innovative Poly(Butylene Terephthalate) Based Nanocomposites: a Preliminary Investigation", Macromolecular Symposia, v.247, p.120-128, 2007.

Acierno, D.; Amendola, E.; Callegaro, G.; Napolitano, G. "Poly(Butylene Terephthalate) nanocomposites containing organoclay prepared via intercalation with polymer precursor", TOP2006 Time of Polymers and Composite, Book of Abstracts, 2006.

Acierno, D.; Scarfato, P.; Amendola, E.; Nocerino, G.; Costa, G. "Preparation and Characterization of PBT Nanocomposites compounded with different montmorilonites", Polymer Engineering and Science, v.44, n.6, p.1012-1018, 2004.

Alexandre, M.; Dubois, P. "Polymer-layered silicate nanocomposites: preparation, properties and uses of a new class of materials", Materials Science and Engineering, v.28, p. 1-63, 2000.

Alyamac, E.; Yilmazer, U. "Effect of Impact Modifier on The Properties of Poly (Ethylene Terephthalate) - Organoclay Nanocomposites", Key Engineering Materials, v.334-335, p.649-652, 2007b.

Alyamac, E.; Yilmazer, U. "Reactive Extrusion of Poly(ethylene terephthalate)-(Ethylene/Methyl Acrylate/Glycidyl Methacrylate)-Organoclay Nanocomposites", Polymer Composites, v.28 , p.251-258, 2007a.

Arcus Bresil - Thematic School - Nano - Organic-based nanostructured materials: From synthesis to macroscopic properties, 2009, Annecy, France, 2009.

ArgusLab 4.0.1, Mark A. Thompson, Planaria Software LLC, Seattle, WA, http://www.arguslab.com

Avalos, F.; Ortiz, J. C.; Zitzumbo, R.; Lopez-Machado, M. A.; Verdejo, R.; Arroyo, M. "Effect of montmorillonite intercalant structure on the cure parameters of natural rubber", European Polymer Journal, v.44, p.3108-3115, 2008.

Barhoumi, N.; Jaziri, M.; Massardier, V.; Cassagnau, P. "Valorization of Poly(butylene terephthalate) Wastes by Blending with Virgin Polypropylene: Effect of the Composition and the Compatibilization", Polymer Engineering and Science, v.48, p.1592-1599, 2008.

Bezzan, A. L.: Blendas Tenacificadas de Poliamida 6 e copolímero de Polipropileno, 2006, Dissertação de Mestrado, Universidade São Francisco.

Calderon, J. U.; Lennox, B.; Kamal, M. R. "Thermally stable phosphonium-montmorillonite organoclays", Applied Clay Science, v.40, p.90-98, 2008.

Canevarolo, S. V.; Técnicas de Caracterização de Polímeros, ARTLIBER, São Paulo, v.1, 2003.

Carastan, D. J.: Obtenção e Caracterização Reológica de Nanocompósitos de Polímeros Estirenicos, 2007, Tese de Doutorado, Universidade de São Paulo.

Cárdenas, M. A.; García-Lopez, D.; Gobernado-Mitre, I.; Merino, J. C.; Pastor, J. M.; Martínez, J. D.; Barbeta, J.; Calveras, D. "Mechanical and free retardant properties of EVA/clay/ATH nanocomposites - Effect of particle size and surface treatment of ATH filler", Polymer Degradation and Stability, v.93, p.2032-2037, 2008.

Carvalho, G. B.; Sousa, J. A. "Compatibilização reativa e tenacificação em blendas poliméricas de PET reciclado com elastômeros oleofínicos", Anais do $10^{\circ}$ Congresso Brasileiro de Polímeros, Foz do Iguaçu, Brasil, Outubro de 2009.

Chang, Y. W.; Kim, S.; Kyung, Y. "Poly(butylene terephthalate) - clay nanocomposites prepared by melt intercalation: morphology and thermomechanical properties", Polymer International, v.54, p.348353, 2005.

Chisholm, B. J.; Moore, R. B.; Barber, G.; Khouri, F.; Hempstead, A.; Larsen, M. Olson, E.; Kelley, J.; Balch, G.; Caraher, J. "Nanocomposites Derived from Sulfonated Poly(butylene terephthalate)", Macromolecules, v.35, p.5508-5516, 2002. 
Cho, J. W.; Paul, D. R. "Nylon 6 nanocomposites by melt compounding", Polymer, v.42, p.1083-1094, 2001.

Coelho, C. P. D.: Obtenção e caracterização de nanocompósitos de poliestireno e argilas esmectíticas, 2008, Dissertação de Mestrado, Universidade de São Paulo.

Cui, L.; Khramovb, D. M.; Bielawski, C. W.; Hunter, D. L.; Yoon, P. J.; Paul, D. R. "Effect of organoclay purity and degradation on nanocomposite performance, Part 1: Surfactant degradation", Polymer, v.49, p.3751-3761, 2008.

Delbem, M. F.; Valera, T. S.; Valenzuela-Diaz, F. R.; Demarquette, N. R. "Modification of a brazilian smectite Clay with different quaternary ammonium salts", Química Nova, v.33, p.309-315, 2010.

Fischer, H. "Polymer nanocomposites: from fundamental research to specific applications", Materials Science and Engineering C, v.23, p.763-772, 2003.

Garcia, E. C. "Nanocompósitos: Novas opções em materiais de embalagem", Boletim de Tecnologia e Desenvolvimento de Embalagens, v.15, p.1-6, 2003.

Hale, W.; Keskkuda, H.; Paul, D. R. "Compatibilization of PBT/ABS blends by methyl metacrylateglycidyl methacrylate-ethyl acrylate terpolymers", Polymer, v.40, p.365-377, 1999.

He, H.; Duchet, J.; Galy, J.; Gerard, J. "Influence of cationic surfactant removal on the thermal stability of organoclays", Journal of Colloid and Interface Science, v.295, p.202-208, 2006.

Hedley, C.B.; Yuan, G.; Theng, B.K.G. "Thermal analysis of montmorillonites modified with quaternary phosphonium and ammonium surfactants", Applied Clay Science, v.35, p.180-188, 2007.

Huang, J. "Poly(butylene terephthalate)/Clay Nanocomposite Compatibilized with Poly(ethylene-coglycidylmethacrylate). II. Nonisothermal Crystallization", Journal of Polymer Science: Part B: Polymer Physics, v.46, p.564-576, 2008a.

Huang, J. "Poly(butylene terephthalate)/Clay Nanocomposite Compatibilized with Poly(ethylene-coglycidylmethacrylate). I. Isothermal Crystallization", Journal of Applied Polymer Science, v.110, p.2195-2204, 2008b.

Lakshmi, M. S.; Narmadha, B.; Reddy, B. S. R. "Enhanced thermal stability and structural characteristics of different MMT-Clay/epoxy-nanocomposite materials", Polymer Degradation and Stability, v.93, p.201-213, 2008.

Laoutid, F.; Bonnaud, L.; Alexandre, M.; Lopez-Cuesta, J.M.; Dubois, P. "New prospects in flame retardant polymer materials: From fundamentals to nanocomposites", Materials Science and Engineering Review, v.63, p.100-125, 2009.

Li, X. C.; Kang, T.; Cho, W.; Lee, J.; Ha, S. S. "Preparation and Characterization of Poly(butyleneterephthalate)/Organoclay Nanocomposite", Macromolecular Rapid Communications, v.22, n.16, p.1306-1312, 2001.

Li, X.; Mishra, J. K.; Seul. S.; Kim, I.; Ha, C. "Microstructure and properties of poly(butylene terephthalate) based nanocomposites", Composite Interfaces, v.11, p.335-346, 2004.

Li, X.; Park, W.; Lee, J.; Ha, C. "Effect of Blending Sequence on the Microstructure and Properties of PBT/EVA-g-MAH/Organoclay Ternary Nanocomposites", Polymer Engineering And Science, v.42, p.2156-2164, 2002.

Liao B.; Song, M.; Liang, H; Pang, Y. "Polymer-layered silicate nanocomposites. 1. A study of poly(ethylene oxide)/ $/ \mathrm{Na}^{+}$- montmorillonite nanocomposites as polyelectrolites and polyethyleneblock-poly(ethylene glycol) copolymer/ $/ \mathrm{Na}^{+}$- montmorillonite nanocomposites as fillers for reinforcement of polyethylene", Polymer, v.42, p.10007-10011, 2001.

Lim, S. K.; Kim, J. W.; Chin, I.; Kwon, Y. K.; Choi, H. J. "Preparation and Interaction Characteristics of Organically Modified Montmorillonite Nanocomposite with Miscible Polymer Blend of Poly(Ethylene Oxide) and Poly(Methyl Methacrylate)", Chemistry of Materials, v.14, p.1989-1994, 2002

Lins, P. G.: Obtenção de argilas organofílicas, 2007, Trabalho de Conclusão de Curso, Universidade de São Paulo.

Liu, X.; Wu, Q.; Berglund, L.; Fan, J.; Qi, Z. "Polyamide 6-clay nanocomposite/polypropylene-graftedmaleic anhydride alloys", Polymer, v.42, p.8235-8239, 2001. 
Luo, J.; Daniel, I. M.; "Characterization and modeling of mechanical behavior of polymer/clay nanocomposites", Composites Science and Technology, v.63, p.1607-1616, 2003.

Martin, P.; Devaux, J.; Legras, R.; Leemans, L.; van Gurp, M.; van Duin, M. "Complex ProcessingMorphology Interrelationships During the Reactive Compatibilization of Blends of Poly(butylenes terephthalate) with Epoxide-Containing Rubber", Journal of Applied Polymer Science, v.91, p.703.718, 2004a.

Martin, P.; Devaux, J.; Legras, R.; van Gurp, M.; van Duin, M. "Competitive reactions during compatibilization of blends of polybutyleneterephthalate with epoxide-containing rubber", Polymer, v.42, p.2463-2478, 2001.

Martin, P.; Gallez, C.; Devaux, J.; Legras, R.; Leemans, L.; van Gurp, M.; van Duin, M. "Reactive compatibilization of blends of polybutyleneterephthalate with epoxide-containing rubber. The effect of the concentrations in reactive functions", Polymer, v.44, p.5251-5262, 2003.

Martin, P.; Maquet, C.; Legras, R.; Bailly, C.; Leemans, L.; van Gurp, M.; van Duin, M. "Particle-inparticle morphology in reactively compatibilized poly(butylenes terephthalate)/epoxide-containing rubber blends", Polymer, v.45, p.3277-3284, 2004b.

Martin, P.; Maquet, C.; Legras, R.; Bailly, C.; Leemans, L.; van Gurp, M.; van Duin, M. "Conjugated effects of the compatibilization and dynamic vulcanization on the phase inversion behavior in poly(butylenes terephthalate)/epoxide-containing rubber reactive polymer blends", Polymer, v.45, p.5111-5125, 2004c.

Morgan, A. B.; Wilkie, C. A. "Flame Retardant Polymer Nanocomposites", John Wiley \& Sons, New Jersey, 2007.

Nirukhe, A. B.; Shertukde, V. V. "Preparation and Characterization of Poly(butylenes terephthalate) Nanocomposites with Various Organoclays", Journal of Applied Polymer Science, v.113, p.585-592, 2009.

Patel, H. A.; Somani, R. S.; Bajaj, H. C.; Jasra, R. V. "Preparation and characterization of phosphonium montmorillonite with enhanced thermal stability", Applied Clay Science, v.35, p.194200, 2007.

Patro, T. U.; Khakhar, D. V.; Misra, A. "Phosphonium-Based Layered Silicate-Poly(ethylene terephthalate) Nanocomposites: Stability, Thermal and Mechanical Properties", Journal of Applied Polymer Science, v.113, p.1720-1732, 2009.

Pavlidou, S.; Papaspyrides, C. D. "A review on polymer-layered silicate nanocomposites", Progress in Polymer Science, v.33, p.1119-1198, 2008.

Santos, P. S.; Tecnologia de Argilas, Vol.1 - Fundamentos, Editora Edgar Blucher, São Paulo, v.1, 1975.

Scarfato, P.; Scatteia, L.; Costa, G.; Acierno, D. "Effect of the Organoclay Structure on Morphology and Rheological Response of PBT Nanocomposites", Macromolecular Symposia, v.228, p.125-137, 2005.

Scatteia, L.; Scarfato, P.; Acierno, D. "Processing, rheology and structure of melt compounded PBTclay nanocomposites having different chemical composition" e-Polymers, 023, 2006.

Scatteia, L.; Scarfato, P.; Acierno, D. "Rheology of PBT-layered silicate nanocomposites prepared by melt compounding", Plastics, Rubbers and Composites, v.33, p.85-91, 2004.

Shi, B. L.; Haber, J. A.; Sundararaj, U. "Influence of Clay Surface Modification on Dispersion and Crystallization in PBT/Montmorillonite Composites", PPS2005 - Americas Regional Meeting Proceedings, CD-ROM, 2005.

Silva, R. P.; Mauler, R. S.; Oliveira, V. B.; Salles, C. A. "Avaliação da Morfologia e Propriedades Termo-Mecânicas em Nanocompósitos de PVC", Polímeros: Ciência e Tecnologia, v.20, p.46-50, 2010.

Sinha Ray, S.; Okamoto, M. "Polymer/layered silicate nanocomposite: a review from preparation to processing", Progress in Polymer. Science., v.28, p.1539-1641, 2003.

Sinha Ray, S.; Pouliot, S; Bousmina, M.; Utracki, L. A. "Role of organically modified layered silicate as an active interfacial modifier in immiscible polystyrene/polypropylene blends", Polymer, v.45, p.8403- 
8413, 2004.

Sinha Ray, S.; Yamada, K.; Okamoto, M.; Fujimoto, Y.; Ogami, A.; Ueda, K. "New polylactide silicate nanocomposites. 5. Designing of materials with derired properties", Polymer, v.44, p.6633-6646, 2003a.

Sinha Ray, S; Bandyopadhyay, J.; Bousmina, M. "Effect of Organoclay on the Morphology and Properties of Poly(propylene)/Poly[(butylene succinate)-co-adipate] Blends", Macromolecular Materials and Engineering, v.292, p.729-747, 2007.

Sperling, L. H. "Polymeric Multicomponent Materials - An Introduction", John Wiley \& Sons, New York, 1997.

Stoeffler, K.; Lafleur, P. G.; Denault, J. "Thermal decomposition of various alkyl onium organoclays: Effect on polyethylene terephthalate nanocomposites properties", Polymer Degradation and Stability, v.93, p.1332-1350, 2008.

Sun, Y.; Hu, G.; Lambla, M.; Kotlar, H. K. "In situ compatibilization of polypropylene and poly(butylenes terephthalate) polymer blends by on-step reactive extrusion", Polymer, v.37, p.41194127, 1996.

Tjong, S. C. "Structural and mechanical properties of polymer nanocompósitos", Materials Science and Engineering Review, v.53, p.73-197, 2006.

Turri, S. "Nanocomposite argila-polimero. Nanocomposite: introduzione e caratteristiche generali", Polimerica - il portale delle materie plastiche, prima parte, http://www.polimerica.it/modules.php?name=Content\&pa=showpage\&pid=65, em 17/02/2005a.

Turri, S. "Nanocomposite argila-polimero. Nanocomposite: materiali e proprietà", Polimerica - il portale delle materie plastiche, terza parte, http://www.polimerica.it/modules.php?name=Content\&pa=showpage\&pid=67, em 17/02/2005c.

Turri, S. "Nanocomposite argila-polimero. Nanocomposite: preparazione e caratterizzazione strutturale", Polimerica - il portale delle materie plastiche, seconda parte ,http://www.polimerica.it/modules.php? name=Content\&pa=showpage\&pid=66, em 17/02/2005b.

Utracki, L.A.; Sepehr, M.; Boccaleri, E. "Synthetic, layered nanoparticles for polymeric nanocomposites (PNCs)", Polymers for Advanced Technology, v.18, p.1-37, 2007.

Valenzuela Díaz, F.R.: Preparação, a nível de laboratório, de algumas argilas esmectíticas organofílicas, 1994, Tese de Doutorado, Universidade de São Paulo.

Valera, T. S.: Reaproveitamento de vidros laminados provenientes de rejeitos industriais e pósconsumo, 2005, Tese de Doutorado, Universidade de São Paulo.

Valera, T. S.; Lins, P. G.; Demarquette, N. R.; Santos, A. M.; Chenal J-M, "Organic modification of a brazilian smectite Clay", 14 ICC - International Clay Conference, Castellaneta Marina, Itália, Junho de 2009.

Valera, T. S.; Lins P. G.; dos Santos, A. M.; Chenal J. M.; Demarquette, N. R. "Organic Modification of Brazilian smectite Clay using different methods", em preparação para Applied Clay Science, 2010.

van Duin, M.; van Gurp, M.; Leemans, L.; Walet, M.; Aussems, M.; Martin, P.; Legras, R.; Machado, A. V.; Covas, J. A. "Interfacial Chemistry and Morphology of In-Situ Compatibilized PA-6 and PBT Based Blends", Macromolecular Symposia, v.198, p.135-145, 2003.

Wu, D.; Zhou, C.; Fan, X.; Mao, D.; Bian, Z. "Linear rheological behaviour and thermal stability of poly(butylene terephthalate)/epoxy/clay ternary nanocomposites", Polymer Degradation and Stability, v.87, p.511-519, 2005a.

Wu, D.; Zhou, C.; Hong, Z.; Mao, D.; Bian, Z. "Study on rheological behaviour of poly(butylene terephthalate) / montmorillonite nanocomposites", European Polymer Journal, v.41, p.2199-2207, 2005b.

Wu, D.; Zhou, C.; Yu, W.; Fan, X. "Effect of Flocculated Structure on Rheology of Poly(butylene terephthalate) / Clay Nanocomposites", Journal of Polymer Science, v.43, p.2807-2818, 2005 c.

WU, S. "Phase structure and adhesion in polymer blends: A criterion for rubber toughening", Polymer, v.26, p.1855-1863, 1985. 
Xi, Y.; Frost, R. L., He, H.; Kloprogge, T.; Bostrom, T. "Modification of Wyoming Montmorillonite Surfaces Using a Cationic Surfactant", Langmuir, v.21, p.8675-8680, 2005.

Xi, Y.; Zhou, Q.; Frost, R. L.; He, H. "Thermal stability of octadecyltrimethylammonium bromide modified montmorillonite organoclay", Journal of Colloid and Interface Science, v.311, p.347-353, 2007.

Xiao, J.; Hu, Y.; Kong, Q.; Song, L.; Wang, Z.; Chen, Z.; Fan, W. "Poly(butylene terephthalate) / Clay Nanocomposites directly Prepared from Pristine Montmorillonite (MMT)", Polymer Bulletin, v.54, p.271-278, 2005b.

Xiao, J.; Hu, Y.; Wang, Z.; Tang, Y.; Chen, Z.; Fan, W. "Preparation and characterization of poly(butylene terephthalate) nanocomposites from thermally stable organic-modified montmorillonite", European Polymer Journal, v.41, n.5, p.1030-1035, 2005a.

Xie, W.; Gao, Z.; Pan, W.; Hunter, D.; Singh, A.; Vaia, R. "Thermal Degradation Chemistry of Alkyl Quaternary Ammonium Montmorillonite", Chemistry of Materials, v.13, p.2979-2990, 2001.

Xie, W.; Xie, R.; Pan, W.; Hunter, D.; Koene, B.; Tan, L.; Vaia, R."Thermal Stability of Quaternary Phosphonium Modified Montmorillonites", Chemistry of Materials, v.14, p.4837-4845, 2002.

Yei, D.; Fu, H.; Chang, Y.; Kuo, S.; Huang, J.; Chang, F. "Thermal Properties of Polystyrene Nanocompósitos Formed from Rigid Intercalation Agent-Treated Montmorillonite", Journal of Polymer Science: Part B: Polymer Physics, v.45, p.1781-1787, 2007.

Yow, B. N.; Ishiaku, U. S.; Ishak, A. M.; Karger-Kocsis, J. "Fracture Behavior of Rubber-Modified Injection Molded Poly(Butylene Terephthalate) with and without Short Glass Fiber Reinforcement", Journal of Applied Polymer Science, v.84, p.1233-1244, 2002.

Yu, Z.; Yan, C.; Dasari, A.; Dai, S.; Mai, Y.; Yang, M. "On Toughness and Stiffness of Poly(butylenes terephthalate) with Epoxide-Containing Elastomer by Reactive Extrusion", Macromolecular Materials and Engineering, v.289, p.763-770, 2004.

Zhang, L.; Hong, Y.; Zhang, T.; Chunzhong, Li. "A Novel Approach to Prepare PBT Nanocomposites with Elastomer-Modified $\mathrm{SiO}_{2}$ Particles", Polymer Composites, v.30, p.673-679, 2009. 


\section{APÊNDICE - A}

Neste APÊNDICE são apresentados os resultados anexos de microscopia e propriedades mecânicas avaliados para o método 1 de troca iônica e processamento a 75rpm e 150rpm, apresentados no Capítulo 3.

\section{Microscopia Ótica}

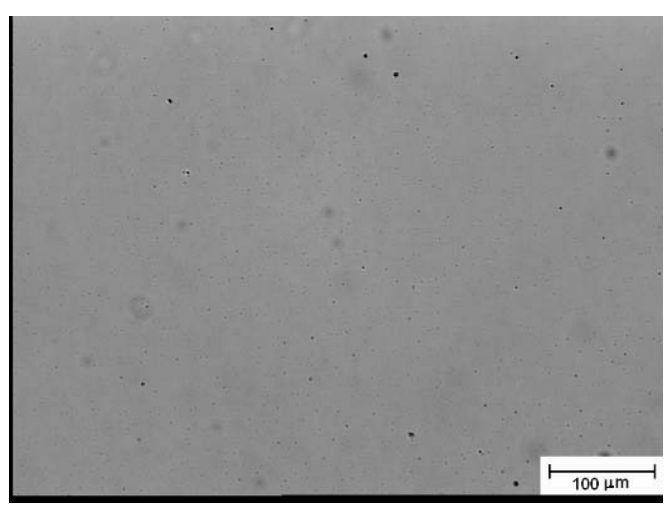

Figura A.1 - PBT 75rpm

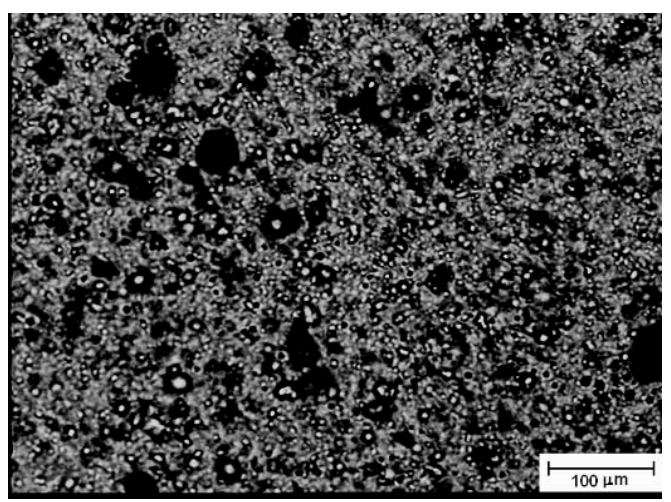

Figura A.3 - PBT / Bra 75rpm

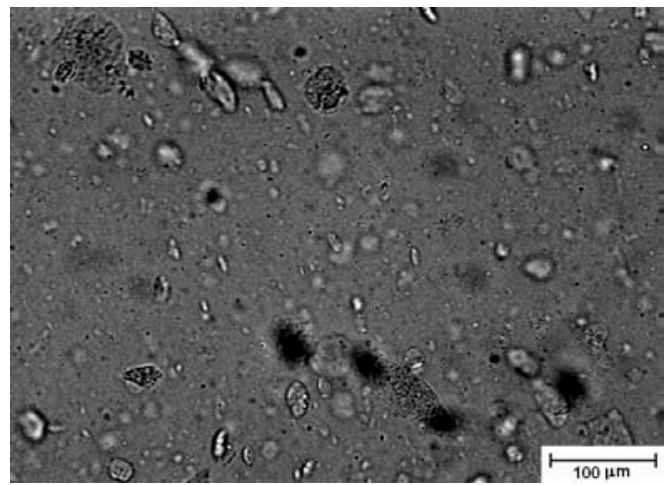

Figura A.5 - PBT / 20A 75rpm

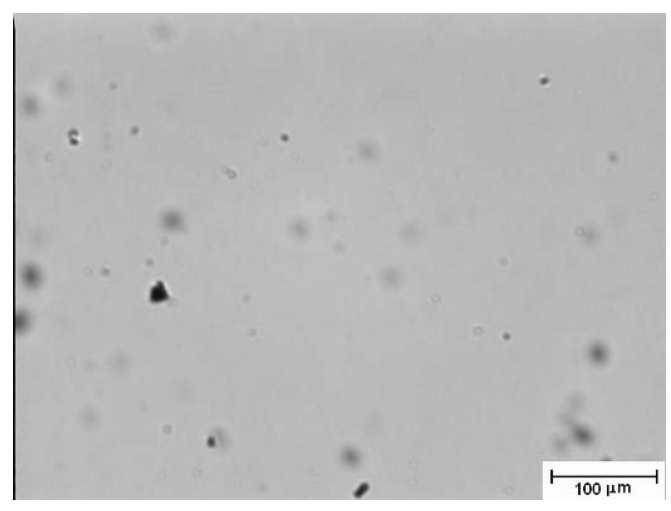

Figura A.2 - PBT 150rpm

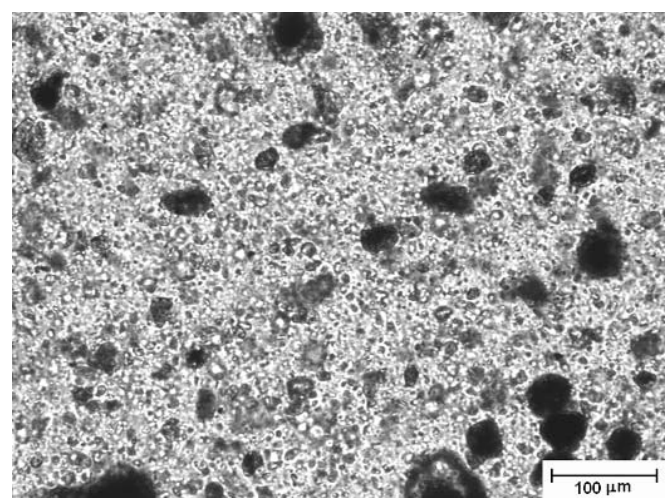

Figura A.4 - PBT / Bra 150rpm

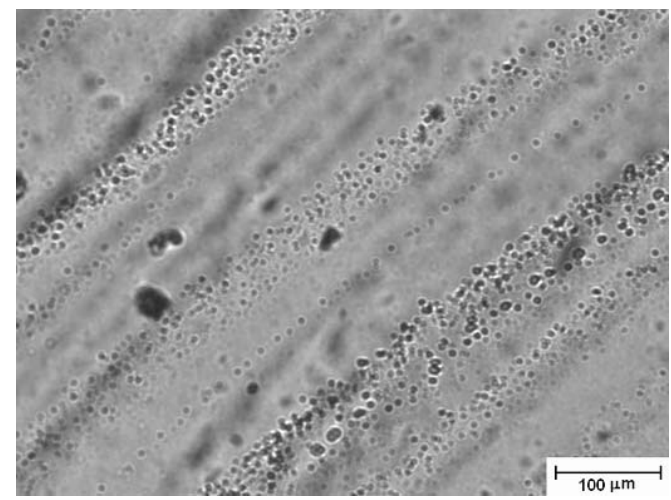

Figura A.6 - PBT / 20A 150rpm 


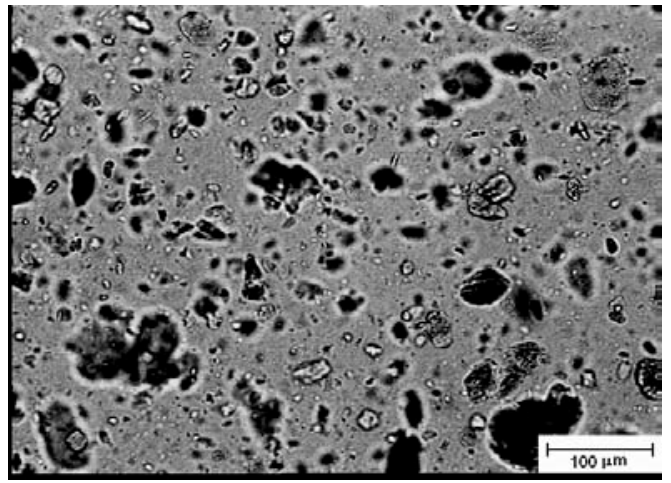

Figura A.7 - PBT / 30B 75rpm

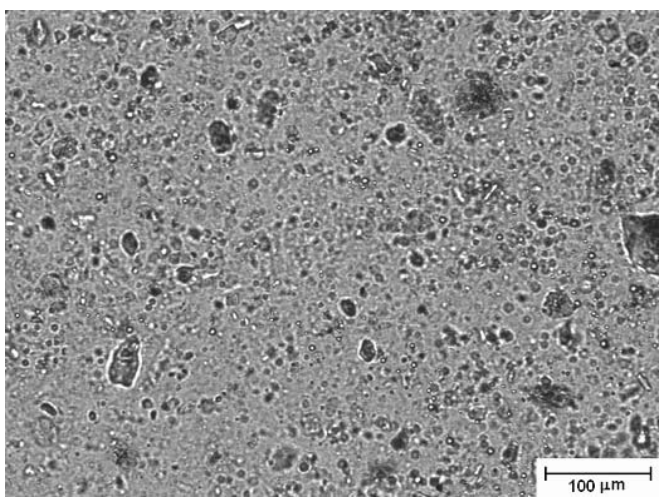

Figura A.9 - PBT / BraCtac 75rpm / met 1

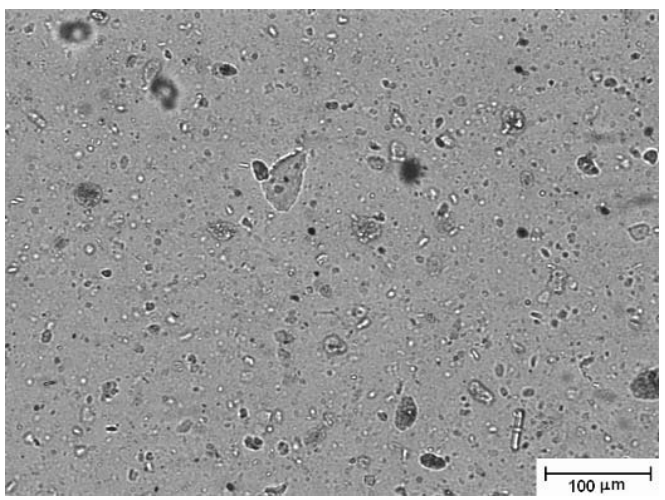

Figura A.11 - PBT / BraCtac 75rpm / met 1 mod

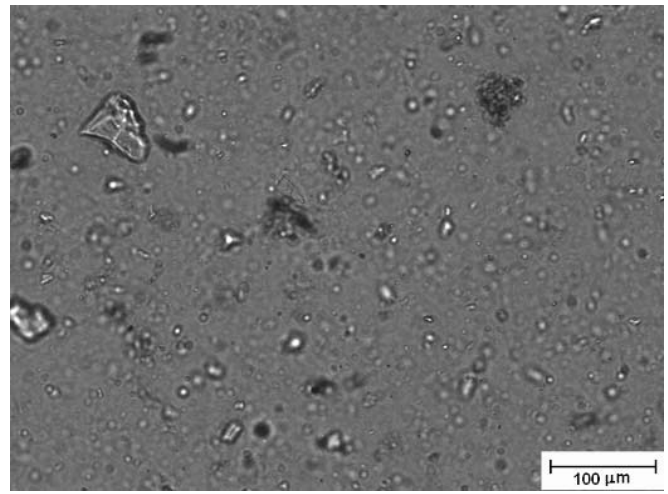

Figura A.13 - PBT / BraPraep 75rpm / met 1

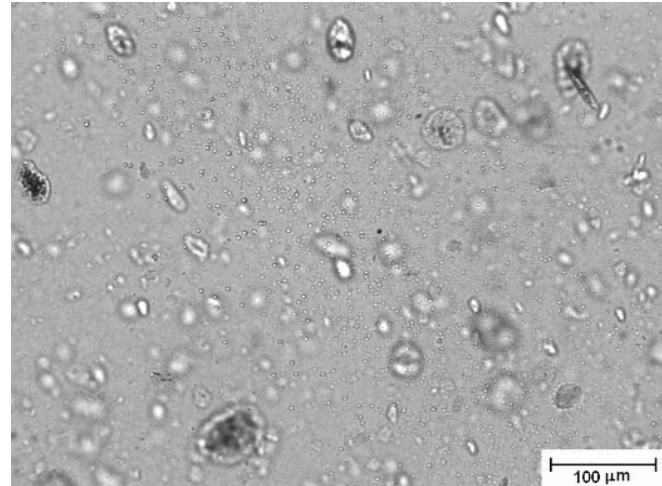

Figura A.8 - PBT / 30B 150rpm

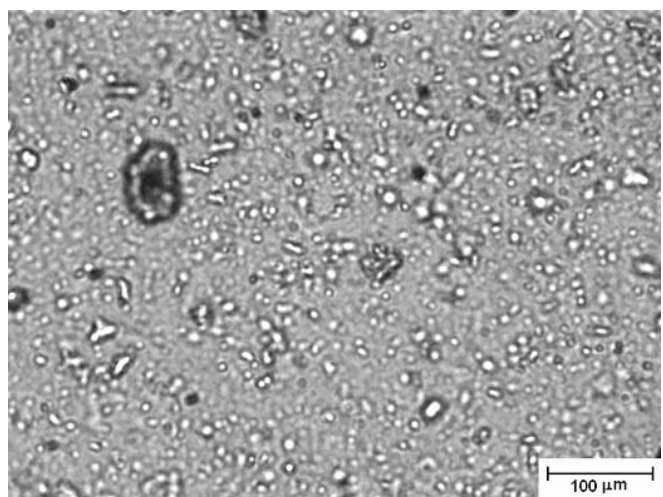

Figura A.10 - PBT / BraCtac 150rpm / met 1

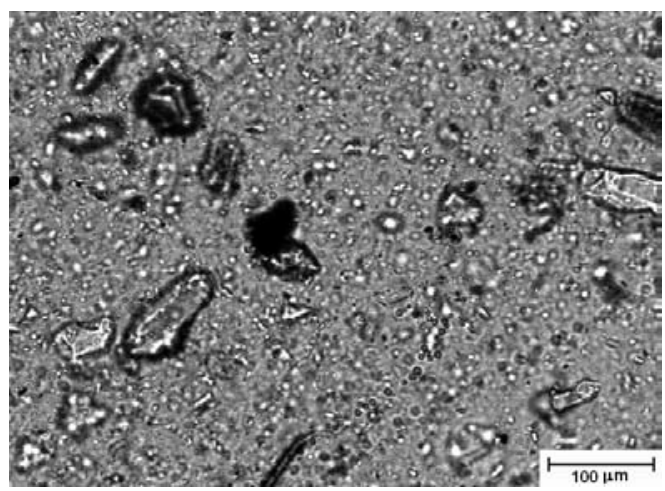

Figura A.12 - PBT / BraCtac 150rpm / met $1 \mathrm{mod}$

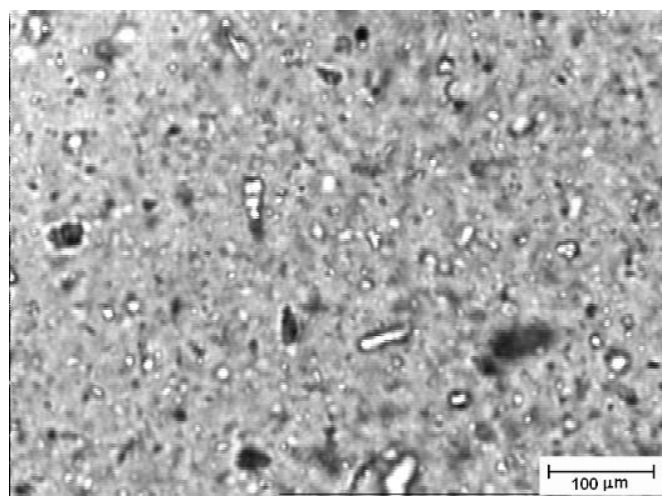

Figura A.14 - PBT / BraPraep 150rpm / met 1 


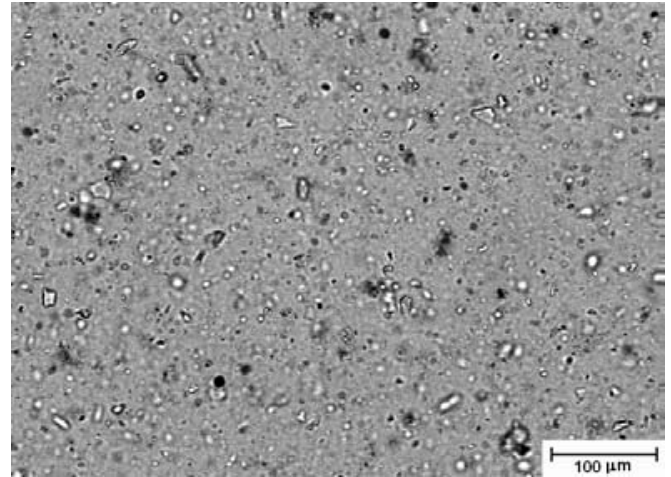

Figura A.15 - PBT / BraPraep 75rpm / met 1 mod

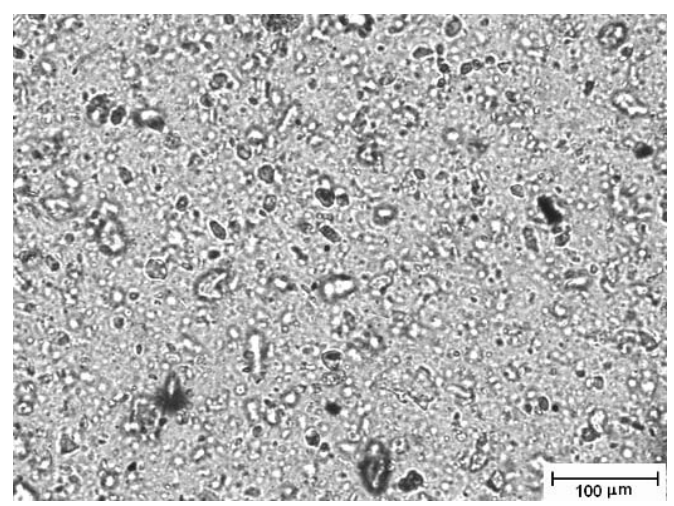

Figura A.17 - PBT / BraDod 75rpm / met 1

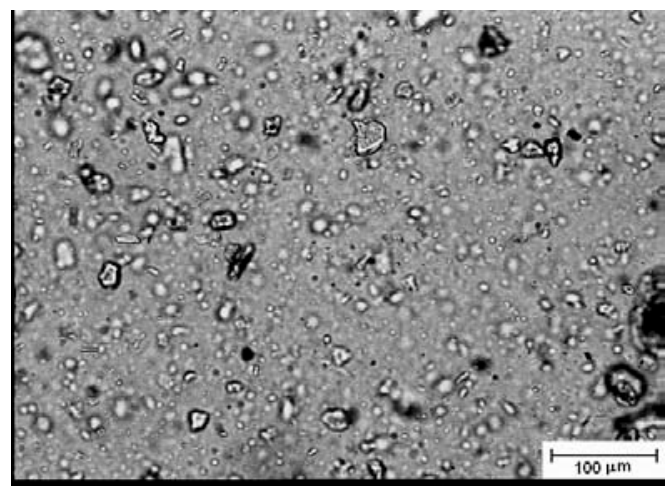

Figura A.19 - PBT / BraDod 75rpm / met 1 mod

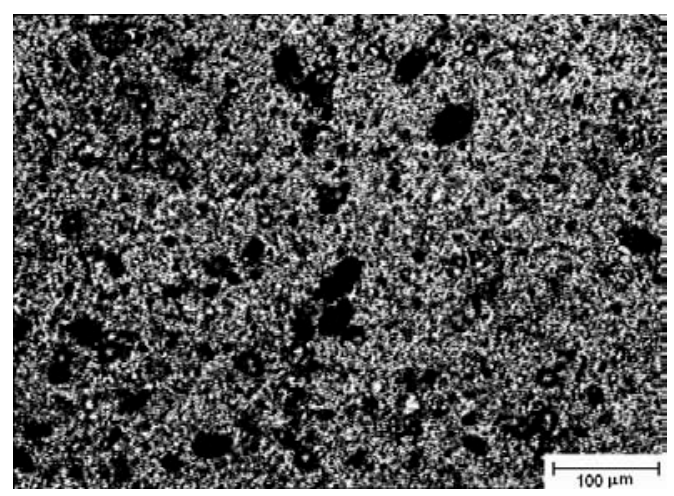

Figura A.21 - PBT / BraBz 75rpm / met 1

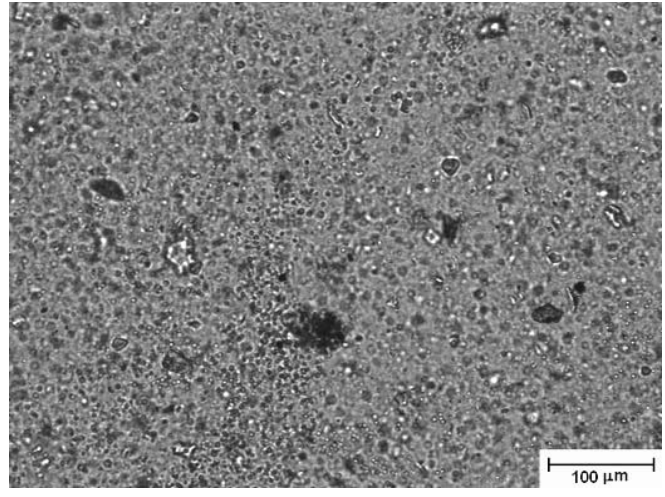

Figura A.16 - PBT / BraPraep 150rpm / met 1 mod

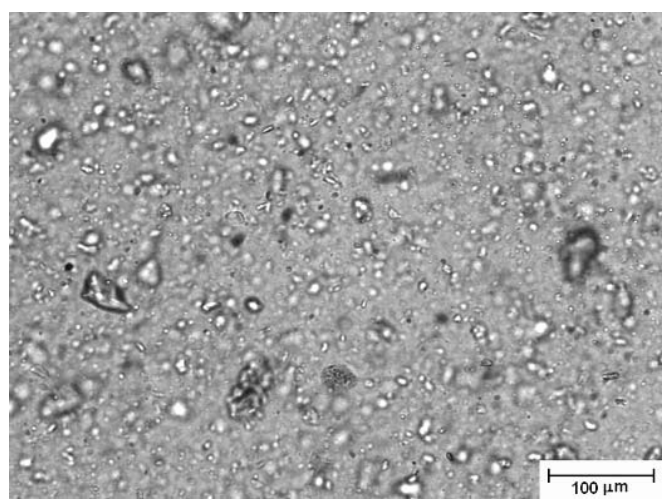

Figura A.18 - PBT / BraDod 150rpm / met 1

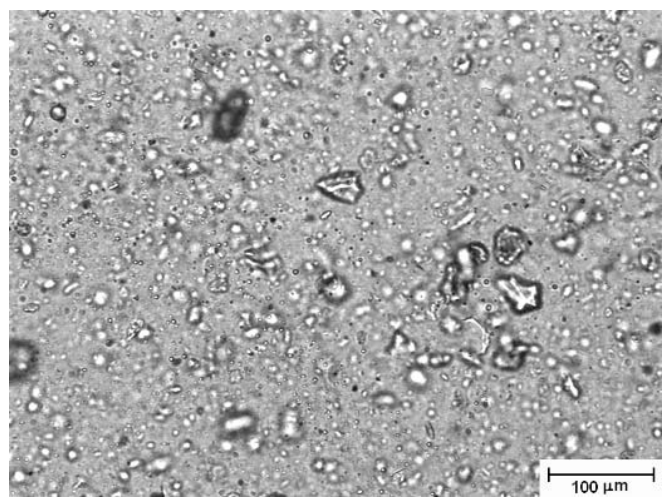

Figura A.20 - PBT / BraDod 150rpm / met 1 mod

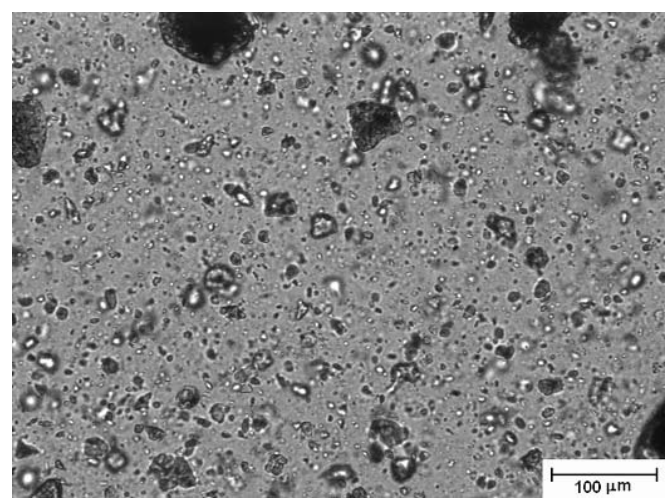

Figura A.22 - PBT / BraBz 150rpm / met 1 


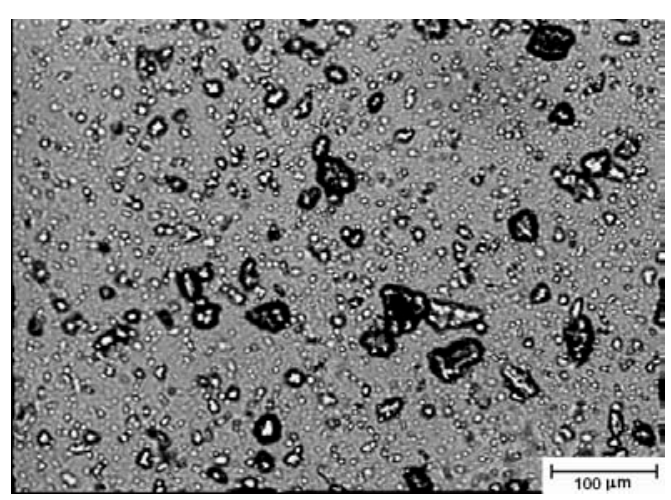

Figura A.23 - PBT / BraBz 75rpm / met 1 mod

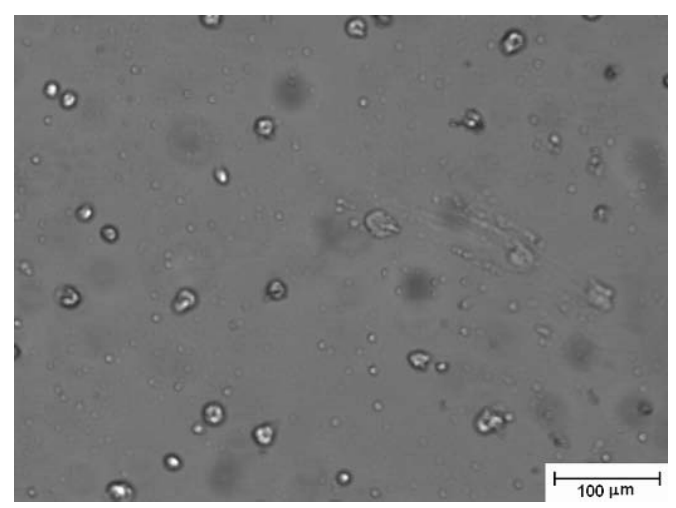

Figura A.25 - PBT / BraTtb / 150rpm / met1

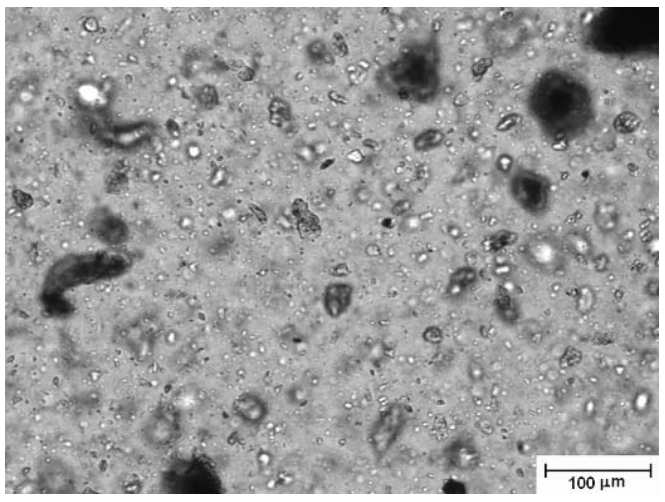

Figura A.27 - PBT / BraTbb / 150rpm / met1

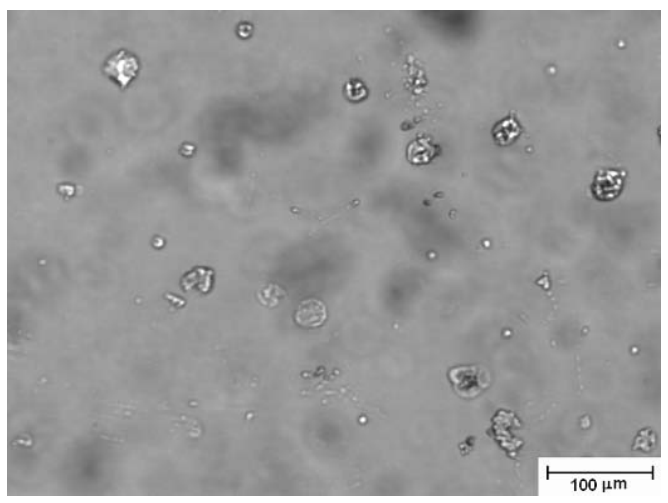

Figura A.29 - PBT / BraTdc / 150rpm / met1

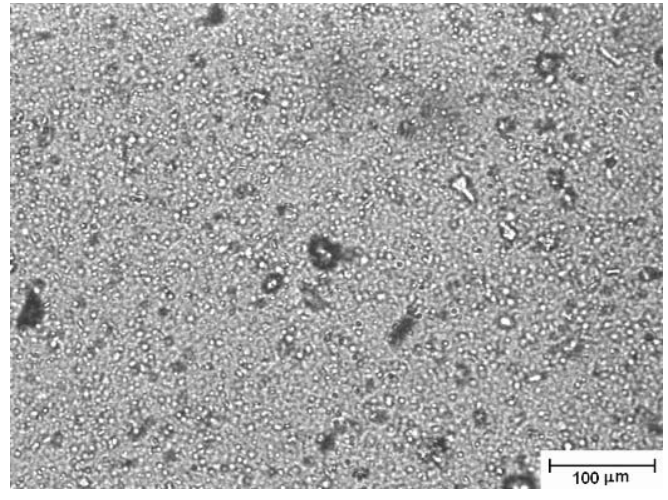

Figura A.24 - PBT / BraBz 150rpm / met 1 mod

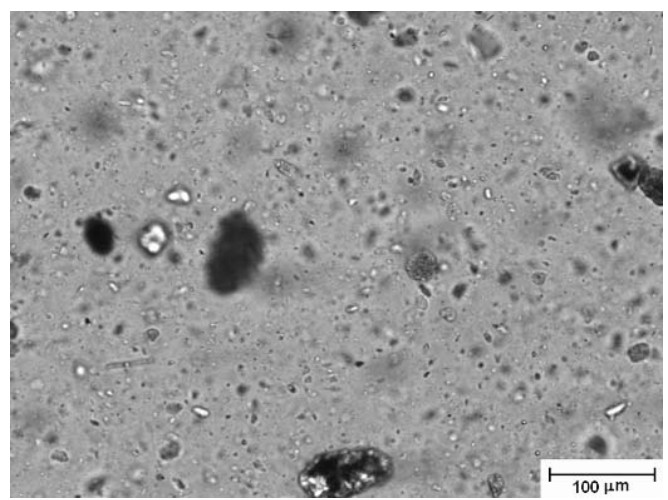

Figura A.26 - PBT / BraTtb / 150rpm / met1mod

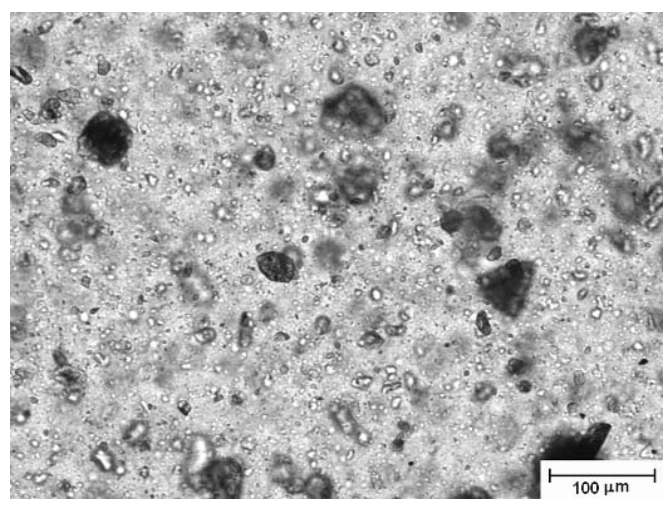

Figura A.28 - PBT / BraTbb / 150rpm / met1mod

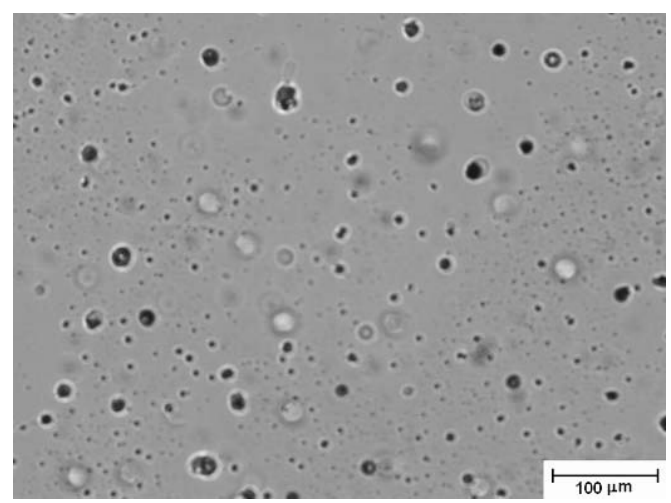

Figura A.30 - PBT / BraTdc / 150rpm / met1mod 


\section{Propriedades Mecânicas}

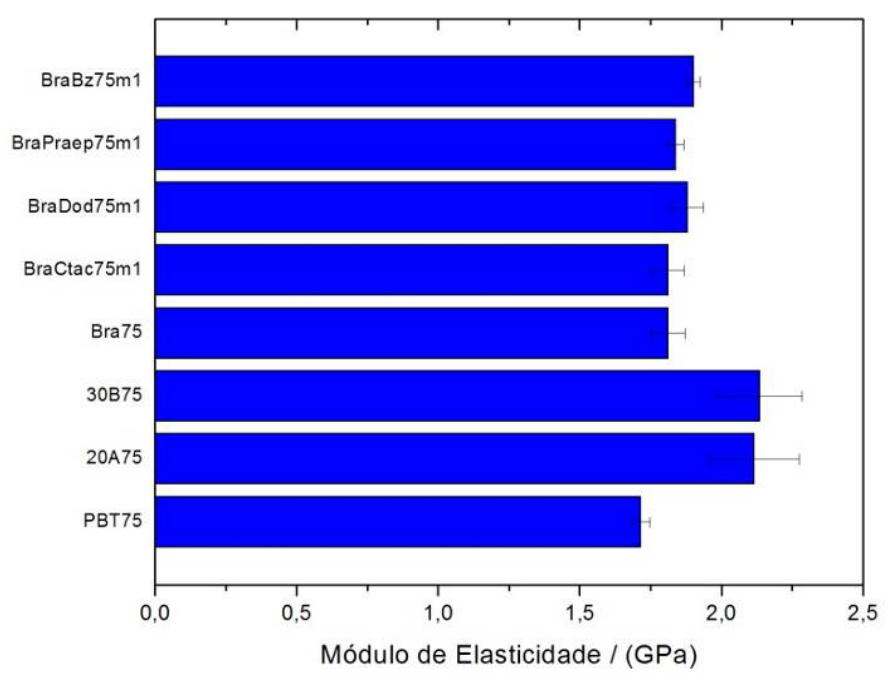

Figura A.31 - Módulo de Elasticidade a 75rpm e método 1

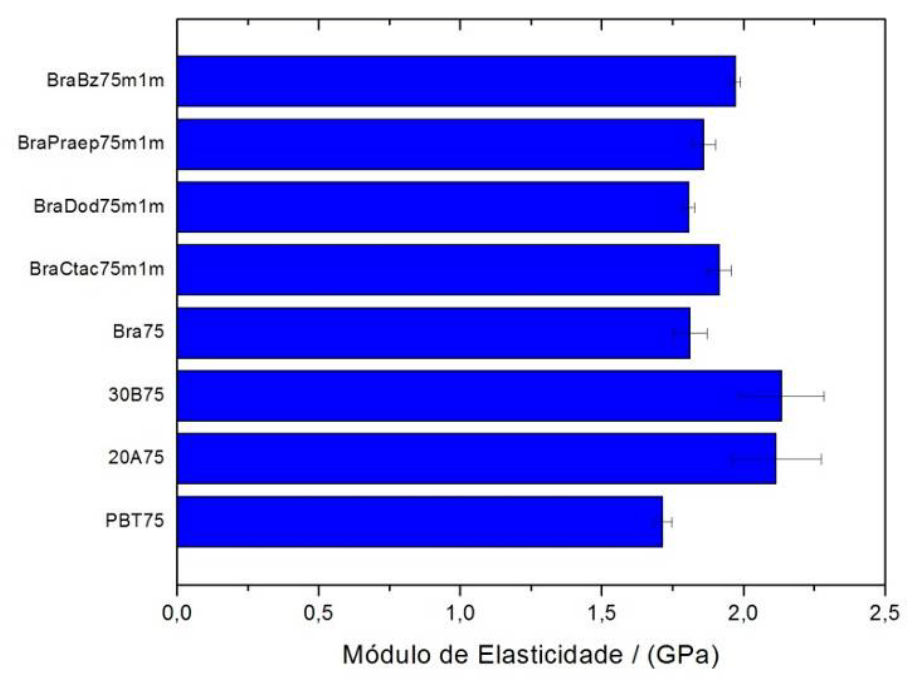

Figura A.32 - Módulo de Elasticidade a 75rpm e método 1 modificado 


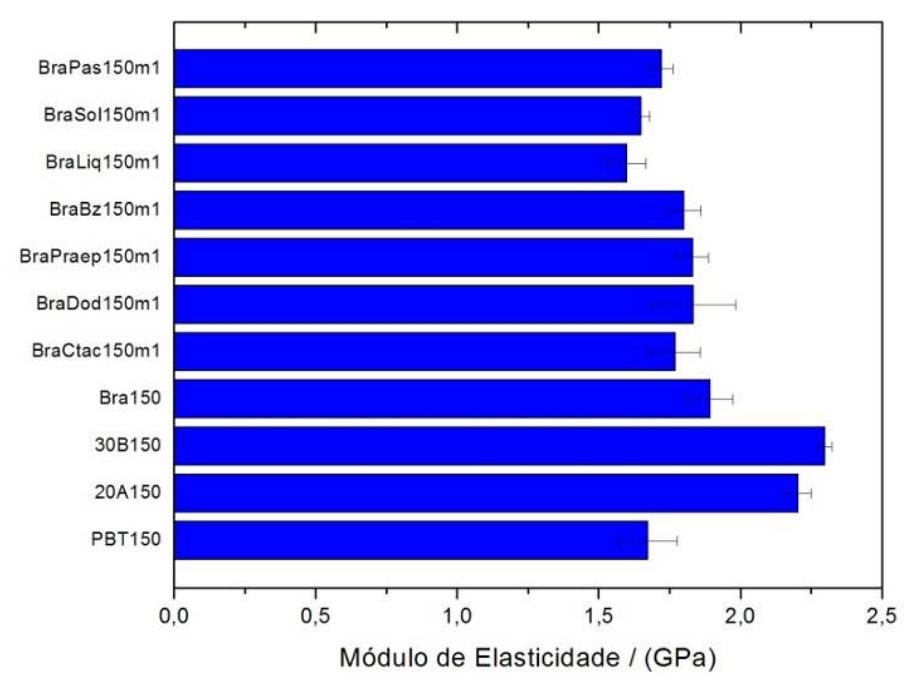

Figura A.33 - Módulo de Elasticidade a 150rpm e método 1

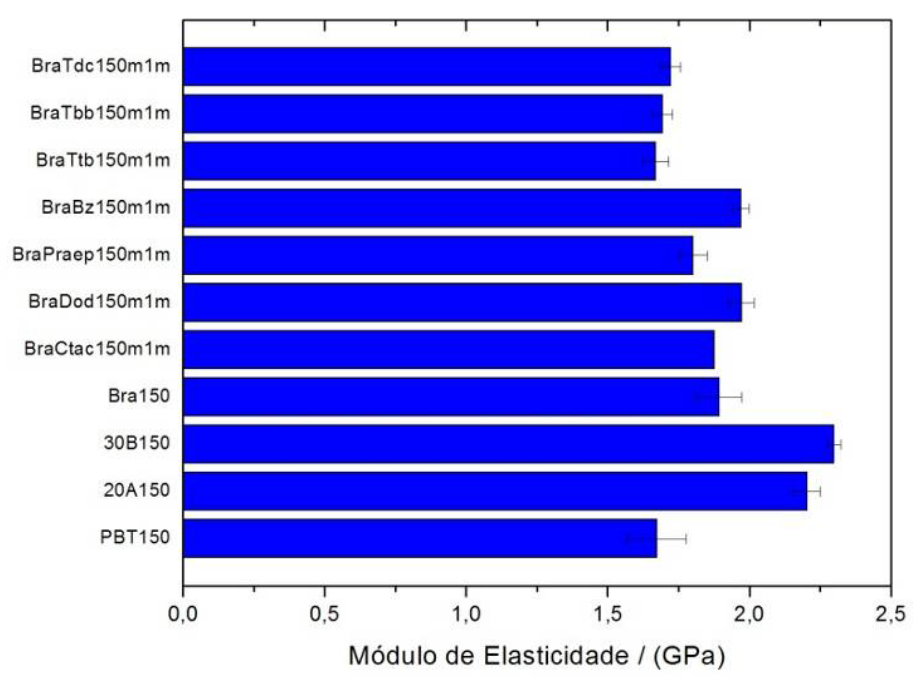

Figura A.34 - Módulo de Elasticidade a 150rpm e método 1 modificado 


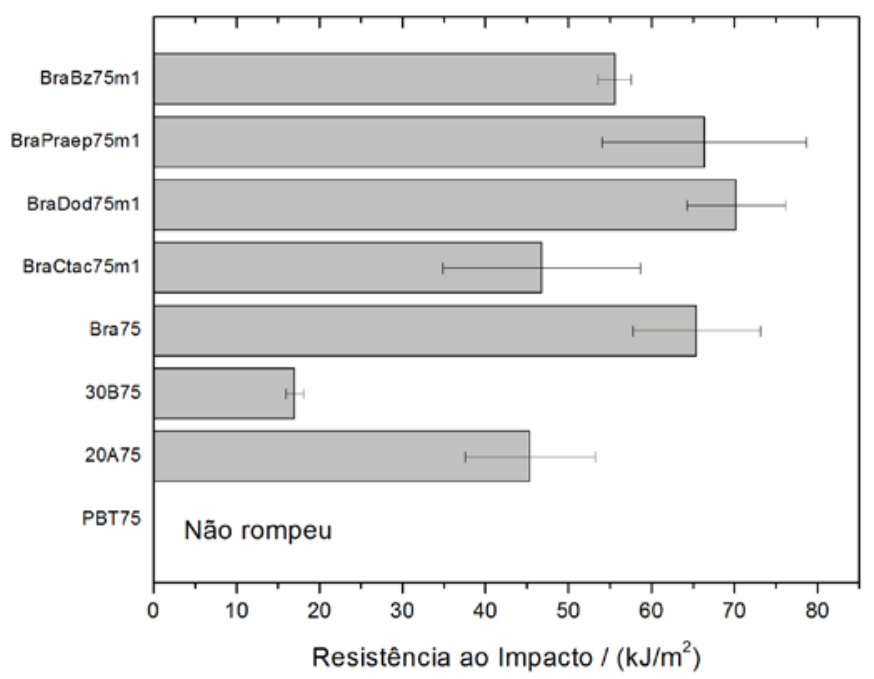

Figura A.35 - Resistência ao impacto a 75rpm e método 1

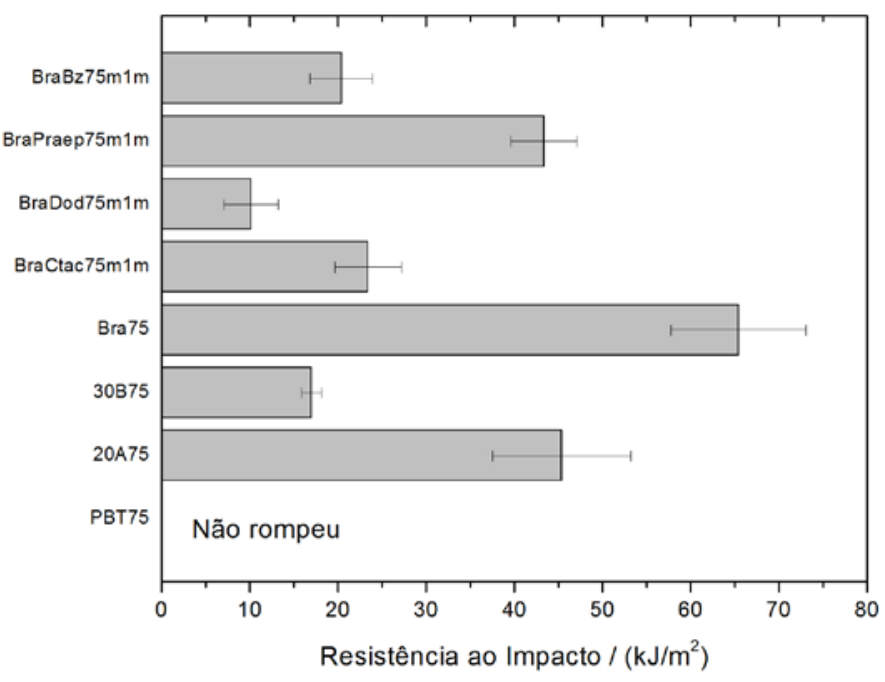

Figura A.36 - Resistência ao impacto a 75rpm e método 1 modificado 


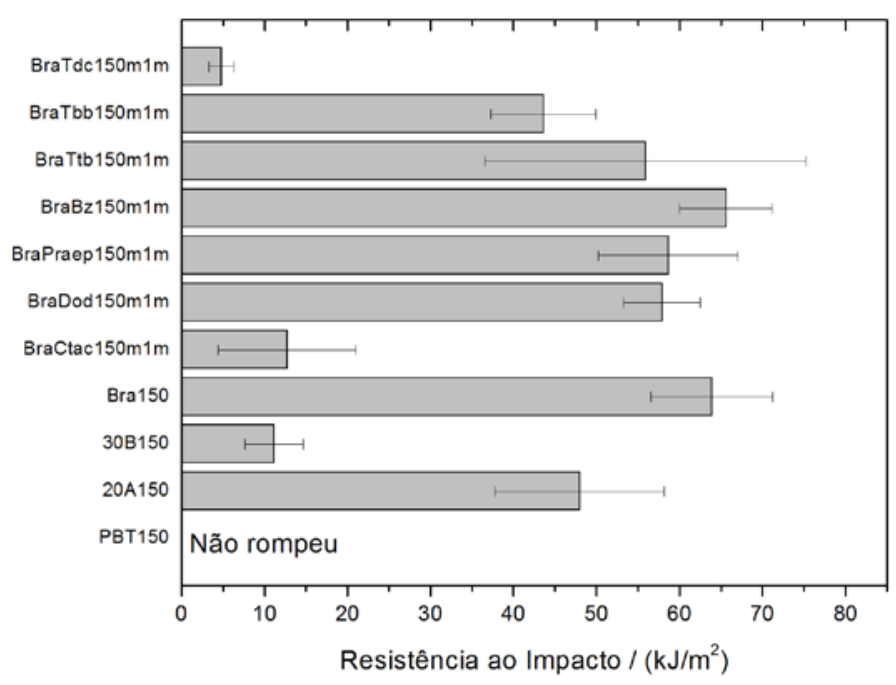

Figura A.37 - Resistência ao impacto a 150rpm e método 1 modificado 


\section{APÊNDICE - B}

Neste apêndice são apresentados resultados anexos das análises termogravimétricas dos sais quaternários e das argilas organofílicas apresentados no Capítulo 2.

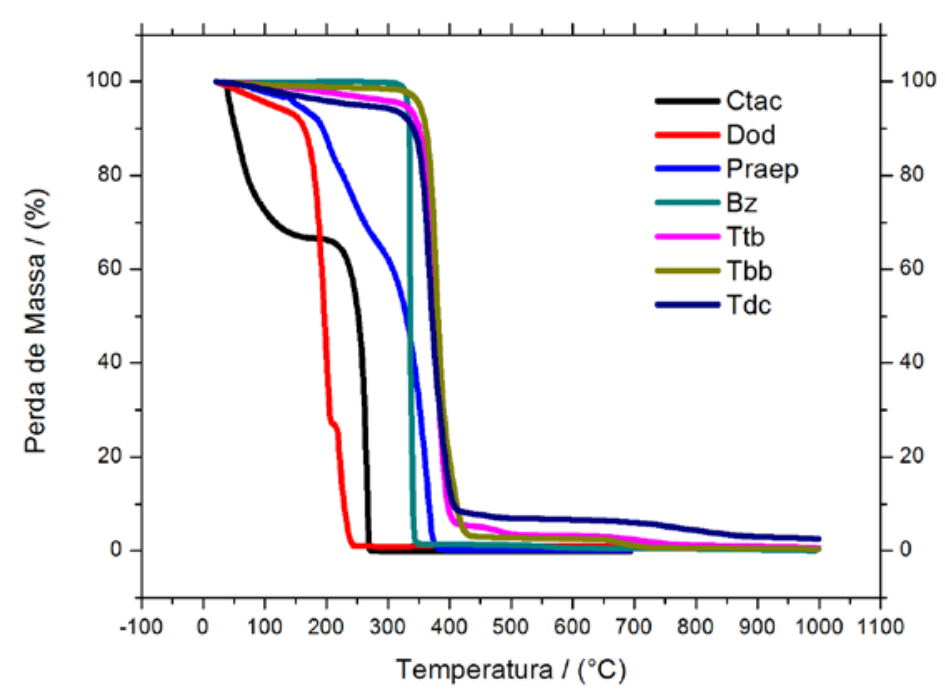

Figura B.1 - Perda de massa para sais de amônio e fosfônio

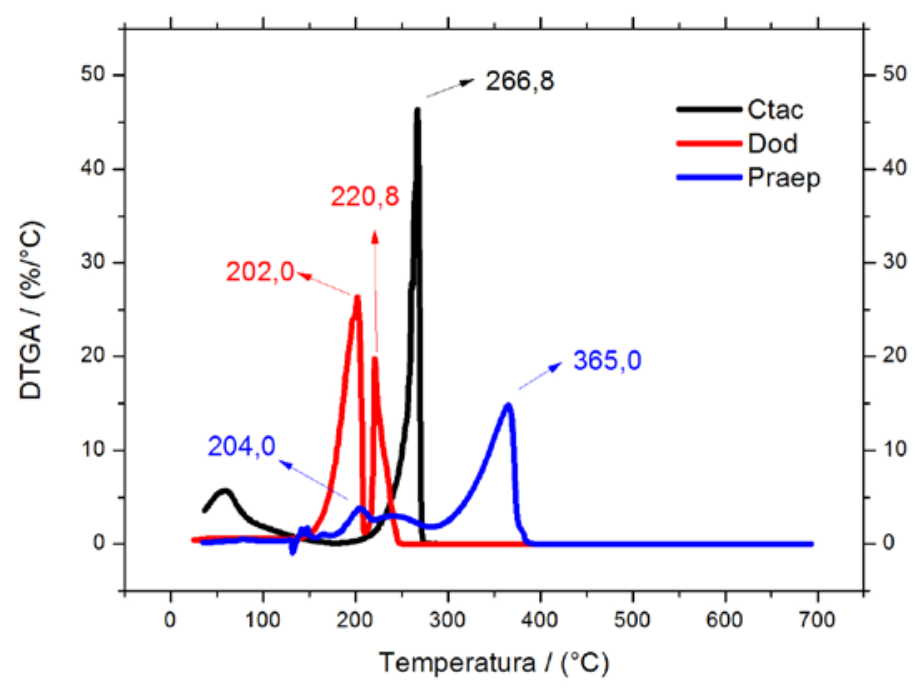

Figura B.2 - DTGA para sais de amônio 


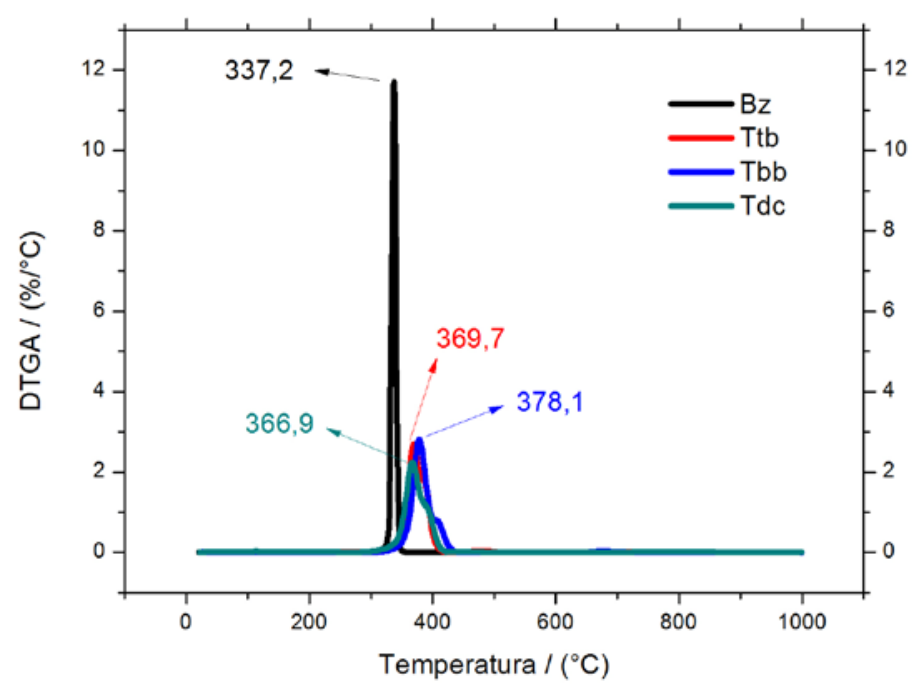

Figura B.3 - DTGA para sais de fosfônio

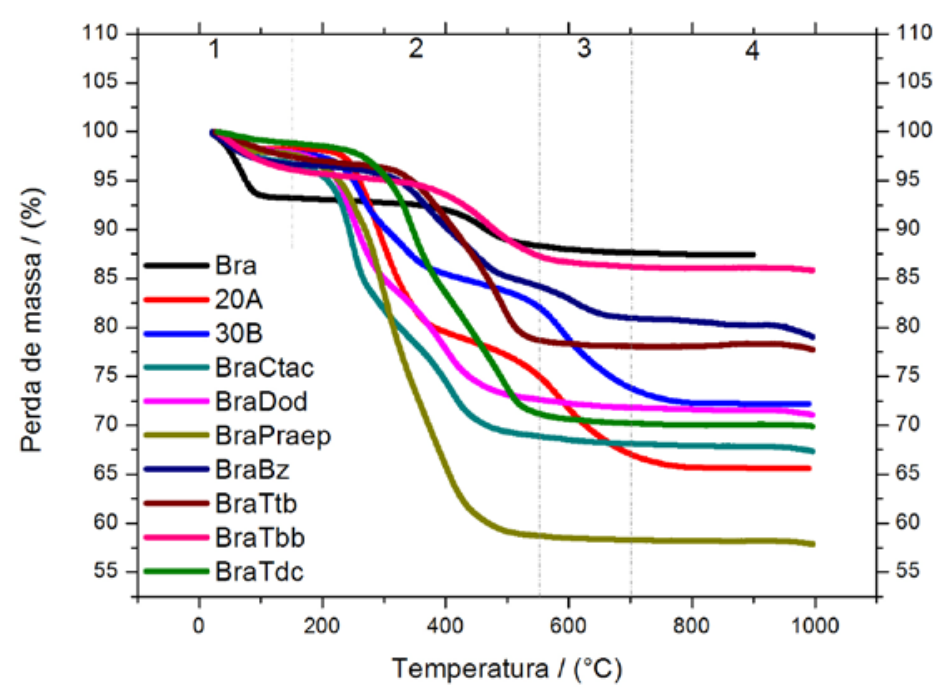

Figura B.4 - Perda de massa para as argilas organofílicas 


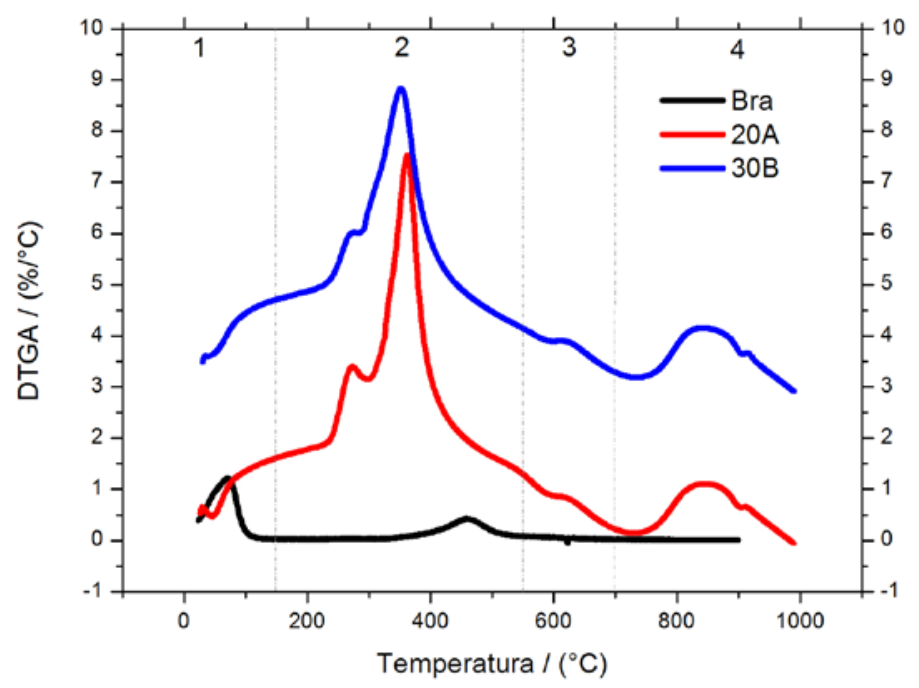

Figura B.5 - DTGA para Bra, Cloisites 20A e 30B 


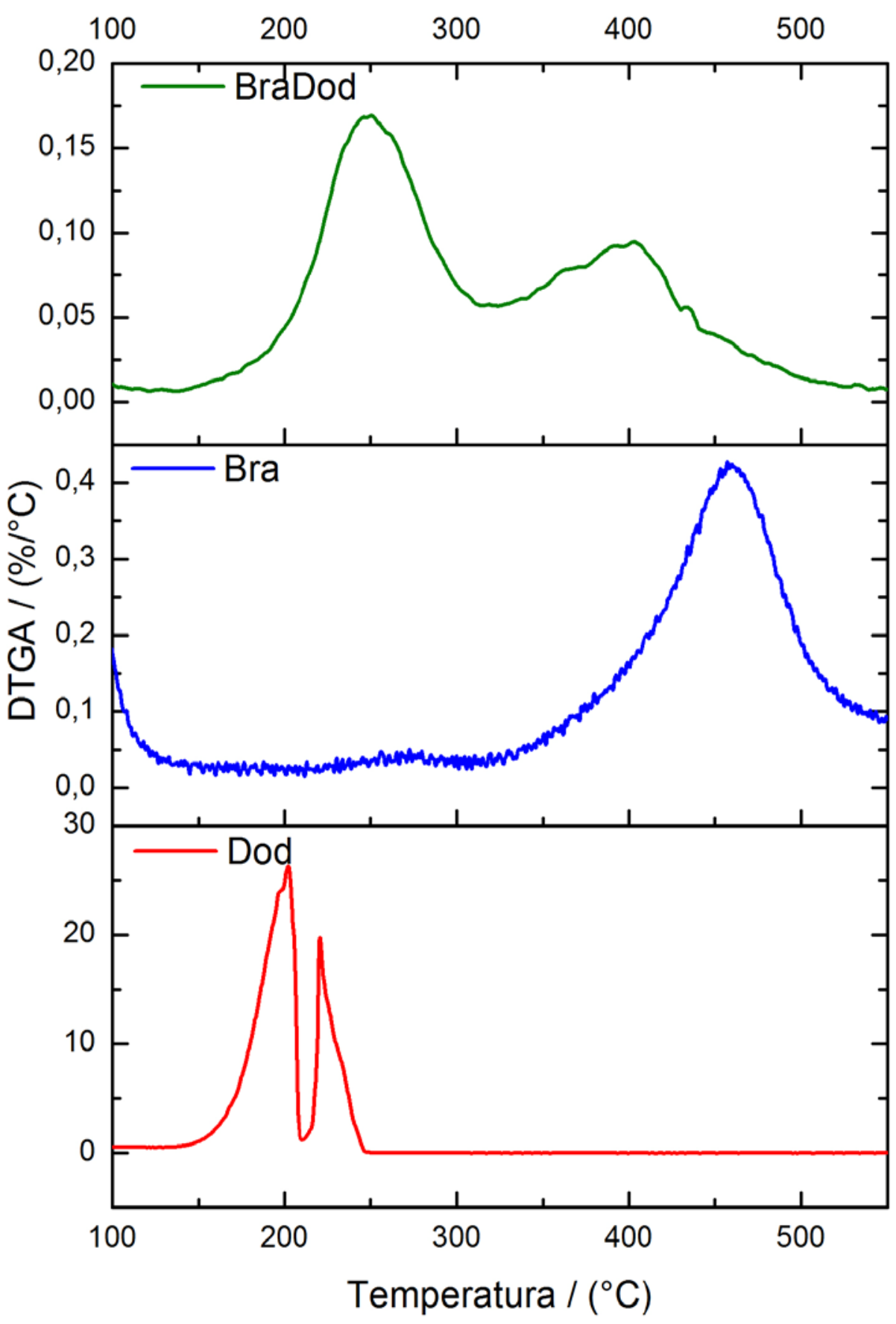

Figura B.6 - DTGA para Dod, Bra e BraDod 


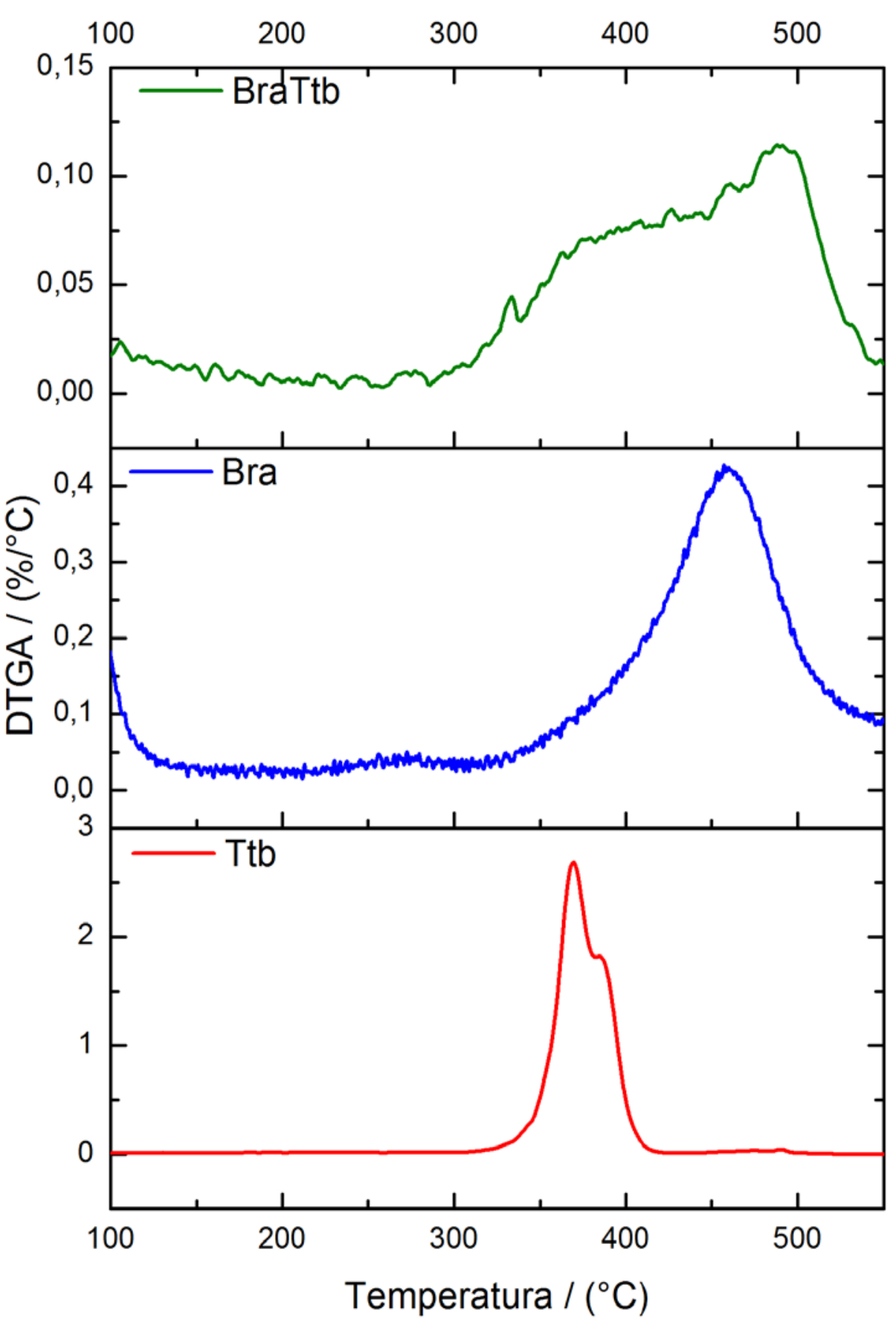

Figura B.7 - DTGA para Ttb, Bra e BraTtb 


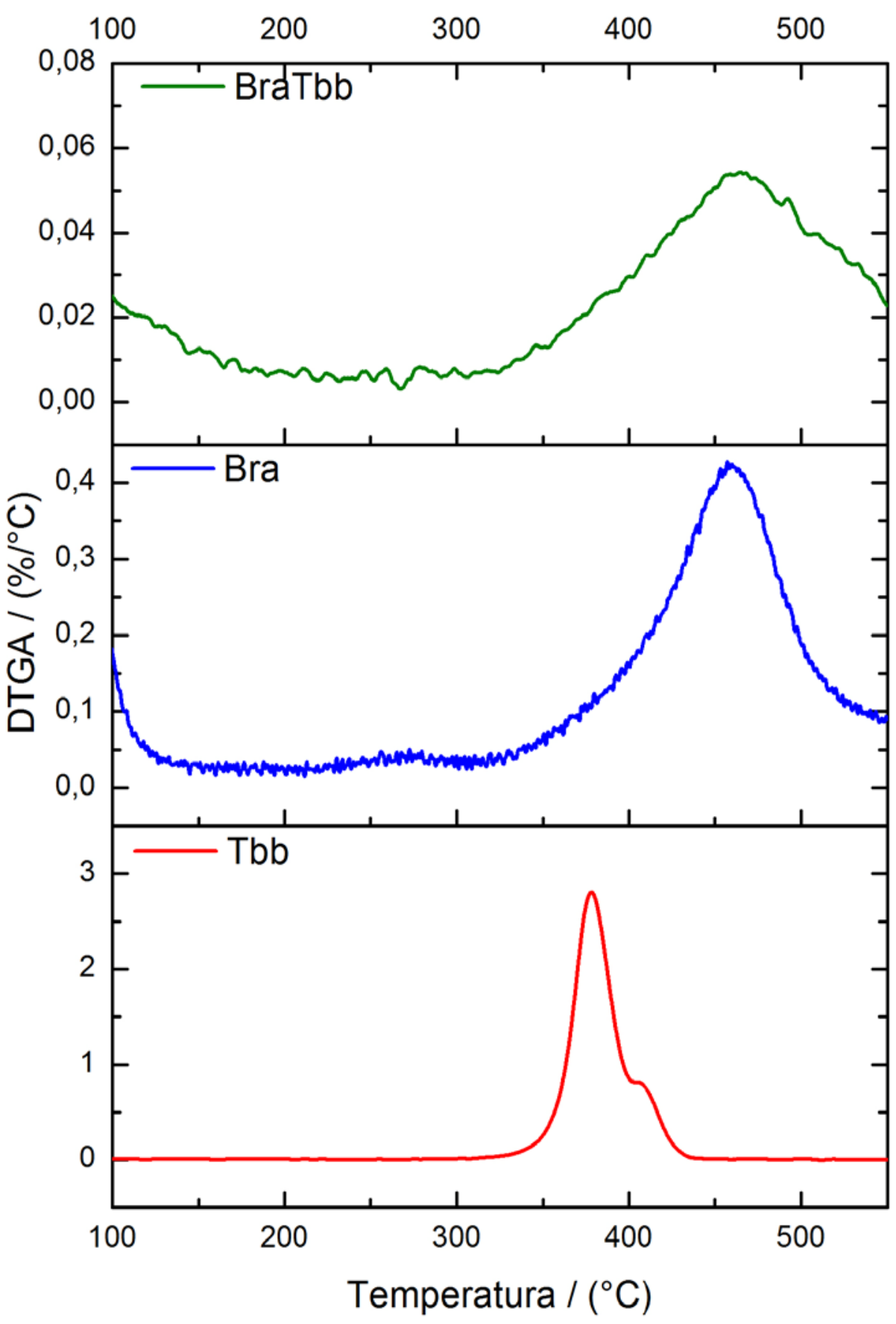

Figura B.8 - DTGA para Tbb, Bra e BraTbb 


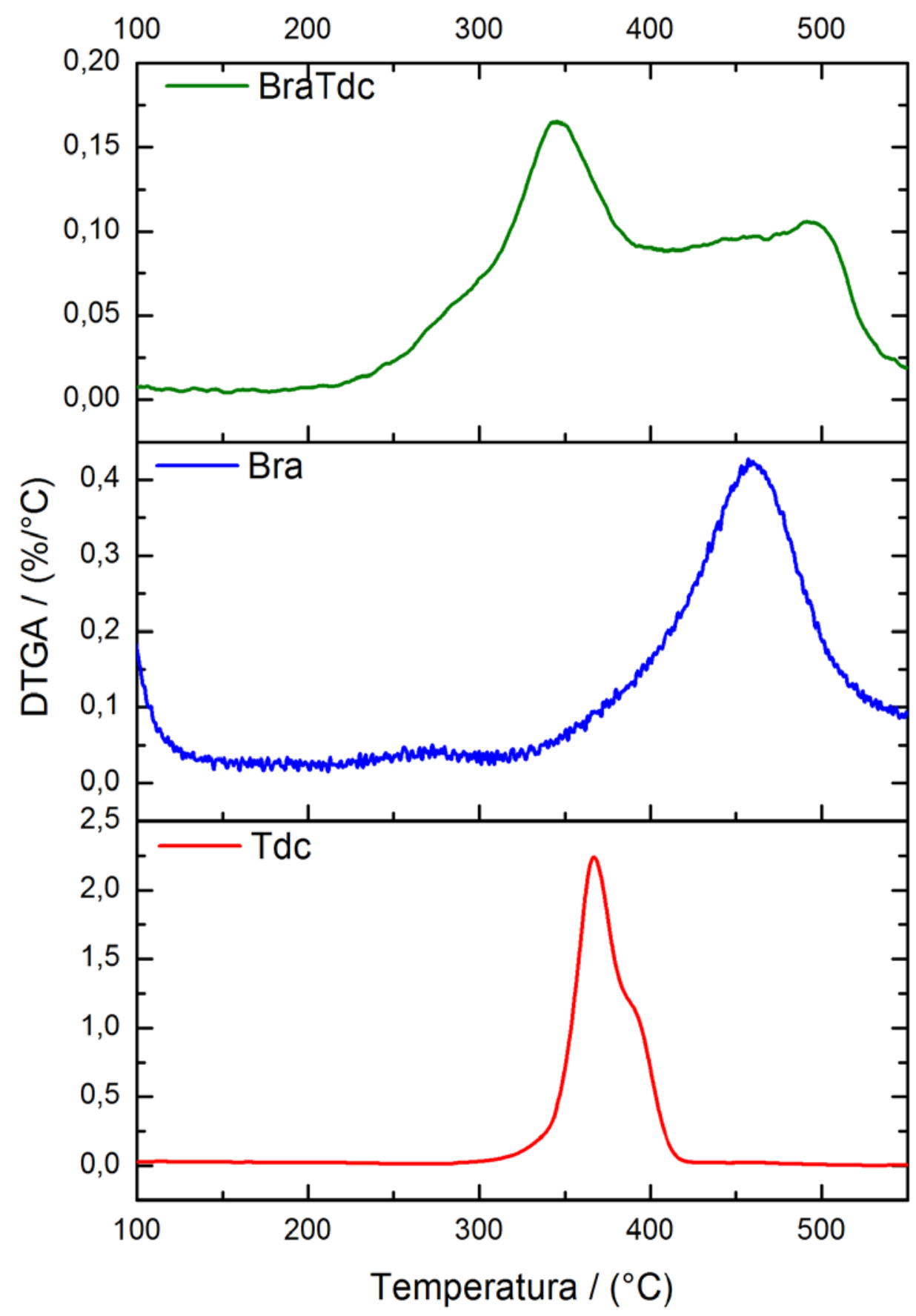

Figura B.9 - DTGA para Tdc, Bra e BraTdc 


\section{APÊNDICE - C}

Neste apêndice são apresentados resultados anexos das análises de XRD, demais micrografias por microscopia ótica e microscopia eletrônica de transmissão, avaliadas no Capítulo 3.

\section{Difração de Raios - X}

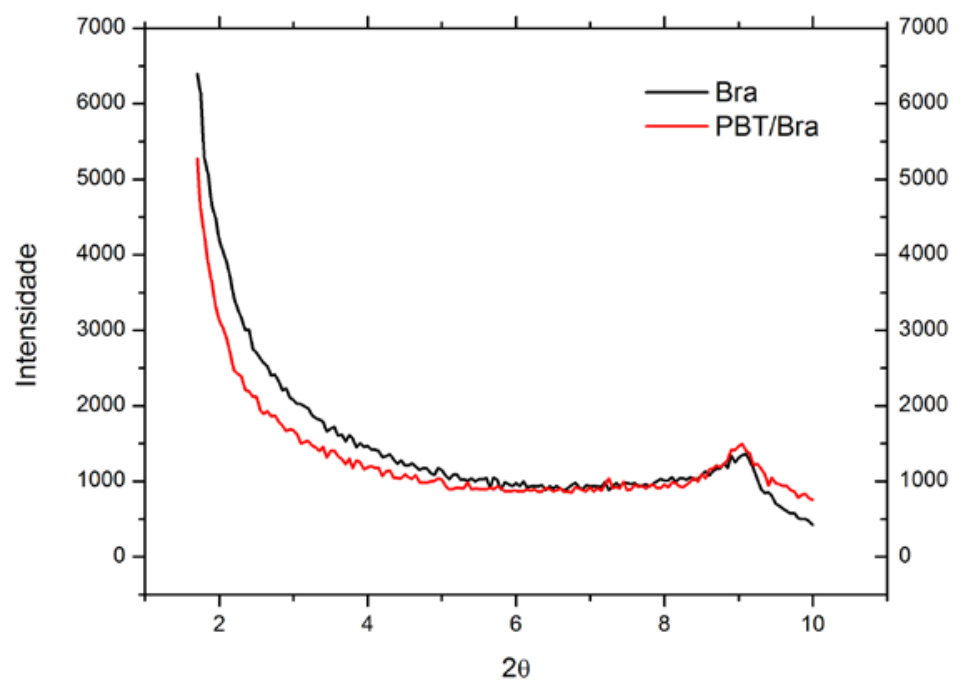

Figura C.1 - Difratogramas para PBT/Bra

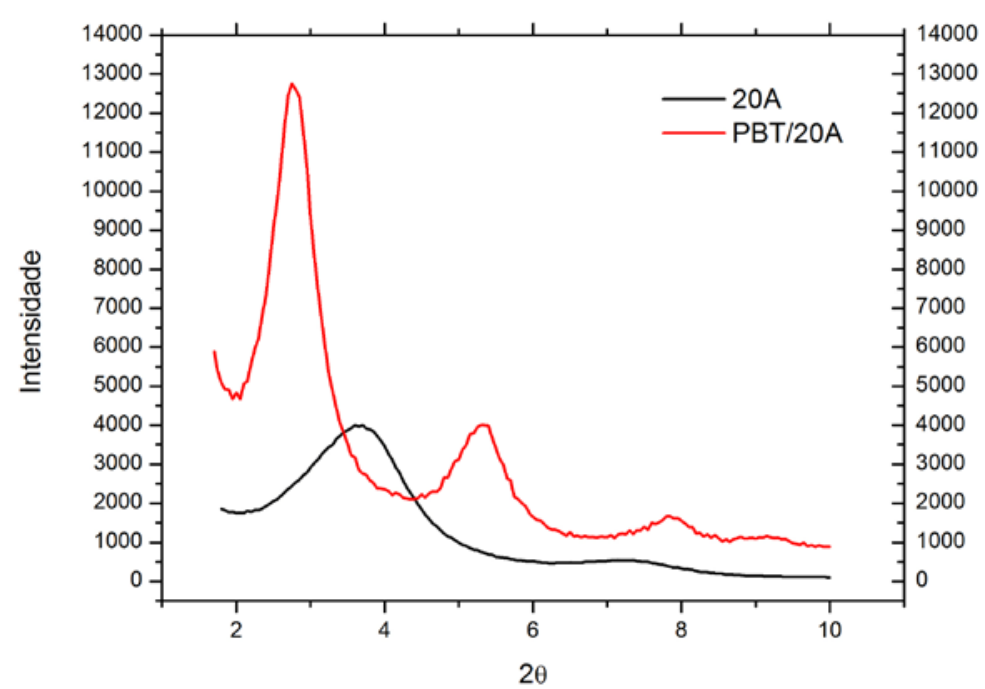

Figura C.2 - Difratogramas para PBT/20A 


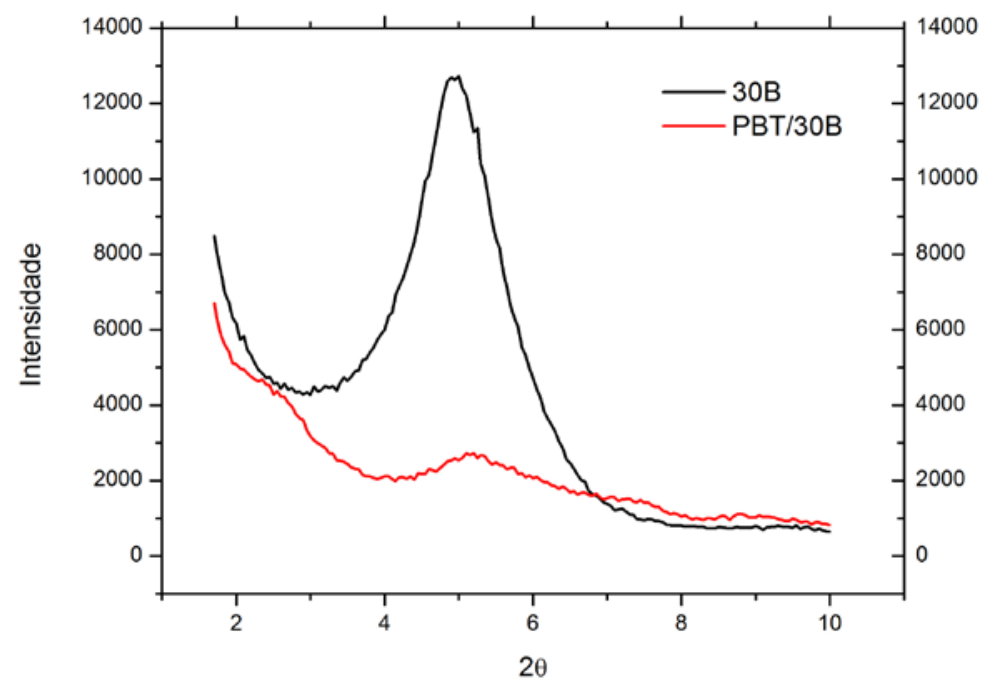

Figura C.3 - Difratogramas para PBT/30B

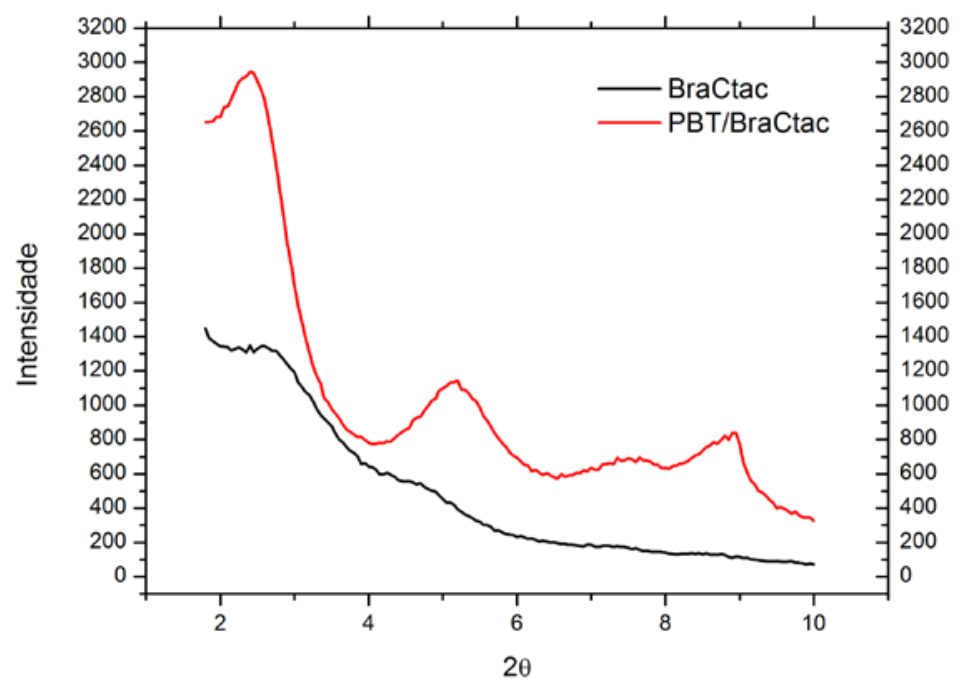

Figura C.4 - Difratogramas para PBT/BraCtac 


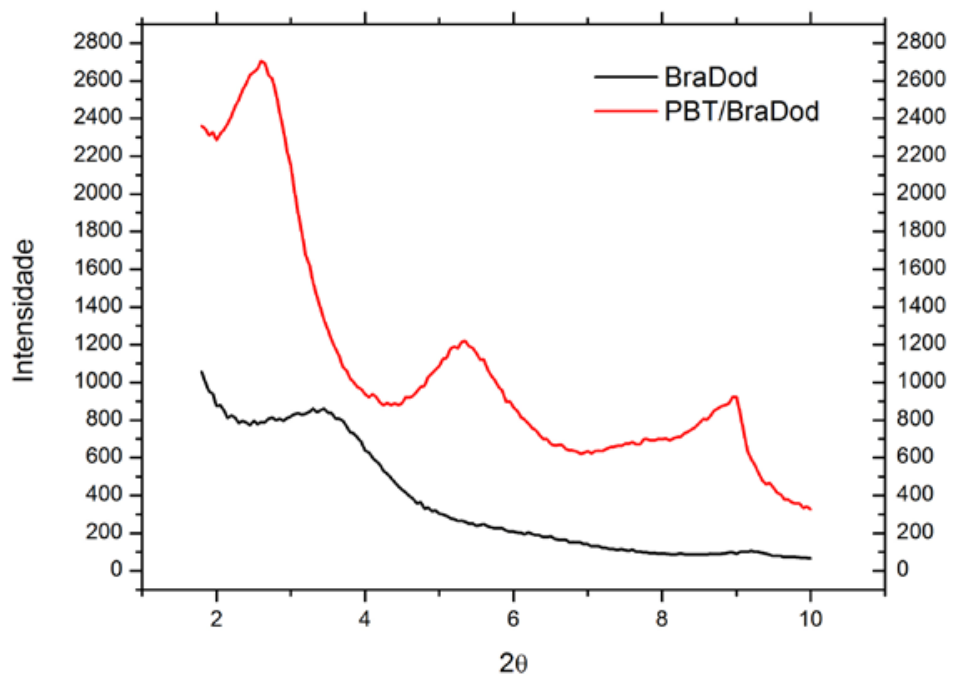

Figura C.5 - Difratogramas para PBT/BraDod

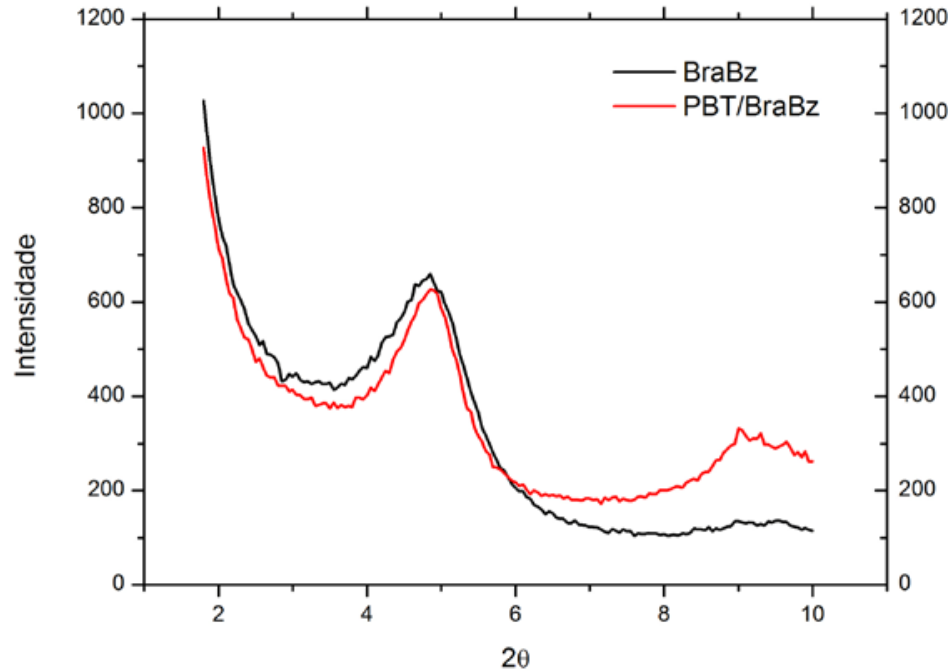

Figura C.6 - Difratogramas para PBT/BraBz 


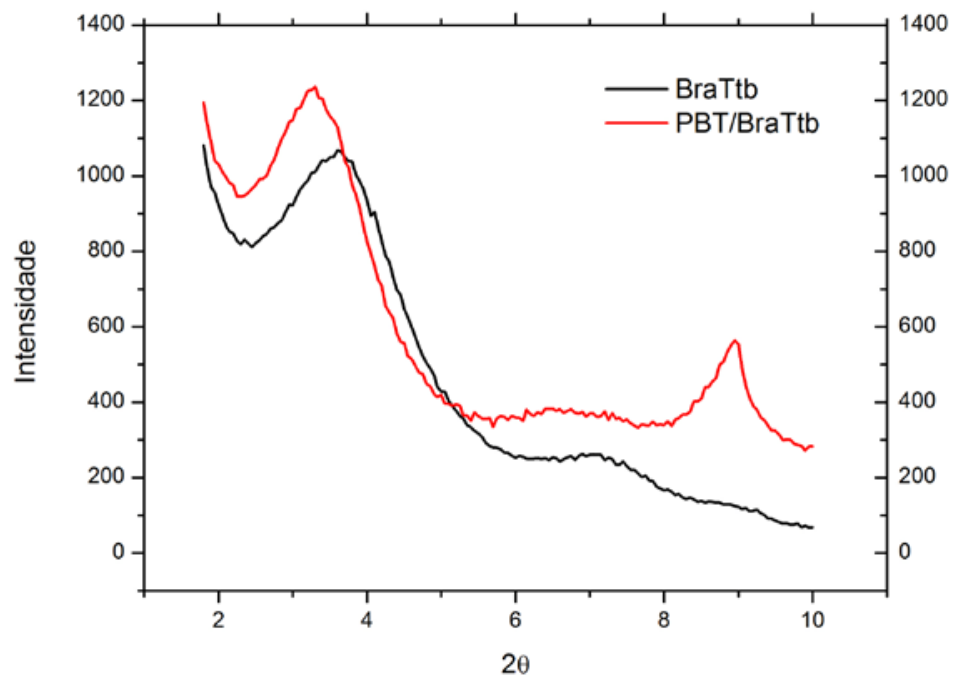

Figura C.7 - Difratogramas para PBT/BraTtb

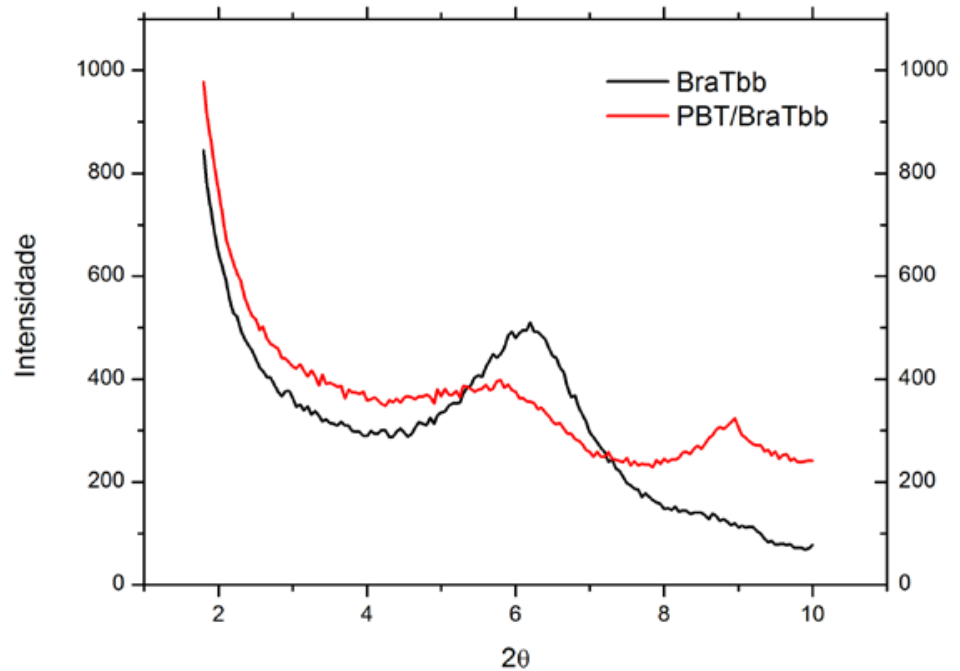

Figura C.8 - Difratogramas para PBT/BraTbb 


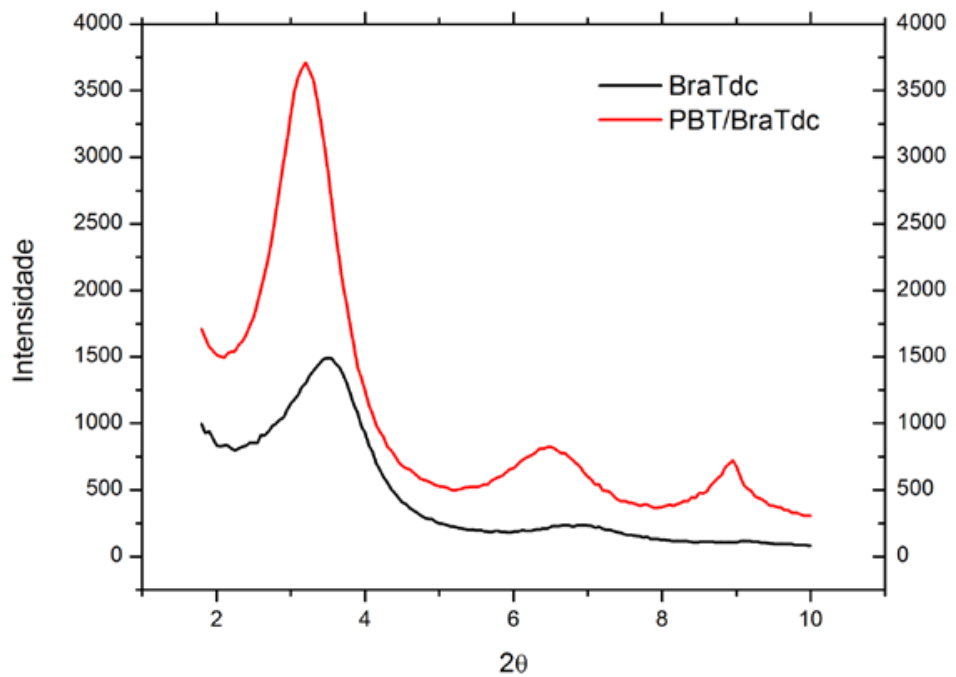

Figura C.9 - Difratogramas para PBT/BraTdc 


\section{Microscopia Eletrônica de Transmissão (TEM)}

As setas brancas indicam lamelas intercaladas e as setas pretas indicam lamelas esfoliadas, o que corroboram os dados de XRD.
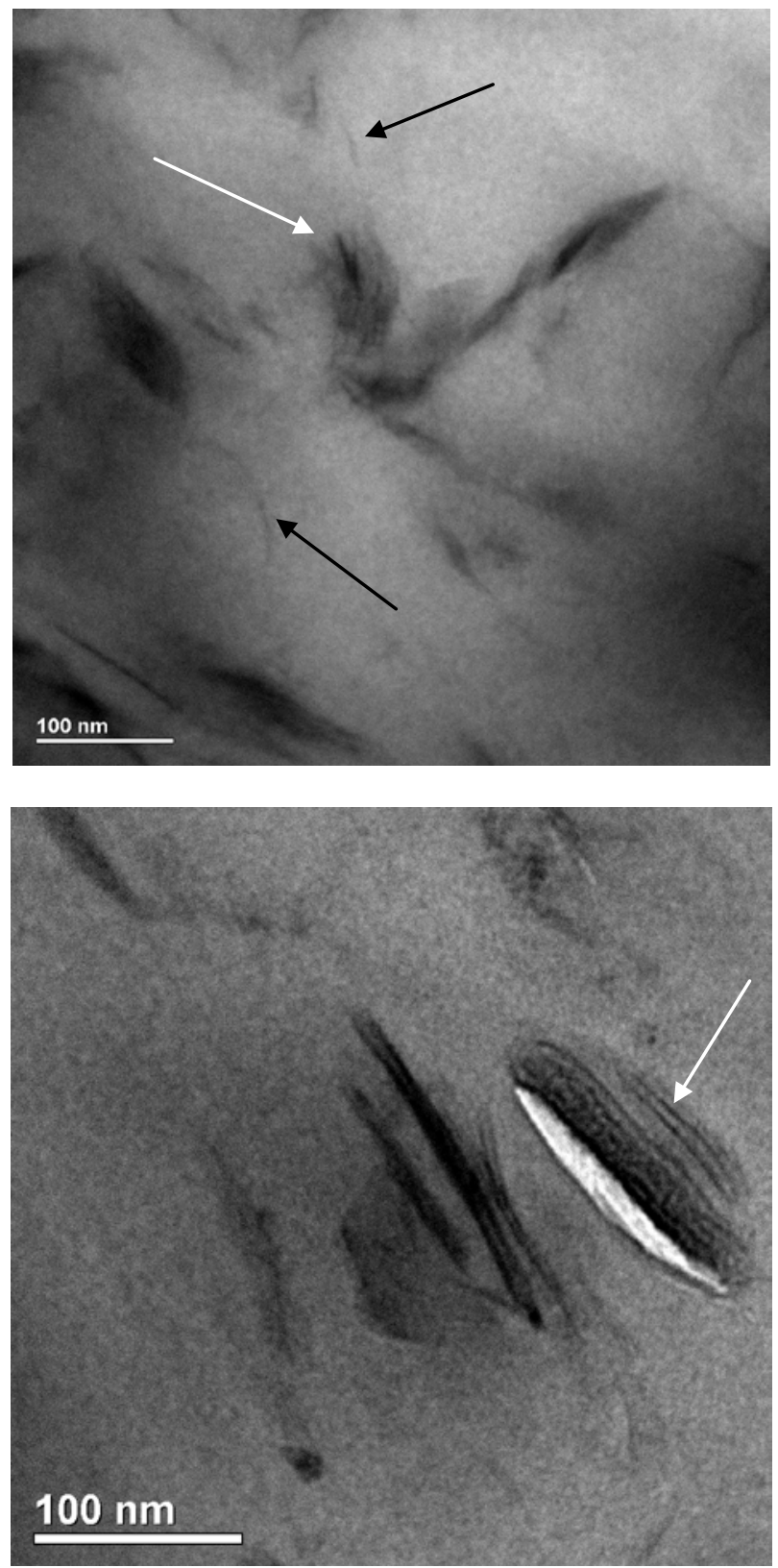

Figura C.10 - Microscopia eletrônica de transmissão para PBT/BraCtac 

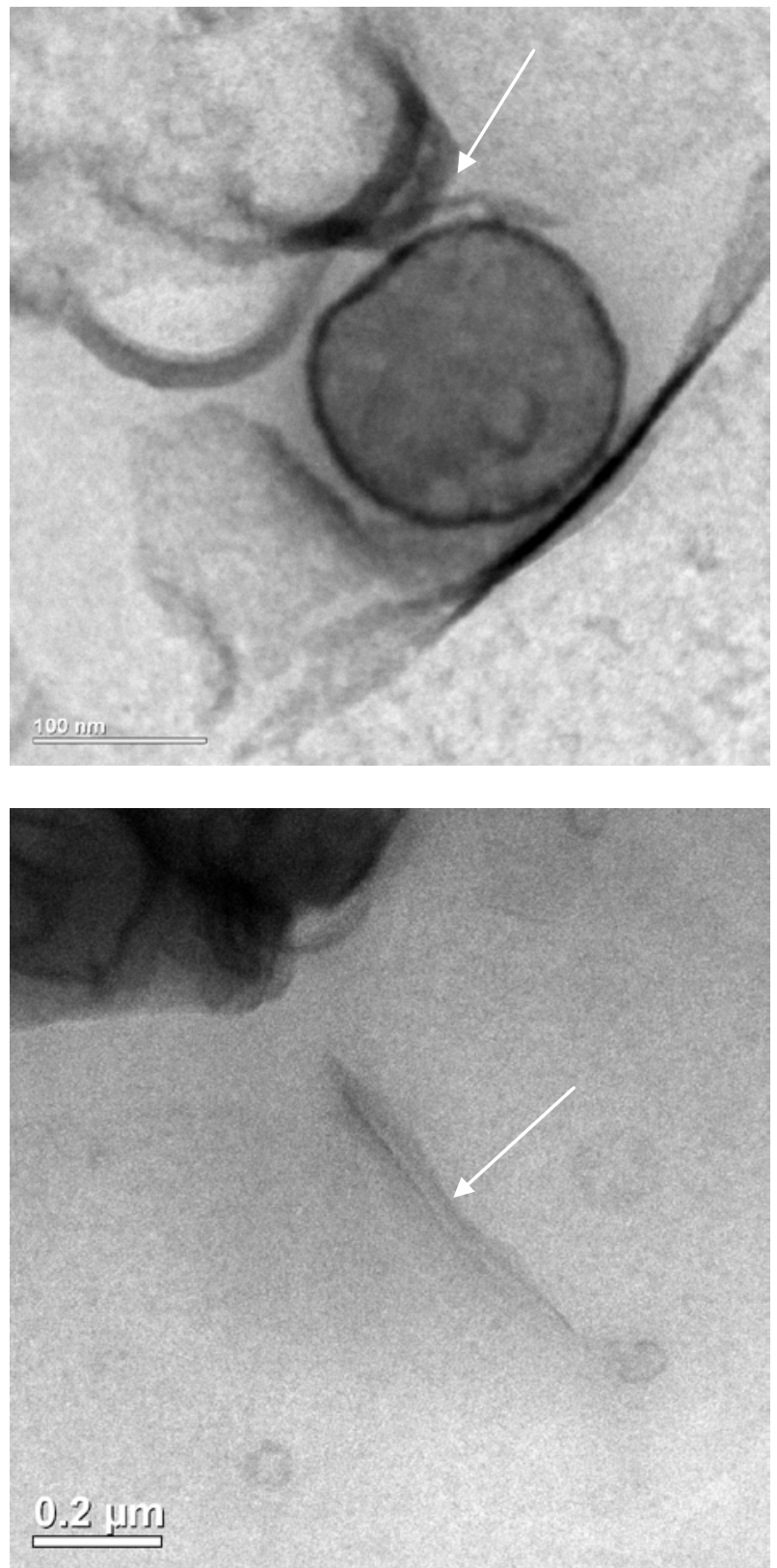

Figura C.11 - Microscopia eletrônica de transmissão para PBT/BraTtb 

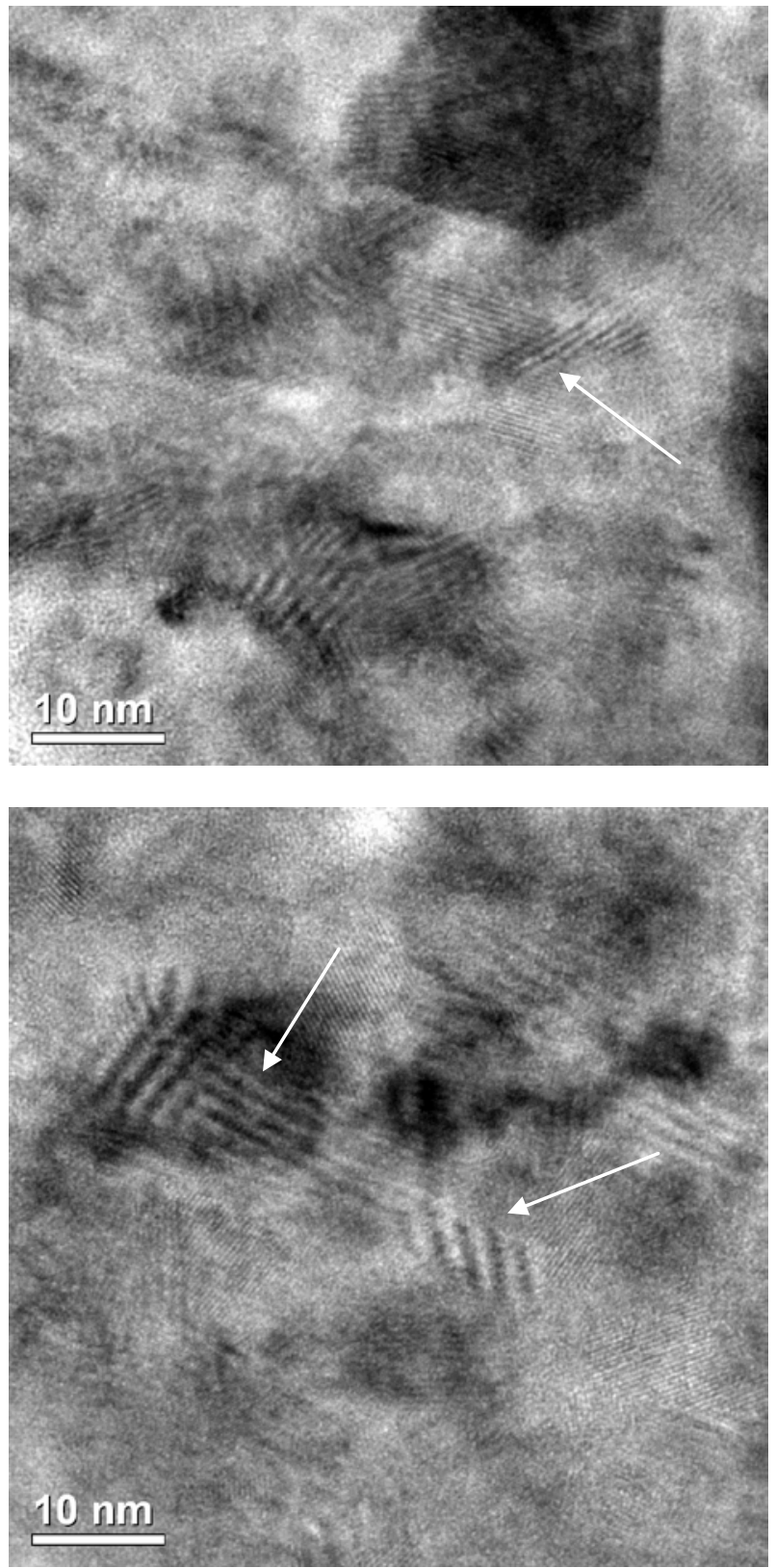

Figura C.12 - Microscopia eletrônica de transmissão para PBT/BraTdc 


\section{Microscopia Ótica}

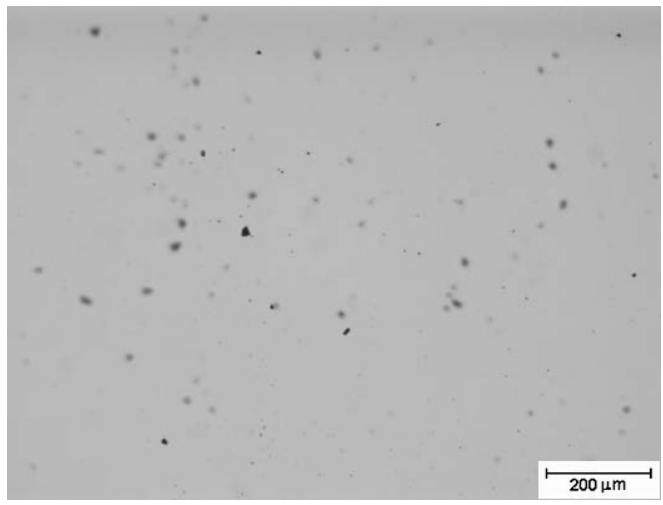

Figura C.13 - PBT

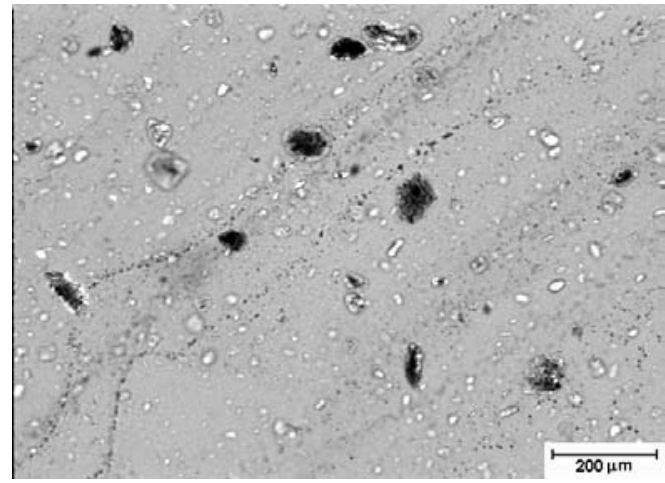

Figura C.15 - PBT / 30B

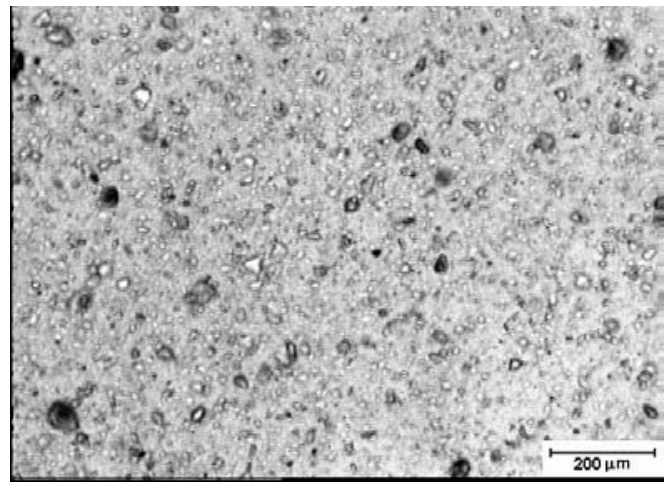

Figura C.17 - PBT / BraDod

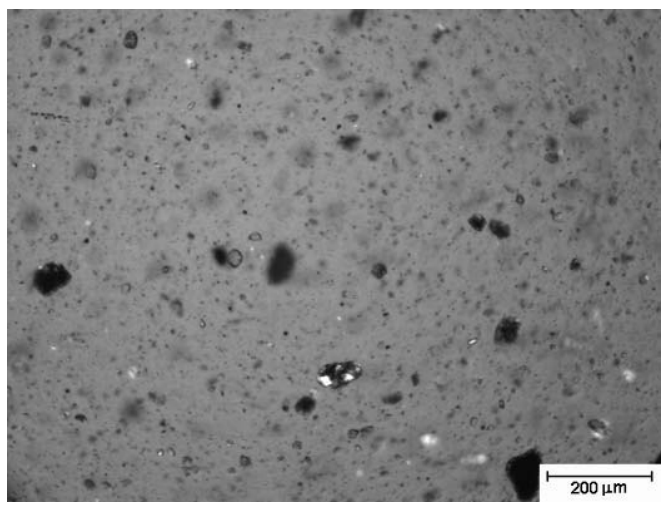

Figura C.19 - PBT / BraTtb

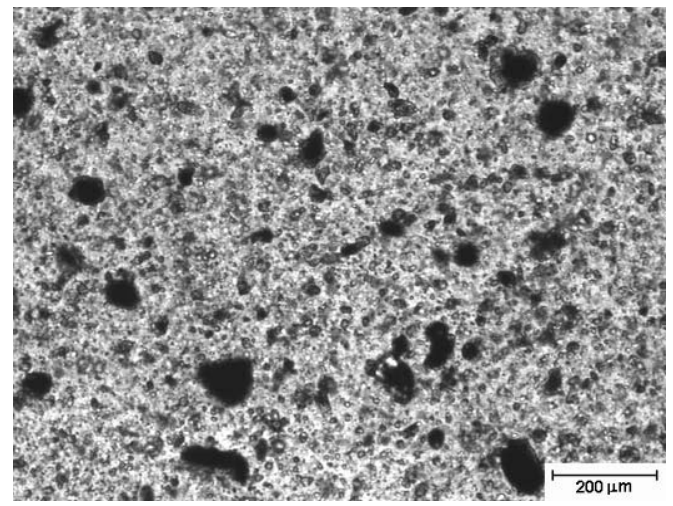

Figura C.14 - PBT / Bra

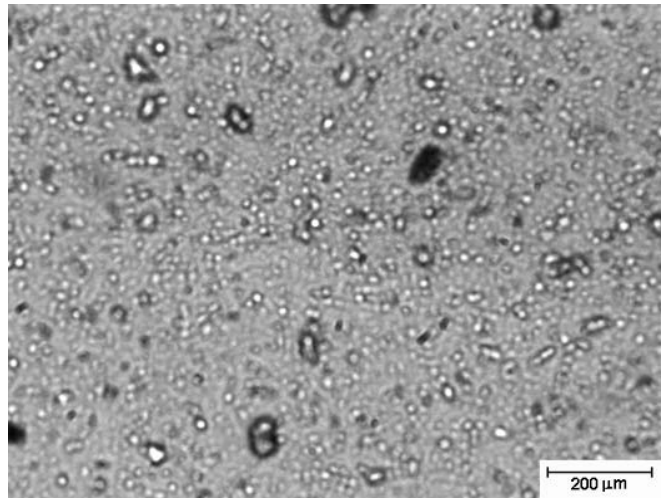

Figura C.16 - PBT / BraCtac

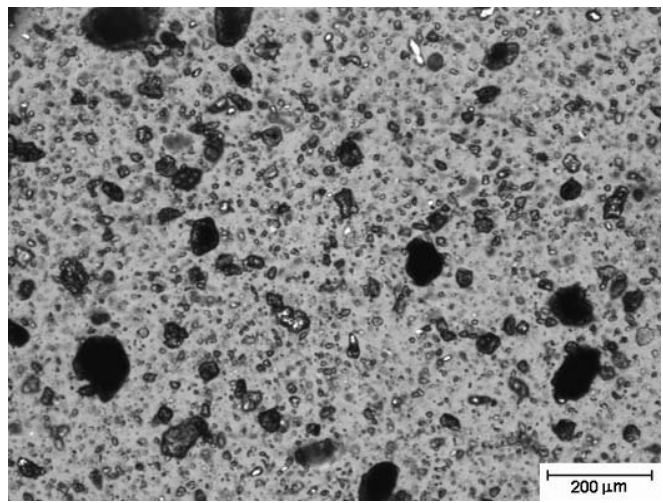

Figura C.18 - PBT / BraBz

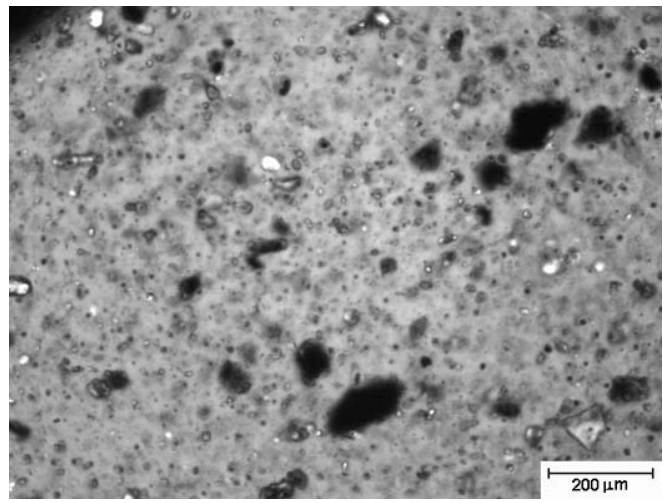

Figura C.20 - PBT / BraTbb 


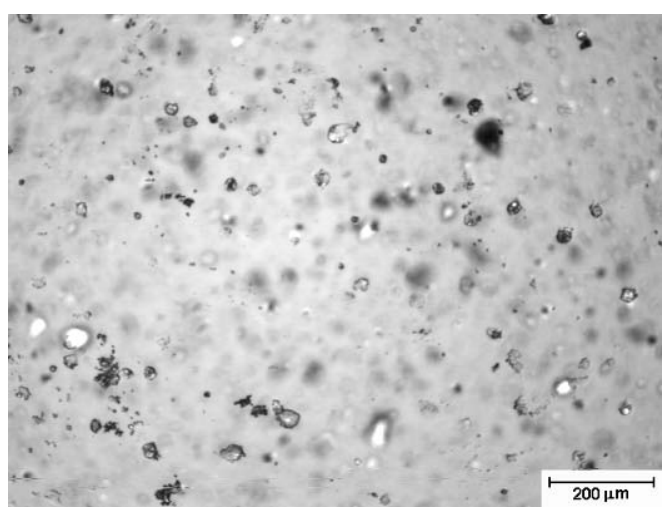

Figura C.21 - PBT / BraTdc 